\title{
Electrode Materials for Supercapacitors: A Review of Recent Advances
}

\author{
Parnia Forouzandeh *, Vignesh Kumaravel and Suresh C. Pillai *
}

Nanotechnology and Bio-Engineering Research Group, Department of Environmental Science, Institute of Technology Sligo, Ash Lane, F91 YW50 Co. Sligo, Ireland; Kumaravel.Vignesh@itsligo.ie

* Correspondence: Parnia.Forouzandeh@mail.itsligo.ie (P.F.); Pillai.Suresh@itsligo.ie (S.C.P.)

Received: 10 July 2020; Accepted: 19 August 2020; Published: 26 August 2020

\begin{abstract}
The advanced electrochemical properties, such as high energy density, fast charge-discharge rates, excellent cyclic stability, and specific capacitance, make supercapacitor a fascinating electronic device. During recent decades, a significant amount of research has been dedicated to enhancing the electrochemical performance of the supercapacitors through the development of novel electrode materials. In addition to highlighting the charge storage mechanism of the three main categories of supercapacitors, including the electric double-layer capacitors (EDLCs), pseudocapacitors, and the hybrid supercapacitors, this review describes the insights of the recent electrode materials (including, carbon-based materials, metal oxide/hydroxide-based materials, and conducting polymer-based materials, 2D materials). The nanocomposites offer larger SSA, shorter ion/electron diffusion paths, thus improving the specific capacitance of supercapacitors (SCs). Besides, the incorporation of the redox-active small molecules and bio-derived functional groups displayed a significant effect on the electrochemical properties of electrode materials. These advanced properties provide a vast range of potential for the electrode materials to be utilized in different applications such as in wearable/portable/electronic devices such as all-solid-state supercapacitors, transparent/flexible supercapacitors, and asymmetric hybrid supercapacitors.
\end{abstract}

Keywords: electrochemistry; 2D materials; energy storage; carbonaceous material; polymers; nanomaterials

\section{Introduction}

Recently, due to the need for preserving natural resources and regulating global energy consumption, there has been a crucial demand for the development of clean energy sources. Among various unconventional electric-power devices, such as supercapacitors (SCs), batteries, and fuel cells, (SCs), which have been used in various fields, (e.g., hybrid cars and electric mass transit vehicles [1], and wearable/portable electronic devices [2], etc.,), SCs have inspired a vast range of research attention owing to their excellent electrochemical performances, including high specific power, superior cycling life and a rapid charging-discharging rate [3]. SCs are a type of capacitor that are also known as ultracapacitors, electrochemical capacitors (ECs) [4], gold capacitors, electrical double-layer capacitors (EDLCs), pseudocapacitors, or power coaches $[5,6]$. The main combination of SC configuration consists of an electrolyte, current collector, and electrodes with large specific surface area (SSA), which enhances the capacitance 10,000 times more than conventional capacitors $[7,8]$ and thin dielectric separators, which provide higher capacitance for SC compared to conventional batteries [9].

The energy storage in SCs is based on the charge-discharge mechanism at the electrode-electrolyte interface [10] in which the principle is similar to conventional capacitors; however, the charge-discharge process is much faster in SCs [11]. The charge storage range for conventional capacitors is between 
micro to millifarads while for SCs is between 100-1000 F for each device retaining low equivalent series resistance (ESR) and specific power [12]. SCs could cover both the specific energy and power density $\left(\mathrm{P}_{\mathrm{d}}\right)$ by several orders of magnitude compared to batteries exploiting proper design and efficient materials, which make them as a flexible energy storage option [12]. The specific energy (energy density) determines how long the energy storage device can be utilized, and the specific power (power density) signifies how rapidly a device can deliver the energy.

The segregating feature of the SC to the conventional capacitor is the absence of dielectric material in the SCs [13]. In comparison to SCs, conventional capacitors store and deliver very high energy density $\left(\mathrm{E}_{\mathrm{d}}\right)$, but the charge and discharge time of batteries is much slower. SCs also show more safety, a low level of heating, device stability, light-weight, and flexible packaging [14-16]. Figure 1, [17], displays the Ragone plot of comparison between conventional capacitor, fuel cells, batteries, and hybrid supercapacitors (HSCs), as various energy storage devices, in terms of power density $\left(\mathrm{P}_{\mathrm{d}}\right)$ and $E_{d}$ in which the HSCs show a significant feature of $P_{d}$ in comparison with batteries and fuel cells but considerably lower $\mathrm{P}_{\mathrm{d}}$ than conventional capacitors.

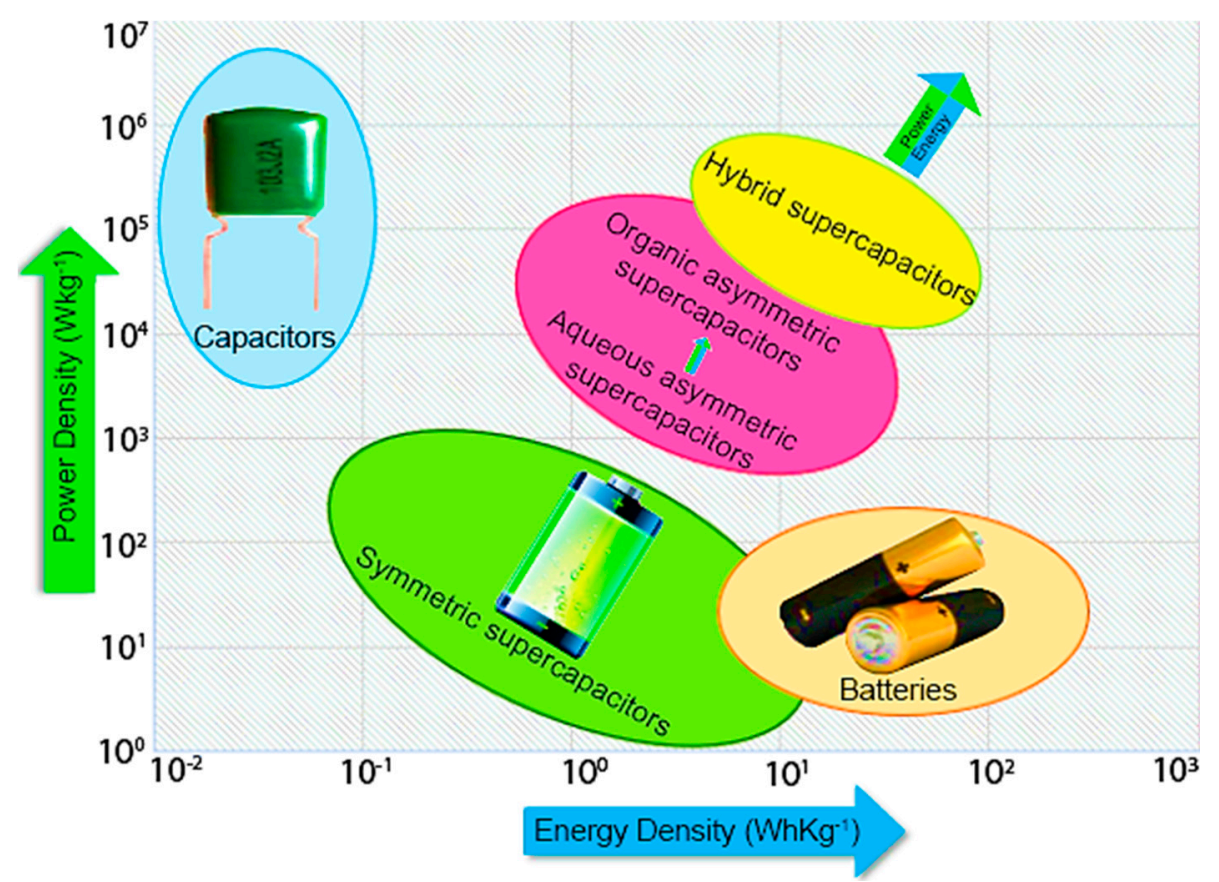

Figure 1. Ragone plot of the power-energy density range for different electrochemical energy storage devices.

According to the charge storage principle, SCs can be categorized into three groups, including (a) EDLCs that exploit double layer electrodes to store the charge in through non-faradic interactions (electrostatically) [18], (b) pseudocapacitors in which the charge storage mechanism is faradaically through oxidation-reduction reactions associated with their various potential [19], and (c) asymmetric supercapacitors (ASSC), in which, the charge storage mechanism of the two electrodes is not similar, and the storage principle is based on both Faradaic and non-Faradic behaviour of used material [13]. Generally, the "asymmetric" word refers to various charge storage mechanisms corresponding to the positive and negative electrodes in the SC device. According to this, the HSC has been categorized as one of the specific class of the ASSC. The energy storage mechanism of a device with supercapacitive materials as the cathode and a battery material as the anode is called HSC. ASSCs provide a high energy density and power density due to the extended operating voltage window (up to about $2.0 \mathrm{~V}$ in the case of aqueous electrolytes, and about $2.7 \mathrm{~V}$ in organic electrolytes, and even more than $4.0 \mathrm{~V}$ in ionic liquids) by taking the advantages of the two different electrode materials, which could 
operate at different potential windows. Figure 2 represents the schematic illustration of the EDLCs, pseudocapacitors, and the HSC.

The main characteristics for these energy storage systems, which provide the ability to distinguish one system from others are including energy density, power density, capacitance/capacity, cell voltage, kinetic storage mechanism, $\mathrm{i}-\mathrm{v}$ relationship, operating temperature, cycle life, self-discharge, and used materials as an electrode, electrolyte, etc. Compared to EDLCs and pseudocapacitors, the HSCs displayed significant advantages such as higher energy density [20], and long cycle life $(>100,000)$ [21], that has been obtained in a higher cell voltage (maximum 0.5) [22]. Lower self-discharge (energy dissipation) is another advantage of HSCs, in comparison with the EDLCs and pseudocapacitor devices [23]. Generally, self-discharge mechanisms, which are associated with various chemical and physical mechanisms, are mainly categorized into three classes: (a) parasitic faradaic reactions, (b) charge redistribution, and (c) ohmic leakage of current between the electrodes [24-26]. Accordingly, self-discharge occurs, if one or the combination of these processes is available.

Selecting a standard lifetime as one of the main parameters of the rechargeable energy storage devices is entirely subjected to the nature of the device, and it is highly linked to the operating conditions such as temperature, voltage, charge-discharge current, the depth of the discharge, and at some stages, the humidity $[17,27]$. It is essential to select the appropriate materials with high purity for both electrolyte and electrodes as it influences the cycling life and the current leakage. Cyclic stability can be estimated through GCD measurements by repeating the cycles continuously at a constant current density [28].

The cycling lifetime of the hybrid system is approximately 5000 cycles, which could vary with respect to the batteries (for non-Li-ion batteries around 500 cycles, and for $\mathrm{Na}$ - and Li-ion batteries around 2000 cycles) [29], and the other types of supercapacitor devices (around 10,000 cycles) [30]. The description of the life cycle is highly relient on the application of the corresponding device, where it can be defined as the number of full charge-discharges before the device capacitance/capacity reduces below $80 \%$ of the start-of-life value [31-33].

In the case of the death state of a battery intended for a hybrid or an ordinary electric vehicle, the life cycle is described as $80 \%$ of the corresponding initial capacity [34]. In the following sections, the cycle lifetime results for various energy storage devices are reported as the percentage of the initial capacity/capacitance of the device that remained after a specified number of cycles. In this review, a detailed description of the features of various electrode materials has been given. The electrochemical properties, preparation methods, and the applications of the materials have been discussed in detail. The following features have reviewed comprehensively: (i) the difference between the "pseudocapacitive" and "battery-type" electrode material, (ii) the importance on the selection of the electrode material, and their properties influencing the SCs performance, and (iii) the major categories of materials (carbonaceous materials, $\mathrm{TMOs} / \mathrm{TM}(\mathrm{OH}) \mathrm{s}$, and $\mathrm{CPs}$ ), and their composites. The advantages and disadvantages of the electrode materials are also briefly compared. The charge storage behaviour of different components has been introduced through recent advances. Then, the importance of the utilization of 2D material (either individually or in combination with other materials) has been comprehensively explained. In the end, an outlook on the significance of the bioderived functional groups into the electrode material, their advantages, and application in various SCs such as transparent SCs, FSCs, and HSCs is given. 

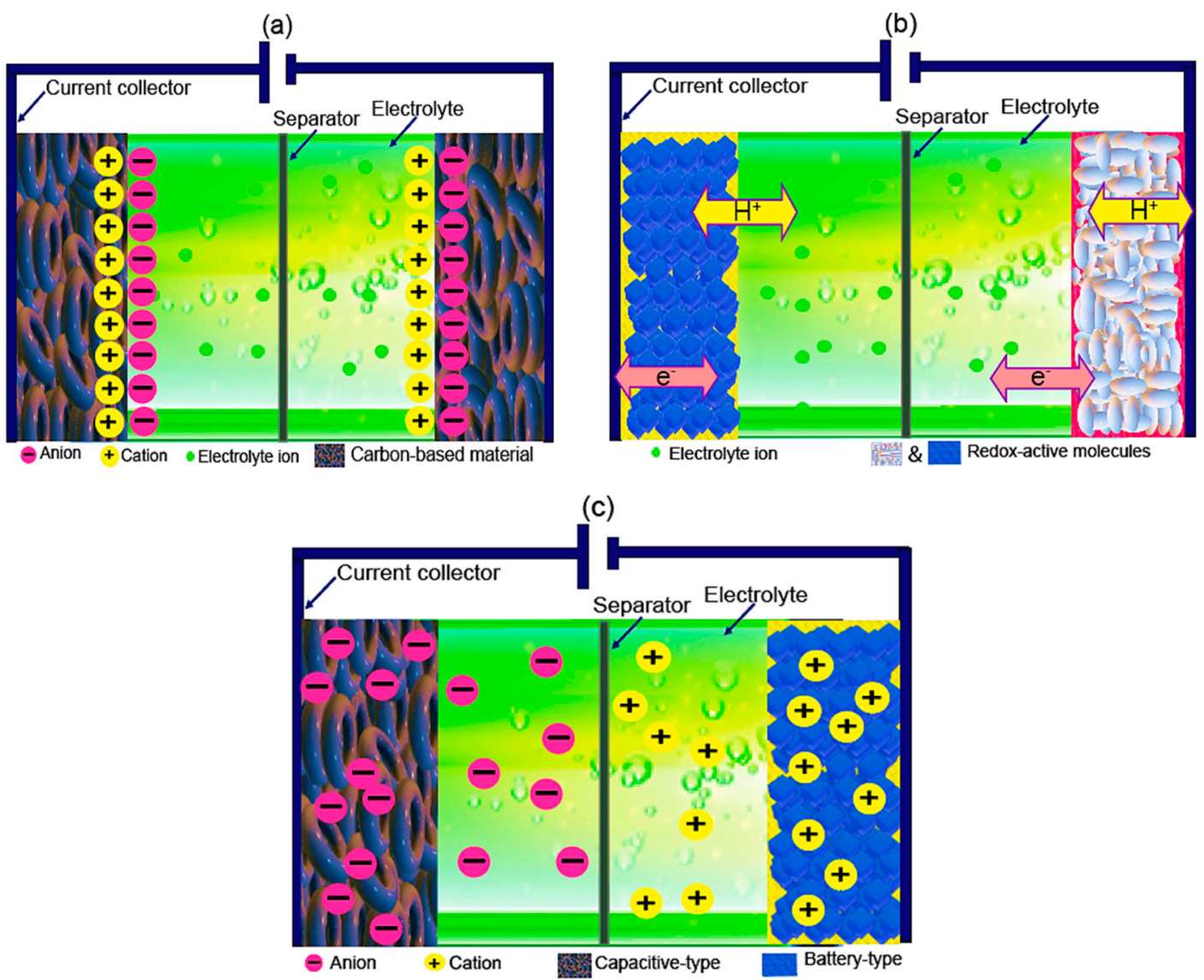

Figure 2. Schematic illustration of supercapacitors: (a) electrical double-layer capacitors (EDLC), (b) Pseudocapacitors, and (c) hybrid supercapacitors (HSCs).

\section{The Distinction between Terminologies Used: Pseudocapacitive and Battery-Like Electrode Materials}

There are various materials, which can be utilized to provide a favorable charge storage mechanism. Generally, the carbonaceous materials are used as capacitive-type electrodes, while transition metal (TM) and conducting polymer-based material can be used as the battery type-electrodes. The battery-type materials can be classified into two groups, including, intercalation-type (intercalation-deintercalation), and conversion-type (two-phase conversion). This classification doesn't mean that charge storage occurs only in one type of mechanism for the electrode materials. The charge storage process of the battery-type electrode materials is associated with both conversion and intercalation-deintercalation behaviour. There are also different electrode materials that exhibit either capacitive or battery-type behavior, depending upon various potential windows, the electrolyte selection, etc. Thus, to simplify the concept, the electrochemical behaviour of the redox-active materials (whether two-phase conversion or intercalation-type) can be described as "pseudocapacitive behaviour".

In the field of supercapacitors, the term "pseudocapacitance" is exploited to define the behavior of electrode materials (e.g., $\mathrm{RuO}_{2}[35,36], \mathrm{MnO}_{2}[37,38]$ ) that exhibit the electrochemical characteristics of a capacitive electrode such as a linear dependency between the stored charge and the potential variation within the certain potential window, however, in this case, the charge storage should be originated from the electron-transfer mechanisms, instead of only relying on the ions accumulation in the electrochemical double layer (EDL), similar to that with activated carbons (AC) [39].

Several types of transition metal oxides (TMOs) have been considered as pseudocapacitive materials in aqueous electrolytes. The charge storage behavior of these materials is associated with their structural and hydration properties as well as the nature of the electrolyte. The structural water provides a large inner surface, which is accessible for ion absorption and leads to improved 
ion diffusion in the inner surface (e.g., $\mathrm{RuO}_{2} \cdot \mathrm{nH}_{2} \mathrm{O}$ ). Thus, the influence of surface-bound water is one of the significant issues, which makes a difference between the aqueous and non-aqueous pseudocapacitive materials. For instance, $\mathrm{MnO}_{2}$ is present in several polymorphs and mainly studied for the pseudocapacitive behavior in a neutral aqueous electrolyte, while it is considered as a battery-like material in alkaline electrolytes. The battery-type behavior in an alkaline electrolyte (e.g., $\mathrm{KOH}$ ) is attributed to the formation of oxyhydroxides during the charging process [40]. Besides, the spinel compounds (e.g., $\mathrm{Mn}_{3} \mathrm{O}_{4}$ [41], $\mathrm{Fe}_{3} \mathrm{O}_{4}$ [42], and $\mathrm{Co}_{3} \mathrm{O}_{4}$ [43]), display both capacitive and battery-like behavior owing to the phase variations, which occurs during the cycling mechanism.

In various studies, the term "pseudocapacitive" has been used for battery-like material such as $\mathrm{Ni}(\mathrm{OH})_{2}[44,45]$ or for other materials that display faradic behavior (even for the materials, that are electrochemically irreversible) [46,47]. This may confuse the reader, since the term "capacitance" with the unit of the farad $(\mathrm{F})$, cannot be applied for the material that their charge storage mechanism is only based on the faradic behavior. For these classes of material, the concept of "capacity" (with the unit of $C$ (coulomb), or $\mathrm{mAh}$ ) is a more significant and suitable term [39]. Figure 3 illustrates the general classification of the pseudocapacitive charge storage mechanism [17].

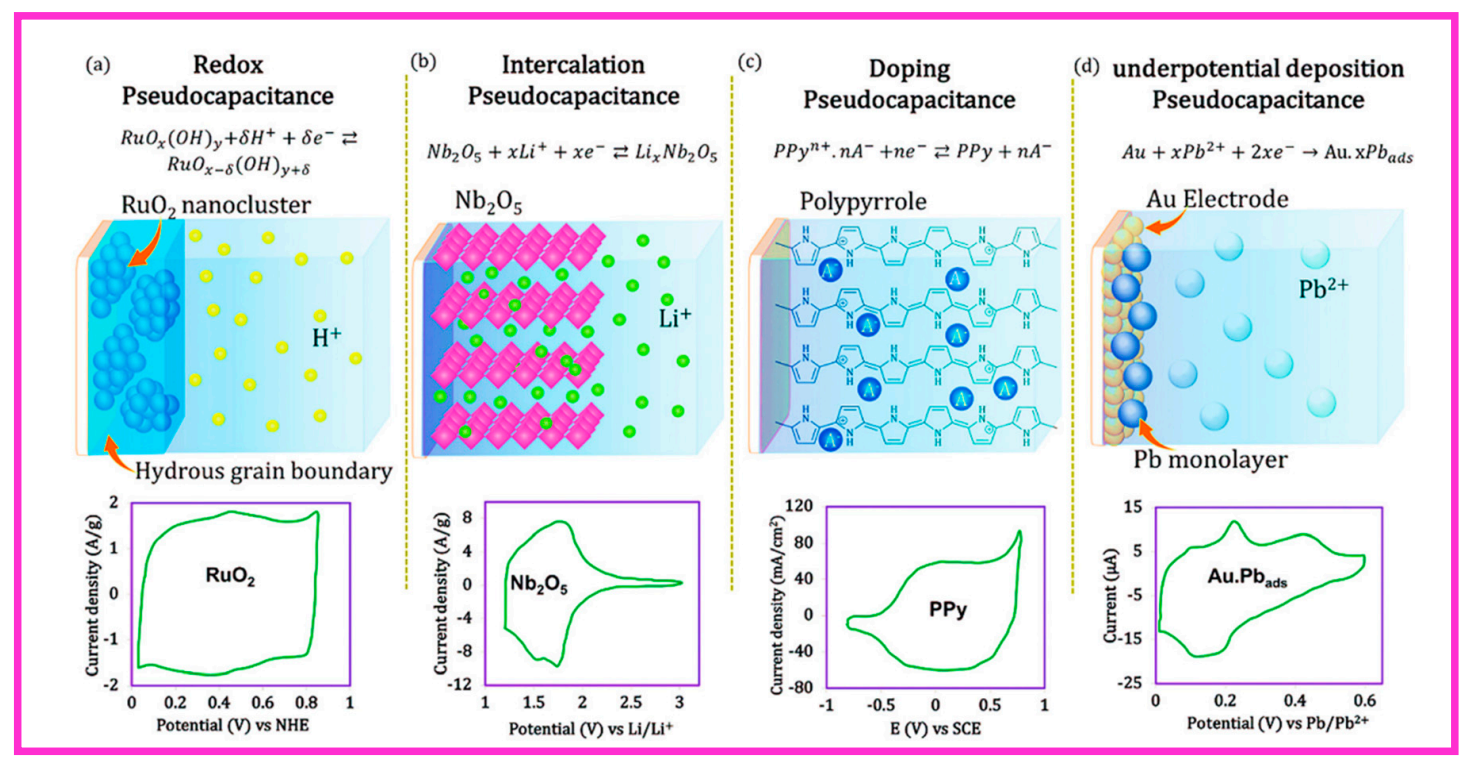

Figure 3. (a) Redox pseudocapacitance, as in $\mathrm{RuO}_{2-\mathrm{x}} \mathrm{H}_{2} \mathrm{O}$. (b) Intercalation pseudocapacitance, as in $\mathrm{Nb}_{2} \mathrm{O}_{5}$. (c) Doping pseudocapacitance, as in polypyrrole, and (d) under potential deposition based pseudocapacitance, such as $\mathrm{Pb}$ deposition on the surface of Au electrode. Reprinted with permission from [17], Copyright 2019, American Chemical Society.

Among these various processes, the intercalation pseudocapacitance is hardly observed, since the charge storage for the corresponding materials is mostly hybrid, which can be defined as a combination of both "battery-type", and "capacitive" behaviors [48]. In order to distinguish between the contributions from battery-like energy storage process and intercalative pseudocapacitance mechanism, the corresponding signatures from the electrochemical measurements (e.g., CVs and GCD), as well as the quantitative kinetics analysis, should be considered, [17,40,49], which are illustrated in Figure 4, [49]. According to the Equation (1) [50], the capacitive contribution and the diffusion-controlled contribution can be examined by investigating the $\mathrm{CV}$ data at different sweep rates, in which the calculated current " $\mathrm{i}$ " follows a power-law relationship with the sweep rate V. The " $a$ " and " $b$ " parameters are changeable, and the $b$ values can be estimated from the slope of the plot of $\log i$ vs. $\log V[49,50]$.

$$
\mathrm{i}(\mathrm{V})=\mathrm{av}^{\mathrm{b}}
$$


As is shown in Figure 4, the " $\mathrm{b}$ " value corresponding to EDLC materials is always equal to 1 , the CVs is rectangular, and in the case of their GCDs, the potential has a linear dependency on time. Pseudocapacitive materials exhibit the CVs in an almost rectangular shape, and the potential of GCDs is practically linear with respect to time. The corresponding " $b$ " value is close to 1 , and as it was mentioned before, the charge storage capability is represented using the F unit. In comparison with EDLCs and pseudocapacitive materials, the battery-type materials show the typical CVs with noticeable redox peaks, and the obvious plateaus are obtained for their corresponding GCDs. The " $\mathrm{b}$ " value for the battery-type material, depends on the nature of material, and it can be 0.5 and higher than 0.5 for conventional bulk battery-type materials or those with specific structural design electrode engineering, and for nanomaterial electrodes, respectively [49].

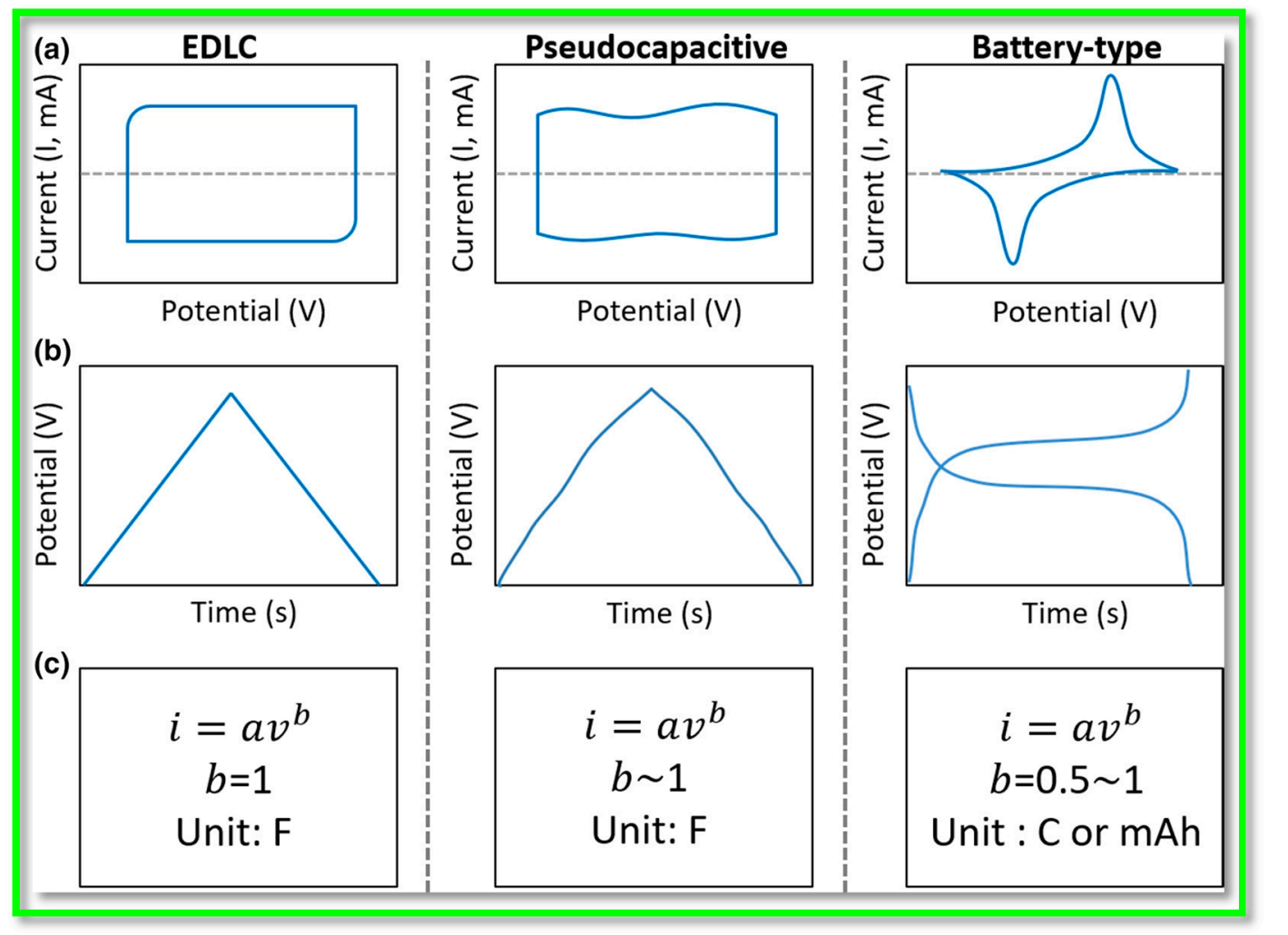

Figure 4. The electrochemical signatures for various type of charge storage mechanisms as EDLC, pseudocapacitive, and battery-type: (a) CVs, and (b) GCDs, along with their (c) quantitative kinetics analysis through the calculation of $\mathrm{b}$ in formula $\mathrm{i}(\mathrm{V})=\mathrm{avb}$. Reprinted with permission from [49], Copyright 2019, Wiley-VCH.

There are several studies, in which the presence of structural water in crystalline oxides resulted in intercalation pseudocapacitance-non-diffusion-controlled proton insertion into the interior of bulk-like oxides. For instance, structural water in layered-hydrated tungsten oxide $\left(\mathrm{WO}_{3} \cdot 2 \mathrm{H}_{2} \mathrm{O}\right)$ induced the transition from battery-like electrochemical behavior to pseudocapacitive behavior for proton intercalation in comparison with the anhydrous $\mathrm{WO}_{3}$ [51].

The substantial difference between battery-like and pseudocapacitive electrode materials is that the charging and discharging time for the pseudocapacitive materials is in the range of seconds-minutes. Therefore, it is worth focusing on emerging pseudocapacitance in order to obtain high energy and high power densities from the same material [40]. 


\section{Electrode Materials}

The selection of electrode materials and their fabrication play a crucial role in enhancing the capacitive performance of SCs [52]. Electrodes of SCs must provide thermal stability, high SSA, corrosion resistance, high electrical conductivity, appropriate chemical stability, and suitable surface wettability. They should also be low-cost and environmentally benign. Besides, their capability of transferring the faradic charge is important to enhance the capacitance performance [53,54].

In fact, the specific capacitance factor is not only affected by surface area, but also there are other essential parameters including the simple morphology manipulation, including pore size distributions, as well as the pore shape, pore sizes, and their availability for the electrolyte $[11,55,56]$.

Thus, two of the most important requirements for designing an SC device are (i) improving the electrochemically active sites by selecting the electrode materials with a high SSA, and (ii) tuning the pore size and pore shape (e.g., circle, vertical rectangle, horizontal rectangle, and square in the case of graphene nanopore [57], and cylindrical, spherical, and slit in the case of the biomass-derived carbon [58]) of the electrode material to make them suitable candidates which ease the transportation of electrolyte ions [11,59].

The electrode material having smaller pores offer higher capacitance and, thus, higher $E_{d}$. However, the smaller the pore size leads to having a higher the equivalent series resistance (ESR), therefore, decreasing the power density. Based on this, the application of the electrode material affects the selection of the materials. For example, for the applications in which having more peak currents is important, the electrode materials should satisfy the criteria of having greater pores, while for the applications that higher $E_{d}$ is required, the electrode materials should have smaller pores $[60,61]$.

Furthermore, the suitable size distribution can improve the retention capability, which is the indication of high $P_{d}$ in an SC device. The effective distribution of micro/mesopores of the electrode material can provide a fast mass and ion transport through a continuous pathway, thus enhance the accessibility of the electrolyte, and make the material an appropriate choice for SC application [62].

The electrode materials are categorized based on three main classes, including carbonaceous materials, TMOs, and conducting polymers (CPs) [63].

Figure 5 shows the classification of the electrode materials for SC application from zero-dimensional (0D) to three-dimensional (3D) structure that is explained in detail through the following sections.

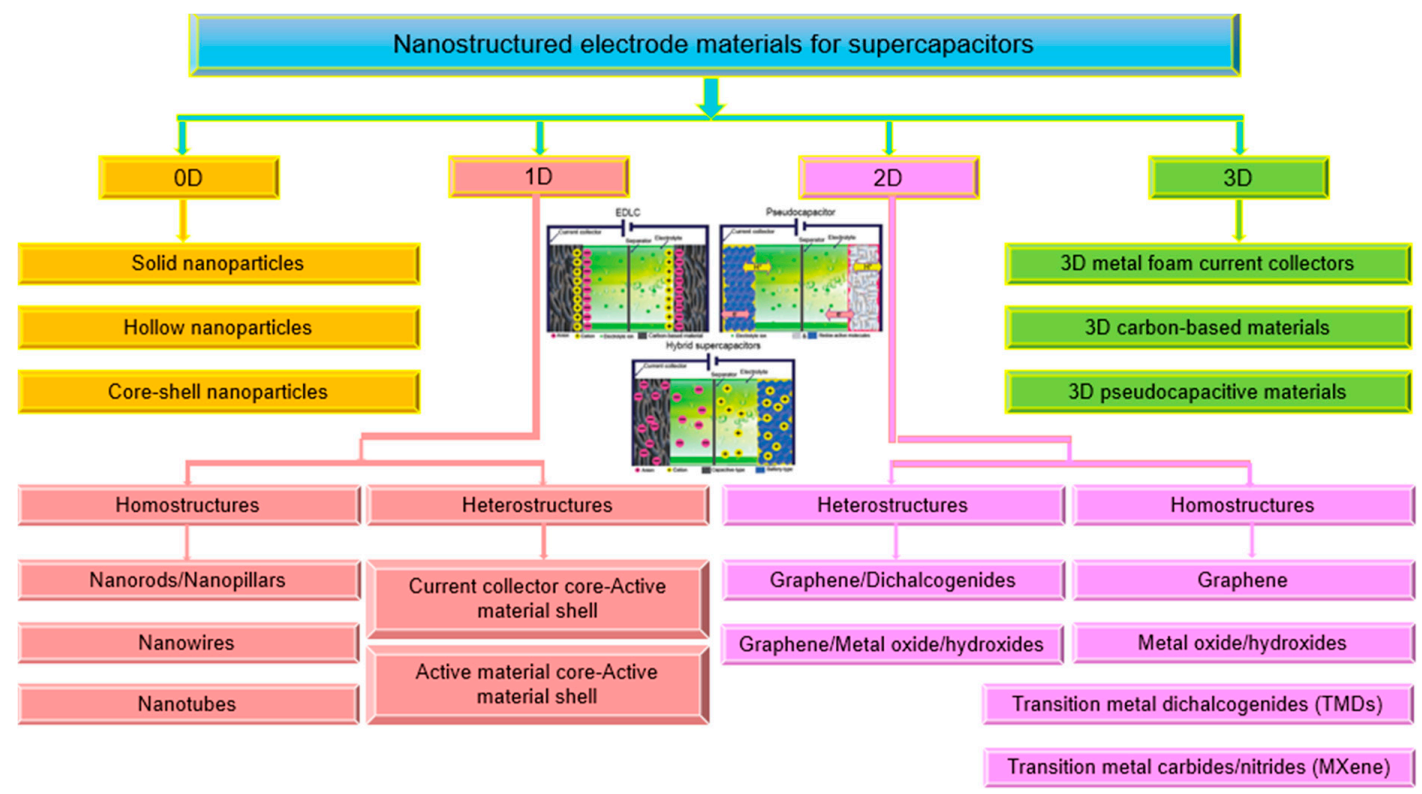

Figure 5. Schematic illustration of the most common supercapacitor electrode materials from 0D to the 3D structure. 


\subsection{Nanostructured Carbon-Based Materials}

The EDLC devices, capacitance mainly derives from the collected charges at the interface between electrodes and the electrolyte. Consequently, the capacitive performance of an EDLC device is extremely affected by the pore sizes, pore distribution and SSAs of the electrode materials $[64,65]$. Becker developed the first EDLC utilizing carbon-based materials in 1975 [66].

Mainly, the carbonaceous materials are utilized as electrode material for EDLCs owing to their improved properties such as high surface area, low cost, eco-friendliness, and their facile synthesis methods [67]. The physicochemical characteristics of the carbon-based material depend on the pore size that is approximately less than $1 \mathrm{~nm}$ [68].

Furthermore, their thermal stability, chemical and electrochemical stability (in various solutions from a strong acidic to basic media), high electrical conductivity, as well as the symmetrical galvanostatic charge-discharge profile and the good rectangular shape of CV curves propose that the carbon-based materials are the useful capacitive materials [54,69-71]. The capacitance of the electrodes extremely relies upon the SSA. Consequently, owing to the large SSA and the high porosity of the carbonaceous materials, they have displayed enhanced capacitance [72].

The charge storage mechanism of the carbon-based electrode mainly depends on the formation of a thin layer known as the Helmholtz layer on the surface of electrode material, which is in contact with the electrolyte ions (both non-dissolved and very weakly-dissolved ions). Secondly, the charge storage derives from the formation of a thicker outer Helmholtz layer, which is made through the existence of the solvated ions conducted by strong electrostatic forces. The indicated layer can be prolonged to a thicker layer, the so-called Gouy-Chapman diffuse layer, through solvated ions and the thermal motion. The degree of charge storage in an EDLC device can be described as the potential difference between the thin inner layer and outer thicker layer (the Helmholtz layers and the Gouy-Chapman diffuse layer), which is known as zeta potential ( $\xi$-potential) [73]. Besides, there is a huge necessity to enhance the capacitance of the carbon-based material to obtain higher $E_{d}$. Introducing the redox-active moieties has provided the pseudocapacitive carbon-based material through different strategies such as utilizing redox-active functional groups [74], chemical doping of the carbon-based material using redox-active small molecules [75] and combining the aromatic isomers adsorbed onto the structure of carbon material [76].

Carbon-based materials could be used in various forms such as powder, fiber, monoliths, and foils in an SC device. In addition to the pore shape and SSA, there are other influential items such as the structure of the material, and pore size distribution, and electrical conductivity that have an important consequence on the electrochemical performance of an SC device [77-79]. There are several common examples of carbon-based material such as, carbon aerogels [80], graphene [81], AC [82], activated carbon fibres (ACF) [82], carbon nanotube (CNT) [83], and carbon cloth(CC) [84] as well as various carbon-based composites, which are suitable to be used as the electrode materials in SC devices, and are explained in detail through the following sections.

\subsubsection{Activated Carbon Materials (ACs)}

Activated carbons are the most commonly used material for EDLC electrodes with moderate cost [85] that show a complex porous structure comprising micropores (smaller than $2 \mathrm{~nm}$ ), mesopores (in the range of $2-50 \mathrm{~nm}$ ), and macropores larger than $50 \mathrm{~nm}$ that lead to having a high SSA $[11,54,69,86]$. Furthermore, although their good electrical conductivitie is lower $\left(1250-2500 \mathrm{Sm}^{-1}\right)$, still, it is suitable for SCs. According to those properties, activated carbons are considered as useful electrode materials for SCs [82,87-92]. Activated carbon can be produced in two steps and involving either chemical or physical activation from various types of carbon-rich organic precursors such as fossil fuels, coke or synthetic polymers, wood, coconut shells [11].

The carbonization step involves the treatment of precursors in the exposure of oxidizing gases, such as $\mathrm{CO}_{2}$, steam, and air, at high temperatures $\left(700-1200^{\circ} \mathrm{C}\right)$ in an inert atmosphere to obtain the amorphous carbon. In the activation step, the applied temperature is lower (400 to $700{ }^{\circ} \mathrm{C}$ ). 
The chemical activation process is carried out in the presence of the activating agents like carbonates, alkalis, chlorides, or acids such as $\mathrm{NaOH}, \mathrm{KOH}, \mathrm{ZnCl}_{2}$, and $\mathrm{H}_{3} \mathrm{PO}_{4}$ that lead to having a porous network in the carbon particles bulk $[87,93]$.

Activated carbon shows plenty of physicochemical properties based on the carbon precursors used and activation methods that have a strong influence on its surface area, porous structure, and the pore size distribution [93].

As mentioned, activated carbon can be obtained from various carbon-rich organic precursors. The obtained coconut shell-based activated carbon exhibits supplementary micropores than the one which is made from charcoal. The research shows that a slighter pore size distribution can be conveniently measured in the case of activated carbon fibre made from activated carbon with the surface area around $2500 \mathrm{~m}^{2} \cdot \mathrm{g}^{-1}$ [15]. Since the electrolyte ions with large size cannot inter to the smaller micropores, for activated carbon, the whole SSA does not contribute to the charge storage mechanism [70,71].

Here, a maximum obtainable surface area was estimated by $3000 \mathrm{~m}^{2} \cdot \mathrm{g}^{-1}$; however, the effective surface area is obtained between 1000 to $2000 \mathrm{~m}^{2} \cdot \mathrm{g}^{-1}$ [93]. Despite those enhancements in the case of specific area and porosity of the activated carbon, there are some reports indicating electrolyte decomposition and dangling bond positions derived by the increase in SSA [94].

The specific capacitance values for the activated carbon electrodes in aqueous electrolytes (between 100 to $\left.300 \mathrm{~F} \cdot \mathrm{g}^{-1}\right)$ is higher than in organic solution $\left(<150 \mathrm{~F} \cdot \mathrm{g}^{-1}\right)$, since the size of the ions for the organic electrode is larger $[11,95]$ Wang et al., shown that by increasing the SSA of AC from $621 \mathrm{~m}^{2} \cdot \mathrm{g}^{-1}$ to $2685 \mathrm{~m}^{2} \cdot \mathrm{g}^{-1}$, the specific capacitance of the electrodes was improved from $17.68 \mathrm{~F} \cdot \mathrm{g}^{-1}$ to $171.2 \mathrm{~F} \cdot \mathrm{g}^{-1}$ [72].

As a result, estimating the pore size suitable for a specified ion size is one of the items that should be considered. Choosing an appropriate method is essential to improve the pore size distribution in the assembly process. According to previous reports, the pore size of $0.8 \mathrm{~nm}$ can be suitable in the case of organic electrolytes, while the pore size of 0.4 or $0.7 \mathrm{~nm}$ can be useful for the aqueous electrolytes [70,71]. Furthermore, the surface functionalization of the carbon material results in an increase faradaic redox reactions and, consequently, enhancement of about 5 to $10 \%$ in capacitance [96]. Achieving a maximum specific capacitance highly depends upon the coordination between the pore size and the ion size $[97,98]$.

One of the significant disadvantages of activated carbon is its low density. Moreno-Fernandez et al. [82] showed that a high specific capacitance value $\left(200 \mathrm{~F} \cdot \mathrm{g}^{-1}\right)$ could be attained through the synthesis of the activated carbon fibre monolith that leads to a higher density by three times more. In another study, $\mathrm{Li}$ et al. [99] have fabricated activated carbon made by lignite at activation temperatures of $650{ }^{\circ} \mathrm{C}$, which displayed cyclic stability over 3000 cycles, a specific capacitance of $207.5 \mathrm{~F} \cdot \mathrm{g}^{-1}$ as an electrode material for SC at a current density of $0.5 \mathrm{~A} \cdot \mathrm{g}^{-1}$.

Recently, hybrid lithium-ion SCs have been fabricated using the agar-derived AC as the cathode material, which stores the charge through the electric double-layer capacitance behaviour. The HSC provides both properties of high $\mathrm{P}_{\mathrm{d}}$ (like capacitors), and high $\mathrm{E}_{\mathrm{d}}$ (like lithium batteries). AC showed an appropriate pore volume and a narrow pore-size distribution that leads to having a large SSA more than $1672 \mathrm{~m}^{2} \cdot \mathrm{g}^{-1}$, the high specific capacitance of $210.4 \mathrm{~F} \cdot \mathrm{g} \cdot \mathrm{AC}^{-1}$. The HSC provided a high $\mathrm{E}_{\mathrm{d}}$ of $308.3 \mathrm{Wh} \cdot \mathrm{kg} \cdot \mathrm{AC}^{-1}$ at a specific power of $0.7 \mathrm{~kW} \cdot \mathrm{kg} \cdot \mathrm{AC}^{-1}[100]$.

The electrochemical performance of the ACs could be improved through different strategies such as the Fermi level position modification of the ACs using ultrasonic radiation [101], modification of the AC surface through oxidation process [102], doping sulfur and oxygen functionalities on the porous structure of ACs [103], fabricating a composite using ACs and other carbon nanomaterials (e.g., carbon nanotubes (CNTs) and carbon nanofibers (CNFs), etc.) [104], and inserting polymers into the carbon substrate to form composite electrodes $[105,106]$.

For instance, Cheng et al. [104] developed a new class nanocomposite electrode through the combination of the conventional ACs and carbon black (CB) with CNTs and CNFs. The resultant electrodes showed excellent electrochemical performance in comparison with that electrode of pure 
AC due to the synergistic effects of combined species. The quaternary nanocomposite electrode (Figure 6a-d) exhibited high capacitance retention in which $91.4 \%$ of capacitance remained after 30,000 charging-discharging cycles at $10 \mathrm{~A} \cdot \mathrm{g}^{-1}$ (Figure 6e). Compared to the AC electrode, the nanocomposite showed enhanced $E_{\mathrm{d}}$ of $29.6 \mathrm{Wh} \cdot \mathrm{L}^{-1}$ at a $\mathrm{P}_{\mathrm{d}}$ of $101.7 \mathrm{~kW} \cdot \mathrm{L}^{-1}$ (Figure $6 \mathrm{f}$ ) as well as a high capacitance of $66.1 \mathrm{~F} \cdot \mathrm{cm}^{-3}$.

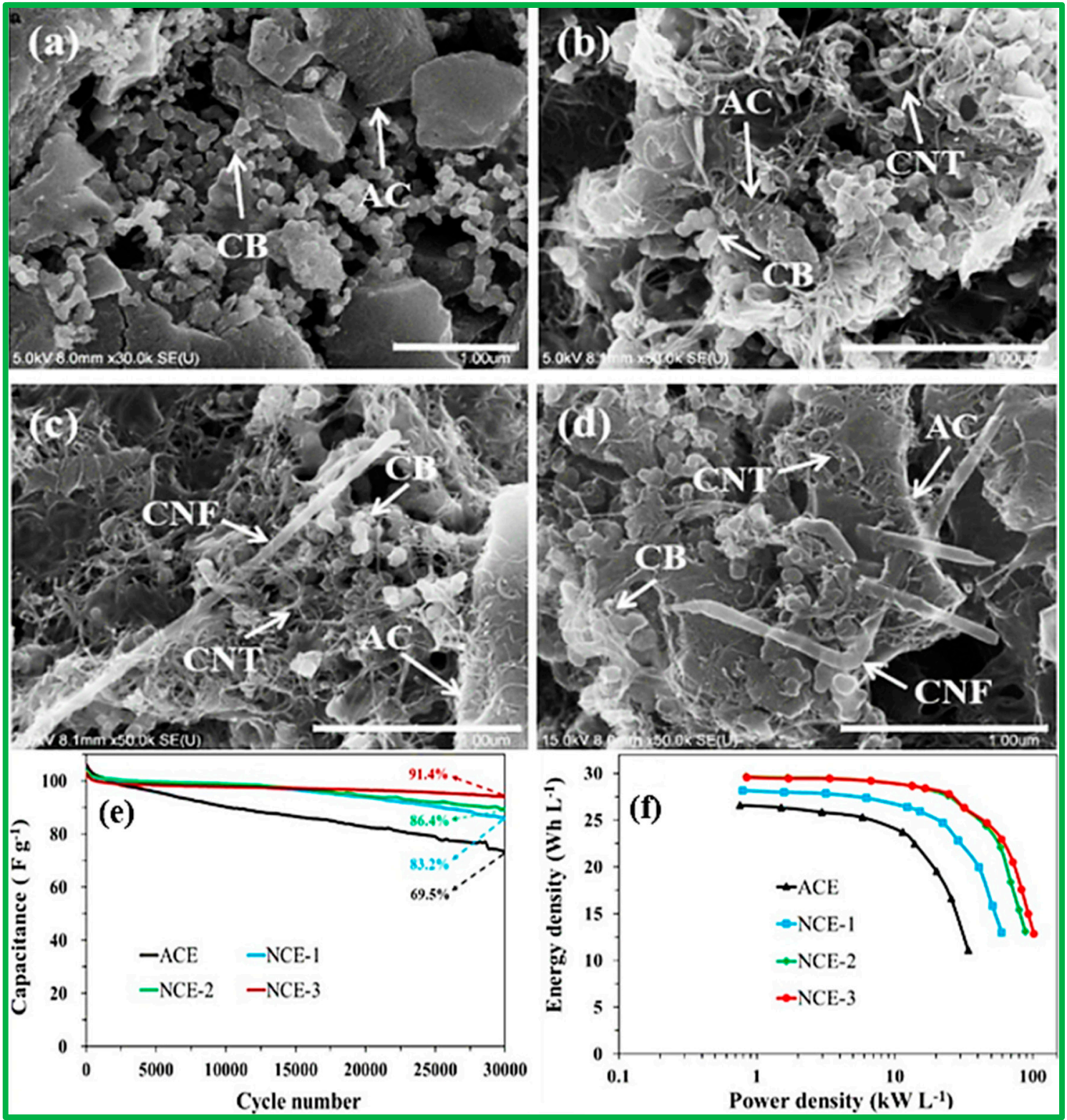

Figure 6. SEM images of (a) binary ACE (activated carbon electrode) composite electrode, with the weight percentage of 90 to 5 for activated carbons (AC)/carbon black (CB). (b) Ternary NCE-1 composite electrode (with the composition of AC/CB/carbon nanotube (CNT) (90/1.25/3.75)). (c) Ternary NCE-2 composite electrode (with the composition of (AC/CB/CNT/carbon nanofibers (CNF) (90/1.25/3.125/0.625)). (d) Quaternary NCE-3 composite electrode (with the composition of $\mathrm{AC} / \mathrm{CB} / \mathrm{CNT} / \mathrm{CNF}(88.75 / 1.25 / 3.75 / 1.25))$. (e) Capacitance retentions of various composite electrodes. (f) Ragone plots of the performance of various composite electrodes according to the total volume of the coating films of the two electrodes of the device. Reprinted with permission from [104], Copyright 2019, Elsevier. 


\subsubsection{Carbon Nanotubes (CNTs)}

Electrodes of CNTs have been developed due to their unique properties, such as their accessible external structure with high SSA and the specific internal network of mesopores, chemical and thermal stability, superior electrical conductivity, and low mass densities.

Furthermore, the mechanical flexibility of the CNTs and their open network provides them with a link to active material, higher interconnection, and to form a continuous distribution that leads to the more utilized SSA [11,107].

The CNT electrodes show lower ESR, and consequently higher power than ACs since the mesoporous structure of CNT networks allows the ions of the electrolyte to diffuse easier and faster [108] (Figure 7a,b). Du et al. decreased the ESR of electrodes outstandingly, through the adopting thin films fabricated by means of a highly concentrated colloidal suspension of CNTs [109]. The CNTs could be fabricated through different methods. Shi et al. [110] stated the importance of CNTs synthesize method on the performance of the electrode. CNTs were grown on 3D porous nickel (Ni) foam by means of the single-step CVD method, in which the resultant electrode exhibited a superior capacitive performance at higher current densities, less ESR, and a capacitance about $127 \%$ greater than the CNT electrode fabricated through the conventional transfer technique. However, the low SSA is the limiting factor for CNT application in high-performance SCs.

CNTs could be used as electrode material for SCs in the form of composite along with other materials such as graphene, metal oxides (MOs), polymer. Q. Cheng [108] studied the electrochemical properties of the graphene, CNTs, and their composite electrode material for SC in various electrolytes. Graphene/CNTs electrodes showed superior electrochemical properties (Figure $7 \mathrm{c}, \mathrm{d}$ ) $\mathrm{E}_{\mathrm{d}}$ of $155.6 \mathrm{Wh} \cdot \mathrm{kg}^{-1}$, and a maximum $P_{d}$ of $263.2 \mathrm{~kW} \cdot \mathrm{kg}^{-1}$ in ionic liquid as well as a specific capacitance of $290.4 \mathrm{~F} \cdot \mathrm{g}^{-1}$. As is shown in Figure 7c, the graphene/CNTs composite exhibited the most rectangular geometry, which is an indication for an outstanding charge dispersion in the electrodes.

Furthermore, they have reported an interesting phenomenon known as "electro-activation", in which the specific capacitance of graphene and graphene/CNTs not only did not reduce after a long time cycling in the $1 \mathrm{M} \mathrm{KCl}$ electrolyte but also have shown a high increase. It has been reported that the ions result in the larger spacing amid the graphene sheets, thus providing a larger surface area, which presents higher available double-layer capacitance (Figure 7e,f).

CNTs can be classified into two main categories such as SWCNTs and multi-walled carbon nanotubes (MWCNTs) [111]. Generally, CNTs can be synthesized via catalytic decomposition of certain hydrocarbons. Several parameters, such as crystalline orders, can be manipulated to obtain a different conformation like SWCNTs and MWCNTs [87]. In the case of the SWCNTs, they usually form bundles, which limits their surface area and only the outermost surface can be available for electrolyte ions [108].

The performance of the single-walled CNTs was profoundly affected by the accessibility of electrode materials and the size of the electrolyte ions [112]. The theoretical SSA for SWCNTs was reported at about $1315 \mathrm{~m}^{2} \cdot \mathrm{g}^{-1}$, while the SSA for MWCNTs was smaller than ACs. This smaller SSA leads to a lower $\mathrm{E}_{\mathrm{d}}$ for CNT in comparison with AC [87]. However, the MWCNTs mesopores structure provides easier ions movement across the electrode-electrolyte interface, their mechanical stability decreases because of the volume change derived from the frequent intercalation and depletion [113]. 


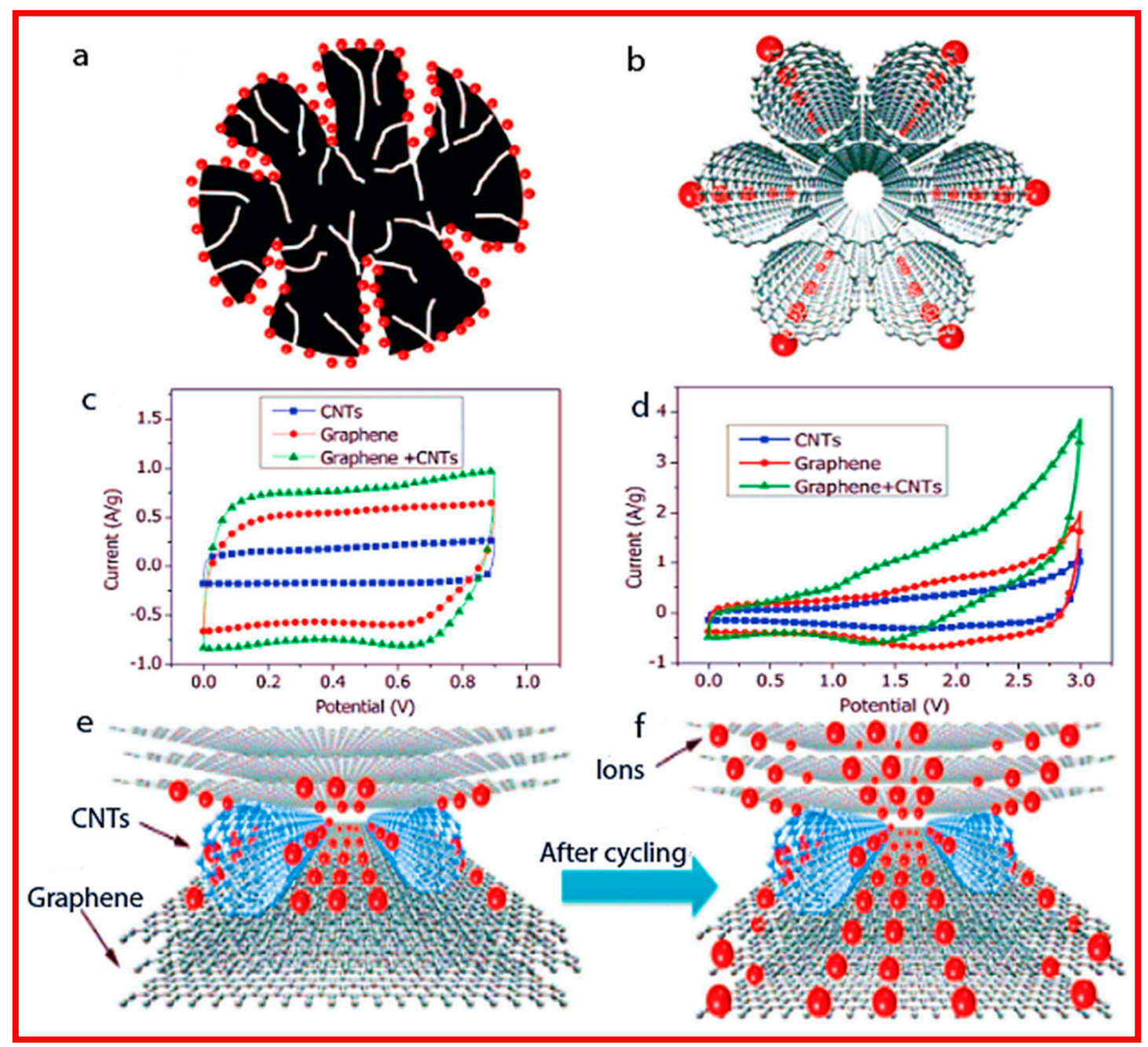

Figure 7. AC with high surface area; however, most of the micropores surface is not available for the electrolyte ions. (a) Single-walled carbon nanotube (SWCNT). (b) Cyclic voltammograms (CVs) for different electrode materials made of CNTs, graphene, and their composite in the aqueous electrolyte at a scan rate of $10 \mathrm{mV} \cdot \mathrm{s}^{-1}$ (c), CVs for the same material as part (c), but in a different electrolyte (1 M TEABF4/PC electrolyte) at the same scan rate of $10 \mathrm{mV} \cdot \mathrm{s}^{-1}$. (d) The illustration of the electro-activation phenomenon to improve the electrode surface area after charging-discharging cycles: Graphene layers before cycling, which are tending to restack. (e) After a long cycle life, the intercalated ions separated the graphene sheets, thus increasing the surface area accessible for electrolyte ions, and consequently an enhancement in the capacitive property of the material. (f) Reprinted with permission from [108], Copyright 2011, Royal Society of Chemistry.

The CNT materials can go through the chemical activation using potassium hydroxide to improve the specific capacitance, which leads to enhancing the surface area of CNT to be two or three times higher while the morphology of the CNT is still defined [87].

The morphology and the purity and of the final CNT material are two crucial factors that affect the specific capacitance of the electrodes [87]. For instance, the MWCNT sheet electrodes were synthesized via catalytically-grown CNTs, which had a diameter of $80 \AA$ and a higher SSA of $430 \mathrm{~m}^{2} \cdot \mathrm{g}^{-1}$ than another CNT with a maximum specific capacitance of $104 \mathrm{~F} \cdot \mathrm{g}^{-1}$ derived from different methods [114]. In another report, the effect of the acid treatment on the specific capacitance of MWCNTs was studied. In comparison with the specific capacitance of the untreated CNTs $\left(\sim 10 \mathrm{~F}^{-1} \mathrm{~g}^{-1}\right)$, the treated MWCNTs provided a specific capacitance of about $50 \mathrm{~F} \cdot \mathrm{g}^{-1}$. According to the FTIR spectrum, the obvious peak corresponds to the $\mathrm{C}-\mathrm{H}$ bond in pristine $\mathrm{CNTs}$ became negligible in the acid-treated MWCNTs, 
which indicated that the acid treatment could chemically modify the $\mathrm{C}-\mathrm{H}$ defects to introduce more oxygen-containing groups such as carboxyl, carbonyl, and hydroxyl groups to the surface of MWCNTs [115].

Xie et al. [53] synthesized hierarchical porous carbon microtubes (HPNCTs) through the simple carbonization and following $\mathrm{KOH}$ activation method utilizing willow catkins. The final product showed a tubular structure, derived from the willow catkins as well as a highly porous morphology as a result of the activation process. The resulting material showed a gravimetric capacitance of $292 \mathrm{~F} \cdot \mathrm{g}^{-1}$, the SSA of $1775.7 \mathrm{~m}^{2} \cdot \mathrm{g}^{-1}$.

CNT materials could be deposited directly onto the conductive substrates. In this case, the CNTs act as mechanical support, which increases electron transport, thus decreasing the contact resistance between the current collectors and active materials [116].

Furthermore, various classes of materials and composites were used to coat the CNTs to enhance the electrochemical properties of the electrode. The CNT current collectors provide high cyclic stability, high rate capability, as well as enhanced $\mathrm{E}_{\mathrm{d}}$ [117].

For instance, Liu et al. [117] fabricated flexible supercapacitors (FSCs) containing high-performance fibrous electrodes using the composite of $\mathrm{MnO}_{2}$ nanorods, which have been loaded on MXene nanosheets (NSs), and coated on carbon nanotube fibres (CNTFs). In this study, the resultant $\mathrm{MnO}_{2} @ \mathrm{MXene} / \mathrm{CNTF}$ displayed high capacitance retention after 5000 cycles, excellent specific capacitance, and superior flexibility. The CNTFs were applied as a current collector with excellent mechanical and electrical properties.

CNTs could be used as an electrode material along with novel MXene materials [118], TMOs [119], and their composites [117], which are the most common electrode materials for the SC.

\subsubsection{Graphene}

Graphene is a one-atom-thick layered 2D structure with $\mathrm{sp}^{2}$-bonded carbon atoms, which are arranged in a honeycomb-designed crystal structure [120-124]. Graphene, as a unique carbon material, shows excellent features including superior mechanical, morphological characteristics, and electrical conductivity, as well as high carrier mobility, large surface area, and high chemical stability [125-127]. Furthermore, the 2D structure of graphene decreases the thickness of the electrode that leads to obtaining a larger potential window, greater flexibility, chemical, and thermal stability [124]. Due to these properties, graphene is a powerful candidate for energy storage applications [123].

Accordingly, graphene could be utilized as electrode material in the application of high-performance SC, since, in comparison with other carbon-based materials such as ACs and CNTs, graphene-based electrodes do not depend on the distribution of pores in the solid-state [128,129]. Another advantage of utilizing the graphene as an electrode material is the accessibility of both exterior surfaces of the graphene sheet by the electrolyte $[68,130,131]$.

A specific capacitance of $205 \mathrm{~F} \cdot \mathrm{g}^{-1}$ has been obtained for the SC fabricated using graphene-based electrodes. The resultant SC showed an $E_{d}$ of $28.5 \mathrm{Wh} \cdot \mathrm{kg}^{-1}$ and a $\mathrm{P}_{\mathrm{d}}$ of $10 \mathrm{~W} \cdot \mathrm{g}^{-1}$ [132]. In another study, the flexible thin films of carbon showed that the final graphene material exhibited an electrical conductivity of $5880 \mathrm{~S} \mathrm{~m}^{-1}$ and a high SSA of $2400 \mathrm{~m}^{2} \cdot \mathrm{g}^{-1}$. The obtained specific capacitance and the $\mathrm{E}_{\mathrm{d}}$ of the graphene material were reported about $120 \mathrm{~F} \cdot \mathrm{g}^{-1}$ and $26 \mathrm{Wh} \cdot \mathrm{kg}^{-1}$, respectively [133].

There are plenty of methods to produce various types of graphene, such as micromechanical exfoliation, epitaxial growth, chemical vapour deposition, unzipping of CNTs, electrochemical and chemical approaches, arch discharge method and intercalation techniques in graphite $[68,130,131]$, Figure 8 illustrates the synthesis of $\mathrm{N}$-doped porous graphene (N-pGr), in which the pGr was obtained through the oxidation of epoxy groups on the surface of reduced graphene oxide $(\mathrm{rGO})$ using $\mathrm{H}_{2} \mathrm{O}_{2}$, in addition to the hydrolysis of hydroxyl functionalities through the parallel breaking of graphene $\mathrm{C}-\mathrm{C}$ bonds $[134,135]$. 


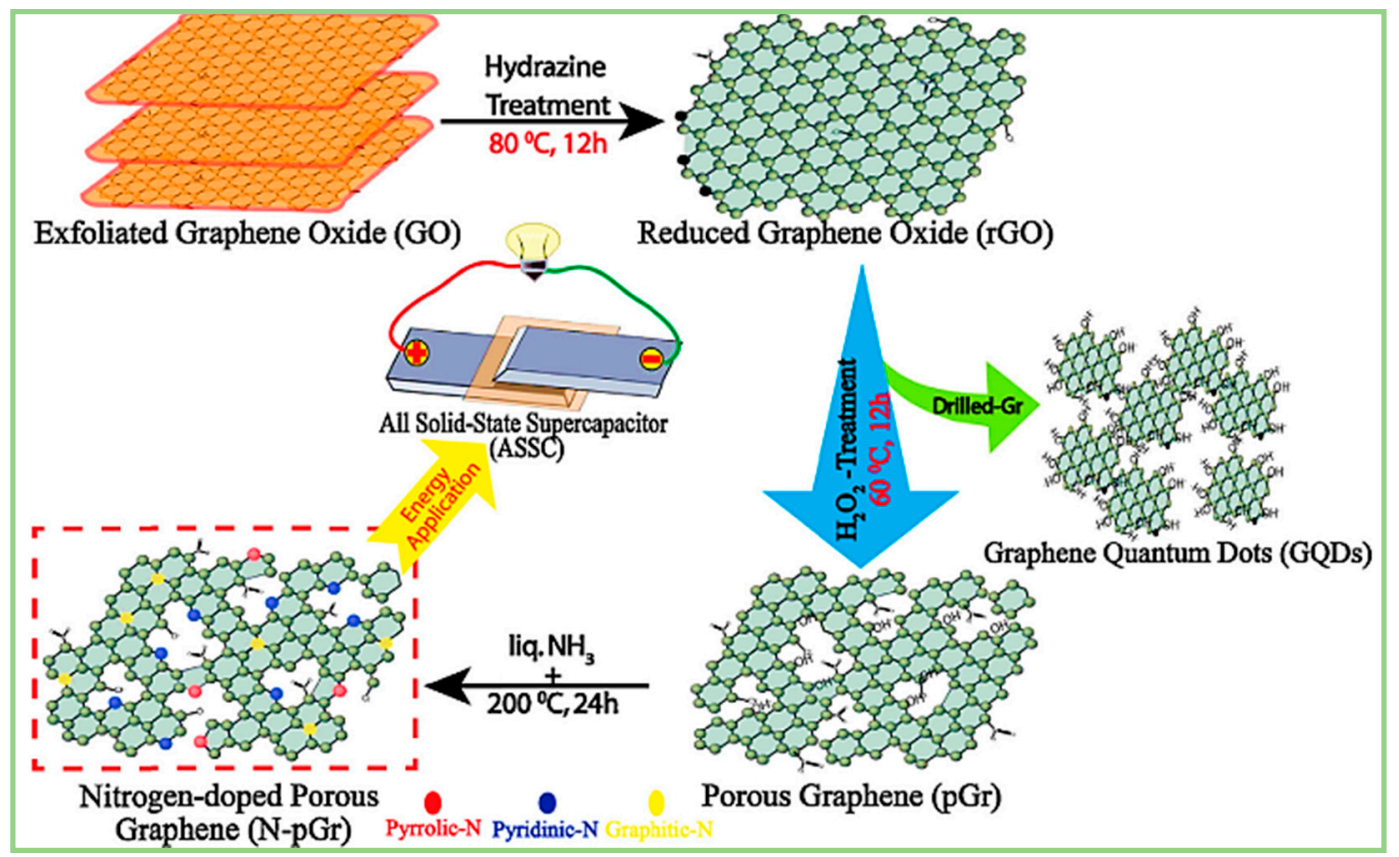

Figure 8. Graphical representation of the synthesis of N-pGr and graphene quantum dots (GQDs) and their potential application for the fabrication of the asymmetric supercapacitors (ASSC) device. Reprinted with permission from [136], Copyright 2017, Elsevier.

Nanostructured graphene oxide (GO) could be synthesized with different morphology such as single layers, few layers, and 3D porous structures through the hydrothermal process. The morphology could be controlled through the process, adding various quantities of $\mathrm{Ni}^{2+}$. Among the various morphologies, the 3D porous structure displayed an optimum specific capacitance of $352 \mathrm{~F} \cdot \mathrm{g}^{-1}$ at a scan rate of $5 \mathrm{mV} \cdot \mathrm{s}^{-1}$ [137].

Ogata et al. [138] prepared the $\mathrm{rGO} / \mathrm{GO} / \mathrm{rGO}$ device, which showed both SC and battery behaviour. The device behaved as a proton-type SC until the operating voltage about $1.2 \mathrm{~V}$, and for voltages higher than $1.5 \mathrm{~V}$, the device provided the redox reaction through the interaction between the oxygenated functional moieties on the rGO and behaving as a battery.

Moreover, Liu et al. [125] solved the problems of water-based electrolytes to function at broader voltage windows, synthesizing a surface compatible and pore accessible graphene for ionic liquid electrolytes. They prepared a mesoporous graphene network which was accessible to the ionic electrolyte and was able to operate a voltage up to $4 \mathrm{~V}$. The synthesized material showed the $\mathrm{E}_{\mathrm{d}}$ of $136 \mathrm{Wh} \cdot \mathrm{kg}^{-1}$, and $90 \mathrm{Wh} \cdot \mathrm{kg}^{-1}$ at $80^{\circ} \mathrm{C}$, and at room temperature, respectively.

In another study, a symmetrical SC was assembled utilizing various electrode materials made of GO, polyvinylidene fluoride (PVDF), and $\mathrm{KOH}$ with a different ratio. Among all the samples in this study, G1p4K6-2, and G1p9K6-4 showed better electrochemical performance, in which, for the sample G1p9K6-4, the maximum $E_{d}$ of $78 \mathrm{Wh} \cdot \mathrm{kg}^{-1}$ at $\mathrm{P}_{\mathrm{d}}$ of $875 \mathrm{Wk} \cdot \mathrm{g}^{-1}$ and high specific capacitance of $185 \mathrm{~F} \cdot \mathrm{g}^{-1}$ at $0.5 \mathrm{~A} \cdot \mathrm{g}^{-1}$ was obtained [139]. The samples were named as Gx1px2Kx3-x4, in which G stands for $\mathrm{GO}, \mathrm{p}$ represents PVDF, $\mathrm{K}$ is for $\mathrm{KOH}, \mathrm{x} 1$ and $\mathrm{x} 2$ signify the relative content ratio of PVDF to $\mathrm{GO}, \mathrm{x} 3$ is the relative content ratio of $\mathrm{KOH}$ : (GO + PVDF), $\mathrm{x} 4$ is the reaction time, and " $\mathrm{t}$ " is the activation time. It was reported that extending the activation time led to having an increase in the effective crystallite size due to the loss of some amorphous carbon in the ignition during the time after completing the activation process. SEM image (Figure 9a) shows the highly porous structures for the sample G1p9K6-4 in comparison with other samples such as G1p4K6-2 (Figure 9b), which is the indication of higher SSA mesopore volume, thus having superior capacitive behaviour of that sample. Figure $9 \mathrm{c}$ represents the CV curves of the symmetric SC. The capacitive performance of the HSG device is presented in different galvanostatic charge-discharge current densities and various 
electrolytes through Figure 9d. The sample G1p9K6-4 having more SSA, revealed a higher $P_{d}$ and $E_{d}$ (Figure 9e), and a larger pore volume (Figure 9f) of $2.05 \mathrm{~cm}^{3} \mathrm{gr}^{-1}$ in nano carbons, which ease the ion transport through the mesopores [139].
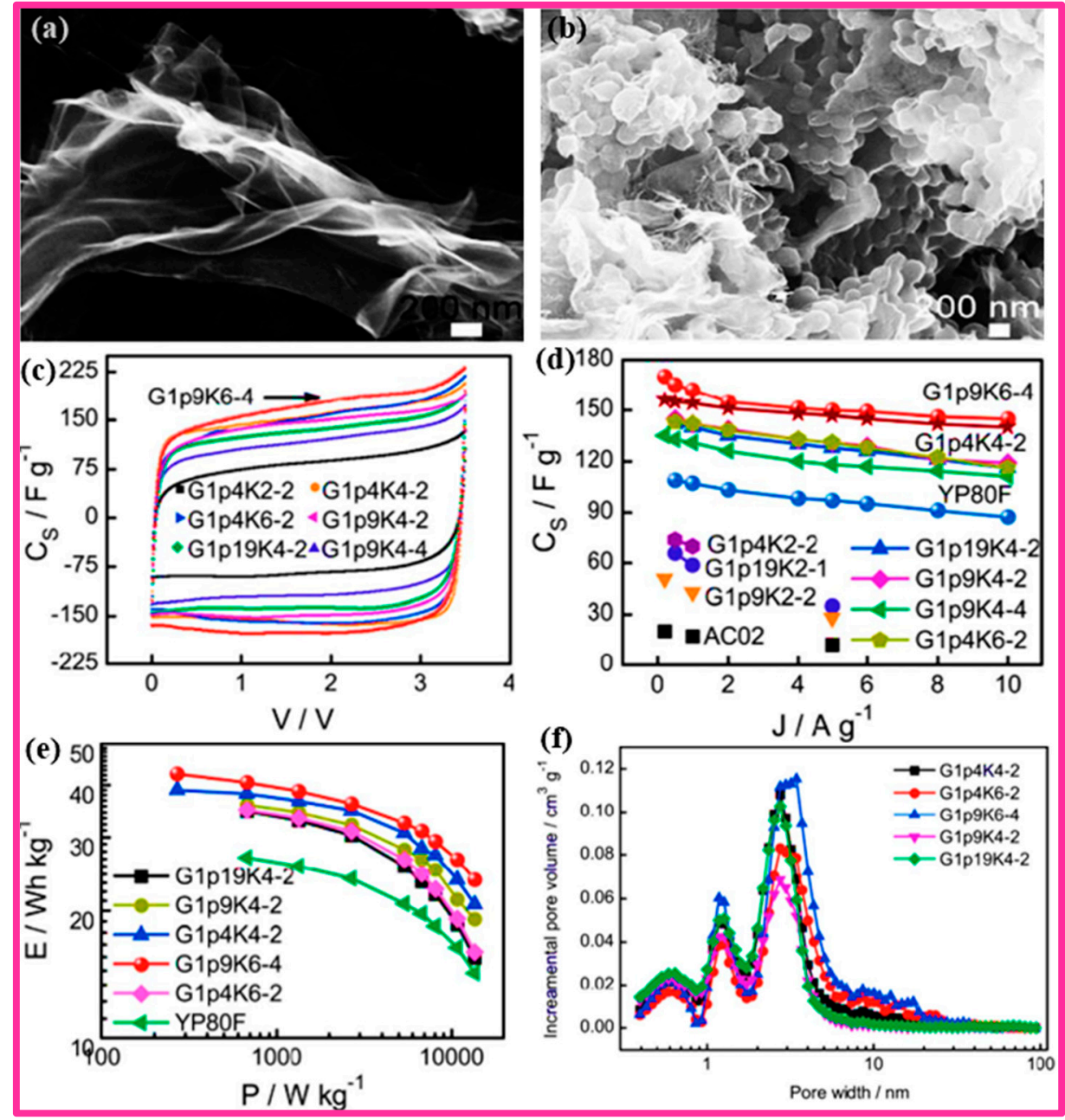

Figure 9. SEM images of the samples (a) G1p4K4-2, and (b) G1p9K6-4, (c)The CV curves illustration for the HSG device electrodes at a scan rate of $20 \mathrm{mV} \cdot \mathrm{s}^{-1}$. (d) The specific capacitance of the various samples in different densities, for the HSG device with the TEABF4 as the electrolyte. (e) Ragone plot for the HSG device including the propylene carbonate + TEABF4, as electrolyte material. (f) The pore size distribution of the HSG electrode material samples. Reprinted with permission from [139], Copyright 2015, Royal Society of Chemistry.

The graphene nanosheets (GNSs) could be used as electrode material for SC in 2D (also known as graphene paper), or 3D structure. In the case of 2D graphene, the layers, stacking could occur owing to the interplanar $\pi-\pi$ interactions and van der Waals forces between the graphene sheets, which leads to a decrease in SSA, limiting the ion diffusion from the electrolyte, thus decrease in the electrochemical performance. There are various strategies to address this problem such as template-assisted growth [140], adding spacers [141,142], and crumpling the graphene layers [143].

For instance, Wang et al. [141] increased the distance between the graphene layers by incorporating a small quantity of the pillared carbon black (CB) nanoparticles, which are used as a spacer. Therefore, the electrochemical properties of the flexible graphene papers improved owing to the resultant open structure, which eases the charge storage and ion transfer.

Besides, graphene-based hydrogels are another class of electrode material that exhibited excellent electrochemical performance for SC owing to their highly porous structure and abundant active sites. 
Recently, an FSC device was fabricated using graphene-based composite hydrogel. The composite was obtained through the modification of the functionalized GQDs. The resultant electrode provided an excellent capacitance value of $451.7 \mathrm{~F} \cdot \mathrm{g}^{-1}$ and good mechanical flexibility.After 10,000 cycles, $89.0 \%$ of capacitance remained [144].

Besides, a redox SC was fabricated using the graphene-based aerogel material as the negative electrode (Nile Blue-conjugated graphene aerogel (NB-GA)), which exhibited excellent pseudocapacitive performance in acidic, neutral and alkaline electrolyte, as well as a high specific capacitance, more than $483 \mathrm{~F} \cdot \mathrm{g}^{-1}$ [142]. Incorporating the pseudocapacitive material between the GNSs prevented the agglomeration of the graphene layers, thus increasing the SSA and the supercapacitive performance. Figure 10 [143] shows that the Nile Blue material fulfils the requirements to be suitable as redox-active material including (a) well physical and chemical conjugation with the graphene surface, (b) having electrochemical behaviour, (c) staying stable over the whole range of $\mathrm{PH}$, etc.

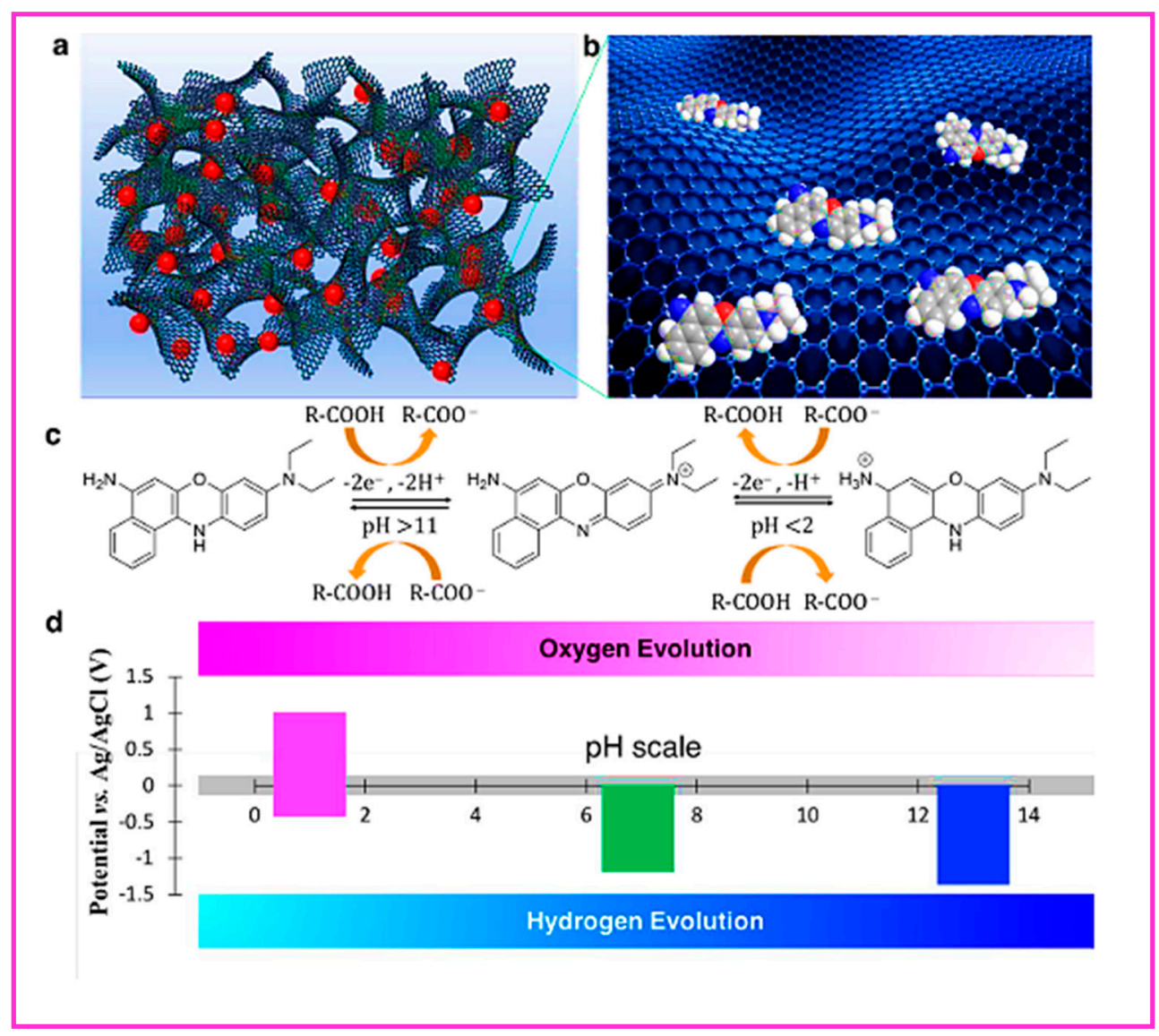

Figure 10. Illustration of the physically-chemically conjugation of Nile Blue. (a) The 3D porous structure of graphene aerogel (b), The possible faradic reactions of Nile Blue in strongly acidic and alkaline electrolyte, (c) The potential windows of the Nile Blue-conjugated graphene aerogel (NB-GA) composite-based electrodes in acidic, neutral, and alkaline media, (d) Potential windows of the NB-GA electrodes in acidic, neutral, and alkaline solutions. Reprinted with permission from [142], Copyright 2019, American Chemical Society.

\subsection{Transition Metal Oxides/Hydroxides-Based Materials}

TM-based compounds are the most common redox-active materials, which are used as electrode materials for SCs, mostly HSCs, specifically in oxides and hydroxides form. Generally, there are various TMs, which are mainly used in the structure of TMOs and transition metal hydroxides (TM $(\mathrm{OHs}))$ such as $\mathrm{Ni}, \mathrm{Fe}, \mathrm{Co}, \mathrm{Ti}, \mathrm{Mo}, \mathrm{V}$ and $\mathrm{Nb}$ [145]. 
TMOs are one of the alternative materials for SCs electrodes with high energy and power owing to their higher specific capacitance and lower resistance in comparison with carbon material, as well as their high conductivity [146]. TMOs and CPs are the most common redox pseudocapacitive materials for owing to one of their properties of showing fast-reversible redox reactions, which lead to high specific capacitances and their long operation cycles [9]. There are different TMOs, as B.E. Conway defined, such as $\mathrm{RuO}_{2}, \mathrm{Fe}_{3} \mathrm{O}_{4}, \mathrm{MnO}_{2}, \mathrm{NiO}, \mathrm{Co}_{3} \mathrm{O}_{4}, \mathrm{IrO}_{2}$ [147] as well as $\mathrm{V}_{2} \mathrm{O}_{5}$ and $\mathrm{CuO}$, [146] in which their charge storage mechanism is based on the faradic behaviour.

Furthermore, there are several examples of various mixed-MOs such as $\mathrm{CuO} @ \mathrm{NiO}$ [148], $\mathrm{CuO} / \mathrm{Cu}_{2} \mathrm{O}$ [149], $\mathrm{Cu} / \mathrm{Cu}_{2} \mathrm{O} @ \mathrm{TiO}_{2}$ [150], $\mathrm{Fe}_{2} \mathrm{O}_{3} @ \mathrm{TiO}_{2}$ [151], $\mathrm{ZnO} @ \mathrm{Co}_{3} \mathrm{O}_{4}$ [152], $\mathrm{Fe}_{2} \mathrm{O}_{3} / \mathrm{Co}_{3} \mathrm{O}_{4}$ [153], $\mathrm{Fe}_{2} \mathrm{O}_{3} / \mathrm{NiCo}_{2} \mathrm{O}_{4}$ [152], $\mathrm{Co}_{3} \mathrm{O}_{4} / \mathrm{ZnFe}_{2} \mathrm{O}_{4}$ [154], $\mathrm{Co}_{3} \mathrm{O}_{4} / \mathrm{NiCo}_{2} \mathrm{O}_{4}$ [155], $\mathrm{ZnO} / \mathrm{ZnFe}_{2} \mathrm{O}_{4}$ [156-158], $\mathrm{Cr}_{2} \mathrm{O}_{3} @ \mathrm{TiO}_{2}$ [159], $\mathrm{NiFe}_{2} \mathrm{O}_{4} / \mathrm{Fe}_{2} \mathrm{O}_{3}$ [160], $\mathrm{NiO@ZnO} \mathrm{[161],} \mathrm{and} \mathrm{ZnO} @ \mathrm{ZnCo}_{2} \mathrm{O}_{4}$ [162], in which by developing a high surface area and the involving the multiple functionalities in the metal organic framework (MOF), they could be fabricated as electrodes for SCs to provide a high performance. Figure 11 shows various precursors that could be utilized to derive the porous MOs along with the corresponding surface area [163].

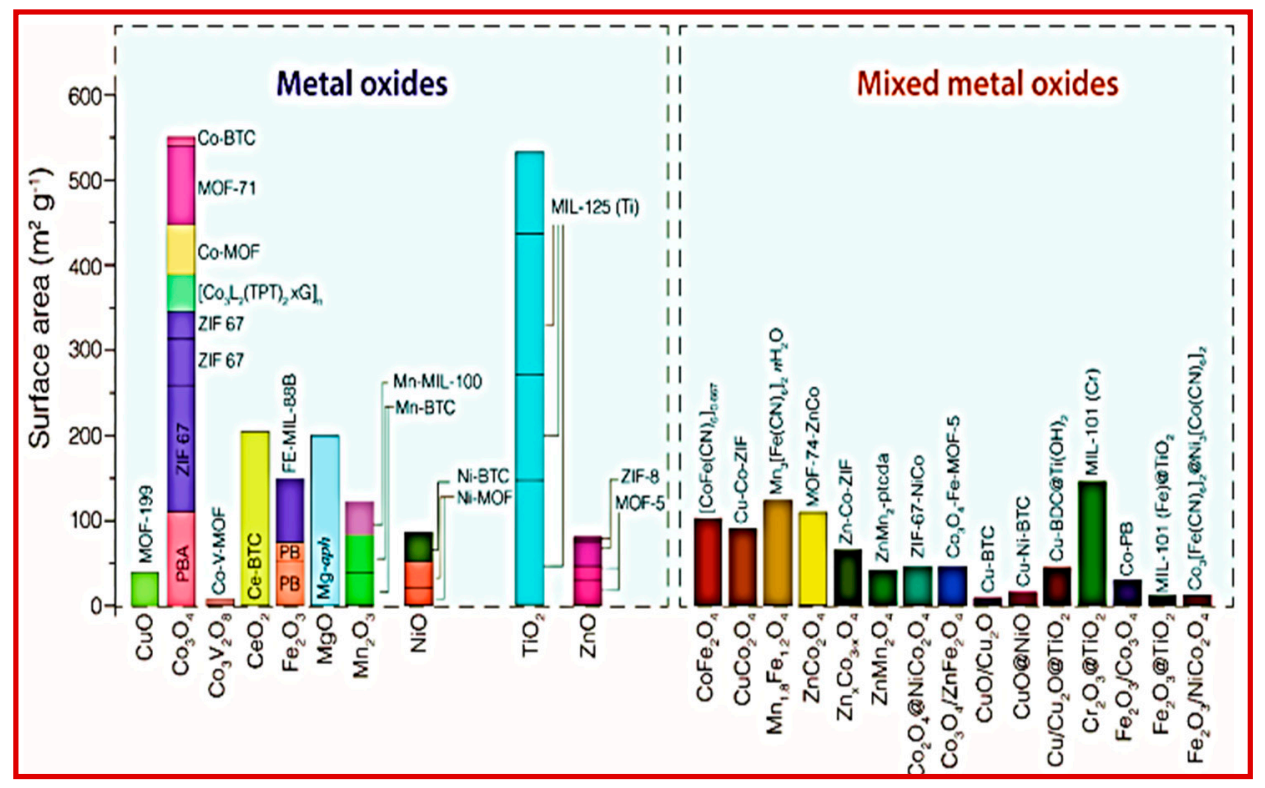

Figure 11. The development of the metal organic framework (MOF) synthesis derived from porous metal oxides (MOs). Bar graphs presentating a variation of MOF precursors, which have been utilized to arise MOs nanostructures ( $\mathrm{CuO}$ [164], $\mathrm{Co}_{3} \mathrm{O}_{4}$ [165-172] $\mathrm{Co}_{3} \mathrm{~V}_{2} \mathrm{O}_{8}$ [173], $\mathrm{CeO}_{2}$ [174], $\mathrm{Fe}_{2} \mathrm{O}_{3}$ [175-177], $\mathrm{MgO}$ [178], $\mathrm{Mn}_{2} \mathrm{O}_{3}$ [179-181], $\mathrm{NiO}$ [182-184], $\mathrm{TiO}_{2}$ [185-187] and $\mathrm{ZnO}$ [188-190]) and nanocomposites $\left(\mathrm{CoFe}_{2} \mathrm{O}_{4}\right.$ [191], $\mathrm{CuCo}_{2} \mathrm{O}_{4}$ [192] $\mathrm{Mn}_{1.8} \mathrm{Fe}_{1.2} \mathrm{O}_{4}$ [193], $\mathrm{ZnCo}_{2} \mathrm{O}_{4}$ [194], $\mathrm{ZnxCo}_{3} \mathrm{x} \mathrm{O}_{4}$ [195], $\mathrm{ZnMn}_{2} \mathrm{O}_{4}$ [196], $\mathrm{Co}_{3} \mathrm{O}_{4} @ \mathrm{NiCo}_{2} \mathrm{O}_{4}$ [155], $\mathrm{Co}_{3} \mathrm{O}_{4} / \mathrm{ZnFe}_{2} \mathrm{O}_{4}$ [154], $\mathrm{CuO} / \mathrm{Cu}_{2} \mathrm{O}$ [149], $\mathrm{CuO@NiO}[148], \mathrm{Cu} / \mathrm{Cu}_{2} \mathrm{O} @ \mathrm{TiO}_{2}$ [150], $\mathrm{Cr}_{2} \mathrm{O}_{3} @ \mathrm{TiO}_{2}$ [159], $\mathrm{Fe}_{2} \mathrm{O}_{3} @ \mathrm{TiO}_{2}$ [151] and $\mathrm{Fe}_{2} \mathrm{O}_{3} / \mathrm{NiCo}_{2} \mathrm{O}_{4}$ [152]). The corresponding surface area values of the attained metal oxide nanostructures and nanocomposites. (Note: PB, Prussian Blue; BTC, benzene-1,3,5-tricarboxylic acid; ptcda, perylene-3,4,9,10-tetracarboxylic dianhydride; $\mathrm{Cu} B \mathrm{BDC}:[\mathrm{Cu}(\mathrm{tpa})(\mathrm{dmf})]$; tpa, terephthalic acid; $\mathrm{DMF}, \mathrm{N}, \mathrm{N}$-dimethylformamide; $\mathrm{Mg}$ aph, $\mathrm{Mg}_{4}$ (adipate $\left.)_{4}(\mathrm{DMA})-\left(\mathrm{H}_{2} \mathrm{O}\right)\right] \cdot 5 \mathrm{DMA} \cdot 2 \mathrm{MeOH} \cdot 4 \mathrm{H}_{2} \mathrm{O} ; \mathrm{DMA}, \mathrm{N}, \mathrm{N}$-dimethylacetamide; $\mathrm{MeOH}$, methanol). Reprinted with permission from [163], Copyright 2017, American chemical Society.

Besides, the layered transition metal hydroxide $(\mathrm{TM}(\mathrm{OH}) \mathrm{s})$ such as $\mathrm{Ni}(\mathrm{OH})_{2}, \mathrm{FeOOH}$, and $\mathrm{Co}(\mathrm{OH})_{2}$, with a large space between their layers provide suitable the redox reactions, enhancing the capacitance value of the electrodes in SCs. However, the TM(OH)s could offer more charge storage in comparison with their oxide form, the electronic conductivity of their corresponding oxides is higher. $\mathrm{TM}(\mathrm{OH})$ s have exhibited lower structure stability, and consequently, lower rate capability or 
less cycling performance compared to their corresponding oxides [197]. However, there are several strategies to address this limitation and improving the cycling stability of the material, such as layered engineering of the $\mathrm{TM}(\mathrm{OH}) \mathrm{s}$ through the anion and cation doping process. For instance, the cycle life of the $\alpha-\mathrm{Ni}(\mathrm{OH})_{2}$ can be improved through the partial substitution of other TM cations such as $\mathrm{Co}^{2+}$, $\mathrm{Ni}^{3+}$, etc., to obtain bimetallic complexes [197].

These species attract the anions to insert into the layer spacing of $\alpha-\mathrm{Ni}(\mathrm{OH})_{2}$ [198]. The anion insertion improves the cycle stability of the material by altering the structure of the primary $\alpha-\mathrm{Ni}(\mathrm{OH})_{2}$ that makes the material to act as a pillar to keep structural stability. The intrinsic pillar effect was stated for the first time by Y. Chen et al. [197]. They fabricated an ASSC using MNC and graphene as electrode material (Figure 12a). It was reported that the structural stability of $\alpha-(\mathrm{Ni} / \mathrm{Co})(\mathrm{OH})_{2}$ was improved owing to the pillar effect of the metaborate groups, which, unlike the external pillar groups in the previous works (such as $\mathrm{SO}_{4}{ }^{2-}, \mathrm{NO}^{3-}$, and $\mathrm{Cl}^{-}$), provides a strong connection between $\left(\mathrm{Ni}_{0.5} \mathrm{Co}_{0.5}\right)(\mathrm{OH})_{2}$ layers through the strong B-O bonds. (Figure $12 \mathrm{~b}$ ) Besides the enhanced stability, the highly $\mathrm{pGr}$ with excellent conductivity led to increasing the $\mathrm{E}_{\mathrm{d}}$ and cycling performance (Figure 12c) of the resultant electrode [197].

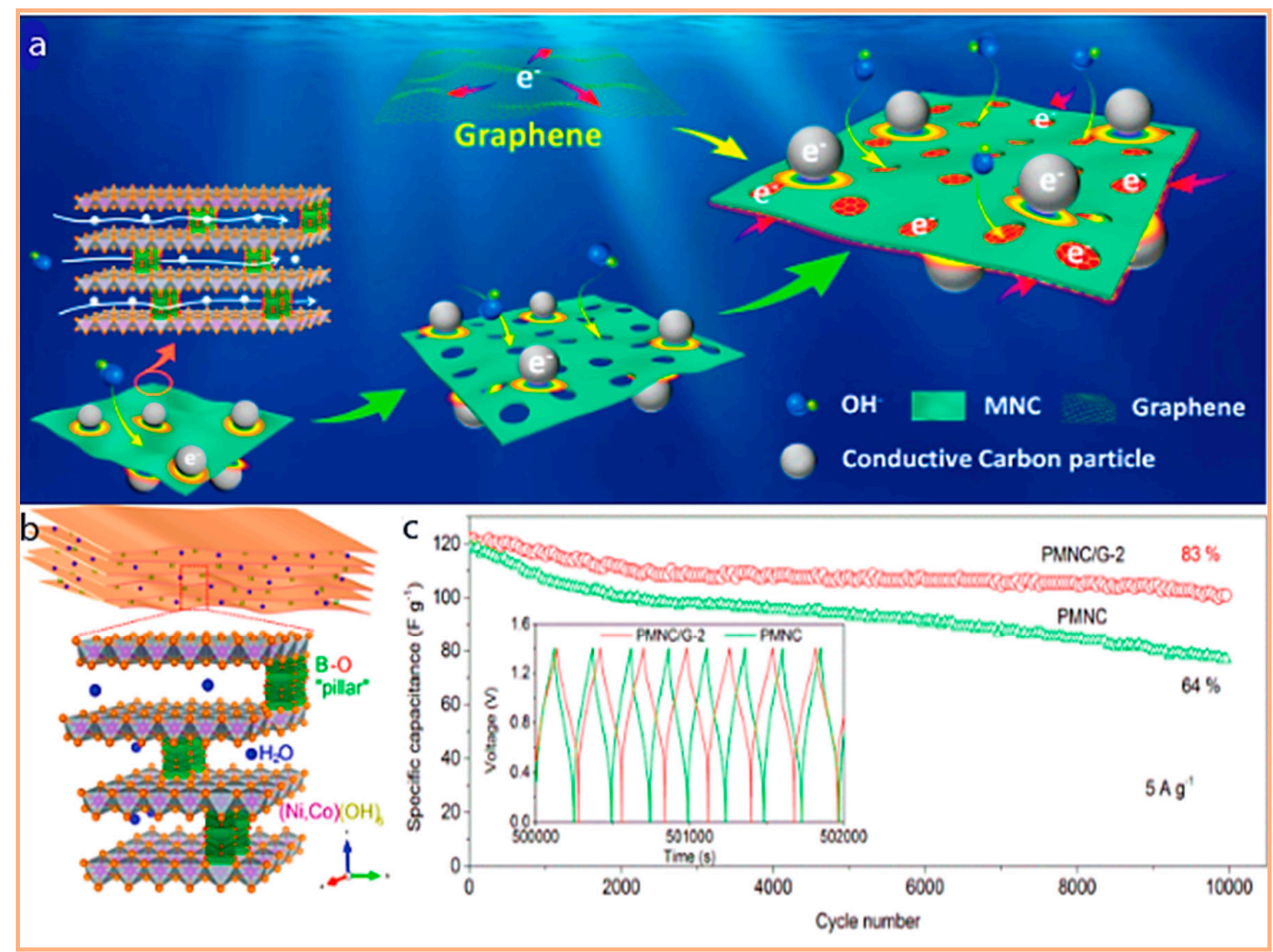

Figure 12. Graphical presentation of PMNC/G-2. (a) The layered structure of $\mathrm{Ni}_{0.5} \mathrm{Co}_{0.5}\left(\mathrm{BO}_{2}\right)_{\mathrm{y}}$ $(\mathrm{OH})_{2-\mathrm{y}} \mathrm{xH}_{2} \mathrm{O}$. (b,c) Cycling performances of PMNC//AC and PMNC/G-2//AC ASSCs. Reprinted with permission from [197], Copyright 2017, American Chemical Society.

As it was mentioned in the introduction section, the battery-type TM can be classified into two main groups depending on their electrochemical reaction in HSC device, including intercalation-type and conversion-type (Figure 13) [199]. However, it is worth mentioning that, although TM-based materials are mainly categorized as battery-type materials, they also exhibit capacitive behaviour. For instance, Feng et al. fabricated the $\mathrm{MnO}_{\mathrm{x}}$ electrode materials by a simple electrodeposition method, which exhibited excellent capacitive performance through tuning the concentration of complexing agents in the plating electrolyte. They reported that the liquid-phase and solid-phase diffusion were 
facilitated due to the formation of the highly porous nanostructure and enhancing the contents of hydrous states such as $\mathrm{H}-\mathrm{O}-\mathrm{H}$, and $\mathrm{Mn}-\mathrm{O}-\mathrm{H}$ for the thick oxide layer [200].

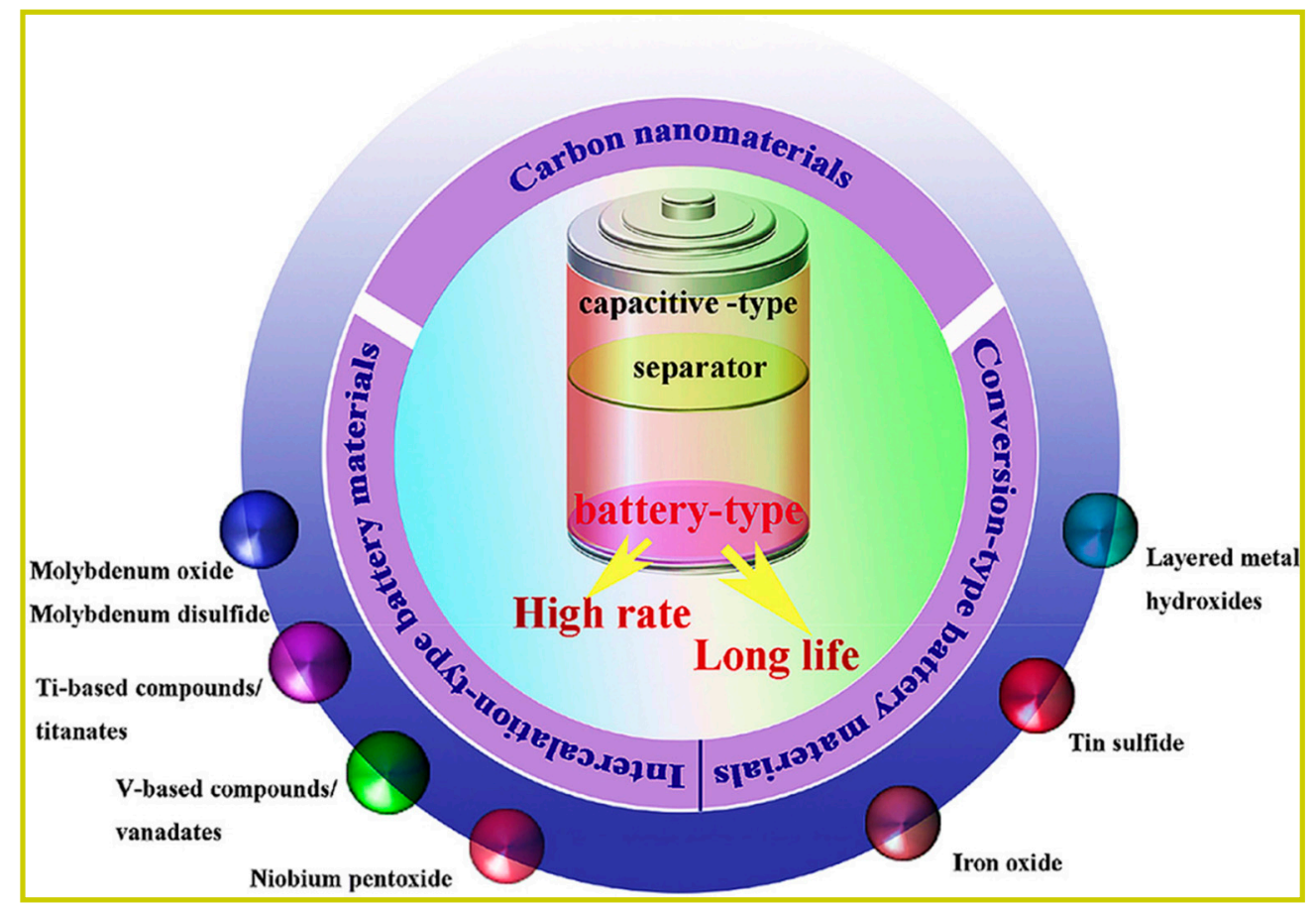

Figure 13. The graphical representation of the battery-type materials according to two electrochemical reaction mechanisms (intercalation and conversion-type battery), utilized in HSCs. Reprinted with permission from [199], Copyright 2020, Elsevier.

\subsubsection{Ruthenium Oxide $\left(\mathrm{RuO}_{2}\right)$}

Ruthenium oxide $\left(\mathrm{RuO}_{2}\right)$ is one of the most studied TMOs for SC electrodes due to its superior chemical and thermal stability, high metallic type conductivity, broad potential window (1.2 V), highly reversible redox reaction, long cycle life, high theoretical capacitance (1200-2200 F.g $\left.{ }^{-1}\right)$, and good rate capability [201].

Furthermore, the superior properties of $\mathrm{RuO}_{2}$ such as its metallic conductivity, field emission behaviour, catalytic activities electrochemical reduction-oxidation properties in both crystalline and amorphous structures, make the $\mathrm{RuO}_{2}$ to be useful for various practical and theoretical applications, including a thick or thin resistor, ferroelectric films and integrated circuit development, and electronic applications, and the most recent in SCs [202].

In addition, such parameters as annealing temperature, particle size, and the crystallinity affect the pseudocapacitive performance of $\mathrm{RuO}_{2},[115,203]$, whereas the higher crystallinity of $\mathrm{RuO}_{2}$ leads to lower specific capacitances because of the compact structure of $\mathrm{RuO}_{2}$ that limits the insertion/depletion of ions and electrons, resulting to an improved electrochemical impedance [36]. Accordingly, most researches were focused on the amorphous $\mathrm{RuO}_{2}$ since the faradic redox reactions on both the exterior surface and the bulk of the material deliver a higher specific capacitance [36].

$\mathrm{RuO}_{2}$ materials are expensive, which could limit their large-scale applications. In order to develop cost-effective materials, the $\mathrm{RuO}_{2}$ hybrids were coupled with other pseudocapacitive or carbonaceous materials to reduce the amount of $\mathrm{RuO}_{2}$ without influencing the activity [204]. For instance, a nanosized $\mathrm{RuO}_{2} /$ polyaniline (PANI)/carbon double-shelled hollow spheres nanocomposite was designed through an in situ electro-polymerization process [205]. 
$\mathrm{RuO}_{2}$ has three oxidation states as $\mathrm{Ru}^{4+}, \mathrm{Ru}^{3+}$, and $\mathrm{Ru}^{2+}[125,203,206]$. The rapid-reversible redox reaction of $\mathrm{RuO}_{2}$ is shown by Eqquation (2) [207]:

$$
\mathrm{RuO}_{\mathrm{x}}(\mathrm{OH})_{\mathrm{y}}+\delta \mathrm{H}^{+}+\mathrm{eH}^{+} \rightarrow \mathrm{RuO}_{\mathrm{x}-\delta}(\mathrm{OH})_{\mathrm{y}} \delta \cdots(0<\delta>2)
$$

There are different methods to synthesis the $\mathrm{RuO}_{2}$ for SC electrode materials. For instance, Zheng et al. [208] synthesized a hydrous $\mathrm{RuO}_{2}$ through a sol-gel technique, which provided a specific capacitance of $720 \mathrm{~F} \cdot \mathrm{g}^{-1}$ at the annealing temperature of $150{ }^{\circ} \mathrm{C}$.

In another research, $\mathrm{RuO}_{2}$ was prepared through electrodeposition technique for SC application resulting in a stable electrode with a large number of cycles and a specific capacitance of $498 \mathrm{~F} \cdot \mathrm{g}^{-1}$ at a scan rate of $5 \mathrm{mV} \cdot \mathrm{s}^{-1}$ [209]. Kim et al. [210] also synthesized $\mathrm{RuO}_{2}$ loading on carbon via the colloidal method resulting in high specific capacitance of $407 \mathrm{~F} \cdot \mathrm{g}^{-1}$ obtained at a $40 \% \mathrm{RuO}_{2}$ loading. The charge storage mechanism of $\mathrm{RuO}_{2}$ is based on four steps, as the electron hopping (a) within $\mathrm{RuO}_{\mathrm{x}} \cdot \mathrm{nH}_{2} \mathrm{O}$, (b) between $\mathrm{RuOx} \cdot \mathrm{nH} 2 \mathrm{O}$ particles, (c) between electrodes and the current collectors, and d) proton diffusion without $\mathrm{RuO}_{x} \cdot \mathrm{nH}_{2} \mathrm{O}$ particles $[36,211]$.

$\mathrm{CV}$ curve for $\mathrm{RuO}_{2}$ was almost rectangular, indicating a suitable capacitive behavior, and compared to another electrode material, $\mathrm{RuO}_{2}$ displayed lesser ESR, and consequently, higher $\mathrm{E}_{\mathrm{d}}$ and $\mathrm{P}_{\mathrm{d}}$ than conductive polymer-based SCs and EDLCs. However, their high cost and poor performance at high current densities [104] limit their application, whereas the researchers focused on reducing the loading of $\mathrm{RuO}_{2}$ via doping with other materials.

The $\mathrm{RuO}_{2}$-GC electrode was fabricated using the GNSs and CNTs, which were deposited onto CNFs. The combination of the $\mathrm{RuO}_{2}$ and carbon-based material provided a specific capacitance of $480.3 \mathrm{~F} \cdot \mathrm{g}^{-1}$ at $0.6 \mathrm{~A} \cdot \mathrm{g}^{-1}$. Furthermore, the composite-based SC showed a high energy density of $30.9 \mathrm{Wh} \cdot \mathrm{kg}^{-1}$ at a power density of $14,000 \mathrm{~W} \cdot \mathrm{kg}^{-1}$ [212].

\subsubsection{Manganese Dioxide $\left(\mathrm{MnO}_{2}\right)$}

$\mathrm{MnO}_{2}$ is one of the most used electrode materials for SCs due to its superior properties such as outstanding capacitive performance in the aqueous electrolytes, low cost, and low environmental impact, which also make it useful for a broad range of applications such as in biosensor, molecular adsorption, energy storage, ion exchange, and catalysis [213,214].

The lesser cost and higher availability of $\mathrm{MnO}_{2}$ in comparison with $\mathrm{RuO}_{2}$-based materials [215-217], as well as another superior of properties such as a broad electrochemical potential window, low toxicity and a high theoretical specific capacitance $\left(1370 \mathrm{~F} \cdot \mathrm{g}^{-1}\right)$, makes it a promising alternative to replace as electrode materials [218-220].

The reversible redox reaction and the existence of various oxidation states for $\mathrm{MnO}_{2}$ lead to a high pseudocapacitance charge storage mechanism which takes place through two reversible mechanisms involving insertion/reinsertion of protons into the bulk of the electrode and secondly, adsorption/desorption of electrolyte cations onto the electrode surface that occur as the transition between III and IV oxidation states of $\mathrm{MnO}_{2}$ [219]. Equation (3) represents the charge storage mechanism as follows:

$$
\mathrm{MnO}_{2}+\mathrm{C}^{+}+\mathrm{e}^{-} \rightarrow \mathrm{MnOOC}
$$

The chemical and physical factors, such as the morphology of the $\mathrm{MnO}_{2}$-based material, play an essential role in the electrochemical performance of $\mathrm{MnO}_{2}$, such as cyclic stability, which is highly dependent on the crystallinity of the porous $\mathrm{MnO}_{2}$. The nanocrystalline and the amorphous $\mathrm{MnO}_{2}$ provide easy accessibility to ion and cation diffusion owing to the porous nature of these compounds [221]. It has been reported that among all crystalline phases, $\alpha$ and $\delta$ show the highest specific capacitances [222].

For instance, Godbane et al. [223] considered the effect of the various structure on the charge storage performance of $\mathrm{MnO}_{2}$, which was prepared in a different allotropic phase such as 1D channels, 2D layers, and 3D interconnected tunnels and reported an optimal specific capacitance $241 \mathrm{~F} \cdot \mathrm{g}^{-1}$ for 
3D interconnected tunnels and the lowest specific capacitance of $28 \mathrm{~F} \cdot \mathrm{g}^{-1}$ for $1 \mathrm{D}$ channels. It was also reported that the electrochemical performance was not affected by SSA.

In another study, Sun et al. [224] showed that the energy storage mechanism relied on the number of manganese $(\mathrm{Mn})$ centres as active sites and reported that the enhancement in the percentage of active $\mathrm{Mn}$ centres by the decrease in crystal size leads to a higher specific capacitance and in contrast with the previous assumptions, the results in this research showed that the morphological surface to volume ratios, (or SSA) affects the electrochemical performance of $\mathrm{MnO}_{2}$-based SCs. Furthermore, the physical and chemical factors affect the electrochemical behaviour of the $\mathrm{MnO}_{2}$, as the hydration state of $\mathrm{MnO}_{2}$ has a significant influence on the specific capacitance, and the cyclic stability is being dependent on the morphology of the resultant material [225].

Among all various types of $\mathrm{MnO}_{2}$ nanostructure, the highest $\mathrm{E}_{\mathrm{d}}$ and Pd were reported for tubular $\mathrm{MnO}_{2}$ nanostructure of about $21.1 \mathrm{Wh} \cdot \mathrm{kg}^{-1}$ and $13.33 \mathrm{~W} \cdot \mathrm{g}^{-1}$, respectively. Despite these superior properties, $\mathrm{SC}$, including $\mathrm{MnO}_{2}$-based electrodes, suffers from low specific capacitance values at high charge-discharge rates and insufficient cycling stability owing to $\mathrm{MnO}_{2}$ dissolution, low conductivity, broad band gaps, and low ionic diffusion constants [226,227].

According to these issues, the flower-like $\mathrm{MnO}_{2} /$ nitrogen-doped graphene nanocomposite was synthesized via a hydrothermal technique, which offered an average specific capacitance of $220 \mathrm{~F} \cdot \mathrm{g}^{-1}$ at of $0.5 \mathrm{~A} \cdot \mathrm{g}^{-1}$ as well as capacitance retention of $98.3 \%$ after 3000 cycles [228].

\subsubsection{Nickel Oxide $(\mathrm{NiO})$}

Micro/nanomaterials such as nickel oxide have fascinated a lot of attention by the researcher as electrode material for electrochemical capacitors because of the shortened diffusion paths, fast redox reactions, and a large SSA in the solid phase [229-233].

$\mathrm{NiO}$ is one of the other promising pseudocapacitive materials for SCs electrodes owing to its properties such as, the high theoretical specific capacitance of $2584 \mathrm{~F} \cdot \mathrm{g}^{-1}$ [234-236], thermal stability, chemical stability, facile synthesis, reasonable cost, abundance, and being environmentally friendly [237]. The pseudocapacitive nature of $\mathrm{NiO}$ and $\mathrm{Ni}(\mathrm{OH})_{2}$ are debatable based on previous literature reports [39]. The $\mathrm{NiO}$ material can exhibit pseudocapacitive behavior. For instance, the $\mathrm{NiO}$ nanoflakes synthesized through the microwave-assisted method displayed a high pseudocapacitive performance as electrode material for supercapacitor, as well as a high conductivity of $33.87 \mathrm{Scm}^{-1}$ at room temperature, and surface area as high as $206 \mathrm{~m}^{2} \mathrm{~g}^{-1}$ [238]. In another study, a $\mathrm{Co}-\mathrm{Ni} / \mathrm{Co}_{3} \mathrm{O}_{4}-\mathrm{NiO}$ nano-heterostructures demonstrated a remarkable pseudocapacitance [44].

$\mathrm{NiO}$, as an electrode material, has a lot of benefits in terms of electrochemical strategy, including accuracy, reliability, excellent electrochemical reaction reactivity, and simplicity [237].

$\mathrm{NiO}$ was obtained through the transformation of nickel hydroxide using the electrochemical strategy. $\mathrm{NiO}$ electrode resulting in this method showed an excellent specific capacitance of $1541 \mathrm{~F} \cdot \mathrm{g}^{-1}$ in $1 \mathrm{M} \mathrm{KOH}$ (at the scan rate of $5 \mathrm{mV} \cdot \mathrm{s}^{-1}$ ). After 3000 cycles, $91.8 \%$ of the capacity retention remained [239]. $\mathrm{NiO}$ could be utilized as electrode materials for SCs in the various forms such as nanowires, nanotubes [240], nanoparticles [241], nanoflowers [242], hierarchically nanoporous films [243], nanorods, and hollow nanofibers.

As other electroactive material, the electrochemical performance of the in the $\mathrm{NiO}$ material also highly depends on the morphology of the nanostructure while the porous structure provides a large active surface area that corresponds to the further faradic active sites. This structure has also been shown a very short pathway for ions. Besides, the $\mathrm{NiO}$ nanorod arrays offer high cycling stability as well as an ultra-high capacitance of $1536 \mathrm{~F} \cdot \mathrm{g}^{-1}$ and $2018 \mathrm{~F} \cdot \mathrm{g}^{-1}$ at high and low current density [244], respectively, which may be associated with the well-aligned arrays, narrow nanorod and the stable chemical bonding of $\mathrm{NiO}$ nanorods on the $\mathrm{Ni}$ substrate [237]. Furthermore, $\mathrm{NiO}$ nanofibers/Ni [245] provided almost 100\% capacitive retention after 8000 cylces, also in the case of $\mathrm{NiO}$ nanoflowers [246], $99.7 \%$ of the capacitance remained after 1000 cycles. 
In another research, a hierarchical shell-core structure was prepared using $\mathrm{NiO}$ nanospines and carbon as an inner core through hydrothermal reaction. NiO nanospines offered unimpeded diffusion paths for ion transport that increase the affinity of the electroactive materials to contribute to the redox reactions, whereas the inner carbon core provides physical support to prevent the volumetric variations of $\mathrm{NiO}$ nanospines which is associated with its good mechanical property. The obtained electrode showed a high specific capacitance of $1161 \mathrm{~F} \cdot \mathrm{g}^{-1}$, a current density of $2 \mathrm{~A} \cdot \mathrm{g}^{-1}$, and even high capacitance retention of $92.4 \%$ was obtained after 3000 cycles at a current density of $2 \mathrm{~A} \cdot \mathrm{g}^{-1}$ [247]. A sandwich-like nickel oxide/nanoporous nickel/metallic glass (NiO/np-Ni/MG) composite electrode was provided through the free-dealloying method in $\mathrm{O}_{2}$-rich $\mathrm{HF}$ solution. The free-standing electrode showed a high volume-specific capacitance of $745.3 \mathrm{~F} \cdot \mathrm{cm}^{-3}$ at $0.5 \mathrm{~A} \cdot \mathrm{cm}^{-3}$ as well as the capacitance retention about $92 \%$ after 6000 cycles, which implies on a relatively excellent cyclic stability [248].

\subsubsection{Nickel Hydroxide $\left(\mathrm{Ni}(\mathrm{OH})_{2}\right)$}

Among $\mathrm{TM}(\mathrm{OH})$ s, Nickel hydroxide has recently attracted attention from researchers owing to its excellent properties such as a high theoretical specific capacitance of $2082 \mathrm{~F} \cdot \mathrm{g}^{-1}$, good rate capability, ready availability, lower cost, environmentally benign nature, and its excellent thermal stability and high chemical stability in strong alkaline electrolytes [249]. Accordingly, $\alpha-\mathrm{Ni}(\mathrm{OH})_{2}$ is the most powerful battery-type material for SC application, which is not only used as positive electrode material in nickel-based batteries, but it is also suitable for electrochemical SCs [250-252]. The electrochemical performance of nickel-based pseudocapacitor electrode materials is estimated based on the redox reaction of $\mathrm{Ni}(\mathrm{OH})_{2}$ or $\mathrm{NiO}$ in alkaline electrolytes, and it can be shown in two general equations for $\mathrm{NiO}$ and $\mathrm{Ni}(\mathrm{OH})_{2}$ in Equations (4) and (5), respectively [237].

$$
\begin{gathered}
\mathrm{NiO}+\mathrm{OH}^{-} \leftrightarrow \mathrm{NiOOH}+\mathrm{e}^{-} \\
\mathrm{Ni}(\mathrm{OH})_{2}+\mathrm{OH}^{-} \leftrightarrow \mathrm{NiOOH}+\mathrm{H}_{2} \mathrm{O}+\mathrm{e}^{-}
\end{gathered}
$$

The supercapacitive performance of the nickel-based materials highly depends on its loading percentage on the electrode, the electrolyte, the morphology and porosity of the material as well as its conductivity and the surface area, whereas the more enhanced depth of the electrochemical process and larger SSA can provide a higher specific capacitance $[253,254]$.

Furthermore, the performance of the $\mathrm{Ni}(\mathrm{OH})_{2}$ depends on several parameters such as the type of microstructure, the precipitation condition, structural defects, and crystallinity [208,255-257], whereas the crystal structure and crystallinity of $\mathrm{Ni}(\mathrm{OH})_{2}$ have a strong influence on the $\mathrm{H}^{+}$mobility and conducting the charge-discharge rate [258]. For instance, Lang et al. [259] prepared a roughly packed $\mathrm{Ni}(\mathrm{OH})_{2}$, in which the poor crystallinity nanoflakes were shaped through the chemical precipitation method, and the synthesized sample exhibited a high specific capacitance of $2055 \mathrm{~F} \cdot \mathrm{g}^{-1}$. The enhanced capacitance and diffusion rates are due to the availability of $\mathrm{OH}^{-}$ions in the electrolyte for the $\mathrm{Ni}(\mathrm{OH})_{2}$ nanoflakes.

Furthermore, nanoflower-like $\mathrm{Ni}(\mathrm{OH})_{2}$ was deposited onto a Ni foam to be used as an electrode for SCs, and the obtained electrode showed an outstanding rate capability with a specific capacitance of $1065 \mathrm{~F} \cdot \mathrm{g}^{-1}$ [260]. In another example, amorphous $\mathrm{Ni}(\mathrm{OH})_{2}$ nano-spheres deposited on a graphite rod and cycled at current densities of $20-70 \mathrm{~A} \cdot \mathrm{g}^{-1}$ in $1 \mathrm{M} \mathrm{KOH}$, exhibited a high specific capacitance in the range of $1868-1330 \mathrm{~F} \cdot \mathrm{g}^{-1}$ that arises from the amorphous structure and the uneven surfaces [261].

Such as other MOs, besides all the advantages, $\mathrm{Ni}(\mathrm{OH})_{2}$, also has several drawbacks, like poor conductivity, low stability, and poor cycle performance that occur because of the massive volume alteration during the charging-discharging mechanism. Heteroatom doping of cobalt $(\mathrm{Co})$ and zinc $(\mathrm{Zn})$ could be utilized to improve the electrochemical performance of $\mathrm{Ni}(\mathrm{OH})_{2}[262,263]$.

$\mathrm{Ni}(\mathrm{OH})_{2}$ could restrict the rate capabilities due to its semiconductor nature, and the aggregation of $\mathrm{Ni}(\mathrm{OH})_{2}$ particles leads to decreasing the electrochemical performances. Different nanocomposites have been produced by highly conductive materials such as graphene and activated carbon to address 
these issues [264]. For instance, the $\mathrm{Ni}(\mathrm{OH})_{2} /$ graphene composites were prepared using a chemical precipitation method in which the loosely 3D structure leads to more active sites and, consequently, more redox reactions. The coupling of graphene leads to enhanced stability and the conductivity of $\mathrm{Ni}(\mathrm{OH})_{2}[265]$.

The graphene sheet with good conductivity provides a larger surface area, whereas the increased interfacial contact with the electrolyte solution governs the electron transfer and the diffusion rate to the enhanced electrochemical performance. The obtained GNSs/Ni(OH) $)_{2}$ composite exhibited a specific capacitance of $2053 \mathrm{~F} \cdot \mathrm{g}^{-1}$, and $97 \%$ of the capacitance remained after 1000 cycles.

$\mathrm{Ni}(\mathrm{OH})_{2}$ composites could also be coupled with other oxides to increase the electrochemical properties. For example, $\mathrm{Co}(\mathrm{OH})_{2}-\mathrm{Ni}(\mathrm{OH})_{2}$ composites were synthesized to achieve a higher specific capacitance in comparison with the $\mathrm{Ni}(\mathrm{OH})_{2}$ or $\mathrm{NiO}$ in which this enhancement is attributed to the mesoporous structure and faster ion diffusion in this regular nanostructure [266,267]. After 1000 continuous charge-discharge cycles, the capacitance retention increased from $41.6 \%$ for the pure $\mathrm{Ni}(\mathrm{OH})_{2}$ electrode to $88.2 \%$ for the composite-based electrode with the weight ratio of 3:2. The weight ratio of $\mathrm{Co}(\mathrm{OH})_{2} / \mathrm{Ni}(\mathrm{OH})_{2}$ profoundly affects the SC behaviour [267].

As it was mentioned in Section 2, the phase characteristics of the electrode material could be modulated through the pillar effect.

Recently, Xiao et al. [268] fabricated the pillar-coordinated $\alpha-\mathrm{Ni}(\mathrm{OH})_{2}\left(\mathrm{Ni}-\left(\mathrm{BO}^{2-}\right)-\mathrm{LDH}\right)$ by exploiting the pillar-coordinated strategy through the etching process of the Ni-MOF precursor, in which the organic ligand was substituted by $\mathrm{OH}^{-}$and $\mathrm{BO}^{2-}$ anions. The maintained MOFs structure provided a highly porous frame and abundant channels, which improved the electrolyte diffusion. They have described that the structure of $\alpha-\mathrm{Ni}(\mathrm{OH})_{2}$ was supported owing to the pillar coordination, which offered a more stable system with a durable redox reaction in strong alkaline electrolyte. The enhanced $\mathrm{Ni}\left(\mathrm{BO}^{2-}\right)$ - $\mathrm{LDH}-4$ exhibited a specific capacitance of $1760 \mathrm{~F} \cdot \mathrm{g}^{-1}$ at $1 \mathrm{~A} \cdot \mathrm{g}^{-1}$, and capacitance retention of $81 \%$ after 10,000 charging-discharging cycles. The HSC fabricated using the resultant $\mathrm{Ni}\left(\mathrm{BO}^{2-}\right)-\mathrm{LDH}-4$ and 3D-rGO as electrodes, has exhibited a high $\mathrm{E}_{\mathrm{d}}$ of $56.5 \mathrm{Wh} \cdot \mathrm{kg}^{-1}$ at the $\mathrm{P}_{\mathrm{d}}$ of $0.111 \mathrm{~kW} \cdot \mathrm{kg}^{-1}$ (Figure 14) [268].

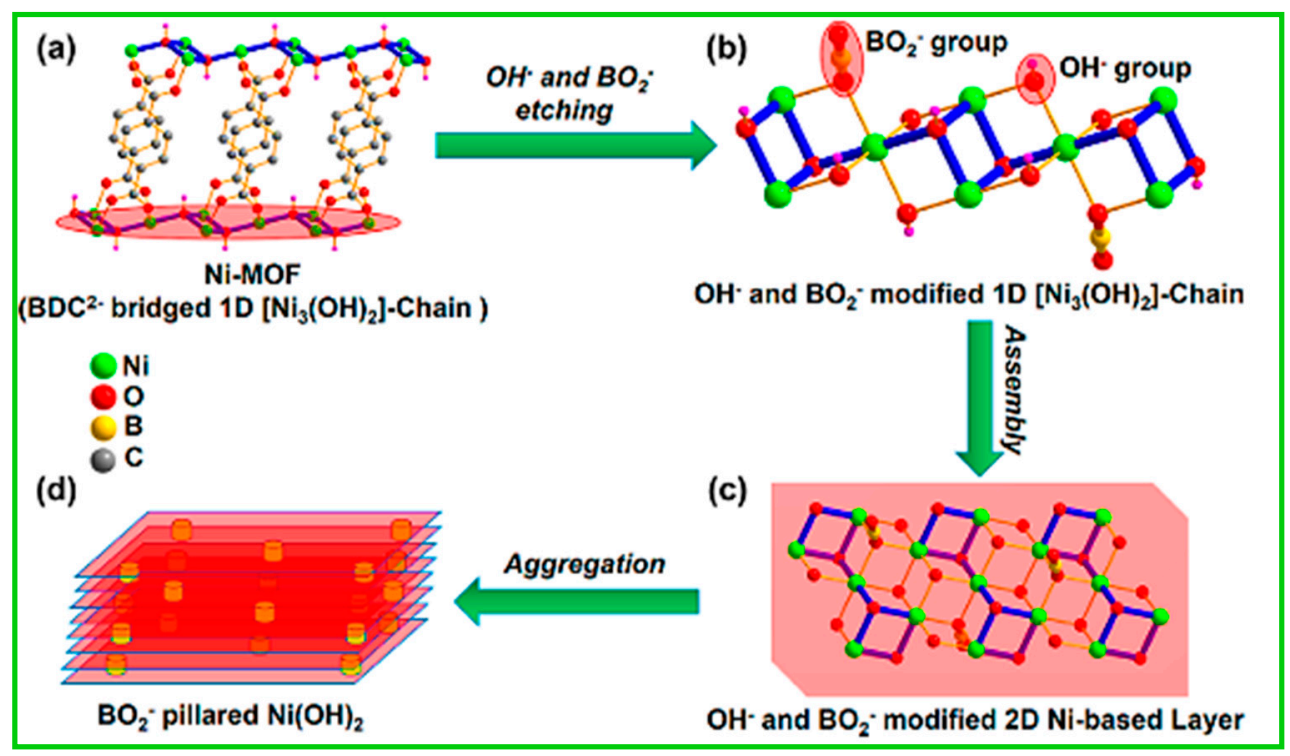

Figure 14. Graphical presentation of the fabrication procedure of the $\mathrm{Ni}\left(\mathrm{BO}^{2-}\right)-\mathrm{LDH}-\mathrm{X}$. Reprinted with permission from [268], Copyright 2020, American Chemical society.

Besides, the electrochemical performance of the $\mathrm{Ni}(\mathrm{OH})_{2}$ (NSs) could be improved through growing the material on the carbon-based substrate to take advantage of the highly porous structure of these materials. For instance, $\mathrm{Ni}(\mathrm{OH})_{2} \mathrm{NSs}$ were deposited on the electrochemically activated carbon 
cloth (ECC) to fabricate the $\mathrm{Ni}(\mathrm{OH})_{2} / \mathrm{ECC}(\mathrm{HT})$ composite (ECN-3), which was fabricated through the one-step ethanol-assisted supercritical deposition process (supercritical fluid deposition). Due to the high permeability, good solvent capability, and low surface tension of the supercritical ethanol fluid, it has the ability to propagate the reactant onto the porous structure of $\mathrm{CC}$; thus the $\mathrm{Ni}(\mathrm{OH})_{2} \mathrm{NSs}$ were distributed perfectly on the $\mathrm{CC}$. This provided significant electrochemical performance for the $\mathrm{Ni}(\mathrm{OH})_{2} \mathrm{NSs} / \mathrm{ECC}$ flexible electrode. The accessibility of the redox sites to electrolyte ions increased owing to the resultant porous structure and obtained channels. The fabricated flexible solid-state SC (including ECC as the anode, and ECN-3 as the cathode), showed an $E_{d}$ of $8.3 \mathrm{mWh} \cdot \mathrm{cm}^{-3}$ at the $P_{d}$ of $20 \mathrm{~mW} \cdot \mathrm{cm}^{-3}$, as well as the capacity retention of $87 \%$ after 10,000 cycles at $50 \mathrm{~mA} \cdot \mathrm{cm}^{-2}$ [84] (Figure 15).
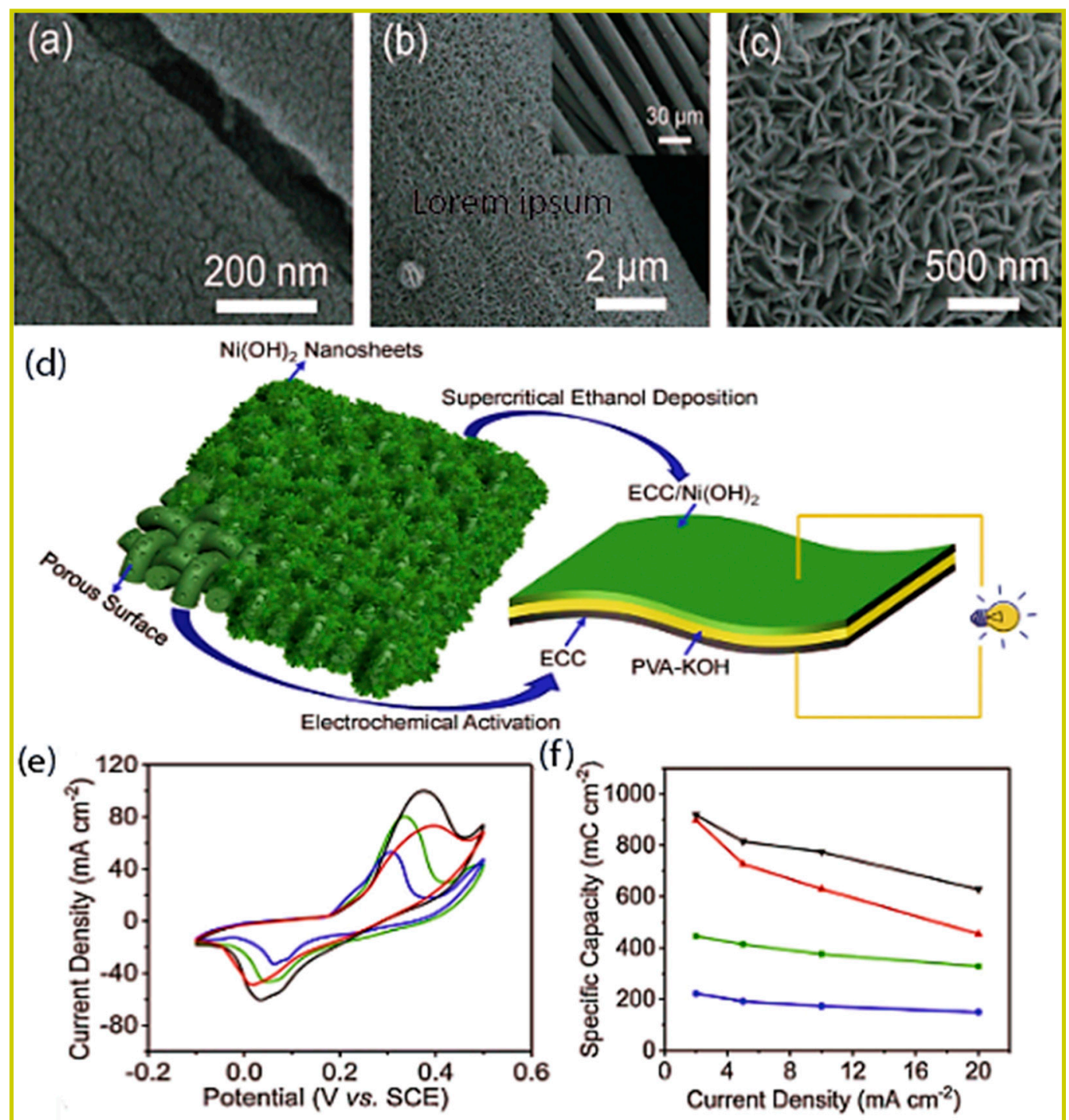

Figure 15. SEM image of the porous surface of electrochemically activated carbon cloth (ECC). (a), SEM images of ECN-3 composite electrode material (the top inset signifies the top-view image of the free-standing electrode at low-resolution mode). (b), SEM image of the compact gown nanosheets (NSs) with a distinct open porous structure. (c), the graphical illustration of the flexible ASC using ECN-3 and ECC electrodes. (d), CVs of various $\mathrm{Ni}(\mathrm{OH})_{2} \mathrm{NSs} / \mathrm{ECC}$ electrodes at $20 \mathrm{mV} \cdot \mathrm{s}^{-1}$. (The samples were fabricated with various amount of nickel nitrate hexahydrate $(0.1 \mathrm{~g}, 0.2 \mathrm{~g}, 0.3 \mathrm{~g}$, and $0.4 \mathrm{~g})$, and named ECN-1, ECN-2, ECN-3, and ECN-4, respectively. (e) Specific capacities of the ECN electrodes at various current densities. (blue line: ECN-1, green line: ECN-2, black line: ECN-3, red line: ECN-4) (f). Reprinted with permission from [84], Copyright 2020, Elsevier. 


\subsubsection{Vanadium Pentoxide $\left(\mathrm{V}_{2} \mathrm{O}_{5}\right)$}

Vanadium $(\mathrm{V})$ oxide or vanadia is an inorganic-intercalation compound with the formula $\mathrm{V}_{2} \mathrm{O}_{5}$, which is generally known as vanadium pentoxide. $\mathrm{V}_{2} \mathrm{O}_{5}$ has attracted a lot of interest from researchers as a suitable electrode for pseudocapacitors in aqueous and organic electrolytes because of its natural abundance, high $\mathrm{E}_{\mathrm{d}}$, low cost, low toxicity, its mixed oxidation states $(+2$ to +5$)$, ease of fabrication, and high capacitance $[269,270]$. The specific capacitance of $350 \mathrm{~F} \cdot \mathrm{g}^{-1}$ was reported for amorphous $\mathrm{V}_{2} \mathrm{O}_{5}$ in $\mathrm{KCl}$ aqueous electrolyte [271]. $\mathrm{V}_{2} \mathrm{O}_{5}$ shows an ultra-high theoretical capacitance of $2120 \mathrm{~F}^{-1} \mathrm{~g}^{-1}$ (under the wide potential window of $1 \mathrm{~V}$ ), that is associated with the higher oxidation state of vanadium, which leads to transfer a higher number of electrons [40]. Nevertheless, low SSA and the low solubility of $\mathrm{V}_{2} \mathrm{O}_{5}$ limits the specific capacitance improvement. Furthermore, $\mathrm{V}_{2} \mathrm{O}_{5}$ is diffusely recommended as electrode material for SCs due to its controllable morphology. There are different methods to obtain the various morphology and structure of $\mathrm{V}_{2} \mathrm{O}_{5}$, such as electrospinning [272], the hydrothermal method [273], template-assisted growth [274], the sol-gel method [275], and so on.

For instance, the $\mathrm{V}_{2} \mathrm{O}_{5}$ nanofibers were synthesized using the electrospinning method, that provided the specific capacitance of $190 \mathrm{~F} \cdot \mathrm{g}^{-1}$ and $250 \mathrm{~F} \cdot \mathrm{g}^{-1}$ in $2 \mathrm{M} \mathrm{KCl}$ electrolyte and $1 \mathrm{M} \mathrm{LiClO}_{4}$ electrolyte, respectively [276]. Besides, the $\mathrm{V}_{2} \mathrm{O}_{5}$ nano-waxberries, nano-wires, and nanoflowers were prepared through the adjustment of the concentration of surfactant using the hydrothermal method [277]. In another study, the $\mathrm{V}_{2} \mathrm{O}_{5}$ nanoporous were synthesized by a facile capping-agent-assisted precipitation process, which resulted in an interconnected nanoporous network. The resultant nanochannels facilitated the accessibility of ions and improved ion diffusion. The achieved $\mathrm{V}_{2} \mathrm{O}_{5}$ showed the maximum specific capacitance of $316 \mathrm{~F} \cdot \mathrm{g}^{-1}$ and $76 \%$ of capacitance retained after 600 cycles [278].

The annealing temperatures have a significant effect on the nanomaterials structure and the electrochemical property of the prepared electrodes using such materials. For instance, the electrochemical performance of the different $\mathrm{V}_{2} \mathrm{O}_{5}$ films was investigated at different temperature. The specific capacitance of $346 \mathrm{~F} \cdot \mathrm{g}^{-1}$ at a scan rate of $5 \mathrm{mV} \cdot \mathrm{s}^{-1}$ was reported for the $\mathrm{V}_{2} \mathrm{O}_{5}$-based material annealed for an hour at $300{ }^{\circ} \mathrm{C}$ which was much higher than those which were annealed at $400{ }^{\circ} \mathrm{C}\left(177 \mathrm{~F} \cdot \mathrm{g}^{-1}\right), 350{ }^{\circ} \mathrm{C}\left(226 \mathrm{~F} \cdot \mathrm{g}^{-1}\right)$, and $250{ }^{\circ} \mathrm{C}\left(241 \mathrm{~F} \cdot \mathrm{g}^{-1}\right)$ [279]. In another study, $\mathrm{V}_{2} \mathrm{O}_{5}$ nanotubes were synthesized through the hydrothermal method, that showed a high specific capacitance of $417.3 \mathrm{mF} \cdot \mathrm{cm}^{-2}$ at a scan rate of $5 \mathrm{mV} \cdot \mathrm{s}^{-1}$ in $0.5 \mathrm{M} \mathrm{Na}_{2} \mathrm{SO}_{4}$ and suitable cycling stability with capacitance retention of $80 \%$ after 3000 cycles [280].

As it is shown in the previous examples, $\mathrm{V}_{2} \mathrm{O}_{5}$-based materials suffer from poor cycling performance and slow rate stability, which are due to the structural instability of $\mathrm{V}_{2} \mathrm{O}_{5}$ during the charge-discharge mechanism, its low conductivity $\left(10^{-2}\right.$ to $\left.10^{-3} \mathrm{~S} \mathrm{~cm}^{-1}\right)$, and slow electrochemical kinetics. To solve the problem associated with the low electrical conductivity of the $\mathrm{V}_{2} \mathrm{O}_{5}$, which is the most critical complication, researchers focused on shortening the diffusion length and electrochemical kinetics improvement of the electrolyte [281,282]. Furthermore, carbonaceous materials composites and metal fibres have been prepared to enhance the electronic conductivity of $\mathrm{V}_{2} \mathrm{O}_{5}$ [283].

In recent decades, to enhance the physicochemical performance of $\mathrm{V}_{2} \mathrm{O}_{5}$, researchers have focused on the development of the $\mathrm{V}_{2} \mathrm{O}_{5}$-based nanocomposite materials that can deliver supreme advantages of pure material [284]. Generally, the $\mathrm{V}_{2} \mathrm{O}_{5}$-based nanocomposites can be categorized into two main groups, including $\mathrm{V}_{2} \mathrm{O}_{5}$-carbon nanocomposites as well as $\mathrm{V}_{2} \mathrm{O}_{5}$-metal element nanocomposites such as $\mathrm{V}_{2} \mathrm{O}_{5} / \mathrm{CNT}$ [285], $\mathrm{V}_{2} \mathrm{O}_{5} / \mathrm{rGO}$ [286], $\mathrm{V}_{2} \mathrm{O}_{5} /$ polypyrrole [287], and $\mathrm{V}_{2} \mathrm{O}_{5} / \mathrm{SnO}_{2}$ [288].

The $\mathrm{E}_{\mathrm{d}}$ and the perdurability of the material could be improved through the synthesis of the composite materials. Heterogeneous structures play a significant role in composites [289].

Recently, the $\mathrm{rGO} / \mathrm{VO}_{2}$ heterostructure was fabricated through a facile hydrothermal process. The resultant material showed a superior characteristic, (in the voltage range between $0.01-3 \mathrm{~V}$ (vs. $\mathrm{Li} / \mathrm{Li}+)$ ), to be used as the anode material, due to its high specific capacity, favourable rate capability, which arises from the mixed valency of $\mathrm{V}$ ions $\left(\mathrm{V}^{3+}\right.$ and $\left.\mathrm{V}^{4+}\right)$ within the as-prepared $\mathrm{VO}_{2}$ matrix that eases the faradic reactions at a low potential. The battery-supercapacitor hybrid (BSH) device was assembled using the rGO@ $\mathrm{VO}_{2}$ as the anode, and the AC@CC as the cathode (Figure 16a). The resultant 
BSH device provided a high $E_{d}$ of $126.7 \mathrm{Wh} \cdot \mathrm{kg}^{-1}$ as well as a supreme gravimetric $\mathrm{P}_{\mathrm{d}}$ of about $10,000 \mathrm{~W} \cdot \mathrm{kg}^{-1}$ (Figure 16b), in the working voltage range between $1 \mathrm{~V}$ to $4 \mathrm{~V}$. Figure $16 \mathrm{c}$ designates that the $2 \mathrm{D} \mathrm{VO}_{2}$ nanoribbons are tightly attached to the large 2D rGO nanosheet [80].

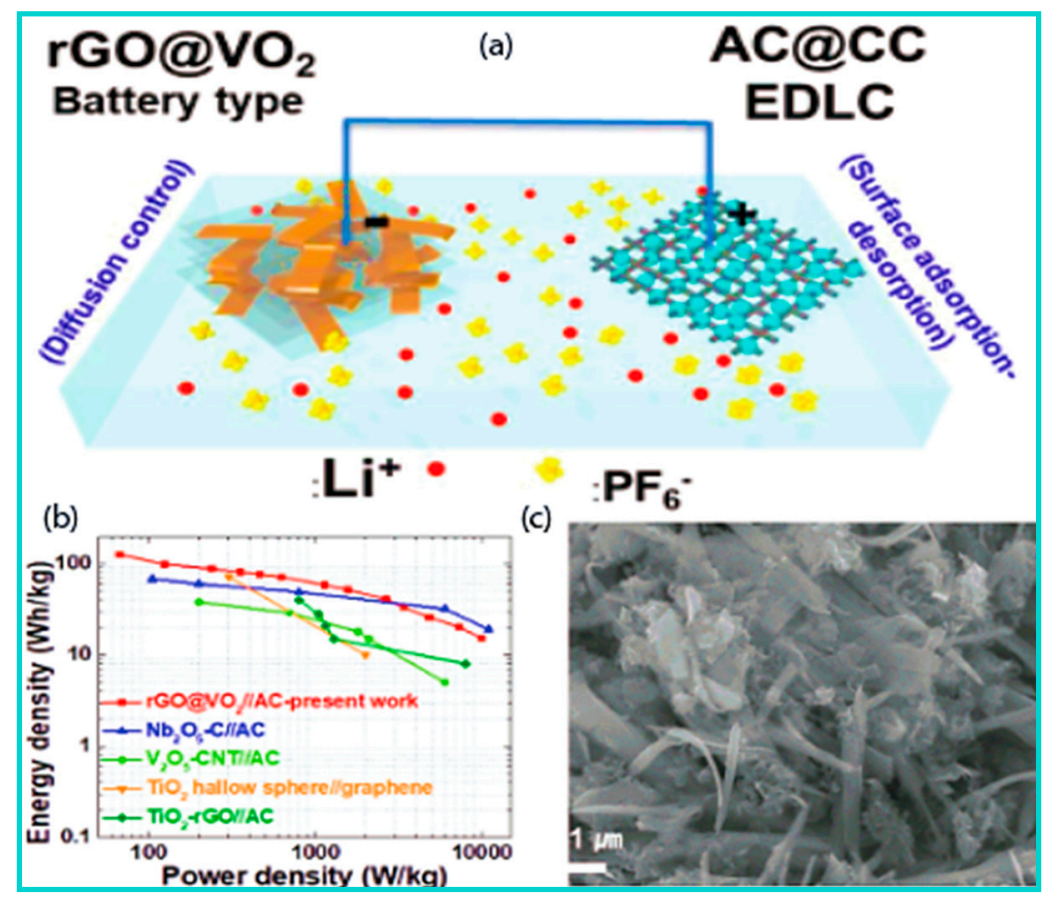

Figure 16. Schematic illustration of the as-fabricated battery-supercapacitor hybrid (BSH) device. (a) Comparative Ragone plot of the various stated hybrid storage devices with the as-fabricated BSH.

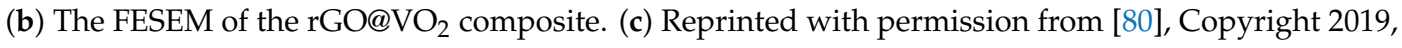
American Chemical Society.

The graphene-decorated $\mathrm{V}_{2} \mathrm{O}_{5}$ nanobelts were synthesized using the hydrothermal method, which revealed a high capacitance of $288 \mathrm{~F} \cdot \mathrm{g}^{-1}$ at a scan rate of $10 \mathrm{mV} \cdot \mathrm{s}^{-1}$ and $82 \%$ of the capacitance remained even after 5000 cycles [290]. Chen et al. [291]. synthesized the $\mathrm{V}_{2} \mathrm{O}_{5}$-based composites in the nanowire structure, interpenetrating $\mathrm{V}_{2} \mathrm{O}_{5}$ into conductive porous $\mathrm{CNT}$ frames using an in-situ hydrothermal method. The prepared nanocomposite-based electrode exhibited a specific capacitance up to $440 \mathrm{~F} \cdot \mathrm{g}^{-1}$ at $0.25 \mathrm{~A} \cdot \mathrm{g}^{-1}$. The ASC device developed based on the $\mathrm{V}_{2} \mathrm{O}_{5} / \mathrm{CNT}$ hybrid composites showed a high $\mathrm{E}_{\mathrm{d}}$ of $16 \mathrm{Wh} \cdot \mathrm{kg}^{-1}$ at a $\mathrm{P}_{\mathrm{d}}$ of $75 \mathrm{~W} \cdot \mathrm{kg}^{-1}$.

Furthermore, the graphene $/ \mathrm{V}_{2} \mathrm{O}_{5}$-xerogel nanocomposites were fabricated utilizing a hydrothermal approach. The prepared electrode provided a good specific capacitance of $195.4 \mathrm{~F} \cdot \mathrm{g}^{-1}$ at a current density of $1 \mathrm{~A} \cdot \mathrm{g}^{-1}$. The electrical conductivity improvement was due to the presence of the graphene, which also improved the SSA of the $\mathrm{V}_{2} \mathrm{O}_{5}$-xerogels approximately twice in comparison with the $\mathrm{V}_{2} \mathrm{O}_{5}$-only xerogels [292]. Besides, Zhang et al. [293] synthesized the $3 \mathrm{D}$ porous $\mathrm{V}_{2} \mathrm{O}_{5}$ hierarchical spheres consisting of stacked platelets through the precipitation of precursor microspheres in aqueous solution at room temperature and the subsequent calcination. The as-obtained $\mathrm{V}_{2} \mathrm{O}_{5}$ hierarchical spheres showed an excellent high-rate capability. The porous $\mathrm{V}_{2} \mathrm{O}_{5}$ hierarchical spheres exhibited a high capacity of up to $473 \mathrm{C} \cdot \mathrm{g}^{-1}$ at $0.2 \mathrm{~A} \cdot \mathrm{g}^{-1}$ as a battery-typed electrode.

Furthermore, crystalline $\alpha-\mathrm{V}_{2} \mathrm{O}_{5}$ powders were successfully exfoliated into wrinkled $\mathrm{V}_{2} \mathrm{O}_{5}$ nanoribbons through a novel processing method based on specific microwave heating and were used to form a strongly bound $\mathrm{V}_{2} \mathrm{O}_{5} / \mathrm{rGO}$ hybrid material using a simple cation-mediated self-assembly mechanism and further thermal annealing treatment. The yield nanoribbons showed a specific capacitance of $423.6 \mathrm{~F} \cdot \mathrm{g}^{-1}$ at $1 \mathrm{~A} \cdot \mathrm{g}^{-1}$. The SSC developed using the hybrid material provides a high 
$E_{\mathrm{d}}$ of $58.8 \mathrm{Wh} \cdot \mathrm{kg}^{-1}$ at and an average $\mathrm{P}_{\mathrm{d}}$ of $500 \mathrm{~W} \cdot \mathrm{kg}^{-1}$ as well as an excellent high-rate capability. The specific capacitance remained nearly constant after up to 1800 charge-discharge cycles [294].

In another study, the reduced $\mathrm{GO} /$ vanadium pentoxide $\left(\mathrm{V}_{2} \mathrm{O}_{5}\right) / \mathrm{PANI}(\mathrm{GVP})$ nanocomposite was fabricated through in situ single-step chemical process, and the as-prepared material showed a high $E_{d}$ of $54.62 \mathrm{Wh} \cdot \mathrm{kg}^{-1}$, the specific capacitance of $273 \mathrm{~F} \cdot \mathrm{g}^{-1}$ (specific capacity of $328.5 \mathrm{C} \cdot \mathrm{g}^{-1}$ ), and $\mathrm{P}_{\mathrm{d}}$ of $1636.5 \mathrm{~W} \cdot \mathrm{kg}^{-1}$ at a current density of $1 \mathrm{~A} \cdot \mathrm{g}^{-1}$. The symmetric and asymmetric SCs using $\mathrm{V}_{2} \mathrm{O}_{5}$-based composites as electrode displayed high $\mathrm{E}_{\mathrm{d}}$ and a wide voltage window that could compete with batteries [295].

Table 1 summarizes the electrochemical measurement results of different metal oxide-based electrode materials and their corresponding fabricated SCs using various types of electrolytes (e.g., liquid, solid/quasi solid-state, and redox-active electrolytes). As it is shown in Table 1, various types of supercapacitors, including SSCs, ASSCs, FSCs, and HSCs can be fabricated utilizing different TMOs and $\mathrm{TM}(\mathrm{OH}) \mathrm{s}$ composited with highly porous and conductive materials such as carbonaceous (e.g., CNTs, CCF, CB, etc.) and CPs, which provide rapid ionic diffusion as well as ion transport owing to their inter- and intraplanar pores. In several examples, the electrical conductivity of the TM(OH)s and $\mathrm{TM}(\mathrm{OH})$ s composite have been increased by utilizing the 2D nanomaterials (graphene, GPCNs, etc.), which leads to faster charge transfer owing to the $2 \mathrm{D}$ structure. The capacitive performance of the composite-based electrode materials and their corresponding supercapacitor was improved by introducing TMOs and $\mathrm{TM}(\mathrm{OH})$ s to carbonaceous materials which increased the hydrophilicity and the conductivity of carbon-based materials offering both EDLC and faradic behaviour to the resultant composite. Besides, in comparison with different mixed TMOs, the ternary metal-based nanomaterials (composed of three various MOs), exhibited excellent electrochemical performance owing to the combination of advantages between three components that can display extraordinary structural stability and synergies. 
Table 1. A comparison of the recent metal oxide-based electrode materials performance utilized in various types of SC devices. (Cs: specific capacitance).

\begin{tabular}{|c|c|c|c|c|c|c|c|c|}
\hline Nanocomposite & $\begin{array}{l}\text { Cs of the Electrode } \\
\text { Material at Current } \\
\text { Density }\left(\mathrm{A} \cdot \mathrm{g}^{-1}\right) \text { or at } \\
\text { Scan Rate }\left(\mathrm{mV} \cdot \mathrm{s}^{-1}\right)\end{array}$ & $\begin{array}{l}\text { Cs of the SC at } \\
\text { Current Density } \\
\left(\mathrm{A} \cdot \mathrm{g}^{-1}\right) \text { or at Scan } \\
\text { Rate }\left(\mathrm{mV} \cdot \mathrm{s}^{-1}\right)\end{array}$ & $E_{d}$ of the $S C$ & $P_{d}$ of the $S C$ & $\begin{array}{c}\text { Capacitance Retention } \\
(\%) / \text { Number of } \\
\text { Cycles/Current Density } \\
\left(\mathrm{A} \cdot \mathrm{g}^{-1}\right) \text { or at Scan } \\
\text { Rate }\left(\mathrm{mV} \cdot \mathrm{s}^{-1}\right)\end{array}$ & Electrolyte & Type of the SC Device & Ref. \\
\hline $\mathrm{MnO}_{2} / \mathrm{GPCNs}$ & $438 \mathrm{~F} \cdot \mathrm{g}^{-1}$ at $0.5 \mathrm{~A} \cdot \mathrm{g}^{-1}$ & $72.4 \mathrm{~F} \cdot \mathrm{g}^{-1}$ & $50.2 \mathrm{Wh} \cdot \mathrm{kg}^{-1}$ & $516 \mathrm{~W} \cdot \mathrm{kg}^{-1}$ & $\begin{array}{l}67.8 /-/ 50 \mathrm{~A} \cdot \mathrm{g}^{-1} \text { for the } \\
\text { electrode, and } 77.8 /-/ 0.5 \\
\text { to } 50 \mathrm{~A} \cdot \mathrm{g}^{-1} \text { for the device }\end{array}$ & $\begin{array}{l}\text { Aqueous } 1.0 \mathrm{M} \\
\mathrm{Na}_{2} \mathrm{SO}_{4}\end{array}$ & $\begin{array}{c}\text { ASSC } \\
\left(\mathrm{MnO}_{2} / \mathrm{GPCN}-\mathrm{SS} / / \mathrm{GPCN}-\mathrm{SS}\right)\end{array}$ & [296] \\
\hline $\mathrm{Mn}_{3} \mathrm{O}_{4} @ \mathrm{NiCO}_{2} \mathrm{O}_{4} @ \mathrm{NiO}$ & $1905 \mathrm{~F} \cdot \mathrm{g}^{-1}$ at $1 \mathrm{~A} \cdot \mathrm{g}^{-1}$ & $216 \mathrm{~F} \cdot \mathrm{g}^{-1}$ at $1 \mathrm{~A} \cdot \mathrm{g}^{-1}$ & $76.8 \mathrm{Wh} \cdot \mathrm{kg}^{-1}$ & $800 \mathrm{~W} \cdot \mathrm{kg}^{-1}$ & $92 / 10,000$ & Aqueous $2 \mathrm{M} \mathrm{KOH}$ & ASSC (MNN//AC) & [297] \\
\hline $\begin{array}{l}\mathrm{MnO}_{2} \text {-coated graphene } \\
\text { paper }\end{array}$ & $385.2 \mathrm{~F} \cdot \mathrm{g}^{-1}$ at $1 \mathrm{mV} \cdot \mathrm{s}^{-1}$ & $\begin{array}{l}76.8 \mathrm{mF} \cdot \mathrm{cm}^{-2} \text { at } \\
0.05 \mathrm{~mA} \cdot \mathrm{cm}^{-2}\end{array}$ & $6.14 \mathrm{mWh} \cdot \mathrm{cm}^{-2}$ & $36 \mathrm{~mW} \cdot \mathrm{cm}^{-2}$ & $82.2 / 5000 /-$ & $\begin{array}{l}\text { Aqueous } 0.1 \mathrm{M} \\
\mathrm{Na}_{2} \mathrm{SO}_{4}\end{array}$ & $\begin{array}{c}\text { Flexible solid-state } \\
\text { ASSC }\left(\mathrm{MnO}_{2} \text {-coated }\right. \\
\text { graphene } \\
\text { paper//graphene paper })\end{array}$ & [298] \\
\hline $\mathrm{MnO}_{2} / \mathrm{CNTs}$ & $1980 \mathrm{Fm}^{-2}$ at $10 \mathrm{~A} \cdot \mathrm{m}^{-2}$ & - & 177 Wh.m ${ }^{-2}$ & $250 \mathrm{~W} \cdot \mathrm{m}^{-2}$ & 87/3000/10 A.m ${ }^{-2}$ & $\begin{array}{l}\text { Aqueous } 1.0 \mathrm{M} \\
\mathrm{Na}_{2} \mathrm{SO}_{4}\end{array}$ & SSC & [299] \\
\hline $\mathrm{CNTs} / \mathrm{MnO}_{2}$ & $1229 \mathrm{~F} \cdot \mathrm{g}^{-1}$ at $1 \mathrm{~A} \cdot \mathrm{g}^{-1}$ & $\begin{array}{l}152 \mathrm{~F} \cdot \mathrm{g}^{-1} \text { at } 0.3 \\
1 \mathrm{~A} \cdot \mathrm{g}^{-1}\end{array}$ & $84.6 \mathrm{Wh} \cdot \mathrm{kg}^{-1}$ & $190 \mathrm{~W} \cdot \mathrm{kg}^{-1}$ & $\begin{array}{l}94.4 / 10,000 /- \text { for the } \\
\text { electrode, and } 91 / 10,000 /- \\
\text { for the device }\end{array}$ & $\begin{array}{l}\text { Aqueous } 1 \mathrm{M} \\
\mathrm{Na}_{2} \mathrm{SO}_{4}\end{array}$ & $\begin{array}{c}\mathrm{ASSC} \\
\left(\mathrm{CNTs} / \mathrm{MnO}_{2} / / \mathrm{AC}\right)\end{array}$ & [300] \\
\hline $\mathrm{Mno}_{2} / \mathrm{CNTs}-60$ & $\begin{array}{l}3.54 \mathrm{Fcm}^{-2} \text { at } \\
1 \mathrm{~mA} \cdot \mathrm{cm}^{-2}\end{array}$ & - & $93.8 \mu$ Wh.cm ${ }^{-2}$ & $193 \mu \mathrm{W} . \mathrm{cm}^{-2}$ & $\begin{array}{l}>98 / 1000 /- \text { for the } \\
\text { electrode }\end{array}$ & $\begin{array}{c}\text { Polymer gel } \\
\text { PVA-LiCl (6 M) }\end{array}$ & SSC & [301] \\
\hline $\mathrm{MnO}_{2} / \mathrm{CNTs}$ & $201 \mathrm{~F} \cdot \mathrm{g}^{-1}$ at $20 \mathrm{~A} \cdot \mathrm{g}^{-1}$ & - & $13.3 \mathrm{Wh} \cdot \mathrm{kg}^{-1}$ & $600 \mathrm{~W} \cdot \mathrm{kg}^{-1}$ & $\begin{array}{l}70 / 10,000 / 1 \mathrm{~A} \cdot \mathrm{g}^{-1} \text { for the } \\
\text { electrode }\end{array}$ & $\begin{array}{l}\text { Aqueous } 1 \mathrm{M} \\
\mathrm{Na}_{2} \mathrm{SO}_{4}\end{array}$ & $\begin{array}{c}\mathrm{ASSC} \\
\left(\mathrm{AC} / / \mathrm{MnO}_{2} / \mathrm{CNTs}\right) \\
\end{array}$ & [302] \\
\hline $\mathrm{MnO}_{2}$-AgCNT-CC & $\begin{array}{l}\text { up to } 325 \mathrm{~F} \cdot \mathrm{g}^{-1} \text { at } \\
1 \mathrm{~A} \cdot \mathrm{g}^{-1}\end{array}$ & - & - & - & - & $\begin{array}{l}\text { Aqueous } 0.5 \mathrm{M} \\
\mathrm{Na}_{2} \mathrm{SO}_{4}\end{array}$ & FSC & [303] \\
\hline CoMCNFs@MnO & $265 \mathrm{~F} \cdot \mathrm{g}^{-1}$ at $0.5 \mathrm{~A} \cdot \mathrm{g}^{-1}$ & $66 \mathrm{~F} \cdot \mathrm{g}^{-1}$ at $0.3 \mathrm{~A} \cdot \mathrm{g}^{-1}$ & 19.27 Wh.kg ${ }^{-1}$ & $217.51 \mathrm{~W} \cdot \mathrm{kg}^{-1}$ & $\begin{array}{l}98.7 / 10,000 / \text { for the } \\
\text { electrode, and } \\
94.9 / 10,000 / \text { for the device }\end{array}$ & Aqueous $3 \mathrm{M} \mathrm{KOH}$ & $\begin{array}{c}\text { ASSC } \\
\left(\mathrm{CoMCNF} @ \mathrm{MnO}_{2} / / \mathrm{CNFs}\right)\end{array}$ & [304] \\
\hline $\mathrm{Mn}_{3} \mathrm{O}_{4} / \mathrm{CNFs}$ & $300.7 \mathrm{~F} \cdot \mathrm{g}^{-1}$ at $5 \mathrm{mV} \cdot \mathrm{s}^{-1}$ & - & $79.4 \mathrm{mWh} \cdot \mathrm{cm}^{-2}$ & - & 100/7500/- & $\begin{array}{l}\text { Aqueous } 1 \mathrm{M} \\
\mathrm{Na}_{2} \mathrm{SO}_{4}\end{array}$ & SSC & [305] \\
\hline $\mathrm{Mn}_{3} \mathrm{O}_{4} / \mathrm{Ni}(\mathrm{OH})_{2}$ & $742 \mathrm{~F} \cdot \mathrm{g}^{-1}$ at $1 \mathrm{~A} \cdot \mathrm{g}^{-1}$ & $43 \mathrm{~F} \cdot \mathrm{g}^{-1}$ at $0.2 \mathrm{~A} \cdot \mathrm{g}^{-1}$ & $15.3 \mathrm{Wh} \cdot \mathrm{kg}^{-1}$ & $168.8 \mathrm{~W} \cdot \mathrm{kg}^{-1}$ & - & Aqueous $1 \mathrm{M} \mathrm{KOH}$ & $\begin{array}{c}\text { ASSC } \\
\left(\mathrm{Mn}_{3} \mathrm{O}_{4} / \mathrm{Ni}(\mathrm{OH})_{2} / / \mathrm{AC}\right) \\
\end{array}$ & [306] \\
\hline Porous graphene@ $\mathrm{Mn}_{3} \mathrm{O}_{4}$ & $208.3 \mathrm{~F} \cdot \mathrm{g}^{-1}$ & $\begin{array}{l}60.1 \mathrm{~F} \cdot \mathrm{g}^{-1} \text { at } \\
0.5 \mathrm{~A} \cdot \mathrm{g}^{-1}\end{array}$ & $30.1 \mathrm{Wh} \cdot \mathrm{kg}^{-1}$ & $475 \mathrm{~W} \cdot \mathrm{kg}^{-1}$ & 86/2000/- & $\begin{array}{l}\text { Aqueous } 1 \mathrm{M} \\
\mathrm{Na}_{2} \mathrm{SO}_{4}\end{array}$ & $\begin{array}{c}\text { ASSC (porous } \\
\text { graphene@ } @ \mathrm{Mn}_{3} \mathrm{O}_{4} / / \mathrm{AG} \text { ) }\end{array}$ & [307] \\
\hline $\mathrm{Zn}_{2} \mathrm{SnO}_{4} / \mathrm{SnO}_{2} / \mathrm{CNT}$ & $702 \mathrm{~F} \cdot \mathrm{g}^{-1}$ at $1 \mathrm{~A} \cdot \mathrm{g}^{-1}$ & - & $98 \mathrm{Wh} \cdot \mathrm{kg}^{-1}$ & $1000 \mathrm{~W} \cdot \mathrm{kg}^{-1}$ & $93 / 15,000$ & Aqueous $6 \mathrm{M} \mathrm{KOH}$ & SSC & [308] \\
\hline
\end{tabular}


Table 1. Cont

\begin{tabular}{|c|c|c|c|c|c|c|c|c|}
\hline Nanocomposite & $\begin{array}{l}\text { Cs of the Electrode } \\
\text { Material at Current } \\
\text { Density }\left(\mathrm{A} \cdot \mathrm{g}^{-1}\right) \text { or at } \\
\text { Scan Rate }\left(\mathrm{mV} \cdot \mathrm{s}^{-1}\right)\end{array}$ & $\begin{array}{l}\text { Cs of the SC at } \\
\text { Current Density } \\
\left(\mathrm{A} \cdot \mathrm{g}^{-1}\right) \text { or at Scan } \\
\text { Rate }\left(\mathrm{mV} \cdot \mathrm{s}^{-1}\right)\end{array}$ & $E_{d}$ of the SC & $P_{d}$ of the SC & $\begin{array}{c}\text { Capacitance Retention } \\
(\%) / \text { Number of } \\
\text { Cycles/Current Density } \\
\left(\mathrm{A} \cdot \mathrm{g}^{-1}\right) \text { or at Scan } \\
\text { Rate }\left(\mathrm{mV} \cdot \mathrm{s}^{-1}\right) \\
\end{array}$ & Electrolyte & Type of the SC Device & Ref. \\
\hline CuO@NiO/PANI/MWCNT & $1372 \mathrm{~F} \cdot \mathrm{g}^{-1}$ at $5 \mathrm{mV} \cdot \mathrm{s}^{-1}$ & - & - & - & $83 / 1500 /-$ & $\begin{array}{c}\text { Aqueous } 3 \mathrm{M} \\
\mathrm{NaOH}\end{array}$ & - & [309] \\
\hline $\mathrm{NiO} / \mathrm{PANI} / \mathrm{CNT}$ & $356 \mathrm{~F} \cdot \mathrm{g}^{-1}$ at $5 \mathrm{mV} \cdot \mathrm{s}^{-1}$ & - & - & - & 93.4/-/- & $\begin{array}{c}\text { Aqueous } 0.1 \mathrm{M}, 10 \\
\text { mL KCl in } \\
\text { acetonitrile }\end{array}$ & - & [310] \\
\hline $\mathrm{ZnO} / \mathrm{MnO}_{\mathrm{x}}$ & $556 \mathrm{~F} \cdot \mathrm{g}^{-1}$ at $1 \mathrm{~A} \cdot \mathrm{g}^{-1}$ & - & $16 \mathrm{Wh} \cdot \mathrm{kg}^{-1}$ & $225 \mathrm{~W} \cdot \mathrm{kg}^{-1}$ & $96 / 10,000 /-$ & $\begin{array}{c}\text { Aqueous } 1 \mathrm{M} \\
\mathrm{Na}_{2} \mathrm{SO}_{4}\end{array}$ & SSC & [311] \\
\hline $\mathrm{RuO}_{2}-\mathrm{CNFs}$ & $188 \mathrm{~F} \cdot \mathrm{g}^{-1}$ at $1 \mathrm{~mA} \cdot \mathrm{cm}^{-2}$ & - & - & - & 93/3000/-for the electrode & Aqueous $6 \mathrm{M} \mathrm{KOH}$ & - & {$[312]$} \\
\hline $\mathrm{RuO}_{2}-\mathrm{ITO}$ nanopillars & $1235 \mathrm{~F} \cdot \mathrm{g}^{-1}$ at $50 \mathrm{mV} \cdot \mathrm{s}^{-1}$ & - & - & - & 75/4000/-for the electrode & $\begin{array}{c}\text { Aqueous } 0.5 \mathrm{M} \\
\mathrm{H}_{2} \mathrm{SO}_{4}\end{array}$ & - & [313] \\
\hline $\mathrm{Co}_{3} \mathrm{O}_{4} @ \mathrm{RuO}_{2}$ nanosheet & - & $3.42 \mathrm{~F} \cdot \mathrm{cm}^{-3}$ & $1.21 \mathrm{mWh} \cdot \mathrm{cm}^{-3}$ & 13.29 & - & Aqueous $3 \mathrm{M} \mathrm{KOH}$ & $\begin{array}{c}\mathrm{ASSC}\left(\mathrm{Co}_{3} \mathrm{O}_{4} @ \mathrm{RuO}_{2}\right. \\
\left.\text { nanosheet } / \mathrm{Co}_{9} \mathrm{~S}_{8}\right)\end{array}$ & [314] \\
\hline $\mathrm{Co}_{3} \mathrm{O}_{4} @ \mathrm{RuO}_{2}$ nanosheet & - & $4.28 \mathrm{~F} \cdot \mathrm{cm}^{-3}$ & $1.44 \mathrm{mWh} \cdot \mathrm{cm}^{-3}$ & $0.89 \mathrm{~W} \cdot \mathrm{cm}^{-3}$ & - & $\begin{array}{c}\text { Solid-state } \\
\text { PVA/KOH gel }\end{array}$ & $\begin{array}{c}\mathrm{ASSC}\left(\mathrm{Co}_{3} \mathrm{O}_{4} @ \mathrm{RuO}_{2}\right. \\
\left.\text { nanosheet/Co } / \mathrm{Co}_{8} \mathrm{~S}_{8}\right)\end{array}$ & [314] \\
\hline carbon $/ \mathrm{Fe}_{3} \mathrm{O}_{4}$ & $536 \mathrm{~F} \cdot \mathrm{g}^{-1}$ at $3 \mathrm{~A} \cdot \mathrm{g}^{-1}$ & $368 \mathrm{~F} \cdot \mathrm{g}^{-1}$ at $1 \mathrm{~A} \cdot \mathrm{g}^{-1}$ & $42 \mathrm{Wh} \cdot \mathrm{kg}^{-1}$ & $14.5 \mathrm{k} \mathrm{W} \cdot \mathrm{kg}^{-1}$ & $77 / 20,000 / 20 \mathrm{~A} \cdot \mathrm{g}^{-1}$ & $\begin{array}{c}\text { Aqueous } 3.5 \mathrm{M} \\
\mathrm{KOH}\end{array}$ & SSC & [315] \\
\hline $\mathrm{Fe}_{2} \mathrm{O}_{3} / \mathrm{GNSs} / \mathrm{CNTs}$ & $675.7 \mathrm{~F} \cdot \mathrm{g}^{-1}$ at $1 \mathrm{~A} \cdot \mathrm{g}^{-1}$ & $\begin{array}{c}169.5 \mathrm{~F}^{-1} \mathrm{~g}^{-1} \text { at } \\
0.5 \mathrm{~A} \cdot \mathrm{g}^{-1}\end{array}$ & $60.3 \mathrm{Wh} \cdot \mathrm{kg}^{-1}$ & - & $82.2 / 5000 / 5 \mathrm{~A} \cdot \mathrm{g}^{-1}$ & Aqueous $6 \mathrm{M} \mathrm{KOH}$ & All-solid-state ASSC & [316] \\
\hline $\mathrm{PANI} / \mathrm{rGO} / \mathrm{Fe}_{2} \mathrm{O}_{3} @ \mathrm{CC}$ & $1124 \mathrm{~F} \cdot \mathrm{g}^{-1}$ at $0.25 \mathrm{~A} \cdot \mathrm{g}^{-1}$ & - & - & - & $82 / 10,000 /-$ & $\begin{array}{c}\text { Aqueous } 1 \mathrm{M} \\
\mathrm{H}_{2} \mathrm{SO}_{4}\end{array}$ & - & [317] \\
\hline $\mathrm{CNT}-\mathrm{Fe}_{3} \mathrm{O}_{4}$ & $373 \mathrm{~F} \cdot \mathrm{g}^{-1}$ at $10 \mathrm{mV} \cdot \mathrm{s}^{-1}$ & $\begin{array}{c}135.2 \mathrm{~F} \cdot \mathrm{g}^{-1} \text { at } \\
10 \mathrm{mV} \cdot \mathrm{s}^{-1}\end{array}$ & $37 \mathrm{Wh} \cdot \mathrm{kg}^{-1}$ & $10 \mathrm{k} \mathrm{W} \cdot \mathrm{kg}^{-1}$ & 100/15,000/- & $\begin{array}{l}\text { Aqueous } 1 \mathrm{M} \\
\mathrm{Na}_{2} \mathrm{SO}_{4}\end{array}$ & $\begin{array}{c}\mathrm{HASSC} \\
\left(\mathrm{CNT}-\mathrm{Fe}_{3} \mathrm{O}_{4} / / \mathrm{CNT}-\mathrm{Mn}_{3} \mathrm{O}_{4}\right)\end{array}$ & [318] \\
\hline $\mathrm{CNT}-\mathrm{Mn}_{3} \mathrm{O}_{4}$ & $453 \mathrm{~F} \cdot \mathrm{g}^{-1}$ at $10 \mathrm{mV} \cdot \mathrm{s}^{-1}$ & $\begin{array}{c}135.2 \mathrm{~F} \cdot \mathrm{g}^{-1} \text { at } \\
10 \mathrm{mV} \cdot \mathrm{s}^{-1}\end{array}$ & $37 \mathrm{Wh} \cdot \mathrm{kg}^{-1}$ & $10 \mathrm{k} \mathrm{W} \cdot \mathrm{kg}^{-1}$ & $100 / 15,000 /-$ & $\begin{array}{l}\text { Aqueous } 1 \mathrm{M} \\
\mathrm{Na}_{2} \mathrm{SO}_{4}\end{array}$ & $\begin{array}{c}\mathrm{HASSC} \\
\left(\mathrm{CNT}-\mathrm{Fe}_{3} \mathrm{O}_{4} / / \mathrm{CNT}-\mathrm{Mn}_{3} \mathrm{O}_{4}\right)\end{array}$ & [276] \\
\hline$(\mathrm{Fe}, \mathrm{Cr})_{2} \mathrm{O}_{3}$ oxide layer & $\begin{array}{c}45.92 \mathrm{mF} \cdot \mathrm{cm}^{-2} \text { at } \\
5 \mathrm{mV} \cdot \mathrm{s}^{-1}\end{array}$ & $\begin{array}{c}16.88 \mathrm{mF} \cdot \mathrm{cm}^{-2} \text { at } \\
5 \mathrm{mV} \cdot \mathrm{s}^{-1}\end{array}$ & $0.57 \mathrm{mWh} \cdot \mathrm{cm}^{-2}$ & $200 \mathrm{~mW} \cdot \mathrm{cm}^{-2}$ & $\begin{array}{l}97 / 10000 / \text {-for the } \\
\text { electrode, and } 90 / 10 \\
\text { 000/-for the device }\end{array}$ & $\begin{array}{l}\text { Polymer gel } \\
\mathrm{LiClO}_{4}-\mathrm{PC}\end{array}$ & Flexible solid-state SSC & {$[306]$} \\
\hline $\mathrm{WS}_{2} @ \mathrm{NiCo}_{2} \mathrm{O}_{4} / \mathrm{CC}$ & $\begin{array}{c}2449.9 \mathrm{mF} \cdot \mathrm{cm}^{-2} \text { at } \\
1 \mathrm{~mA} \cdot \mathrm{cm}^{-2}\end{array}$ & - & $45.67 \mathrm{Wh} \cdot \mathrm{kg}^{-1}$ & $992.83 \mathrm{~W} \cdot \mathrm{kg}^{-1}$ & $85.59 / 5000 / 2 \mathrm{~mA} \cdot \mathrm{cm}^{-2}$ & Aqueous $3 \mathrm{M} \mathrm{KOH}$ & Flexible solid-state SSC & [319] \\
\hline $\mathrm{CoO} / \mathrm{NiO}-\mathrm{Cu} @ \mathrm{CuO}$ & $\begin{array}{c}2035 \mathrm{mF} \cdot \mathrm{cm}^{-2} \text { at } \\
2 \mathrm{~mA} \cdot \mathrm{cm}^{-2}\end{array}$ & - & $69.3 \mathrm{Wh} \cdot \mathrm{kg}^{-1}$ & $1080 \mathrm{~W} \cdot \mathrm{kg}^{-1}$ & $90.3 / 5000 /$ & $\begin{array}{c}\text { Solid-state } \\
\text { PVA/KOH hydrogel }\end{array}$ & Solid-state aASSC & [320] \\
\hline
\end{tabular}


Table 1. Cont

\begin{tabular}{|c|c|c|c|c|c|c|c|c|}
\hline Nanocomposite & $\begin{array}{l}\text { Cs of the Electrode } \\
\text { Material at Current } \\
\text { Density }\left(A \cdot g^{-1}\right) \text { or at } \\
\text { Scan Rate }\left(\mathrm{mV} \cdot \mathrm{s}^{-1}\right)\end{array}$ & $\begin{array}{l}\text { Cs of the SC at } \\
\text { Current Density } \\
\left(A \cdot g^{-1}\right) \text { or at Scan } \\
\text { Rate }\left(\mathrm{mV} \cdot \mathrm{s}^{-1}\right)\end{array}$ & $E_{d}$ of the SC & $P_{d}$ of the SC & $\begin{array}{c}\text { Capacitance Retention } \\
(\%) / \text { Number of } \\
\text { Cycles/Current Density } \\
\left(\mathrm{A} \cdot \mathrm{g}^{-1}\right) \text { or at Scan } \\
\text { Rate }\left(\mathrm{mV} \cdot \mathrm{s}^{-1}\right)\end{array}$ & Electrolyte & Type of the SC Device & Ref. \\
\hline $\begin{array}{l}\text { NiO@Nanofiber-based } \\
\text { composite }\end{array}$ & - & 161 at $1.0 \mathrm{~A} \cdot \mathrm{g}^{-1}$ & $22 \mathrm{Wh} \cdot \mathrm{kg}^{-1}$ & $491.9 \mathrm{~W} \cdot \mathrm{kg}^{-1}$ & $\sim 96.0 / 5000 / 10 \mathrm{~A} \cdot \mathrm{g}^{-1}$ & Li gel & $\begin{array}{l}\text { Flexible transparent } \\
\text { SSC }\end{array}$ & {$[321$} \\
\hline $\mathrm{Ni}(\mathrm{OH})_{2} @ \mathrm{CCF}$ & 502.00 at $1 \mathrm{~A} \cdot \mathrm{g}^{-1}$ & $\begin{array}{c}131.43 \mathrm{~F} \cdot \mathrm{g}^{-1} \text { at } \\
0.25 \mathrm{~A} \cdot \mathrm{g}^{-1}\end{array}$ & $35.78 \mathrm{Wh} \cdot \mathrm{kg}^{-1}$ & $0.35 \mathrm{k} \mathrm{W} \cdot \mathrm{kg}^{-1}$ & $\begin{array}{l}102.61 \text { even at a bending } \\
\text { angle of } 180^{\circ}\end{array}$ & Aqueous $6 \mathrm{M} \mathrm{KOH}$ & $\begin{array}{l}\text { Flexible and wearable } \\
\text { SSC }\end{array}$ & {$[322$} \\
\hline Ni-Mn-oxides & $1215.5 \mathrm{~F} \cdot \mathrm{g}^{-1}$ at $2 \mathrm{mV} \cdot \mathrm{s}^{-1}$ & $\begin{array}{c}196.5 \mathrm{~F} \cdot \mathrm{g}^{-1} \text { at } \\
1.5 \mathrm{~A} \cdot \mathrm{g}^{-1}\end{array}$ & $132.3 \mathrm{Wh} \cdot \mathrm{kg}^{-1}$ & $1651 \mathrm{~W} \cdot \mathrm{kg}^{-1}$ & 97/3000/- & $\begin{array}{c}\text { Aqueous } 1 \mathrm{M} \\
\mathrm{Na}_{2} \mathrm{SO}_{4}\end{array}$ & $\begin{array}{c}\text { ASSC } \\
\text { (Ni-Mn-oxide//AC) }\end{array}$ & {$[323$} \\
\hline $\begin{array}{c}\mathrm{V}_{2} \mathrm{O}_{5} / \mathrm{Pt} / \text { conductive } \\
\text { printing paper }\end{array}$ & $343 \mathrm{~F} \cdot \mathrm{g}^{-1}$ at $10 \mathrm{mV} \cdot \mathrm{s}^{-1}$ & $160 \mathrm{~F} \cdot \mathrm{g}^{-1}$ & $355 \mathrm{Wh} \cdot \mathrm{kg}^{-1}$ & $0.2 \mathrm{~kW} \cdot \mathrm{kg}^{-1}$ & 91/5000/- & $\begin{array}{c}\text { Urea-LiClO }{ }_{4}-\mathrm{PVA} \\
\text { (ULP) }\end{array}$ & $\begin{array}{c}\text { Wearable SSC } \\
\text { pseudocapacitor }\end{array}$ & {$[324$} \\
\hline $\begin{array}{l}\mathrm{VO}_{2} / \text { graphene@ } \mathrm{NiS}_{2} \\
\text { hybrid aerogel }\end{array}$ & $1280.0 \mathrm{~F} \cdot \mathrm{g}^{-1}$ at $1 \mathrm{~A} \cdot \mathrm{g}^{-1}$ & $\begin{array}{l}222.2 \mathrm{~F} \cdot \mathrm{g}^{-1} \text { at } \\
2 \mathrm{mV} \cdot \mathrm{s}^{-1}\end{array}$ & $60.2 \mathrm{Wh} \cdot \mathrm{kg}^{-1}$ & $350.0 \mathrm{~W} \cdot \mathrm{kg}^{-1}$ & $86.2 / 10,000 /-$ & PVA/KOH gel & $\begin{array}{c}\text { All-solid state ASSC } \\
\left(\mathrm{VO}_{2} / \text { graphene@ } @ \mathrm{NiS}_{2}\right. \\
\text { hybrid } \\
\text { aerogel//graphene } \\
\text { aerogel) }\end{array}$ & {$[325$} \\
\hline $\begin{array}{c}\text { Gradient } \\
\text { oxygen-vacant } \mathrm{V}_{2} \mathrm{O}_{5} / \text { PEDOT }\end{array}$ & - & $\begin{array}{l}614 \mathrm{~F} \cdot \mathrm{g}^{-1} \text { at } \\
0.5 \mathrm{~A} \cdot \mathrm{g}^{-1}\end{array}$ & $85 \mathrm{Wh} \cdot \mathrm{kg}^{-1}$ & $250 \mathrm{~W} \cdot \mathrm{kg}^{-1}$ & $122 / 50000$ & $\begin{array}{c}\text { Aqueous } 1 \mathrm{M} \\
\mathrm{Na}_{2} \mathrm{SO}_{4}\end{array}$ & SSC & {$[326$} \\
\hline
\end{tabular}




\subsection{Conducting Polymer-Based Material (CPs)}

Different CPs are another pseudocapacitive electrode material that has been widely researched because of their relatively high capacitance, high $\mathrm{E}_{\mathrm{d}}$, adjustable redox activity through chemical modification, good conductivity in doped states, high voltage windows as well as facile production, low environmental impact, and low cost [327-329].

$\mathrm{CPs}$ can store the charge in its bulk, since no structural alterations such as phase changes occur during the charge/discharge mechanism. Due to this, CPs can offer a higher capacitance because of the larger surface areas and redox storage capabilities [330-333].

In comparison with other carbon-based electrode materials, CPs have higher conductivity, capacitance, and low equivalent series resistance [334,335]. The specific capacitances in CPs derive from the fast-reversible redox reactions resulting from the $\pi$-conjugated polymer chains [90], in which the ions move to the polymer backbone through the oxidation process, also known as doping, and during the reduction process or de-doping, they are released back into the electrolyte solution. However, despite all the advantages, the reduction-oxidation in CPs causes mechanical stress and consequently limiting the stability and degradation through several charge-discharge cycles $[13,336]$. One of the other disadvantages CPs which hinders their performance is the low power densities, arise from the slow ion diffusion rates in bulk [337].

Sharma et al. [338] perceived a 50\% decline in initial capacitance of the PPy-based SC electrode, just after 1000 cycles. Accordingly, the loss of Cs of PANI nanorods was about 29.5\% after 1000 cycles. Therefore, the main concern related to CP-based electrodes is low cycling stability.

There are various methods for the synthesis of CPs, and among all, the oxidation of monomers via chemical or electrochemical approaches is the most commonly used approach [201].

The synthesized polymers arise in either two or three general states. As-formed polymers tend to be in the oxidized or "p-doped" state rather than the reduced or "n-doped" state. In the p-doped state, the polymer backbone is positively charged and exhibits a high electronic conductivity (between 1 to $100 \mathrm{Scm}^{-1}$ ) [339]. Currently, p-dopable polymers are attracting more attention from researchers in comparison with non-dopable polymers due to their stable performances [330].

The CP-based electrodes for SC exist in three various configurations including (a) the $\mathrm{p}-\mathrm{p}$ configuration in which both electrode materials are the same p-doped polymer (b) the SCs n-p type in which both electrode materials made from the same polymers, but one is positively charged (p-doped) and the other one is negatively charged (n-doped) electrodes and (c) p-doped and p-p' SCs containing two various $\mathrm{p}$-doped CPs with various oxidation and reduction electroactivities [334,339-347]. Notably, the n-p type polymer conformation has massive potential for high $E_{d}$ and $P_{d}$ [335].

The CPs electrode materials have limited pseudocapacitors from reaching their potential due to a lack of proficient n-doped conducting material and low cycling stability [334]. Various types of CPs commonly used for SC electrodes, including PANI, polythiophene (PTh), PPy, polyindole (PIND), polyfurane, poly(p-phenylene), poly(p-phenylenevinylene), poly 3,4-ethylenedioxythiophene (PEDOT) besides different derivatives, in which PTh is either p-doped or n-doped, while PANI and PPy can be only $\mathrm{p}$-dopable, and their $\mathrm{n}$-doping potential is much lesser than the reduction potential of the common electrolyte [346-348].

Conducting polymer hydrogels are successful candidates for FSC electrodes [349]. There are different strategies to synthesing the polymer hydrogel including (a) in situ polymerization of monomers into the insulating polymer matrix [349,350], (b) introducing crosslinkers through the polymerization process in order to develop the gelation [351]. However, the resultant $\mathrm{CP}$ hydrogels fabricated by the first method often provide a favourable mechanical performance; their electrochemical performance is not satisfying. The $\mathrm{CP}$ hydrogels synthesized through the second method have shown good electrochemical behaviour. Nevertheless, the processability and fabrication of the self-standing hydrogel with a favorable mechanical performance is difficult. Besides, synthesizing a polymer hydrogel electrolyte, which has both high electronic conductivity, and good electrochemical performance is challenging. 
For instance, Yang et al. [352] exploited a simple macromolecular interaction assisted route to synthesize a self-standing CP hydrogel composed by PANI and PEDOT. The resultant hydrogel showed a high mechanical performance, good electronic conductivity, and good electrochemical properties simultaneously, owing to the synergic effect between PANI and PEDOT. The assembled all-hydrogel-state SC device exhibited good areal capacitance of $808.2 \mathrm{mF} \cdot \mathrm{cm}^{-2}$, as well as a high $\mathrm{E}_{\mathrm{d}}$ of $0.63 \mathrm{mWh} \cdot \mathrm{cm}^{-3}$ at a high $\mathrm{P}_{\mathrm{d}}$ of $28.42 \mathrm{~mW} \cdot \mathrm{cm}^{-3}$ (Figure 17).

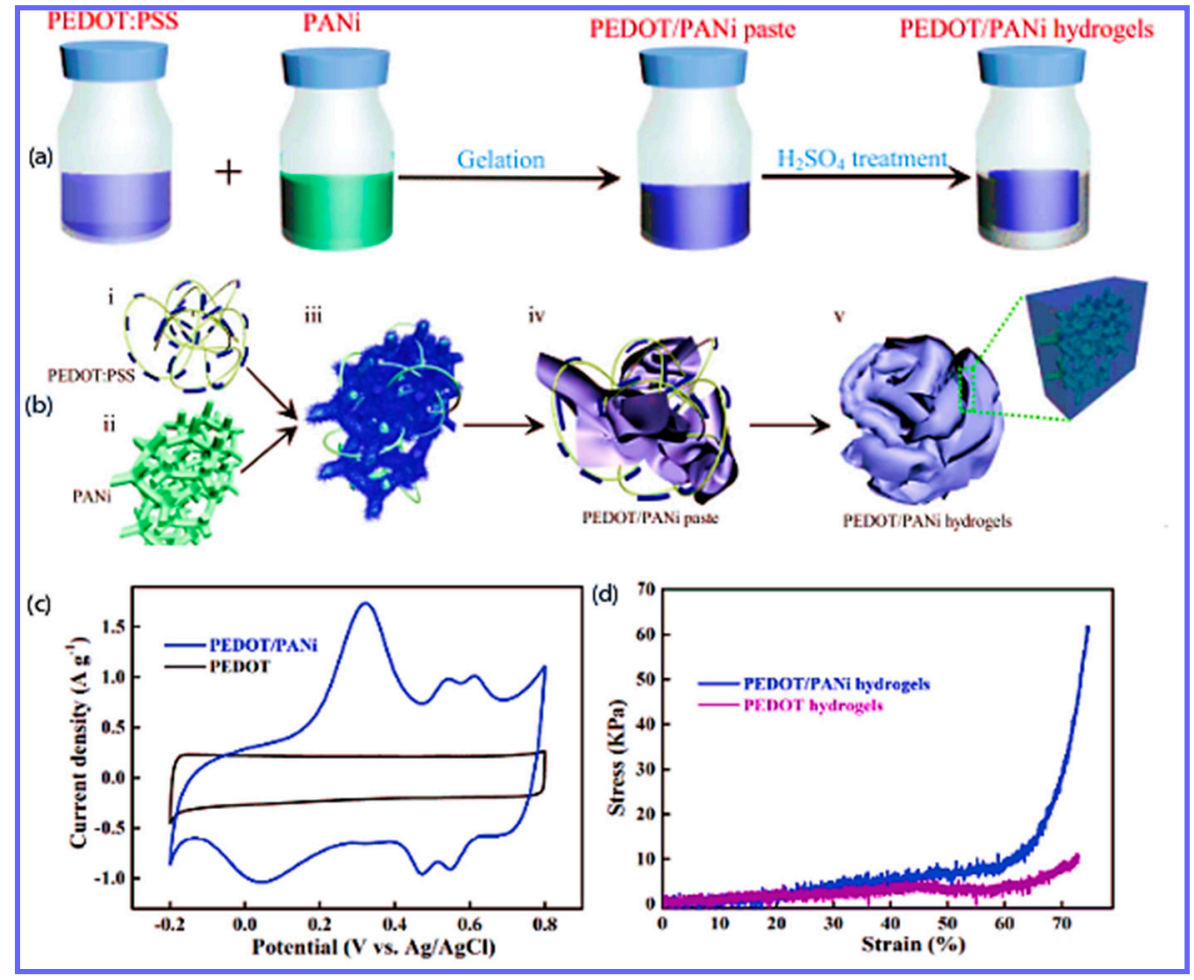

Figure 17. Graphical presentation of PEDOT/PANI hydrogels fabrication through two-step mechanism(a), Graphical presentation of the formation process of the PEDOT/PANI hydrogels. (b) The comparative CVs of PEDOT and PEDOT/PANI at $5 \mathrm{mV} \cdot \mathrm{s}^{-1}$. (c), Compressive stress-strain curve of PEDOT/PANI hydrogels. (d) Reprinted with permission from [352], Copyright 2020, American Chemical Society.

Conducting polymer hydrogels could also be used as the electrolyte in FSCs due to their resistance against the deformation and physical damage. For instance, an FSC was fabricated by inserting the PEI-PVA-Bn-LiCl hydrogel electrolyte, (polyethyleneimine/polyvinyl alcohol/4-formylphe-nylboronic acid/Lithium chloride), within the two MWCNT electrodes, which showed a specific capacitance of $16.7 \mathrm{mF} \cdot \mathrm{cm}^{-2}$, an enlarged operating potential window of $1.4 \mathrm{~V}$, as well as high cycling stability, and superior mechanical stability [353] (Figure 18). 
(a)
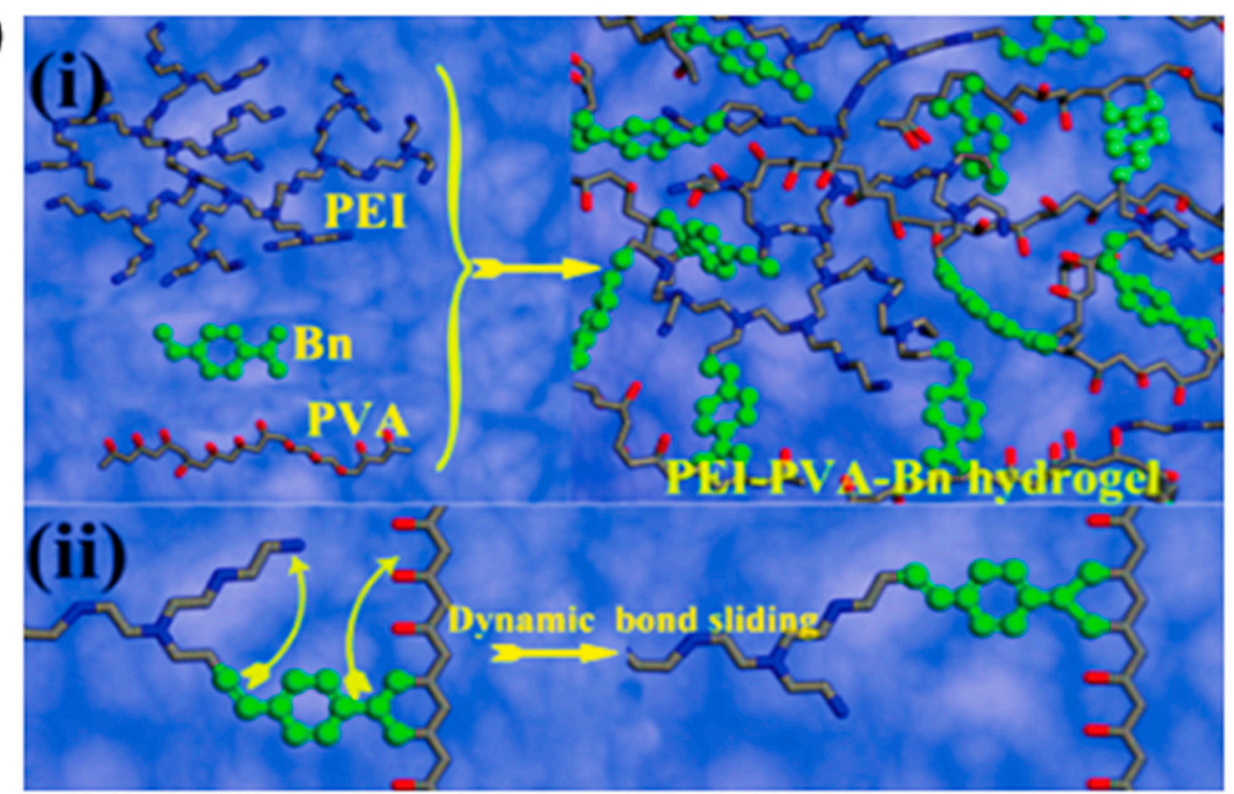

(b)

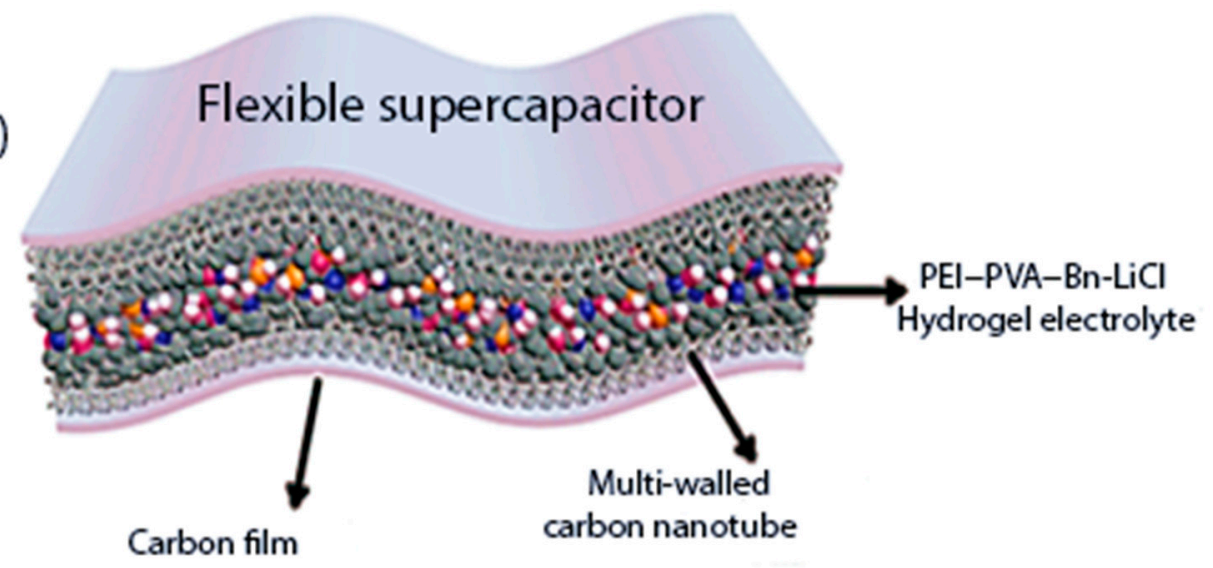

Figure 18. (a) The structure of the PEI-PVA-Bn hydrogel network (i) and the sliding development of the dynamic cross-linking sites. (ii) Graphical presentation of the SC consisting the PEI-PVA-Bn-LiCl-1 hydrogel electrolyte and MWCNT electrode. (b) Reprinted with permission from [353], Copyright 2020, American Chemical Society.

\subsubsection{Polyaniline (PANI)}

PANI is one of the most common CPs electrode material owing to its high conductivity, light-weight, superior capacitive performance for energy storage, facile synthesis, and low cost [354]. Furthermore, PANI is mechanically flexible, environment-friendly [355].

Besides these advantages, PANI is susceptible to rapid degradation in performance because of the repetitive charge-discharge cycles, (swelling and shrinkage). To address this problem the combination of PANI with carbon materials was utilized as the PANI layer, and it was coated on MOs/carbon composite to form a ternary hybrid composite (PANI/MOs/carbon) [355], which provided the reinforced cyclic stability for PANI and improved the capacitance as well [356].

Furthermore, PANI shows a wide range of electrochromic properties, such as exhibiting various colours, which is due to its many oxidation and protonation forms. These characteristics make it a useful candidate for the fabrication of electrochromic SCs [335].

Here, Wang et al. [342] synthesized PANI as the active material for an SC through an electrochemical polymerization method. It provided a high specific capacitance of $950 \mathrm{~F} \cdot \mathrm{g}^{-1}$ at $1 \mathrm{~A} \cdot \mathrm{g}^{-1}$. Here, it was 
reported that the array in unique nanowire structure leads to the reduction of diffusion paths, also the charge transfer resistance, which allows the material to have a high specific capacitance at high current densities.

The pathway of the polymerization (solution (Sol), emulsion (Eml), interfacial (Int)) affects the capacitance value of the CPs, whereas PANI-Int nanosphere, PANI-Eml nano-petal, and PANI-Sol nanocrystal, [357] were exhibited the Cs of, 300, 424 and $460 \mathrm{~F} \cdot \mathrm{g}^{-1}$, the $\mathrm{E}_{\mathrm{d}}$ of $15,21.2$, and $23 \mathrm{Wh} \cdot \mathrm{kg}^{-1}$, respectively at $P_{d}$ of $200 \mathrm{~W} \cdot \mathrm{kg}^{-1}$.

\subsubsection{Polypyrrole (PPy)}

The requirement of developing energy storage devices for high-performance electrode materials can be derived from the structure-controlled conductive polymer hydrogels with mechanical flexibility and adjustable electrochemical properties. PPy is one of these conductive polymers that attract too much attention from the researchers. It has a higher density and greater flexibility compared to other $\mathrm{CPs}$. It can endure a fast redox reaction for the charge storage, as well as showing a high electrical conductivity value between 10 to $500 \mathrm{~S} \cdot \mathrm{cm}^{-1}$ [358].

For example, a conductive polypyrrole hydrogels nanostructure was synthesized through an interfacial polymerization technique and obtained the 3D porous PPy network that showed excellent rate capabilities and high specific capacitance of $380 \mathrm{~F} \cdot \mathrm{g}^{-1}$ [345].

In another example, by coating the lignin with PPy, the Lignin-PPy composite was prepared through the polymerization of PPy in a process with and without the existence of methyl orange that is resulting in the development of PPy films of nanotubular and globular morphology. The experiment was conducted with the composite of carbon-based materials in nitrogen atoms by pyrolysis in an $\mathrm{N}_{2}$ atmosphere. It was reported that the SSA of the synthesized materials improved by 10 times more than that of pure carbon materials [359].

\subsection{Nanocomposite-Based Materials}

Nanocomposite-based electrodes integrated carbon-based material with either CPs or MOs and put them together to achieve a faradaic (chemical) and a non-faradaic (physical) charge storage mechanism in a single electrode.

Pseudocapacitive materials increase the capacitance of the nanocomposite while the SSA increases owing to the presence of the carbonaceous materials. There are various types of nanocomposites for the SC electrodes such as carbon-carbon composites, carbon-MOs composites, carbon-CPs composites and MOs-CPs composites that in the last case CNTs can be used as a supporting backbone for homogeneous distribution of CPs or MOs which leads to producing a high electric double-layer capacitance and pseudocapacitance. The specific capacitance of such categories of electrodes is higher than individual carbon, CPs, or MOs electrodes $[63,360]$.

\subsubsection{Carbon-Carbon Composites}

The high capacitance in the carbon material arises from the effective SSA, which is reachable to the electrolyte ions. Therefore, improving the SSA of the carbon-based materials leads to having higher energy and $\mathrm{P}_{\mathrm{d}}$ in SC. There are various types of carbon materials which can be used to build the carbon-based composites. In the case of graphene, the dispersion is problematic and must be improved. In order to find a solution, non-covalent functionalized graphene was synthesized [81]. Other drawbacks are associated with GO in which the material tends to restack and aggregate due to the presence of the van der Waals forces through the chemical reduction process, which leads to having a less accessible surface area to the electrolyte ions. The restacking issue can be solved by providing the intrapore for the solution using the SWCNTs [67].

The electrode fabricated using the SWCNTs inserted in graphene aerogels provided a high specific capacitance of $245.5 \mathrm{~F} \cdot \mathrm{g}^{-1}$ in $5 \mathrm{M} \mathrm{KOH}$. The graphene aerogel SC showed excellent cycle stability and a high rate capability [361]. 


\subsubsection{Carbon-MOs Composites}

As it was mentioned before, TMOs have low specific capacitance, poor electronic conductivity, and low electrochemical stability. The nanocomposite made of the combination of TMOs and the carbon material can improve the performance of the SCs. Therefore, in addition to the MOs and mixed MOs, there are different composites of MOs and carbon-based material, which has exhibited a higher surface area than those of pure metal oxide and carbon material [362].

One of the most important benefits of CNTs is that they can go through the surface functionalization process by various materials such as CPs and MOs, or they can be oxidized to solve the problem with the presence of some impurities. Accordingly, there is a lot of research carried out to compare the performance of the nanocomposite with pure materials. For instance, the composite of $\mathrm{MnO}_{2} / \mathrm{CNT}$ was prepared through a facile hydrothermal method, and the $\mathrm{MnO}_{2} / \mathrm{CNT}$ nanocomposite electrode showed a higher rate capability and specific capacitance in comparison with the pure $\mathrm{MnO}_{2}$ and CNT electrodes. It was reported that the high specific capacitance for the prepared nanocomposite could be due to the high SSA of the $\mathrm{MnO}_{2}$ and the highly porous structure [363].

In another study, $\mathrm{MnO}_{2} / \mathrm{CNS}$ exhibited ultra-high stability, with $96.1 \%$ of the capacitance retention at a current density of $5 \mathrm{~A} \cdot \mathrm{g}^{-1}$ even after 5000 cycles. It was reported that the superior capacity and cycling stability of $\mathrm{MnO}_{2} / \mathrm{CNS}$ were mainly because of the strong coupling between the carbon NSs and the in situ formed $\mathrm{MnO}_{2}$ nanosheet arrays (NSAs) with large SSA [364]. Furthermore, various hybrid materials such as $\mathrm{Co}_{3} \mathrm{O}_{4} / \mathrm{CNTs}$ [365], $\mathrm{Co}_{3} \mathrm{O}_{4} /$ grapheme [366,367] and $\mathrm{Co}_{3} \mathrm{O}_{4} / \mathrm{CNFs}$ [368] were synthesized with a huge surface area and consequently an improved electrical conductivity.

Besides, an ASC device was fabricated using $\mathrm{MnO}_{2}$ and graphene, whereas the pure graphene was used as the anode and the composite of $\mathrm{MnO}_{2}$-coated/graphene was used as the cathode. The pure graphene electrodes showed capacitance of $245 \mathrm{~F} \cdot \mathrm{g}^{-1}$ at a current density of $1 \mathrm{~mA}$ while after depositing

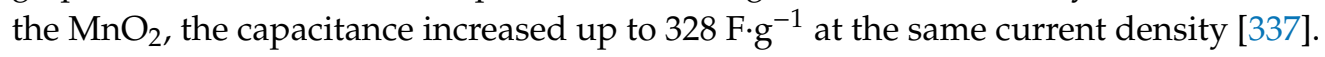

A hybrid NiO/GF(graphene foam) nanocomposite was synthesized for the fabrication of a hybrid electrode for ASSCs that displayed a high specific capacitance of $1225 \mathrm{~F} \cdot \mathrm{g}^{-1}$ at $2 \mathrm{~A} \cdot \mathrm{g}^{-1}$. An ASSC was fabricated using HPNCNTs (hierarchical porous nitrogen-doped CNTs) as the negative electrode and $\mathrm{NiO} / \mathrm{GF}$ as the positive electrode as well as in the aqueous $\mathrm{KOH}$ as the electrolyte, which showed a superior electrochemical performance due to the excellent capacitance of individual $\mathrm{NiO} / \mathrm{GF}$ and HPNCNTs, and the synergetic effect between the two electrodes. For the resultant device, a high $\mathrm{E}_{\mathrm{d}}$ of $32 \mathrm{Wh} \cdot \mathrm{kg}^{-1}$ at a $\mathrm{P}_{\mathrm{d}}$ of $700 \mathrm{~W} \cdot \mathrm{kg}^{-1}$ has been reported. Even after 2000 cycles, $94 \%$ of the capacitance remained [369].

Furthermore, the synthesized $\mathrm{CoNi}_{2} \mathrm{~S}_{4} /$ graphene (CNS/GR) nanocomposite exhibited a specific capacitance of $2009.1 \mathrm{~F} \cdot \mathrm{g}^{-1}$ at $1 \mathrm{~A} \cdot \mathrm{g}^{-1}$ and the capacitance could be reserved at $755.4 \mathrm{~F} \cdot \mathrm{g}^{-1}$ at $4 \mathrm{~A} \cdot \mathrm{g}^{-1}$ after 2000 cycles [370]. In another study, Perera et al. [371] fabricated a coin cell type ASC exploiting carbon fiber as a cathode and $\mathrm{V}_{2} \mathrm{O}_{5}-\mathrm{CNT}$ as an anode that showed $\mathrm{P}_{\mathrm{d}}$ of $5.26 \mathrm{~kW} \cdot \mathrm{kg}^{-1}$ and an $\mathrm{E}_{\mathrm{d}}$ of around $46.3 \mathrm{Wh} \cdot \mathrm{kg}^{-1}$.

Besides, the synthesized CNTs/NCSMnO ${ }_{2}$ composites showed a specific capacitance of $312.5 \mathrm{~F} \cdot \mathrm{g}^{-1}$ at $1 \mathrm{~A} \cdot \mathrm{g}^{-1}$ with capacitance retention of $92.7 \%$ after 4000 cycles. The ASC was fabricated using ACs (-ve electrode) and the $\mathrm{CNTs} / \mathrm{NCS} / \mathrm{MnO}_{2}$ composite (+ve electrode), which displayed a high specific capacitance and a stable potential window of $1.8 \mathrm{~V}$ with $\mathrm{E}_{\mathrm{d}}$ of $27.3 \mathrm{Wh} \cdot \mathrm{kg}^{-1}$ at $\mathrm{P}_{\mathrm{d}}$ of $4500 \mathrm{~W} \cdot \mathrm{kg}^{-1}$ [165].

Another alternative is the $\mathrm{RuO}_{2}$-based composites in which the composition of $\mathrm{RuO}_{2}$ and the carbonaceous materials such as AC, CNTs, carbon aerosols, and graphene provides higher capacitive properties and lesser cost in comparison with the pure $\mathrm{RuO}_{2}$ based electrodes [372-374]. The MWCNT/ $\mathrm{RuO}_{2}$ composite was assembled by inserting the $\mathrm{RuO}_{2}$ into MWCNTs in an acidic solution showing a maximum specific capacitance as high as $628 \mathrm{~F} \cdot \mathrm{g}^{-1}$ for different loading of the $\mathrm{RuO}_{2}$ films [375].

As it was mentioned before, CNTs could be utilized to support the hollow-structured nanoparticles. For instance, one of the main problems of the $\mathrm{RuO}_{2}$-based electrodes are cracking the $\mathrm{RuO}_{2}$ structure leading to poor long-term stability, which is due to the developed strain during the charge-discharge 
cycles [376,377]. In order to address this issue, Wang et al. [378] utilized a novel core-shell-templated method to assemble a CNT-supported hollow-structured $\mathrm{RuO}_{2}$ nanoparticle $(\mathrm{hRuO} / \mathrm{CNT})$, in which there was no crack formation reported for the nanocomposite electrode. The fabricated electrode also has provided a high specific capacitance of $655.0 \mathrm{~F} \cdot \mathrm{g}^{-1}$ at a current density of $5 \mathrm{~A} \cdot \mathrm{g}^{-1}$. Guan et al. [379] fabricated the composite using needle-like $\mathrm{Co}_{3} \mathrm{O}_{4}$ deposited on graphene as electrode materials for SC. The resultant electrodes show a specific capacitance of $157 \mathrm{~F} \cdot \mathrm{g}^{-1}$ at a current density of $0.1 \mathrm{~A} \cdot \mathrm{g}^{-1}$.

Furthermore, there many examples of nanocomposites, or the single-phase materials of $\mathrm{Ni}_{\mathrm{x}} \mathrm{Co}_{3-\mathrm{x}} \mathrm{S}_{4}$ were synthesized with excellent energy storage properties. For instance, nanowires [380], nanoneedles [381], and (NSs) [382], of $\mathrm{NiCo}_{2} \mathrm{~S}_{4} /(\mathrm{GO})$ [383], $\mathrm{Ni}_{0.3} \mathrm{Co}_{2.7} \mathrm{~S}_{4}, \mathrm{NiCo}_{2} \mathrm{~S}_{4}$ hierarchical structures [384] and $\mathrm{NiCo}_{2} \mathrm{~S}_{4} /(\mathrm{CNTs})$ [385], etc. For instance, $\mathrm{NiCo}_{2} \mathrm{~S}_{4}$ nanotubes were synthesized through the sacrificial templates, which showed the capacitance of $933 \mathrm{~F} \cdot \mathrm{g}^{-1}$ at $1 \mathrm{~A} \cdot \mathrm{g}^{-1}$ [386].

Ternary $\mathrm{NiCo}_{2} \mathrm{~S}_{4}$ provides more redox reactions due to having a higher electronic conductivity in comparison with $\mathrm{Ni}_{\mathrm{x}} \mathrm{Co}_{3-\mathrm{x}} \mathrm{S}_{4}$ that decrease the charge transfer resistance, and consequently, a slighter interior resistance (IR) loss at higher current density. Therefore, a grater $\mathrm{P}_{\mathrm{d}}$ and larger rate capability and can be obtained [376]. Besides, Ni-Co-Mn hydroxide nanoneedles were synthesized through a facile hydrothermal technique, which provided a specific capacitance of about $1400 \mathrm{~F} \cdot \mathrm{g}^{-1}$, higher $\mathrm{E}_{\mathrm{d}}$ and $\mathrm{P}_{\mathrm{d}}\left(30 \mathrm{Wh} \cdot \mathrm{kg}^{-1}\right.$ and $39 \mathrm{~kW} \cdot \mathrm{kg}^{-1}$, respectively), in comparison with the Ni-Co-S electrodes. There was no report of the capacitance loss even after 3000 cycles [387].

Carbon-based materials and its composites that are used for the SC electrodes can be compared in terms of various parameters, including surface area, pore size, specific capacitance, stability, rate capability, and cost. The composites consist of the MOs, and the carbon materials are one of the powerful candidates for the electrode materials, which can provide an excellent specific capacitance, good performance, and good rate capability as well as stability and less cost [376].

For instance, a ternary nanocomposite has been fabricated using the $\mathrm{MnO}_{2}$ nanorods and $\mathrm{rGO}$ NSs, which were reinforced on the poly(3,4-ethylenedioxythiophene)-poly(styrenesulfonate) (PEDOT: PSS) (Figure 19a-e). The resultant composite (MGP) was used as electrode material for SC application and showed an improved specific capacitance of $633 \mathrm{~F} \cdot \mathrm{g}^{-1}$ at a current density of $0.5 \mathrm{~A} \cdot \mathrm{g}^{-1}$. The device remained stable $100 \%$ even after and 5000 cycles. The capacitance of the material is associated with both double-layer and pseudocapacitive mechanisms. Figure 19f,g shows asymmetrical CV curves for all different electrode materials $\left(\mathrm{MnO}_{2}, \mathrm{MG}\left(\mathrm{MnO}_{2} / \mathrm{rGO}\right)\right.$, and $\left.\mathrm{MGP}\right)$, in which a larger area under the $\mathrm{CV}$, dedicated to MGP, is an indication for a higher supercapacitance behaviour MGP compared to $\mathrm{MnO}_{2}$ and $\mathrm{MG}$ [388].

Besides, W. Peng fabricated the $\mathrm{NiCo}_{2} \mathrm{~S}_{4} / \mathrm{rGO}$ nanospheres composite through a one-step hydrothermal method. The resultant composites showed an excellent specific capacitance of $1406 \mathrm{~F} \cdot \mathrm{g}^{-1}$ and outstanding cycle stability of $82.36 \%$ after 2000 charge-discharge cycles at the current density of $1 \mathrm{~A} \cdot \mathrm{g}^{-1}$, that were higher than the pure $\mathrm{NiCo}_{2} \mathrm{~S}_{4}$ material $\left(792 \mathrm{~F} \cdot \mathrm{g}^{-1}\right.$ and $64.77 \%$ after the same number of cycles) [389].

In another study, iron cyclotetraphosphate $\left(\mathrm{Fe}_{2} \mathrm{P}_{4} \mathrm{O}_{12}\right)$-carbon composite was utilized as an electrode material for SCs. They reported that the phosphorus doping in the porous carbon structure and the presence of the functional groups in the phytic acid-derived carbon had increased the redox couple, thus improving the pseudocapacitive performance of the composite, which attributed to the highly reversible redox reaction. However, capacitive behaviour has been reported as the predominant charge storage mechanism, which mainly occurred in the acidic medium. They have displayed that the charge storage behaviour and the stability of the composite do not only depend on the electrode material but also are highly dependent on the electrolyte selection. $\mathrm{Fe}_{2} \mathrm{P}_{4} \mathrm{O}_{12}$ composite exhibited high stability in the $0.5 \mathrm{M} \mathrm{H}_{2} \mathrm{SO}_{4}$, a capacitance of $251 \mathrm{~F} \cdot \mathrm{g}^{-1}$ at a current density of $1 \mathrm{~A} \cdot \mathrm{g}^{-1}$, as well as a constant capacitance without any loss even after 9000 cycles [390]. 


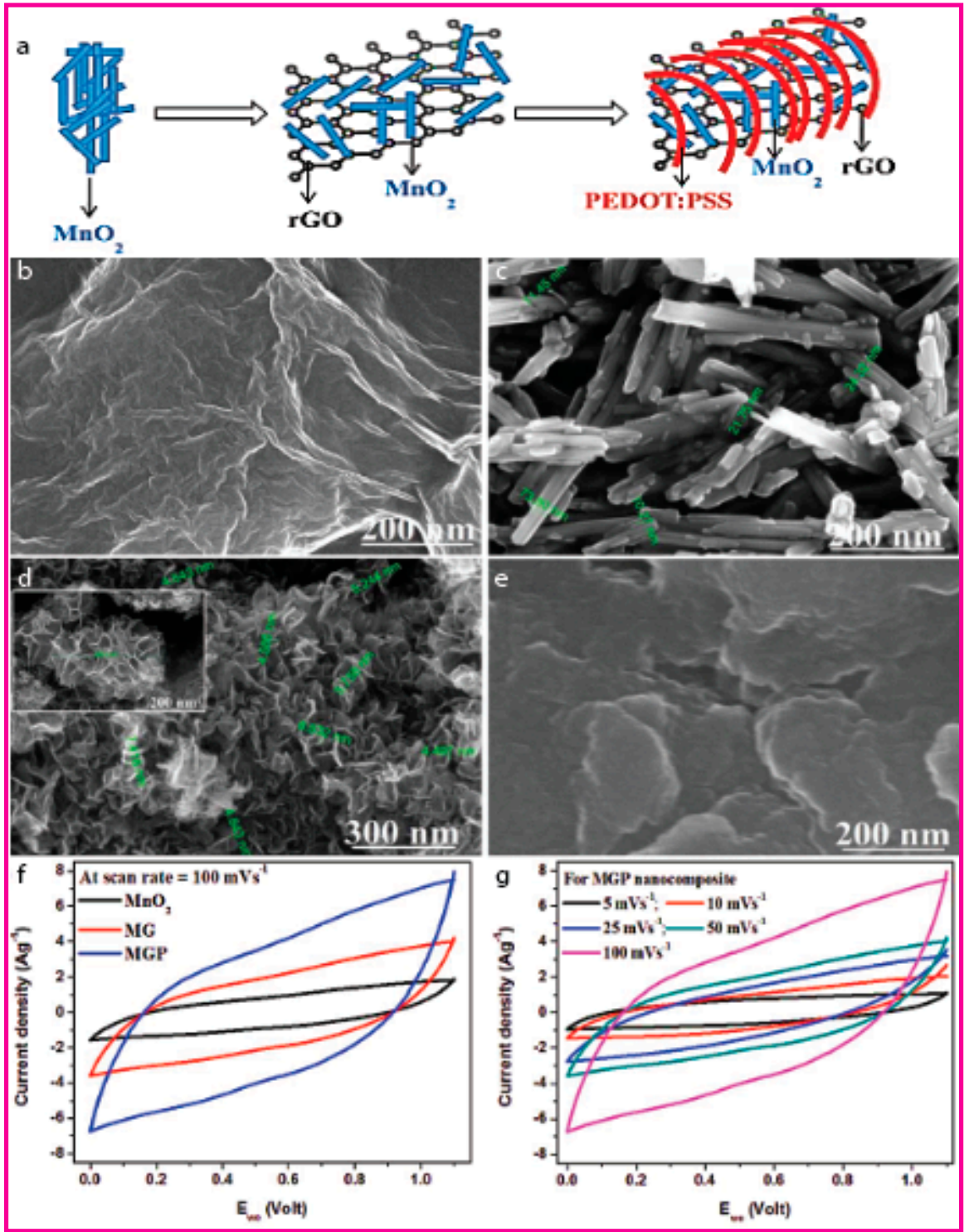

Figure 19. (a) The presentation of the MGP nanocomposite fabrication. The FESEM images of (b) $\mathrm{GO}$, (c) $\mathrm{MnO}_{2}$ nanorods, (d) MG nanocomposite and (e) MGP nanocomposite. The CVs of (f) all the electrode material samples at a scan rate of $100 \mathrm{mV} \cdot \mathrm{s}^{-1}$ and $(\mathrm{g})$ the MGP nanocomposite at various scan rates. Reprinted with permission from [388], Copyright 2017, Royal Society of Chemistry.

\subsubsection{Carbon-CPs Composites}

There are different carbonaceous materials that can be coupled with CPs to form a nanocomposite. For instance, the nanocomposite using the activated carbon as the cathode and CPs as the anode can provide a higher $E_{d}$ and $P_{d}$ in comparison with EDLCs and an enhanced cycling performance compared to pseudocapacitors [360].

As an example, a composite electrode was fabricated through the colloidal self-assembly method using graphene-MWCNT-PPY nanofibers [83,391-395].

The freestanding PEDOT-PSS/SWCNTs composites exhibited the specific capacitance of $104 \mathrm{~F} \cdot \mathrm{g}^{-1}$ at $0.2 \mathrm{~A} \cdot \mathrm{g}^{-1}, \mathrm{P}_{\mathrm{d}}$ of $825 \mathrm{~W} \cdot \mathrm{kg}^{-1}$, and $\mathrm{E}_{\mathrm{d}}$ of $7 \mathrm{Wh} \cdot \mathrm{kg}^{-1}$. Furthermore, $90 \%$ of the capacitance left after 1000 cycles [396].

In another study, PEDOT/PSS and MWNT composites showed a specific capacitance of

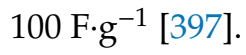


There are various types of electrodes fabricated using PANI. However, the low rate capability and relatively poor cycle stability limit their applications; still, single-phase PANI materials have been extensively considered as promising electrodes for SCs. There are various nanocomposites formed through the coupling of PANI nanostructures and carbon-based materials that show a better performance than that of PANI or carbon-based electrodes in which carbon material plays an important role because they can be considered as the efficient stabilizer for PANI materials with high availability in different morphologies [398].

For example, rGO aerogel-PANI composite was synthesized through the electro-deposition method in which the PANI arrays deposited on the rGO aerogel. Generally, the poor cyclability, $\mathrm{E}_{\mathrm{d}}$, and flexibility of rGO aerogels limit its application. The prepared composite has shown a rich open pore network and high capacitance due to the unique capacitance of the PANI as well as a high conductivity which arise from the cross-linked framework of 3D aerogel [399].

The specific capacitance of the resultant composite was reported of $432 \mathrm{~F} \cdot \mathrm{g}^{-1}$ at a current density of $1 \mathrm{~A} \cdot \mathrm{g}^{-1}$ and the stability of the materials in various bending conditions was outstanding. It provided an $\mathrm{E}_{\mathrm{d}}$ of $25 \mathrm{Wh} \cdot \mathrm{kg}^{-1,}$ and $85 \%$ of the capacitance remained after 10,000 cycles [399]. In another study, an FSC, was fabricated using the prepared composite of PANI/etched carbon fiber cloth (eCFC), which exhibited $88 \%$ capacity retention and a higher specific capacitance $\left(1035 \mathrm{~F} \cdot \mathrm{g}^{-1}\right.$ at $\left.1 \mathrm{~A} \cdot \mathrm{g}^{-1}\right)$, compared to that of PANI nanowires at all current densities [400].

The graphene/PANI nanofiber composite was synthesized through the one-step in-situ polymerization method showing the specific capacitance of $526 \mathrm{~F} \cdot \mathrm{g}^{-1}$ at $0.2 \mathrm{~A} \cdot \mathrm{g}^{-1}$ current density [401]. The fabricated GNSs/PANI composite showed capacitance of $532.3 \mathrm{~F} \cdot \mathrm{g}^{-1}$ at $2 \mathrm{mV} \cdot \mathrm{s}^{-1}$, and $99.6 \%$ capacitance has remained at $50 \mathrm{mV} \cdot \mathrm{s}^{-1}$ [402]. Besides, a CNT hydrogel coupled with PANI has shown a specific capacitance of $680 \mathrm{mF} \cdot \mathrm{cm}^{-2}$ at $1 \mathrm{~mA} \cdot \mathrm{cm}^{-2}$ [403]. In another study, the synthesized PANI nanorods/graphite NS composite showed a specific capacitance of $1665 \mathrm{~F} \cdot \mathrm{g}^{-1}$ at a current density of $1 \mathrm{~A} \cdot \mathrm{g}^{-1}[404]$.

Han et al. [405] fabricated electrodes using the composite of PEDOT/PSS and GO in $1 \mathrm{M} \mathrm{H}_{2} \mathrm{SO}_{4}$, showing a specific capacitance of $108 \mathrm{~F} \cdot \mathrm{g}^{-1}$ and capacity retention of $78 \%$ after 1200 cycles. Furthermore, the symmetric (PPy/PPy) and asymmetric (PPy/AC) SCs have been fabricated utilizing Cladophora algae-derived cellulose as a binder which has exhibited the capacitance in the range of $0.45 \mathrm{~F}$ to $3.8 \mathrm{~F}[406]$.

In another study, three different composites have been synthesized through in-situ polymerization using GNSs, CNTs, and PANI. The GNSs/PANI composite exhibited a higher specific capacitance of $1046 \mathrm{~F} \cdot \mathrm{g}^{-1}$. The capacitance for the GNSs/CNT/PANI and CNT/PANI composites were reported of $1035 \mathrm{~F} \cdot \mathrm{g}^{-1}$ and $780 \mathrm{~F} \cdot \mathrm{g}^{-1}$. The capacitance reduced only $6 \%$ for GNSs/CNT/PANI, $52 \%$ GNSs/PANI, and $67 \%$ for CNT/PANI after 1000 cycles [407].

Polyphenylene diamine and hydrogen exfoliated GNSs have been prepared, which exhibited a specific capacitance of $248 \mathrm{~F} \cdot \mathrm{g}^{-1}$ at $2 \mathrm{~A} \cdot \mathrm{g}^{-1}$, and the assembled electrode showed an $\mathrm{E}_{\mathrm{d}}$ of $8.6 \mathrm{Wh} \cdot \mathrm{kg}^{-1}$ and a $\mathrm{P}_{\mathrm{d}}$ of $0.5 \mathrm{~kW} \cdot \mathrm{kg}^{-1}[408]$.

In another study, the prepared graphene-based PVA composites showed 10 times enhancement in Young's modulus with a tensile strength $150 \%$ better as well as the graphene loading of $1.8 \mathrm{vol} \%$ [409]. The PEDOT/PSS CNTs composite showed a specific capacitance in the range of $85 \mathrm{~F} \cdot \mathrm{g}^{-1}$ to $150 \mathrm{~F} \cdot \mathrm{g}^{-1}$. The $E_{d}$ was reported up to $0.92 \mathrm{Wh} \cdot \mathrm{kg}^{-1}$, and $\mathrm{P}_{\mathrm{d}}$ varied from $100 \mathrm{~W} \cdot \mathrm{kg}^{-1}$ to $3000 \mathrm{~W} \cdot \mathrm{kg}^{-1}$ [335].

A hybrid 2D MoS 2 NSs and 1D PANI nanowires were used as the SC electrode. The $\mathrm{MoS}_{2} / \mathrm{PANI}$ hybrid electrode showed capacitance of about $485 \mathrm{~F} \cdot \mathrm{g}^{-1}$ at a current density of $1 \mathrm{mAcm}^{2}$. The higher performance was reported about $812 \mathrm{~F} \cdot \mathrm{g}^{-1}$, which was for the 1:2 ratio of $\mathrm{MoS}_{2}$ and PANI that can be associated with the synergistic interactions between conductive $2 \mathrm{D} \mathrm{MoS}_{2} \mathrm{NSs}$ with a large surface area and 1D PANI. The related $E_{d}$ to that ratio and also the $P_{d}$ was reported as high as $112 \mathrm{~W} \cdot \mathrm{kg}^{-1}$ and $0.6 \mathrm{~kW} \cdot \mathrm{kg}^{-1}$, respectively [410]. 


\subsubsection{MOs-CPs Composites}

The MOs/CPs-based material is another alternative composite for electrode material which provides an enhanced electrochemical characteristic in SCs resulting from the compatibility between the MOs and CPs [23,411].

The specific capacitance, rate capability, and cyclic stability can be increased, in comparison with pure MOs and pure CPs material for electrodes, by developing the composites of MOs coupled with $\mathrm{CPs}$, which leads to improved conductivity of the electrodes.

For instance, the PPy coated $\mathrm{MoO}_{3}$ was synthesized through the in-situ polymerization method, which exhibited the specific capacitance of $110 \mathrm{~F} \cdot \mathrm{g}^{-1}$ at a current density of $100 \mathrm{~m} \mathrm{~A} \cdot \mathrm{g}^{-1}$ as well as an $E_{d}$ of $20 \mathrm{Wh} \cdot \mathrm{kg}^{-1}$ at $P_{d}$ of $75 \mathrm{~W} \cdot \mathrm{kg}^{-1}$. ASC was assembled using the AC as the -ve electrode and the $\mathrm{PPy} / \mathrm{MoO}_{3}$ as the +ve electrode and in $0.5 \mathrm{M} \mathrm{K}_{2} \mathrm{SO}_{4}$ aqueous solution that showed an $\mathrm{E}_{\mathrm{d}}$ of $12 \mathrm{Wh} \cdot \mathrm{kg}^{-1}$ at $\mathrm{P}_{\mathrm{d}}$ of $3 \mathrm{~kW} \cdot \mathrm{kg}^{-1}$ [412].

The PANI/ $\mathrm{MnO}_{2}$ nanocomposite was [413] prepared through the exchange reaction between PANI, and n-octadecyltrimethylammonium-intercalated $\mathrm{MnO}_{2}$ in N-methyl-2-pyrrolidone solvent in which the Fourier transform infrared (FTIR) spectroscopy results indicated the desirable interactions between $\mathrm{MnO}_{2}$ layers and intercalated PANI. It also has been found that the PANI still shows a proper conductivity after insertion into the layered $\mathrm{MnO}_{2}$. The composite exhibited a specific capacitance of $330 \mathrm{~F} \cdot \mathrm{g}^{-1}$ at the current density of $1 \mathrm{~A} \cdot \mathrm{g}^{-1}$ that was $187 \mathrm{~F} \cdot \mathrm{g}^{-1}$ and $208 \mathrm{~F} \cdot \mathrm{g}^{-1}$ higher than pristine PANI and $\mathrm{MnO}_{2}$, respectively, which is the result of the synergistic effect of PANI and $\mathrm{MnO}_{2}$. After 1000 cycles, $94 \%$ of the initial capacitance remained.

The MOs-CPs composite could be used extensively as an electrode material for both flexible and non-flexible planar SCs to improve different parameters such as the capacitance, $\mathrm{E}_{\mathrm{d}}$, and power density.

As an example, Raj et al. [414] synthesized $\mathrm{Co}_{3} \mathrm{O}_{4}$-PIND, (cobalt oxide-conducting polyindole), as electrode material for a non-flexible $\mathrm{SC}$, which was fabricated in a free-binder system and showed a specific capacitance of $1805 \mathrm{~F} \cdot \mathrm{g}^{-1}$ and $1625 \mathrm{~F} \cdot \mathrm{g}^{-1}$ at the current density of $2 \mathrm{~A} \cdot \mathrm{g}^{-1}$ at $25 \mathrm{~A} \cdot \mathrm{g}^{-1}$, respectively.

There is also various electrode material composite, fabricated using carbon-based material, MOs and CPs, in which the ternary nanocomposite has exhibited improved electrochemical performance compared to those of corresponding individual components as electrode materials for SC.

\section{Two-Dimensional (2D) Electrode Materials and Their Modification Methods}

Since the tremendous discovery of exfoliated monocrystalline graphitic films in 2004 [415], the $2 \mathrm{D}$ material with a layered structure has appealed much interest from scientists due to their fantastic properties.

During 16 years after the successful mechanical exfoliation of graphene from three-dimensional (3D) graphite, various 2D nanomaterial has been obtained through various preparation and exfoliation methods, from different layered precursor materials such as hexagonal boron nitride (hBN) [416], metal nitrides (MNs) [416], TMOs [417], black phosphorus (BP) [418], transition metal dichalcogenides (TMDs) [419], metal-organic frameworks (MOFs) [420], covalent organic frameworks (COFs) [421], layered double hydroxides (LDHs) [422], graphitic carbon nitride $\left(\mathrm{g}-\mathrm{C}_{3} \mathrm{~N}_{4}\right)$ [423], and different MAX phase (e.g., $\mathrm{Ti}_{2} \mathrm{AlC}$ ) [424], as well as other precursors, which are utilized to obtain the 2D transition metal carbides, carbonitrides, and nitrides called "MXene" [425].

The structure and electrochemical properties (including the energy storage mechanism and etc.) of various 2D materials, as well as their application as the electrode in SC devices, was explained in detail in our previous study [426] (Figure 20). 


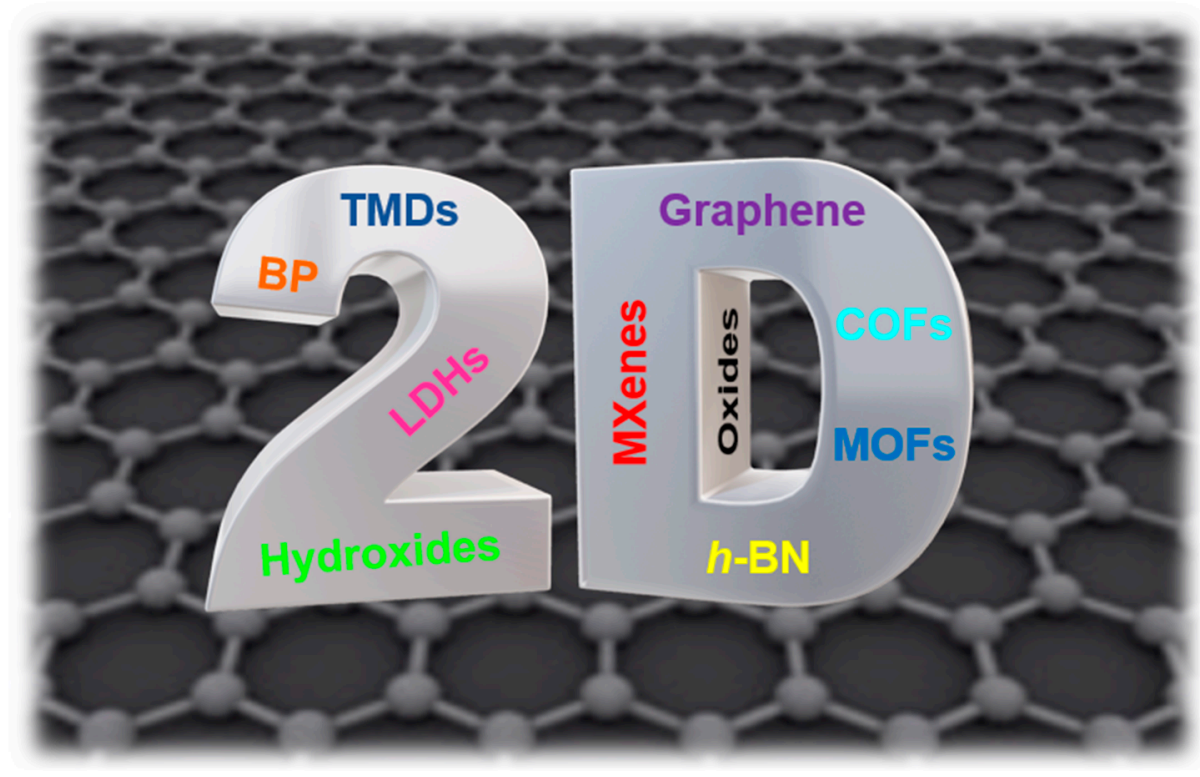

Figure 20. A graphical presentation of different types of ultrathin 2D nanomaterials.

As it was mentioned in the previous sections, the efficiency of the SC device could be enhanced mainly by improving the electrode materials and modifying the electrolyte material. Here, we have summarized different modification methods, which provide more interesting outlooks on the study of 2D materials, in addition to their exclusive intrinsic properties. There are some common modification techniques to enlarge the surface area, which lead to enhancing the charge storage ability of the electrode materials, thus improving the properties of 2D materials. These techniques can be categorized into several groups including alloying [427], hybridization [428] intercalation [429], nanosizing, the top-down method [430], vertical/lateral heterojunctions [431], external field modification [432], strain engineering [433], and stacking order of the atomic layers [434].

There are different studies with regards to the enhancement of the capacitive performance of the 2D material through a core-shell formation strategy.

For instance, the hierarchical $\mathrm{NiCo}_{2} \mathrm{O}_{4} @$ polypyrrole core-shell nanowires were embedded onto the hemp-derived carbon (HDC) microfiber as fiber-shaped electrode material for flexible planar SC, for which the as-fabricated electrode $\left(\mathrm{HDC} @ \mathrm{NiCo}_{2} \mathrm{O}_{4} @ P P y\right)$ exhibited an excellent rate performance as a specific capacitance of $2055 \mathrm{~F} \cdot \mathrm{g}^{-1}$ was attained at $1 \mathrm{~A} \cdot \mathrm{g}^{-1}$ that was higher than that of the $\mathrm{HDC} @ \mathrm{NiCO}_{2} \mathrm{O}_{4}$ composites which exhibited $1506 \mathrm{~F} \cdot \mathrm{g}^{-1}$ under the same conditions. The specific capacitance $\left(742 \mathrm{~F} \cdot \mathrm{g}^{-1}\right)$ was remained still higher than that of the HDC@NiCo $\mathrm{O}_{4}$ composites $\left(402 \mathrm{~F} \cdot \mathrm{g}^{-1}\right.$ at $\left.50 \mathrm{~A} \cdot \mathrm{g}^{-1}\right)$, even after increasing the current density up to $50 \mathrm{~A} \cdot \mathrm{g}^{-1}$. After 5000 cycles, $90 \%$ of the initial capacity was left. The fabricated fiber-shaped all-solid-state SSC showed high physical flexibility, good stability, and an $\mathrm{E}_{\mathrm{d}}$ of $17.5 \mathrm{Wh} \cdot \mathrm{kg}^{-1}$ at $\mathrm{P}_{\mathrm{d}}$ of $500 \mathrm{~W} \cdot \mathrm{kg}^{-1}$ [435]. The improvements in the pseudocapacitive performance arise from the high electrical conductivity of carbon microfiber and the PPY.

Yim et al. developed the nanospheres in core-shell structure through the electrodeposition method utilizing the 2D arrayed of polystyrene (PS) monolayer as the core and the $\mathrm{RuO}_{2}$ nanoparticles as the shell, in which the resultant nanospheres showed an excellent capacitive performance including a superior areal capacitance, well bonded to the current collector materials compared to that of planar $\mathrm{RuO}_{2}$-based electrode (Figure 21) [436]. 


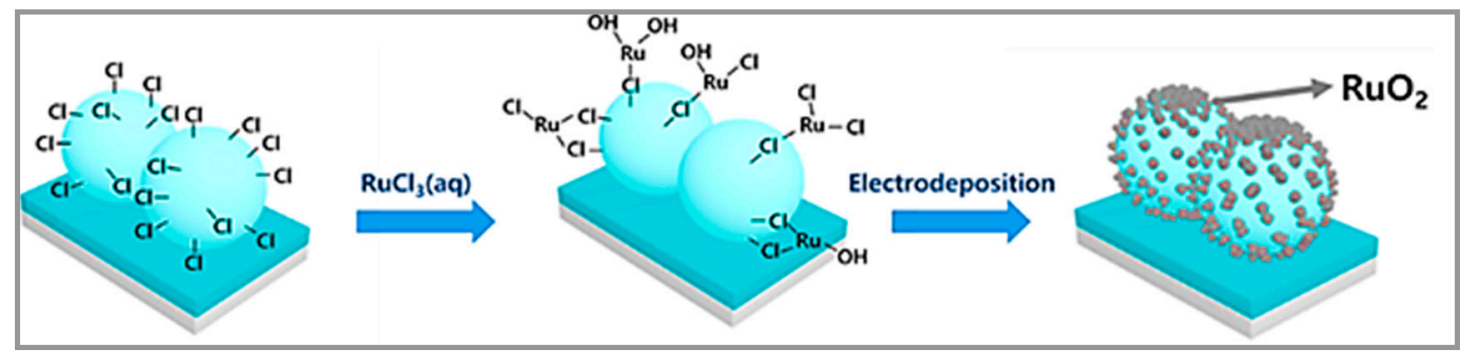

Figure 21. Illustration of the preparation process of the $\mathrm{PS} / \mathrm{RuO}_{2}$ core-shells, including the surface modification of PS through the formation of the $\mathrm{Ru}-\mathrm{Cl}$ bonds on $\mathrm{Cl}$, terminated groups before the electrodeposition step. Reprinted with permission from [436], Copyright. 2018, American Chemical Society.

There are several examples of different 2D materials that have been utilized for SC applications in addition to the mentioned examples in this review so far, and in our previous review, [426] in which we have described and highlighted the development of the 2D electrode materials such as MXene, MOFs, TMDs, COFs, MNs, BP, and perovskite (PSK).

Recently, three new $\beta$-ketoenamine-linked COFs have been fabricated using Schiff-base $[3+3]$ polycondensations of 1,3,5-triformylphloroglucinol (TFP-3OHCHO) along with three tris(aminophenyl)-presenting derivatives-featuring amino, carbazole, and pyridine linkages, respectively under the solvothermal conditions [437].

$\beta$-ketoenamine connected naphthalene based porous covalent organic framework (TFP-NDA-COF) has been developed through a simple Schiff base condensation polymerization reaction between triformylphloroglucinol (TFP) and 1,5-napthalenediamine (NDA). Further, this material was utilized for the SC application in which the resultant electrode showed a specific capacitance up to $379 \mathrm{~F} \cdot \mathrm{g}^{-1}$ at $2 \mathrm{mV} \cdot \mathrm{s}^{-1}$ scan rate and $348 \mathrm{~F} \cdot \mathrm{g}^{-1}$ at the current density of $0.5 \mathrm{~A} \cdot \mathrm{g}^{-1}$. It has shown an excellent supercapacitive behaviour and high chemical stability (75\%) even after 8000 cycles which could be associated with the high SSA, high-porosity in the polymer network, the presence of naphthalene moiety for facile $\pi$ conjugation as well as nitrogen as a hetero atom for redox activity [438].

The synthesized TFP-COFs were used in the SC and for gas storage applications and showed enhanced performance such as excellent crystallinity and superior electrochemical specific capacitance of $291.1 \mathrm{~F} \cdot \mathrm{g}^{-1}$ as well as a high BET SSA up to $686 \mathrm{~m}^{2} \cdot \mathrm{g}^{-1}$. The improved performance can be associated with the conjugated enamine structures with redox-active triphenyl amino, carbazole, and pyridine units. The presence of more highly planar monomer units in the hexagonal structures of the synthesized $\mathrm{COFs}$ provided a stronger quadrupolar interaction with the included $\mathrm{CO}_{2}$ molecules [437].

It has been reported that the PEDOT-modified DAAQ-TFP COF films exhibited excellent high-rate performance and a better current response in the CV compared to that of pristine DAAQ-TFP COF film that can be associated with the wiring effect of PEDOT chains which ease the electron transport between electrodes and the redox-active sites of the DAAQ-TFP COF. Though, the ion transfer is enhanced through the vertical pore channels by shortening the diffusion length [439].Romero et al. [440] developed the COFs of polyimine with many metal ions, including $\mathrm{Fe}^{3+}, \mathrm{Co}^{2+}$, and $\mathrm{Ni}^{2+}$.

There are several disadvantages for COFs, such as less stability and electrical conductivity, which limits their application. A strategy has been exploited to eliminate these restrictions in which the CPs were confined within the porous frameworks that enhanced the cycle stability along with maintaining the mechanical stability and electrical conductivity [364]. For instance, Dichtel et al. [441] obtained a very high-rate charging $\left(10-1600{ }^{\circ} \mathrm{C}\right)$ with higher $\mathrm{E}_{\mathrm{d}}$ by exploiting this procedure via a simple electro-polymerization of EDOT into the COF pores.

Chandra et al. developed the COFs $\left[\mathrm{TpPa}-(\mathrm{OH})_{2}, \mathrm{TpBD}-(\mathrm{OH})_{2}\right]$ as electrode materials for SCs. Figure 22 [442] illustrates the XRD pattern, the $\mathrm{N}_{2}$ adsorption curves, and the pore size distribution along with the TEM images of COFs. The resultant TpPa- $(\mathrm{OH})_{2}$ presented a specific capacitance of 
$416 \mathrm{~F} \cdot \mathrm{g}^{-1}$ at a current density of $0.5 \mathrm{~A} \cdot \mathrm{g}^{-1}$ with $66 \%$ Cs retention after 10,000 cycles. The high specific capacitance is ascribed to the specific molecular control of redox-active units in the COF.

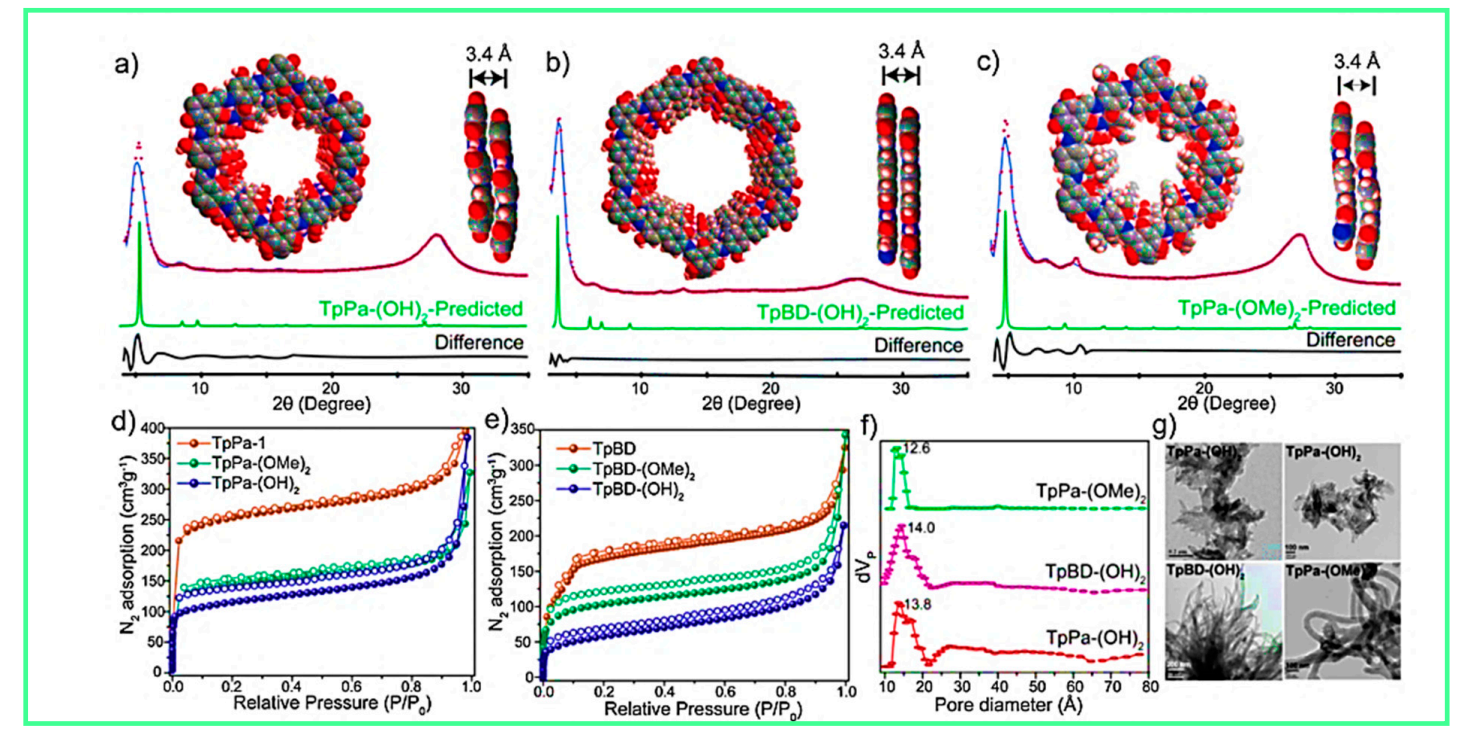

Figure 22. Evaluation of the observed (blue), predicted (green), and refined (red) PXRD patterns with their alteration (black) for (a) TpPa- $(\mathrm{OH})_{2},(\mathbf{b}) \mathrm{TpBD}-(\mathrm{OH})_{2}$, and (c) TpPa- $(\mathrm{OMe})_{2}$. Inset figures display the pore structure and $\pi-\pi$ stacking distance for each of the COFs. Comparison of $\mathrm{N}_{2}$ adsorption isotherms at $77 \mathrm{~K}$ for $(\mathbf{d}) \mathrm{TpPa}$ series [TpPa- $(\mathrm{OH})_{2}$ (blue), TpPa-(OMe $)_{2}$ (green), and TpPa-1 (brown)] and (e) TpBD series [TpBD-(OH) 2 (blue), TpBD-(OMe) $)_{2}$ (green), and TpBD (brown)]. (f) Pore size distribution and (g) TEM images for TpPa- $(\mathrm{OH})_{2}, \mathrm{TpBD}-(\mathrm{OH})_{2}, \mathrm{TpPa}-(\mathrm{OMe})_{2}$, and TpBD-(OMe $)_{2}$. Reprinted with permission from [442], Copyright 2017, American Chemical Society.

Recently, a COF complex was prepared as electrode material for flexible and extensible SCs using a template of hydroxyl-ended hyperbranched polymer $(\mathrm{OHP})$ through a simple solid-state mechanical mixing process. Further, the COF@OHP complex was impregnated on a microporous carbon nanotube film (CNTF) to build a composite membrane (CHCM). The electrode showed superior electrochemical performance, including a high gravimetric capacitance of $249 \mathrm{~F} \cdot \mathrm{g}^{-1}$ as well as a superior lifespan in which $80 \%$ of initial capacitance remained after 10,000 charge-discharge cycles [443].

Furthermore, to obtain a high power/energy density SC device, the advance electrode materials are required to provide desirable properties depending upon the specific application. There are various approaches to improving the electrochemical properties of the "old" pseudocapacitive material such as $\mathrm{MnO}_{2}$ and $\mathrm{RuO}_{\mathrm{x}}$ to obtain the "advanced" pseudocapacitive material such as TMDs (such as MoS etc.,) and MOFs [426,444] For example, the functionalized of hybridization of 2D-TMDs with various carbon-based supporting materials to increase more active sites, and ease the charge transferability has been reported in several studies [418,445-447], (Figure 23) [428]. 


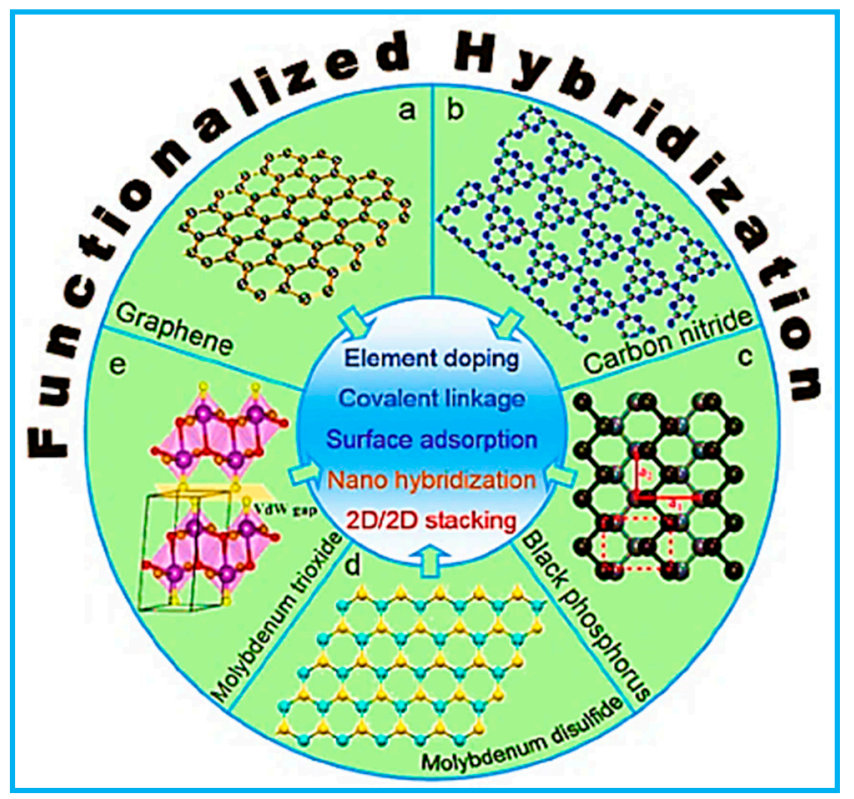

Figure 23. Functionalized hybridization of different 2D-materials through diverse strategies to combine various types of materials. Reprinted with permission from [428], Copyright 2019, Wiley-VCH.

TMDs have fascinated a lot of interests owing to their excellent physicochemical properties including high surface area, semiconducting ability, low cost, high chemical stability, high mechanical performance, facile synthesis by means of different fabrication techniques such as mechanical exfoliation, direct sonication in solvents, chemical vapour deposition (CVD) and, etc. [419,448-450].

For instance, an ASC device was fabricated by using flowerlike $\mathrm{MoS}_{2} / \mathrm{GNSs}$ as the negative and $\mathrm{MnO}_{2} / \mathrm{GNSs}$ as the positive electrodes in which the $\mathrm{MoS}_{2} / \mathrm{GNSs}$ electrode displayed excellent electrochemical performance, such as high specific capacitance of $320 \mathrm{~F} \cdot \mathrm{g}^{-1}$ at $2 \mathrm{~A} \cdot \mathrm{g}^{-1}$. In addition, the resultant all-solid-state ASC achieved a remarkable $\mathrm{E}_{\mathrm{d}}$ of $78.9 \mathrm{Wh} \cdot \mathrm{kg}^{-1}$ at a $\mathrm{P}_{\mathrm{d}}$ of $284.1 \mathrm{~W} \cdot \mathrm{kg}^{-1}$ [451].

Besides all the advantages, the interlayer interactions and high surface energy of the 2D-TMDs layers result in an increase in the restacking possibility of the layers, thus decreasing the number of active sites [452]. One of the efficient solutions to overcome the above disadvantages as well as increase the TMD activity for real advanced applications is to fabricate the new functional hybrid materials by coupling the 2D-TMDs with a highly conductive supporting material $[419,445,453]$.

Furthermore, boron nitride (BN) is another excellent member of the 2D material, which has exhibited a superior dielectric property, high thermal conductivity. The BN layered material has shown superior stability and excellent dispersion in the organic electrolyte. With all these properties, BN material cannot be utilized alone as the SC electrode material, since its bandgap is large (between $4 \mathrm{eV}$ to $5 \mathrm{eV}$ ). However, this drawback could be addressed through the bandgap engineering of the $\mathrm{BN}$ materials [454].

Recently, the PANI-coated CNTs has been grown on the exfoliated BN sheets to improve the electrochemical properties of the BN material. The resultant nanocomposite exhibited a specific capacitance of $515 \mathrm{~F} \cdot \mathrm{g}^{-1}$ as well as an $\mathrm{E}_{\mathrm{d}}$ of $46 \mathrm{Wh} \cdot \mathrm{kg}^{-1}$ in a three-electrode system.After 10,000 cycles, $98 \%$ of the capacitance remained. The nanohybrid ternary composite has also been used as electrode material in an ASSC, which provides an excellent $\mathrm{E}_{\mathrm{d}}$ of $62 \mathrm{Wh} \cdot \mathrm{kg}^{-1}$ and capacitance retention about $91 \%$ after 5000 cycles [455]. In another study, a ternary nanocomposite was synthesized through the hydrothermal method using $\mathrm{rGO}$, exfoliated $\mathrm{BN} N S s$, and $\mathrm{Ni}(\mathrm{OH})_{2}$. The resultant nanocomposite $\left(\mathrm{rGO} / \mathrm{BN} / \mathrm{Ni}(\mathrm{OH})_{2}\right)$ exhibited a maximum specific capacitance of $349 \mathrm{~F} \cdot \mathrm{g}^{-1}$ as well as a high $\mathrm{E}_{\mathrm{d}}$ of $48 \mathrm{Wh} \cdot \mathrm{kg}^{-1}$, and a $\mathrm{P}_{\mathrm{d}}$ of $118 \mathrm{~W} \cdot \mathrm{kg}^{-1}$ in $0.5 \mathrm{M} \mathrm{KOH}$ at a current density of $0.5 \mathrm{~mA} \cdot \mathrm{cm}^{-2}$ [456].

$\mathrm{BP}$ is another strong candidate that is comprised of phosphorene layers connected by the Van der Waals interaction [457]. One of the attractive characteristics of the BP material is the interlayer 
distance $(0.55 \mathrm{~nm})$, which is larger than that of graphene. This criterion makes the BP material to be suitable as electrode materials, owing to their capability of enhancing the ion intercalation, thus improving the electrochemical properties of the corresponding SC device [458].

Recently, the R-BP/SPC (red-black phosphorus/sulfonated porous carbon) composite was synthesized via the sonochemical method. The hybrid composite was utilized as the electrode in a SSC, which provided a high specific capacitance of $364.5 \mathrm{~F} \cdot \mathrm{g}^{-1}$ at a current density of $0.5 \mathrm{~A} \cdot \mathrm{g}^{-1}$. They reported superior capacitance retention of $89 \%$ after 10,000 cycles [459].

The oxygen vacancy is a significant factor that affects the ionic diffusion and conductivity of electrode materials, where the enhanced number of oxygen vacancies can decline the diffusion resistance [460] as a result, the porous networks can deliver higher SSA and increased the number of oxygen vacancies, thus improving the specific capacity/capacitance.

Similar PSKs exhibit different electrochemical behaviours in various types of electrolytes (pseudocapacitive behaviour and battery-like behavior). The charge storage performance of the PSKs with battery-like behaviour should be calculated by specific capacity $\left(\mathrm{mAh} \cdot \mathrm{g}^{-1} \mathrm{or} \mathrm{C} \cdot \mathrm{g}^{-1}\right)$ rather than specific capacitance $\left(\mathrm{F}^{-\mathrm{g}^{-1}}\right)$ [461].

The electrode materials with ultrathin nanosheet structures can achieve high specific capacity/capacitance and long-term stability because such structure decreases the strain resulted from the volume change during the charge-discharge process, thus providing more contact between the active material and electrolyte due to the high SSA [462].

PSK material is one of the novel alternative materials, which have attracted a lot of attention as electrode materials for SCs. PSK could be utilized as the anode material for SCs to provide an anion intercalation process. PSK oxides are promising multi-functional materials due to their enhanced physicochemical properties and the controllable oxygen vacancy number, which could be tuned through various techniques to improve the properties of the PSK oxides material as anodes for anion-intercalation SC. The number of oxygen vacancies and the high SSA of PSK oxides could enhance the electrochemical performance of SCs.

The electrical properties of PSKs could be changed through altering the temperature, in which most PSKs achieve a high conductivity at high temperature due to their structure with high oxygen diffusion rate and stability, which are different from that of those metals in the structure $[463,464]$.

For example, the sphere $\mathrm{La}_{0.85} \mathrm{Ca}_{0.15} \mathrm{MnO}_{3}$ (LCM) and $\mathrm{LaMnO}_{3}$ (LMO) have been compared in terms of the morphology, chemical properties, specific capacitance and intrinsic resistance of the electroactive material itself. The specific capacitance was reported of $198 \mathrm{~F} \cdot \mathrm{g}^{-1}$ and $187 \mathrm{~F} \cdot \mathrm{g}^{-1}$ at the current density of $0.5 \mathrm{~A} \cdot \mathrm{g}^{-1}$ for $\mathrm{La} 0.85 \mathrm{Sr} 0.15 \mathrm{MnO}_{3}$ and $\mathrm{LaMnO}_{3}$, respectively [465].

Recently, the effect of A-site substitution on the crystalline structure of LMO PSK by using Ca or $\mathrm{Sr}$ substituentswas studied. The LCM and $\mathrm{La}_{0.85} \mathrm{Sr}_{0.15} \mathrm{MnO}_{3}$ (LSM) electrodes showed a specific capacitance of $140.5 \mathrm{mF} \cdot \mathrm{cm}^{-2}$ and $129.0 \mathrm{mF} \cdot \mathrm{cm}^{-2}$ at $0.5 \mathrm{~mA} \cdot \mathrm{cm}^{-2}$ in an aqueous electrolyte, respectively, which are four times higher than that of LMO (Figure 24) [466]. 


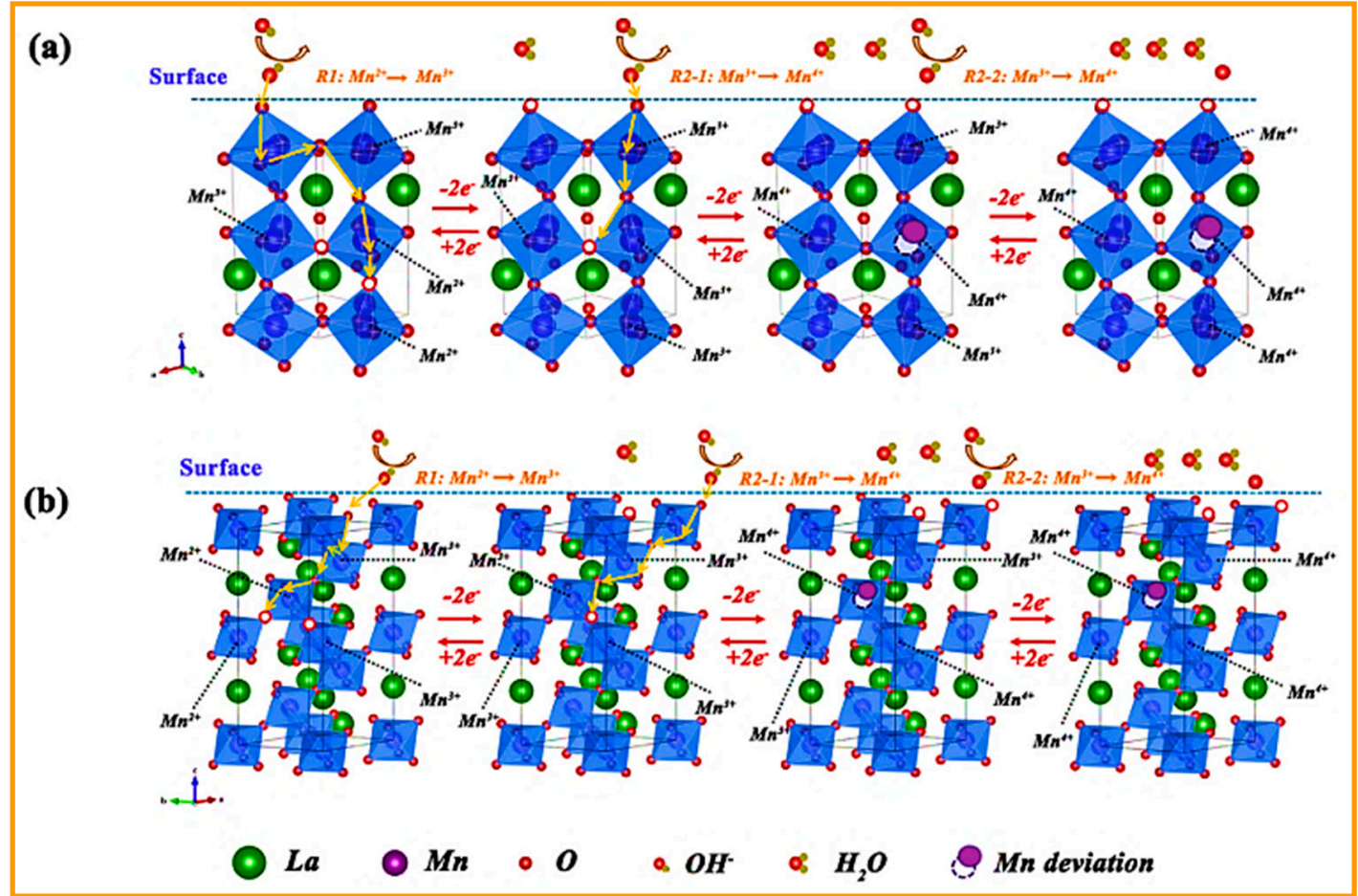

Figure 24. Crystal structures and the corresponding oxygen intercalation processes of A-site substituted compositions: (a) LCM; (b) LSM. Reprinted with permission from [466], Copyright 2020, Elsevier.

Sharma et al. prepared strontium titanate as the electrode material for SSC through the sol-gel method. The resultant electrode displayed a high capacitance of $592 \mathrm{~F} \cdot \mathrm{g}^{-1}$ at $5 \mathrm{mV} \cdot \mathrm{s}^{-1}$ because of the mesoporous structure, and large SSA, of the electrode materials as well as a high mass transfer rate of electrolytic ions. The fabricated SSC using strontium titanate electrodes and aqueous electrolyte exhibited a high specific capacitance of $212.5 \mathrm{~F} \cdot \mathrm{g}^{-1}$ at $0.63 \mathrm{~A} \cdot \mathrm{g}^{-1}$, high $\mathrm{E}_{\mathrm{d}}$ of $27.8 \mathrm{Wh} \cdot \mathrm{kg}^{-1}$ with a $\mathrm{P}_{\mathrm{d}}$ of $1921 \mathrm{~W} \cdot \mathrm{kg}^{-1}$. Furthermore, the device showed high cycling stability of $99 \%$ after 5000 cycles, and good capacitance retention of $74.5 \%$ at $2.5 \mathrm{~A} \cdot \mathrm{g}^{-1}$. The flexible and solid-state symmetric cell also exhibited high energy and $\mathrm{P}_{\mathrm{d}}$ of $3.62 \mathrm{Wh} \cdot \mathrm{kg}^{-1}$ and $965 \mathrm{~W} \cdot \mathrm{kg}^{-1}$, respectively [467].

PSK materials are also a powerful candidate for flexible energy storage/conversion, such as flexible PSK solar cells and FSCs [2,468]. Table 2 summarizes the recent advances on the 2D nanomaterials as the electrode for supercapacitor devices as well as their reported charge storage mechanisms. As is shown in Table 2, the electrochemical performance of the supercapacitor can be improved using nanocomposites made by materials, which display different charge storage mechanism to obtain a battery-type nanocomposite. 2D material such as BN NSs and MXene flakes exhibit EDLC behaviour, while MOFs, COFs, and PSK can provide pseudocapacitance. Moreover, the EDLC behaviour of the 2D-based electrode materials can be improved through the incorporation of the carbonaceous materials, as the extra pseudocapacitance can be obtained by the utilization of various TMOs and CPs. 
Table 2. A comparison of various 2D nanomaterials utilized as the electrode in SC devices.

\begin{tabular}{|c|c|c|c|c|c|}
\hline 2D Nanomaterial & $\begin{array}{l}\text { Type of the Corresponding } \\
\text { Composite-Based } \\
\text { Electrode Material }\end{array}$ & $\begin{array}{c}\text { Charge Storage Behavior of the Resultant Composite-Based } \\
\text { Electrode Material }\end{array}$ & $\begin{array}{l}\text { Cs of the Electrode } \\
\text { Material at Current } \\
\text { Density }\left(\mathrm{A} \cdot \mathrm{g}^{-1}\right) \text { or at } \\
\text { Scan Rate }\left(\mathrm{mV} \cdot \mathrm{s}^{-1}\right)\end{array}$ & $\begin{array}{l}\text { Capacitance Retention } \\
(\%) / \text { Number of Cycles }\end{array}$ & Ref. \\
\hline MXene & CoF/MXene & $\begin{array}{c}\text { The faradaic charge storage mechanism of CoF NPs and the EDLC } \\
\text { behaviour of MXene flakes resulted in a battery-like charge-discharge } \\
\text { behaviour for the resultant composite. }\end{array}$ & $1268.75 \mathrm{~F} \cdot \mathrm{g}^{-1}$ at $1 \mathrm{~A} \cdot \mathrm{g}^{-1}$ & $97 / 5000$ & [469] \\
\hline $\mathrm{BN}$ & $\begin{array}{l}\text { Ternary nanohybrids } \\
\left(\mathrm{m}_{\mathrm{K}}-\mathrm{BN} / \mathrm{CNT} / \mathrm{PANI}\right)\end{array}$ & $\begin{array}{c}\text { The combination of EDLC and pseudocapacitive behaviour. (Pure BN } \\
\text { and modified BN exhibited EDLC behaviour mainly. } \mathrm{m}_{\mathrm{K}}-\mathrm{BN} \text { showed } \\
\text { the maximum pseudocapacitive involvement }(28 \%) \text { with respect to BN } \\
\text { and } \mathrm{m}_{\mathrm{H}}-\mathrm{BN} \text {. The maximum pseudocapacitive contribution has been } \\
\text { reported for the ternary composites.) }\end{array}$ & $515{\mathrm{~F} \cdot \mathrm{g}^{-1}}^{-1}$ & $98 / 10,000$ & [455] \\
\hline h-BN & $(\mathrm{h}-\mathrm{BN}) / \mathrm{rGO}$ & $\begin{array}{l}\text { A prominent pseudo nature combined with EDLC was observed due } \\
\text { to the EDLC behaviour of graphene and the intrinsic pseudocapacitive } \\
\text { nature of h-BN heteroatoms. }\end{array}$ & $\sim 824 \mathrm{~F} \cdot \mathrm{g}^{-1}$ at $4 \mathrm{~A} \cdot \mathrm{g}^{-1}$ & $100 / 4000$ & [454] \\
\hline BP & BP thin film & EDLC behaviour & & $94.3 / 50,000$ & [470] \\
\hline TMDs & $\mathrm{MoS}_{2} @ \mathrm{HCNBs}$ & $\begin{array}{l}\text { The domination of EDLC with slight faradaic pseudocapacitance, } \\
\text { which arises from the faradaic charge transfer Mo in } \mathrm{MoS}_{2} \text { structure }\end{array}$ & $560 \mathrm{~F} \cdot \mathrm{g}^{-1}$ at $0.2 \mathrm{~A} \cdot \mathrm{g}^{-1}$ & $94.4 / 5000$ & [471] \\
\hline PSK & Mesoporous $\mathrm{CoTiO}_{3}$ PSK & Pseudocapacitive behavior of the $\mathrm{CoTiO}_{3}$ microrods & $608.4 \mathrm{~F} \cdot \mathrm{g}^{-1}$ at $5 \mathrm{mV} \cdot \mathrm{s}^{-1}$ & $82.3 / 1950$ & [472] \\
\hline LDHs & $\mathrm{NiCo}-\mathrm{LDHs}$ & The EDLC behaviour and faradic behaviour contribution & $1272 \mathrm{C} \cdot \mathrm{g}^{-1}$ at $2 \mathrm{~A} \cdot \mathrm{g}^{-1}$ & $103.9 / 5000$ & \\
\hline COFs & $\begin{array}{l}\text { pyridyl-hydroxyl } \\
\text { functionalized COFs }\end{array}$ & $\begin{array}{l}\text { The domination of EDLC due to the high surface area of COFs } \\
\text { (through the formation of the EDLC between the COF surface and the } \\
\mathrm{H}^{+} \text {ions) along with a pseudocapacitance, which increased by } \\
\text { increasing the number of } \mathrm{OH} \text { groups }\end{array}$ & $546 \mathrm{~F} \cdot \mathrm{g}^{-1}$ at $0.5 \mathrm{~A} \cdot \mathrm{g}^{-1}$ & $100 / 10,000$ & [473] \\
\hline MOFs & NiCo-MOF@PNTs & $\begin{array}{l}\text { The pseudocapacitive behaviour, which was derived from the faradaic } \\
\text { reactions of } \mathrm{Ni}^{2+} \mathrm{Ni}^{3+} \text { and } \mathrm{Co}^{2+} / \mathrm{Co}^{3+} \text {, as well as an extra } \\
\text { pseudocapacitance due to the presence of the PNTs. }\end{array}$ & $1109 \mathrm{~F} \cdot \mathrm{g}^{-1}$ at $0.5 \mathrm{~A} \cdot \mathrm{g}^{-1}$ & $79.1 / 10,000$ & [474] \\
\hline
\end{tabular}




\section{Applications and Future Perspectives}

Recent studies on the development of various electrode materials, the investigation of the SC operation and their charge storage mechanisms have enabled novel perspectives on the utilization of advanced electrode materials in the asymmetric flexible hybrid supercapacitor (ASFHSC) increasingly in the future. The configuration of hybrid-asymmetric superconductor provides the advantage of having a wide operating potential window, which results from the unique potential range of cathodes and anodes [475]. However, the HSCs exploit the advantages of both battery and supercapacitor electrodes, to provide high energy density and power density, respectively. Still, there are several challenges with regard to the fabrication of such systems, including the cost-efficient and scalable fabrication methods, developing the effective procedures to provide more control on the surface features (e.g., porosity, morphology, etc.) of the materials.

FSCs have commanded a lot of concentration as one of the most important energy storage research focuses owing to their extraordinary capacitive behaviour, higher power density, higher rate capability, and higher cyclic stability in comparison with batteries and higher $\mathrm{E}_{\mathrm{d}}$ compared to the traditional capacitors [476], which provide them with a vast range of potential to be utilized in various applications. Each category of SC has its own specific features and applications, such as in portable/wearable electronic devices as well as in computer and mobile phones [2,477], high power sources for heavy lift trucks or cranes [478,479], the self-powered SCs in medical applications (e.g., flexible artificial skin, artificial intelligence, portable or implantable medical/biomedical devices) [480,481], solar applications [482-484]. There are several SC companies such as ELTON (Russia), Nesscap (Korea), CAP-XX (Australia), and Nippon Chemicon (Japan), which are developing various kind of SCs for different applications [485].

Generally, the selection of the electrode material is one of the intense issues in the fabrication of an FSCs to obtain the appropriate mechanical strength and a high capacitance using the free-standing and binder-free electrodes, which are the main constituents of FSCs [476]. The electrode material for FSCs, as other classes of SCs, should fulfil the requirements of having a superior electrical conductivity, high tensile strain, large SSA, favourable chemical and thermal stability, high flexibility, wide potential window, and having enormous surface functional groups. For instance, among the carbon-based materials, graphene is one of the most powerful candidates for electrode material in FSCs owing to its large specific surface and high flexibility, which gives graphene the ability to be bent into large angles and provides a wide variety on the microstructures [486,487]. Recently, aerogels exhibited promising properties for 3D printed energy storage applications. For instance, graphene aerogels are commonly exploited owing to their high specific surface area, mechanical properties as well as tunable pore structures and porosity [488]. Therefore, as it has been reported in different studies $[476,487]$ that carbonaceous materials could be used as a backbone, in the composite material along with redox-active materials such as MOs and CPs, or could be integrated with novel 2D materials such as MXene $[489,490]$ to fabricate the appropriate flexible film as the electrode material for flexible/transparent SCs. Furthermore, incorporating the redox-active small molecules and bioderived functional groups into the pseudocapacitive material, as well as their utilization to increase the capacitance of the carbon-based material, have been provided more efficient, lower cost, non-toxic electrodes for SC application through eco-friendly synthesis [491,492].

\section{Conclusions}

The charge storage mechanisms, electrochemical behaviour and the principles of these materials have been investigated through several examples of recent advances. In this review, we have also described the distinction between the term "asymmetric" and "hybrid" as well as the difference between various electrochemical behaviour for the electrode materials including "battery-type" and "pseudocapacitive" behaviour. Besides, the main characteristic of the energy storage system including capacitance/capacity, operating temperature, energy density, power density, cell voltage, kinetic storage mechanism, I-V characteristics, cycling lifetime, self-discharge, and the nature of electrode materials have been briefly explained. The electrochemical signatures of EDLC, pseudocapacitive, and 
battery-like materials, including the CVs, GCDs, and i-v relationship, have been investigated. Three main groups of the electrode material include carbon-based material, metal oxides/hydroxides, and conductive polymers. Carbonaceous materials are promising electrodes to provide high specific surface area, favorable chemical and thermal stability as well as low electrical resistance, however their low energy density, which arises from their surface or quasi-surface energy storage, limits their application for large-scale. MOs such as $\mathrm{RuO}_{2}, \mathrm{~V}_{2} \mathrm{O}_{5}$, and $\mathrm{MnO}_{2}$, exhibited an outstanding improvement as electrode materials (both the cathode and the anode) due to their variety, excellent specific capacitance, and environmental friendlyness. However, their low electrical conductivity is one of the drawbacks, which weakens their rate capability and consequently the $\mathrm{P}_{\mathrm{d}}$ of the corresponding material. Conducting polymers have shown facile processability, improved conductivity, favourable flexibility, and advanced $\mathrm{E}_{\mathrm{d}}$ owing to their redox-active heteroatoms; however, there are some drawbacks such as volume shrinking/expansion, which restrict the cyclic performance of the CPs during the charging-discharging process. Apart from the mentioned advantage of different materials, still, there are several drawbacks for each group of materials. For example, in the case of the pseudocapacitive materials, the mass loading and the thickness of the active material must be accurately considered, since when the mass loading/thickness of the active material is very low, or the charge-discharge mechanisms are directed at a low current density, the energy performance may be observed as high mistakenly.

The composite-based or hybrid electrodes designed employing 1D, 2D, and 3D nanomaterials exhibited higher SSA, offer shorter diffusion paths for electrons and ions, thus improving the pseudocapacitance. The recent examples of the developed 2D nanomaterial such as hBN, MNs, BP, TMOs, TMDs, MOFs, COFs, MXene, and PSK has been given. Furthermore, we have extensively reviewed the importance of different nanocomposite made of various carbonaceous materials, TMOs, $\mathrm{TM}(\mathrm{OH}) \mathrm{s}, \mathrm{CPs}$, and 2D material, which provided advanced properties for the electrode material such as larger SSA, higher conductivity (to provide a favourable charge transfer kinetics through the high availability for the electrolyte), facile manipulation of morphology (e.g., pore shape, particle distributions/dimensions), higher mechanical, chemical, and thermal stability as well as enhanced electrochemical properties such as higher specific capacitance, energy and $\mathrm{P}_{\mathrm{d}}$ for the corresponding SC compared to that of the pure electrode material. In addition to the appropriate material selection, the electrochemical properties of the energy storage devices can be enhanced through the proper combination of the positive and negative electrodes, especially in the case of hybrid devices, where the battery-type and supercapacitor-type materials with various chemical natures are responsible for providing the high energy and high power densities, respectively.

Author Contributions: Conceptualization, S.C.P.; original draft preparation, P.F.; editing and review, V.K. and S.C.P.; supervision, S.C.P. All authors have read and agreed to the published version of the manuscript.

Funding: This work was supported by the "Presidents Bursary funding", through the Institute of Technology Sligo.

Conflicts of Interest: The authors declare no conflict of interest.

\section{Abbreviations}

$\begin{array}{ll}\text { SCs } & \text { Supercapacitors } \\ \text { EDLCs } & \text { Electric double-layer capacitors } \\ \text { SSCs } & \text { Symmetric supercapacitors } \\ \text { ASSCs } & \text { Asymmetric supercapacitors } \\ \text { HSCs } & \text { Hybrid supercapacitors } \\ \text { FSCs } & \text { Flexible supercapacitors } \\ \text { ASFHSC } & \text { Asymmetric flexible hybrid supercapacitor } \\ \text { E }_{\mathrm{d}} & \text { Energy density } \\ \text { CVs } & \text { Cyclic voltammograms } \\ \text { SSA } & \text { Specific surface area } \\ \text { OD } & \text { Zero-dimensional }\end{array}$




\begin{tabular}{|c|c|}
\hline$P_{d}$ & Power density \\
\hline 1D & One-dimensional \\
\hline $2 \mathrm{D}$ & Two-dimensional \\
\hline $3 \mathrm{D}$ & Three-dimensional \\
\hline NSs & Nanosheets \\
\hline NSAs & Nanosheet arrays \\
\hline $\mathrm{CB}$ & Carbon black \\
\hline $\mathrm{CC}$ & Carbon cloth \\
\hline $\mathrm{CCF}$ & Carbonized cotton fabric \\
\hline CNTs & Carbon nanotubes \\
\hline CNFs & Carbon nanofibers \\
\hline MCNFs & Multi-channel carbon nanofiber \\
\hline ECC & Electrochemically activated carbon \\
\hline TPC & Templated porous carbon \\
\hline SPC & Sulfurated porous carbon \\
\hline HCNBs & Hollow carbon nano bowls \\
\hline rGO & Reduced graphene oxide \\
\hline GQDs & Graphene quantum dot \\
\hline PGr & Porous graphene \\
\hline GNSs & Graphene nanosheets \\
\hline GPCNs & Graphene-like porous carbon nanosheets \\
\hline MOs & Metal oxides \\
\hline TMs & Transition metal \\
\hline TMOs & Transition metal oxide \\
\hline $\mathrm{TM}(\mathrm{OH}) \mathrm{s}$ & Transition metal hydroxide \\
\hline TMDs & Transition metal dichalcogenides \\
\hline COFs & Covalent organic frameworks \\
\hline MOFs & Metal organic framework \\
\hline PANI & Polyaniline \\
\hline PTh & Polythiophene \\
\hline PPy & Polypyrrole \\
\hline PIND & Polyindole \\
\hline PEDOT & Poly 3,4-ethylenedioxythiophene \\
\hline PVA & Poly vinyl alcohol \\
\hline PS & Polystyrene \\
\hline $\mathrm{BN}$ & Boron nitrides \\
\hline PNTs & Polypyrrole nanotubes \\
\hline hBN & Hexagonal boron nitride \\
\hline $\mathrm{BP}$ & Black phosphorous \\
\hline PSK & Perovskite \\
\hline MXene & 2D transition metal carbides, Carbonitrides, \\
\hline
\end{tabular}

\section{References}

1. Simon, P.; Gogotsi, Y.; Dunn, B. Where Do Batteries End and Supercapacitors Begin? Science 2014, 343, 1210-1211. [CrossRef] [PubMed]

2. Li, C.; Islam, M.; Moore, J.; Sleppy, J.; Morrison, C.; Konstantinov, K.; Dou, S.X.; Renduchintala, C.; Thomas, J. Wearable energy-smart ribbons for synchronous energy harvest and storage. Nat. Commun. 2016, 7, 1-10. [CrossRef] [PubMed]

3. Winter, M.; Brodd, R.J. What are batteries, fuel cells, and supercapacitors? Chem. Rev. 2004, 104, 4245-4269. [CrossRef] [PubMed]

4. Kötz, R.; Carlen, M. Principles and applications of electrochemical capacitors. Electrochim. Acta 2000, 45, 2483-2498. [CrossRef]

5. Lewandowski, A.; Galinski, M. Practical and theoretical limits for electrochemical double-layer capacitors. J. Power Sources 2007, 173, 822-828. [CrossRef] 
6. Bohlen, O.; Kowal, J.; Sauer, D.U. Ageing behaviour of electrochemical double layer capacitors. J. Power Sources 2007, 173, 626-632. [CrossRef]

7. Huang, J.; Sumpter, B.G.; Meunier, V. Theoretical Model for Nanoporous Carbon Supercapacitors. Angew. Chem. Int. Ed. 2008, 47, 520-524. [CrossRef]

8. Lu, Z.; Raad, R.; Safaei, F.; Xi, J.; Liu, Z.; Foroughi, J. Carbon Nanotube Based Fiber Supercapacitor as Wearable Energy Storage. Front. Mater. 2019, 6, 1-14. [CrossRef]

9. Lokhande, P.E.; Chavan, U.S.; Pandey, A. Materials and Fabrication Methods for Electrochemical Supercapacitors: Overview. Electrochem. Energy Rev. 2020, 3, 155-186. [CrossRef]

10. Kakaei, K.; Esrafili, M.D.; Ehsani, A. Graphene-Based Electrochemical Supercapacitors. Interface Sci. Technol. 2019, 27, 339-386.

11. Zhang, L.; Zhao, X.S. Carbon-based materials as supercapacitor electrodes. Chem. Soc. Rev. 2009, 38, 2520-2531. [CrossRef] [PubMed]

12. Chmiola, J.; Yushin, G.; Gogotsi, Y.; Portet, C.; Simon, P.; Taberna, P.L. Anomalous increase in carbon at pore sizes less than 1 nanometer. Science 2006, 313, 1760-1763. [CrossRef] [PubMed]

13. Wang, G.; Zhang, L.; Zhang, J. A review of electrode materials for electrochemical supercapacitors. Chem. Soc. Rev. 2012, 41, 797-828. [CrossRef] [PubMed]

14. Li, J.; Cheng, X.; Shashurin, A.; Keidar, M. Review of Electrochemical Capacitors Based on Carbon Nanotubes and Graphene. Graphene 2012, 1, 1-13. [CrossRef]

15. Pan, H.; Li, J.; Feng, Y.P. Carbon nanotubes for supercapacitor. Nanoscale Res. Lett. 2010, 5, 654-668. [CrossRef]

16. Forse, A.C.; Merlet, C.; Griffin, J.M.; Grey, C.P. New perspectives on the charging mechanisms of supercapacitors. J. Am. Chem. Soc. 2016, 138, 5731-5744. [CrossRef]

17. Noori, A.; El-Kady, M.F.; Rahmanifar, M.S.; Kaner, R.B.; Mousavi, M.F. Towards establishing standard performance metrics for batteries, supercapacitors and beyond. Chem. Soc. Rev. 2019, 48, 1272-1341. [CrossRef]

18. Woo, J.; Ahn, T.; Hun, J.; Myoun, J.; Kim, J. Electrochimica Acta Nanosheets based mesoporous NiO microspherical structures via facile and template-free method for high performance supercapacitors. Electrochim. Acta 2011, 56, 4849-4857. [CrossRef]

19. Xing, Z.; Chu, Q.; Ren, X.; Ge, C.; Qusti, A.H.; Asiri, A.M.; Al-Youbi, A.O.; Sun, X. $\mathrm{Ni}_{3} \mathrm{~S}_{2}$ coated ZnO array for high-performance supercapacitors. J. Power Sources 2014, 245, 463-467. [CrossRef]

20. Xia, Q.; Yang, H.; Wang, M.; Yang, M.; Guo, Q.; Wan, L.; Xia, H.; Yu, Y. High Energy and High Power Lithium-Ion Capacitors Based on Boron and Nitrogen Dual-Doped 3D Carbon Nanofibers as Both Cathode and Anode. Adv. Energy Mater. 2017, 7, 1701336. [CrossRef]

21. Ding, J.; Wang, H.; Li, Z.; Cui, K.; Karpuzov, D.; Tan, X.; Kohandehghan, A.; Mitlin, D. Peanut shell hybrid sodium ion capacitor with extreme energy-power rivals lithium ion capacitors. Energy Environ. Sci. 2015, 8 , 941-955. [CrossRef]

22. Khomenko, V.; Raymundo-Piñero, E.; Béguin, F. High-energy density graphite/AC capacitor in organic electrolyte. J. Power Sources 2008, 177, 643-651. [CrossRef]

23. Chen, H.; Cong, T.N.; Yang, W.; Tan, C.; Li, Y.; Ding, Y. Progress in electrical energy storage system: A critical review. Prog. Nat. Sci. 2009, 19, 291-312. [CrossRef]

24. Andreas, H.A. Self-Discharge in Electrochemical Capacitors: A Perspective Article. J. Electrochem. Soc. 2015, 162, A5047-A5053. [CrossRef]

25. Black, J.; Andreas, H.A. Effects of charge redistribution on self-discharge of electrochemical capacitors. Electrochim. Acta 2009, 54, 3568-3574. [CrossRef]

26. Abbas, Q.; Béguin, F. Influence of the iodide/iodine redox system on the self-discharge of AC/AC electrochemical capacitors in salt aqueous electrolyte. Prog. Nat. Sci. Mater. Int. 2015, 25, 622-630. [CrossRef]

27. Kötz, R.; Hahn, M.; Gallay, R. Temperature behavior and impedance fundamentals of supercapacitors. J. Power Sources 2006, 154, 550-555. [CrossRef]

28. Xiao, H.; Yao, S.; Liu, H.; Qu, F.; Zhang, X.; Wu, X. NiO nanosheet assembles for supercapacitor electrode materials. Prog. Nat. Sci. Mater. Int. 2016, 26, 271-275. [CrossRef]

29. Peters, J.; Buchholz, D.; Passerini, S.; Weil, M. Life cycle assessment of sodium-ion batteries. Energy Environ. Sci. 2016, 9, 1744-1751. [CrossRef] 
30. Ding, J.; Hu, W.; Paek, E.; Mitlin, D. Review of Hybrid Ion Capacitors: From Aqueous to Lithium to Sodium. Chem. Rev. 2018, 118, 6457-6498. [CrossRef] [PubMed]

31. Lu, Y.; Li, B.; Zheng, S.; Xu, Y.; Xue, H.; Pang, H. Syntheses and Energy Storage Applications of M x S y $(\mathrm{M}=\mathrm{Cu}, \mathrm{Ag}, \mathrm{Au})$ and Their Composites: Rechargeable Batteries and Supercapacitors. Adv. Funct. Mater. 2017, 27, 1703949. [CrossRef]

32. Chemali, E.; Preindl, M.; Malysz, P.; Emadi, A. Electrochemical and Electrostatic Energy Storage and Management Systems for Electric Drive Vehicles: State-of-the-Art Review and Future Trends. IEEE J. Emerg. Sel. Top. Power Electron. 2016, 4, 1117-1134. [CrossRef]

33. Talaie, E.; Bonnick, P.; Sun, X.; Pang, Q.; Liang, X.; Nazar, L.F. Methods and Protocols for Electrochemical Energy Storage Materials Research. Chem. Mater. 2017, 29, 90-105. [CrossRef]

34. Liu, Q.; Li, Z.-F.; Liu, Y.; Zhang, H.; Ren, Y.; Sun, C.-J.; Lu, W.; Zhou, Y.; Stanciu, L.; Stach, E.; et al. Graphene-modified nanostructured vanadium pentoxide hybrids with extraordinary electrochemical performance for Li-ion batteries. Nat. Commun. 2015, 6, 6127. [CrossRef]

35. Ardizzone, S.; Fregonara, G.; Trasatti, S. Inner and outer active surface of $\mathrm{RuO}_{2}$ electrodes. Electrochim. Acta 1990, 35, 263-267. [CrossRef]

36. Zheng, J.P. Hydrous Ruthenium Oxide as an Electrode Material for Electrochemical Capacitors. J. Electrochem. Soc. 1995, 142, 2699. [CrossRef]

37. Lee, H.Y.; Goodenough, J.B. Supercapacitor Behavior with $\mathrm{KCl}$ Electrolyte. J. Solid State Chem. 1999, 144, 220-223. [CrossRef]

38. Brousse, T.; Toupin, M.; Dugas, R.; Athouël, L.; Crosnier, O.; Bélanger, D. Crystalline $\mathrm{MnO}_{2}$ as Possible Alternatives to Amorphous Compounds in Electrochemical Supercapacitors. J. Electrochem. Soc. 2006, 153, A2171. [CrossRef]

39. Brousse, T.; Bélanger, D.; Long, J.W. To Be or Not To Be Pseudocapacitive? J. Electrochem. Soc. 2015, 162, A5185-A5189. [CrossRef]

40. Augustyn, V.; Simon, P.; Dunn, B. Pseudocapacitive oxide materials for high-rate electrochemical energy storage. Energy Environ. Sci. 2014, 7, 1597. [CrossRef]

41. Lee, J.W.; Hall, A.S.; Kim, J.D.; Mallouk, T.E. A facile and template-free hydrothermal synthesis of $\mathrm{Mn}_{3} \mathrm{O}_{4}$ nanorods on graphene sheets for supercapacitor electrodes with long cycle stability. Chem. Mater. 2012, 24, 1158-1164. [CrossRef]

42. Wang, S.-Y.; Ho, K.-C.; Kuo, S.-L.; Wu, N.-L. Investigation on Capacitance Mechanisms of $\mathrm{Fe}_{3} \mathrm{O}_{4}$ Electrochemical Capacitors. J. Electrochem. Soc. 2006, 153, 75-80. [CrossRef]

43. Xia, X.-H.; Tu, J.-P.; Wang, X.-L.; Gu, C.-D.; Zhao, X.-B. Mesoporous $\mathrm{Co}_{3} \mathrm{O}_{4}$ monolayer hollow-sphere array as electrochemical pseudocapacitor material. Chem. Commun. 2011, 47, 5786. [CrossRef] [PubMed]

44. Singh, A.K.; Sarkar, D.; Khan, G.G.; Mandal, K. Designing one dimensional Co-Ni/Co $3 \mathrm{O}_{4}-\mathrm{NiO}$ core/shell nano-heterostructure electrodes for high-performance pseudocapacitor. Appl. Phys. Lett. 2014, 104, 133904. [CrossRef]

45. Wang, H.; Yi, H.; Chen, X.; Wang, X. Facile synthesis of a nano-structured nickel oxide electrode with outstanding pseudocapacitive properties. Electrochim. Acta 2013, 105, 353-361. [CrossRef]

46. Kandalkar, S.G.; Gunjakar, J.L.; Lokhande, C.D. Preparation of cobalt oxide thin films and its use in supercapacitor application. Appl. Surf. Sci. 2008, 254, 5540-5544. [CrossRef]

47. Senthilkumar, B.; Sankar, K.V.; Vasylechko, L.; Lee, Y.-S.; Selvan, R.K. Synthesis and electrochemical performances of maricite- $\mathrm{NaMPO}_{4}(\mathrm{M}=\mathrm{Ni}, \mathrm{Co}, \mathrm{Mn})$ electrodes for hybrid supercapacitors. RSC Adv. 2014, 4, 53192-53200. [CrossRef]

48. Augustyn, V.; Come, J.; Lowe, M.A.; Kim, J.W.; Taberna, P.-L.; Tolbert, S.H.; Abruña, H.D.; Simon, P.; Dunn, B. High-rate electrochemical energy storage through $\mathrm{Li}+$ intercalation pseudocapacitance. Nat. Mater. 2013, 12, 518-522. [CrossRef]

49. Jiang, Y.; Liu, J. Definitions of Pseudocapacitive Materials: A Brief Review. Energy Environ. Mater. 2019, 2, 30-37. [CrossRef]

50. Wang, J.; Polleux, J.; Lim, J.; Dunn, B. Pseudocapacitive Contributions to Electrochemical Energy Storage in $\mathrm{TiO}_{2}$ (Anatase) Nanoparticles. J. Phys. Chem. C 2007, 111, 14925-14931. [CrossRef]

51. Mitchell, J.B.; Lo, W.C.; Genc, A.; LeBeau, J.; Augustyn, V. Transition from Battery to Pseudocapacitor Behavior via Structural Water in Tungsten Oxide. Chem. Mater. 2017, 29, 3928-3937. [CrossRef] 
52. Lai, L.; Yang, S.; Wang, L.; Teh, B.K.; Zhong, J.; Chou, H.; Chen, L.; Chen, W.; Shen, Z.; Ruoff, R.S.; et al. Preparation of supercapacitor electrodes through selection of graphene surface functionalities. ACS Nano 2012, 6, 5941-5951. [CrossRef] [PubMed]

53. Xie, L.; Sun, G.-H.; Su, F.; Guo, X.; Kong, Q.; Li, X.; Huang, X.; Wan, L.; Song, W.; Li, K.; et al. Hierarchical porous carbon microtubes derived from willow catkins for supercapacitor applications. J. Mater. Chem. A 2016, 4, 1637-1646. [CrossRef]

54. Frackowiak, E.; Béguin, F. Carbon materials for the electrochemical storage of energy in capacitors. Carbon 2001, 39, 937-950. [CrossRef]

55. Kim, B.K.; Sy, S.; Yu, A.; Zhang, J. Electrochemical Supercapacitors for Energy Storage and Conversion. Handb. Clean Energy Syst. 2015, 1-25. [CrossRef]

56. Sevilla, M.; Mokaya, R. Energy storage applications of activated carbons: Supercapacitors and hydrogen storage. Energy Environ. Sci. 2014, 7, 1250-1280. [CrossRef]

57. Pongprayoon, P.; Chaimanatsakun, A. Revealing the Effects of Pore Size and Geometry on the Mechanical Properties of Graphene Nanopore Using the Atomistic Finite Element Method. Acta Mech. Solida Sin. 2019, 32, 81-92. [CrossRef]

58. Dai, G.; Zhang, L.; Liao, Y.; Shi, Y.; Xie, J.; Lei, F.; Fan, L. Multi-Scale Model for Describing the Effect of Pore Structure on Carbon-Based Electric Double Layer. J. Phys. Chem. C 2020, 124, 3952-3961. [CrossRef]

59. Yu, Z.; Tetard, L.; Zhai, L.; Thomas, J. Supercapacitor electrode materials: Nanostructures from 0 to 3 dimensions. Energy Environ. Sci. 2015, 8, 702-730. [CrossRef]

60. Shang, T.; Xu, Y.; Li, P.; Han, J.; Wu, Z.; Tao, Y.; Yang, Q.-H. A bio-derived sheet-like porous carbon with thin-layer pore walls for ultrahigh-power supercapacitors. Nano Energy 2020, 70, 104531. [CrossRef]

61. Miller, J.M. Deposition of Ruthenium Nanoparticles on Carbon Aerogels for High Energy Density Supercapacitor Electrodes. J. Electrochem. Soc. 1997, 144, 309. [CrossRef]

62. Chen, L.; Zhang, X.-D.; Liang, H.-W.; Kong, M.; Guan, Q.-F.; Chen, P.; Wu, Z.-Y.; Yu, S.-H. Synthesis of Nitrogen-Doped Porous Carbon Nanofibers as an Efficient Electrode Material for Supercapacitors. ACS Nano 2012. [CrossRef] [PubMed]

63. Vangari, M.; Pryor, T.; Jiang, L. Supercapacitors: Review of materials and fabrication methods. J. Energy Eng. 2013, 139, 72-79. [CrossRef]

64. Qi, F.; Xia, Z.; Sun, R.; Sun, X.; Xu, X.; Wei, W.; Wang, S.; Sun, G. Graphitization induced by KOH etching for the fabrication of hierarchical porous graphitic carbon sheets for high performance supercapacitors. J. Mater. Chem. A 2018, 6, 14170-14177. [CrossRef]

65. He, X.; Ma, H.; Wang, J.; Xie, Y.; Xiao, N.; Qiu, J. Porous carbon nanosheets from coal tar for high-performance supercapacitors. J. Power Sources 2017, 357, 41-46. [CrossRef]

66. Becker, H.I.; General Electric Company. Low Voltage Electrolytic Capacitor. U.S. Patent 2,800,616, 1957. Available online: https://patentimages.storage.googleapis.com/a2/f8/a9/b7d5c04a415c8b/US2800616.pdf (accessed on 8 June 2020).

67. Iro, Z.S.; Subramani, C.; Dash, S.S. A brief review on electrode materials for supercapacitor. Int. J. Electrochem. Sci. 2016, 11, 10628-10643. [CrossRef]

68. Chen, S.M.; Ramachandran, R.; Mani, V.; Saraswathi, R. Recent Advancements in Electrode Materials for the Highperformance Electrochemical Supercapacitors-A Review. Int. J. Electrochem. Sci. 2014, 9, 4072-4085.

69. Arbizzani, C.; Mastragostino, M.; Soavi, F. New trends in electrochemical supercapacitors. J. Power Sources 2001, 100, 164-170. [CrossRef]

70. Raymundo-Piñero, E.; Kierzek, K.; Machnikowski, J.; Béguin, F. Relationship between the nanoporous texture of activated carbons and their capacitance properties in different electrolytes. Carbon N. Y. 2006, 44, 2498-2507. [CrossRef]

71. Arenillas, A.; Menéndez, J.A.; Reichenauer, G.; Celzard, A.; Fierro, V.; Hodar, F.J.M.; Bailón-Garcia, E.; Job, N. Organic and Carbon Gels: From Laboratory Synthesis to Applications; Springer: Berlin, Germany, 2019; p. 195. [CrossRef]

72. Wang, C.-M.; Wen, C.-Y.; Chen, Y.-C.; Chang, J.-Y.; Ho, C.-W.; Kao, K.-S.; Shih, W.-C.; Chiu, C.-M.; Shen, Y.-A. The influence of specific surface area on the capacitance of the carbon electrodes supercapacitor. In Proceedings of the 2nd International Conference on Industrial Application Engineering 2015, Kitakyushu, Japan, 28-31 March 2015; pp. 439-442. [CrossRef] 
73. Varghese, J.; Wang, H.; Pilon, L. Simulating Electric Double Layer Capacitance of Mesoporous Electrodes with Cylindrical Pores. J. Electrochem. Soc. 2011, 158, A1106. [CrossRef]

74. He, Y.-T.; Zhang, Y.; Li, X.; Lv, Z.; Wang, X.; Liu, Z.; Huang, X. Capacitive mechanism of oxygen functional groups on carbon surface in supercapacitors. Electrochim. Acta 2018, 282, 618-625. [CrossRef]

75. Zhan, C.; Zhang, Y.; Cummings, P.T.; Jiang, D.E. Enhancing graphene capacitance by nitrogen: Effects of doping configuration and concentration. Phys. Chem. Chem. Phys. 2016, 18, 4668-4674. [CrossRef] [PubMed]

76. Zhao, Y.; Wang, X.; Wang, N.; Li, M.; Li, Q.; Liu, J. Unraveling Factors Leading to High Pseudocapacitance of Redox-Active Small Aromatics on Graphene. J. Phys. Chem. C 2019, 123, 994-1002. [CrossRef]

77. Yang, H.; Kannappan, S.; Pandian, A.S.; Jang, J.H.; Lee, Y.S.; Lu, W. Graphene supercapacitor with both high power and energy density. Nanotechnology 2017, 28. [CrossRef] [PubMed]

78. Boddula, R.; Ahamed, M.I.; Asiri, A.M. Inorganic Nanomaterials for Supercapacitor Design; CRC Press: Boca Raton, FL, USA, 2019.

79. Iro, Z.S.; Subramani, C.; Hafeez, H.Y. Study of asymmetric hybrid supercapacitor using carbon and metal oxides as electrode materials. Indian J. Sci. Technol. 2016, 9. [CrossRef]

80. Sahoo, R.; Lee, T.H.; Pham, D.T.; Luu, T.H.T.; Lee, Y.H. Fast-Charging High-Energy Battery-Supercapacitor Hybrid: Anodic Reduced Graphene Oxide-Vanadium(IV) Oxide Sheet-on-Sheet Heterostructure. ACS Nano 2019, 13, 10776-10786. [CrossRef]

81. Chen, Y.; Zhang, X.; Zhang, H.; Sun, X.; Zhang, D.; Ma, Y. High-performance supercapacitors based on a graphene-activated carbon composite prepared by chemical activation. RSC Adv. 2012, 2, 7747-7753. [CrossRef]

82. Moreno-Fernandez, G.; Ibañez, J.; Rojo, J.M.; Kunowsky, M. Activated Carbon Fiber Monoliths as Supercapacitor Electrodes. Adv. Mater. Sci. Eng. 2017, 2017, 1-8. [CrossRef]

83. Shi, K.; Zhitomirsky, I. Fabrication of polypyrrole-coated carbon nanotubes using oxidant-surfactant nanocrystals for supercapacitor electrodes with high mass loading and enhanced performance. ACS Appl. Mater. Interfaces 2013, 5, 13161-13170. [CrossRef]

84. Zou, Q.; Khalafallah, D.; Wu, Z.; Chen, J.; Zhi, M.; Hong, Z. Supercritical ethanol deposition of $\mathrm{Ni}(\mathrm{OH})_{2}$ nanosheets on carbon cloth for flexible solid-state asymmetric supercapacitor electrode. J. Supercrit. Fluids 2020, 159, 104774. [CrossRef]

85. Syarif, N.; Tribidasari, I.; Wibowo, W. Direct Synthesis Carbon/Metal Oxide Composites for Electrochemical Capacitors Electrode. Int. Trans. J. Eng. Manag. Appl. Sci. Technol. 2012, 3, 21-34. Available online: http://tuengr.com/V03/21-34.pdf (accessed on 3 January 2020).

86. Bessaguet, C.; Dantras, E.; Lacabanne, C.; Chevalier, M.; Michon, G. Piezoelectric and mechanical behavior of NaNbO3/PEKK lead-free nanocomposites. J. Non. Cryst. Solids 2017, 459, 83-87. [CrossRef]

87. Pandolfo, A.G.; Hollenkamp, A.F. Carbon properties and their role in supercapacitors. J. Power Sources 2006, 157, 11-27. [CrossRef]

88. Simon, P.; Gogotsi, Y. Materials for Electrochemical Capacitors. Nat. Mater. 2008, 7, 845-854. [CrossRef] [PubMed]

89. Salunkhe, R.R.; Lin, J.; Malgras, V.; Dou, S.X.; Kim, J.H.; Yamauchi, Y. Large-scale synthesis of coaxial carbon nanotube/ $\mathrm{Ni}(\mathrm{OH})_{2}$ composites for asymmetric supercapacitor application. Nano Energy 2015, 11, 211-218. [CrossRef]

90. Yan, J.; Wang, Q.; Wei, T.; Fan, Z. Recent Advances in Design and Fabrication of Electrochemical Supercapacitors with High Energy Densities. Adv. Energy Mater. 2014, 4, 1300816. [CrossRef]

91. Choudhary, N.; Li, C.; Moore, J.; Nagaiah, N.; Zhai, L.; Jung, Y.; Thomas, J. Asymmetric Supercapacitor Electrodes and Devices. Adv. Mater. 2017, 29. [CrossRef]

92. Yuan, C.; Wu, H.B.; Xie, Y.; Lou, X.W.D. Mixed Transition-Metal Oxides: Design, Synthesis, and Energy-Related Applications. Angew. Chem. Int. Ed. 2014, 53, 1488-1504. [CrossRef]

93. Simon, P.; Burke, A. Nanostructured carbons: Double-layer capacitance and more. Electrochem. Soc. Interface 2008, 17, 38-43.

94. Raymundo-Piñero, E.; Leroux, F.; Béguin, F. A high-performance carbon for supercapacitors obtained by carbonization of a seaweed biopolymer. Adv. Mater. 2006, 18, 1877-1882. [CrossRef]

95. Ali, A.; Jamal, R.; shao, W.; Rahman, A.; Osman, Y.; Abdiryim, T. Structure and properties of solid-state synthesized poly(3,4-propylenedioxythiophene)/nano-ZnO composite. Prog. Nat. Sci. Mater. Int. 2013, 23, 524-531. [CrossRef] 


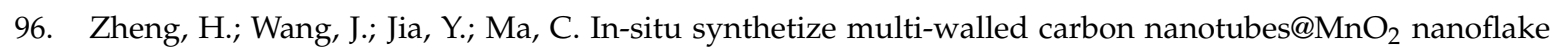
core-shell structured materials for supercapacitors. J. Power Sources 2012, 216, 508-514. [CrossRef]

97. Ania, C.O.; Khomenko, V.; Raymundo-Piñero, E.; Parra, J.B.; Béguin, F. The Large Electrochemical Capacitance of Microporous Doped Carbon Obtained by Using a Zeolite Template. Adv. Funct. Mater. 2007, 17, 1828-1836. [CrossRef]

98. Zhong, C.; Deng, Y.; Hu, W.; Qiao, J.; Zhang, L.; Zhang, J. A review of electrolyte materials and compositions for electrochemical supercapacitors. Chem. Soc. Rev. 2015, 44, 7484-7539. [CrossRef]

99. Li, L.; Wang, X.; Wang, S.; Cao, Z.; Wu, Z.; Wang, H.; Gao, Y.; Liu, J. Activated Carbon Prepared from Lignite as Supercapacitor Electrode Materials. Electroanalysis 2016, 28, 243-248. [CrossRef]

100. Zhang, M.; Cheng, J.; Zhang, L.; Li, Y.; Chen, M.-S.; Chen, Y.; Shen, Z. Activated carbon by one-step calcination of deoxygenated agar for high voltage lithium ion supercapacitor. ACS Sustain. Chem. Eng. 2020, 8, 3637-3643. [CrossRef]

101. Bordun, I.; Pohrebennyk, V.; Sadowa, M.; Ptashnyk, V.; Klos-Witkowska, A.; Martsenyuk, V. Impedance spectroscopy of supercapacitors on the basis on modified by the ultrasound activated carbon material. In Proceedings of the 2017 IEEE 9th International Conference on Intelligent Data Acquisition and Advanced Computing Systems: Technology and Applications, IDAACS 2017, Bucharest, Romania, 21-23 September 2017; pp. 86-90. [CrossRef]

102. Grishchenko, L.M.; Tsapyuk, G.G.; Ricco, M.; Diyuk, V.E.; Boldyrieva, O.Y.; Mariychuk, R.; Matushko, I.P.; Pontiroli, D.; Lisnyak, V.V.; Scaravonati, S. Enhancing the Performance of Supercapacitor Activated Carbon Electrodes by Oxidation. In Proceedings of the 2020 IEEE 40th International Conference on Electronics and Nanotechnology, ELNANO, Kyiv, Ukraine, 22-24 April 2020; Igor Sikordky Kyiv Polytechnic Instituite: Kyiv, Ukraine; pp. 173-177. [CrossRef]

103. Maria, F.R.; Raj, S.; Jaya, N.V.; Boopathi, G.; Kalpana, D.; Pandurangan, A. S-doped activated mesoporous carbon derived from the Borassus flabellifer flower as active electrodes for supercapacitors. Mater. Chem. Phys. 2019, 240, 122151. [CrossRef]

104. Cheng, F.; Yang, X.; Zhang, S.; Lu, W. Boosting the supercapacitor performances of activated carbon with carbon nanomaterials. J. Power Sources 2019, 450, 227678. [CrossRef]

105. Chen, W.C.; Wen, T.C.; Teng, H. Polyaniline-deposited porous carbon electrode for supercapacitor. Electrochim. Acta 2003, 48, 641-649. [CrossRef]

106. Inal, I.I.G.; Gokce, Y.; Aktas, Z. Waste tea derived activated carbon/polyaniline composites as supercapacitor electrodes. In Proceedings of the 2016 IEEE International Conference on Renewable Energy Research and Applications, ICRERA 2016, Birmingham, UK, 20-23 November 2016; pp. 458-462. [CrossRef]

107. Frackowiak, E.; Metenier, K.; Bertagna, V.; Beguin, F. Supercapacitor electrodes from multiwalled carbon nanotubes. Appl. Phys. Lett. 2000, 77, 2421-2423. [CrossRef]

108. Cheng, Q.; Tang, J.; Ma, J.; Zhang, H.; Shinya, N.; Qin, L.C. Graphene and carbon nanotube composite electrodes for supercapacitors with ultra-high energy density. Phys. Chem. Chem. Phys. 2011, 13, 17615-17624. [CrossRef] [PubMed]

109. Du, C.; Yeh, J.; Pan, N. High power density supercapacitors using locally aligned carbon nanotube electrodes. Nanotechnology 2005, 16, 350-353. [CrossRef]

110. Shi, R.; Jiang, L.; Pan, C. A Single-Step Process for Preparing Supercapacitor Electrodes from Carbon Nanotubes. Soft Nanosci. Lett. 2011, 1, 11-15. [CrossRef]

111. Rajender, I.; Mohammad, B.; Ahmer, F.; Asiri, A.M. Morphology Design Paradigms for Supercapacitors; CRC Press: Boca Raton, FL, USA, 2019.

112. Li, X.; Rong, J.; Wei, B. Electrochemical Behavior of Single-Walled Carbon Nanotube Supercapacitors under Compressive Stress. ACS Nano 2010, 4, 6039-6049. [CrossRef]

113. Dillon, A.C. Carbon Nanotubes for Photoconversion and Electrical Energy Storage. Chem. Rev. 2010, 110, 6856-6872. [CrossRef]

114. Niu, C.; Sichel, E.K.; Hoch, R.; Moy, D.; Tennent, H. High power electrochemical capacitors based on carbon nanotube electrodes. Appl. Phys. Lett. 1997, 70, 1480-1482. [CrossRef]

115. Peng, C.; Jin, J.; Chen, G.Z. A comparative study on electrochemical co-deposition and capacitance of composite films of conducting polymers and carbon nanotubes. Electrochim. Acta 2007, 53, 525-537. [CrossRef] 
116. Wang, G.; Hou, C.; Wang, H. (Eds.) Flexible and Wearable Electronics for Smart Clothing; Wiley: Hoboken, NJ, USA, 2020.

117. Liu, Q.; Yang, J.; Luo, X.; Miao, Y.; Zhang, Y.; Xu, W.; Yang, L.; Liang, Y.; Weng, W.; Zhu, M. Fabrication of a fibrous $\mathrm{MnO}_{2} @ \mathrm{MXene/CNT}$ electrode for high-performance flexible supercapacitor. Ceram. Int. 2020, 46, 11874-11881. [CrossRef]

118. Yang, L.; Zheng, W.; Zhang, P.; Chen, J.; Tian, W.; Zhang, Y.; Sun, Z. MXene/CNTs films prepared by electrophoretic deposition for supercapacitor electrodes. J. Electroanal. Chem. 2018, 830-831, 1-6. [CrossRef]

119. Shimamoto, K.; Tadanaga, K.; Tatsumisago, M. All-solid-state electrochemical capacitors using $\mathrm{MnO}_{2}$ /carbonnanotube composite electrode. Electrochim. Acta 2013, 109, 651-655. [CrossRef]

120. Alam, S.N.; Sharma, N.; Kumar, L. Synthesis of Graphene Oxide (GO) by Modified Hummers Method and Its Thermal Reduction to Obtain Reduced Graphene Oxide (rGO)*. Graphene 2017, 6, 1-18. [CrossRef]

121. Geim, A.K. Graphene: Status and prospects. Science 2009, 324, 1530-1534. [CrossRef] [PubMed]

122. Geim, A.K.; Novoselov, K.S. The rise of graphene. Nat. Mater. 2007, 6, 183-191. [CrossRef] [PubMed]

123. Pumera, M. Graphene-based nanomaterials and their electrochemistry. Chem. Soc. Rev. 2010, 39, 4146-4157. [CrossRef]

124. Tan, Y.B.; Lee, J.M. Graphene for supercapacitor applications. J. Mater. Chem. A 2013, 1, 14814-14843. [CrossRef]

125. Liu, C.; Yu, Z.; Neff, D.; Zhamu, A.; Jang, B.Z. Graphene-Based Supercapacitor with an Ultrahigh Energy Density. Nano Lett. 2010, 10, 4863-4868. [CrossRef] [PubMed]

126. Carbon Nanotube Fibres and Yarns: Production, Properties and Applications in Google Books. Available online: https://books.google.ie/books?id=uI6vDwAAQBAJ\&pg=PA268\&lpg=PA268\&dq=H.+M.+Cheng, +IEEE,+(2010)+49\&source=bl\&ots=u8jvoQ_eMN\&sig=ACfU3U2SIRQFIU2dHpKz1sdHXKK0VnyyMg\& $\mathrm{hl}=\mathrm{en} \& \mathrm{sa}=$ X\&ved=2ahUKEwjv5suTz-zmAhU-XRUIHX_jAz0Q6AEwAXoECAkQAQ\#v=onepage\&q=H. M.Cheng\%2CIEEE (accessed on 24 June 2020).

127. Wang, H.; Hao, Q.; Yang, X.; Lu, L.; Wang, X. A nanostructured graphene/polyaniline hybrid material for supercapacitors. Nanoscale 2010, 2, 2164-2170. [CrossRef]

128. Karthika, P.; Rajalakshmi, N.; Dhathathreyan, K.S. Functionalized Exfoliated Graphene Oxide as Supercapacitor Electrodes. Soft Nanosci. Lett. 2012, 2, 59-66. [CrossRef]

129. Kim, T.; Jung, G.; Yoo, S.; Suh, K.S.; Ruoff, R.S. Activated Graphene-Based Carbons as Supercapacitor Electrodes with Macro- and Mesopores. ACS Nano 2013, 7, 6899-6905. [CrossRef]

130. Sinniah, G.K.; Shah, M.Z.; Siong, H.C. The needs for changes in travel behaviour towards a Low Carbon Society. In Proceedings of the 26th International Business Information Management Association Conference-Innovation Management and Sustainable Economic Competitive Advantage: From Regional Development to Global Growth, IBIMA 2015, Madrid, Spain, 11-12 November 2015; pp. 3868-3876.

131. Kuilla, T.; Bhadra, S.; Yao, D.; Kim, N.H.; Bose, S.; Lee, J.H. Recent advances in graphene based polymer composites. Prog. Polym. Sci. 2010, 35, 1350-1375. [CrossRef]

132. Wang, Y.; Shi, Z.; Huang, Y.; Ma, Y.; Wang, C.; Chen, M.; Chen, Y. Supercapacitor devices based on graphene materials. J. Phys. Chem. C 2009, 113, 13103-13107. [CrossRef]

133. Zhang, L.L.; Zhao, X.; Stoller, M.D.; Zhu, Y.; Ji, H.; Murali, S.; Wu, Y.; Perales, S.; Clevenger, B.; Ruoff, R.S. Highly conductive and porous activated reduced graphene oxide films for high-power supercapacitors. Nano Lett. 2012, 12, 1806-1812. [CrossRef]

134. Paek, E.; Pak, A.J.; Kweon, K.E.; Hwang, G.S. On the origin of the enhanced supercapacitor performance of nitrogen-doped graphene. J. Phys. Chem. C 2013, 117, 5610-5616. [CrossRef]

135. Palaniselvam, T.; Kashyap, V.; Bhange, S.N.; Baek, J.B.; Kurungot, S. Nanoporous Graphene Enriched with $\mathrm{Fe} / \mathrm{Co}-\mathrm{N}$ Active Sites as a Promising Oxygen Reduction Electrocatalyst for Anion Exchange Membrane Fuel Cells. Adv. Funct. Mater. 2016, 26, 2150-2162. [CrossRef]

136. Singh, S.K.; Dhavale, V.M.; Boukherroub, R.; Kurungot, S.; Szunerits, S. N-doped porous reduced graphene oxide as an efficient electrode material for high performance flexible solid-state supercapacitor. Appl. Mater. Today 2017, 8, 141-149. [CrossRef]

137. Li, N.; Tang, S.; Dai, Y.; Meng, X. The synthesis of graphene oxide nanostructures for supercapacitors: A simple route. J. Mater. Sci. 2014, 49, 2802-2809. [CrossRef] 
138. Ogata, C.; Kurogi, R.; Hatakeyama, K.; Taniguchi, T.; Koinuma, M.; Matsumoto, Y. All-graphene oxide device with tunable supercapacitor and battery behaviour by the working voltage. Chem. Commun. 2016, 52, 3919-3922. [CrossRef] [PubMed]

139. Zhang, H.; Wang, K.; Zhang, X.; Lin, H.; Sun, X.; Li, C.; Ma, Y. Self-generating graphene and porous nanocarbon composites for capacitive energy storage. J. Mater. Chem. A 2015, 3, 11277-11286. [CrossRef]

140. Karnan, M.; Subramani, K.; Sathish, M. Template Assisted Synthesis of Nitrogen doped 3D-Graphene for Supercapacitor Applications. Mater. Today Proc. 2017, 4, 12144-12151. [CrossRef]

141. Wang, G.; Sun, X.; Lu, F.; Sun, H.; Yu, M.; Jiang, W.; Liu, C.; Lian, J. Flexible Pillared Graphene-Paper Electrodes for High-Performance Electrochemical Supercapacitors. Small 2012, 8, 452-459. [CrossRef]

142. Shabangoli, Y.; Rahmanifar, M.S.; Noori, A.; El-Kady, M.F.; Kaner, R.B.; Mousavi, M.F. Nile Blue Functionalized Graphene Aerogel as a Pseudocapacitive Negative Electrode Material across the Full pH Range. ACS Nano 2019, 13, 12567-12576. [CrossRef] [PubMed]

143. Casiraghi, C.; Hartschuh, A.; Lidorikis, E.; Qian, H.; Harutyunyan, H.; Gokus, T.; Novoselov, K.S.; Ferrari, A.C. Rayleigh imaging of graphene and graphene layers. Nano Lett. 2007, 7, 2711-2717. [CrossRef] [PubMed]

144. Xu, L.; Cheng, C.; Yao, C.; Jin, X. Flexible supercapacitor electrode based on lignosulfonate-derived graphene quantum dots/graphene hydrogel. Org. Electron. 2020, 78, 105407. [CrossRef]

145. Nguyen, T.; Montemor, M.F. Redox active materials for metal compound based hybrid electrochemical energy storage: A perspective view. Appl. Surf. Sci. 2017, 422, 492-497. [CrossRef]

146. Conway, B.E. Transition from Supercapacitor to Battery Behavior in Electrochemical Energy Storage. J. Electrochem. Soc. 1991, 138, 1539-1548. [CrossRef]

147. Zhang, Y.; Ma, Q.; Feng, K.; Guo, J.; Wei, X.; Shao, Y.; Zhuang, J.; Lin, T. Effects of microstructure and electrochemical properties of $\mathrm{Ti} / \mathrm{IrO}_{2}-\mathrm{SnO}_{2}-\mathrm{Ta}_{2} \mathrm{O}_{5}$ as anodes on binder-free asymmetric supercapacitors with $\mathrm{Ti} / \mathrm{RuO}_{2}-\mathrm{NiO}$ as cathodes. Ceram. Int. 2020, 46, 17640-17650. [CrossRef]

148. Guo, W.; Sun, W.; Wang, Y. Multilayer CuO@NiO Hollow Spheres: Microwave-Assisted Metal-Organic-Framework Derivation and Highly Reversible Structure-Matched Stepwise Lithium Storage. ACS Nano 2015, 9, 11462-11471. [CrossRef]

149. Hu, L.; Huang, Y.; Zhang, F.; Chen, Q. $\mathrm{CuO} / \mathrm{Cu}_{2} \mathrm{O}$ composite hollow polyhedrons fabricated from metal-organic framework templates for lithium-ion battery anodes with a long cycling life. Nanoscale 2013, 5, 4186-4190. [CrossRef]

150. Mondal, I.; Pal, U. Synthesis of MOF templated $\mathrm{Cu} / \mathrm{CuO} @ \mathrm{TiO}_{2}$ nanocomposites for synergistic hydrogen production. Phys. Chem. Chem. Phys. 2016, 18, 4780-4788. [CrossRef]

151. Dekrafft, K.E.; Wang, C.; Lin, W. Metal-organic framework templated synthesis of $\mathrm{Fe}_{2} \mathrm{O}_{3} / \mathrm{TiO}_{2}$ nanocomposite for hydrogen production. Adv. Mater. 2012, 24, 2014-2018. [CrossRef]

152. Huang, G.; Zhang, L.; Zhang, F.; Wang, L. Metal-organic framework derived $\mathrm{Fe}_{2} \mathrm{O}_{3} @ \mathrm{NiCo}_{2} \mathrm{O}_{4}$ porous nanocages as anode materials for Li-ion batteries. Nanoscale 2014, 6, 5509-5515. [CrossRef] [PubMed]

153. Kaneti, Y.V.; Zakaria, Q.M.D.; Zhang, Z.; Chen, C.; Yue, J.; Liu, M.; Jiang, X.; Yu, A. Solvothermal synthesis of $\mathrm{ZnO}$-decorated $\alpha-\mathrm{Fe}_{2} \mathrm{O}_{3}$ nanorods with highly enhanced gas-sensing performance toward n-butanol. J. Mater. Chem. A 2014, 2, 13283-13292. [CrossRef]

154. Zhou, X.; Li, X.; Sun, H.; Sun, P.; Liang, X.; Liu, F.; Hu, X.; Lu, G. Nanosheet-Assembled $\mathrm{ZnFe}_{2} \mathrm{O}_{4} \mathrm{Hollow}$ Microspheres for High-Sensitive Acetone Sensor. ACS Appl. Mater. Interfaces 2015, 7, 15414-15421. [CrossRef] [PubMed]

155. Hu, H.; Guan, B.; Xia, B.; Lou, X.W. Designed formation of $\mathrm{Co}_{3} \mathrm{O}_{4} / \mathrm{NiCo}_{2} \mathrm{O}_{4}$ double-shelled nanocages with enhanced pseudocapacitive and electrocatalytic properties. J. Am. Chem. Soc. 2015, 137, 5590-5595. [CrossRef] [PubMed]

156. Yang, X.; Xue, H.; Yang, Q.; Yuan, R.; Kang, W.; Lee, C.S. Preparation of porous $\mathrm{ZnO} / \mathrm{ZnFe}_{2} \mathrm{O}_{4}$ composite from metal organic frameworks and its applications for lithium ion batteries. Chem. Eng. J. 2017, 308, 340-346. [CrossRef]

157. Hou, L.; Lian, L.; Zhang, L.; Pang, G.; Yuan, C.; Zhang, X. Self-sacrifice template fabrication of hierarchical mesoporous bi-component-active $\mathrm{ZnO} / \mathrm{ZnFe}_{2} \mathrm{O}_{4}$ sub-microcubes as superior anode towards high-performance lithium-ion battery. Adv. Funct. Mater. 2015, 25, 238-246. [CrossRef]

158. Cao, H.; Zhu, S.; Yang, C.; Bao, R.; Tong, L.; Hou, L.; Zhang, X.; Yuan, C. Metal-organic-framework-derived two-dimensional ultrathin mesoporous hetero- $\mathrm{ZnFe} 2 \mathrm{O}_{4} / \mathrm{ZnO}$ nanosheets with enhanced lithium storage properties for Li-ion batteries. Nanotechnology 2016, 27, 465402. [CrossRef] 
159. Zhang, W.; Liu, Y.; Lu, G.; Wang, Y.; Li, S.; Cui, C.; Wu, J.; Xu, Z.; Tian, D.; Huang, W.; et al. Mesoporous metal-organic frameworks with size-, shape-, and space-distribution-controlled pore structure. Adv. Mater. 2015, 27, 2923-2929. [CrossRef]

160. Huang, G.; Zhang, F.; Zhang, L.; Du, X.; Wang, J.; Wang, L. Hierarchical $\mathrm{NiFe}_{2} \mathrm{O}_{4} / \mathrm{Fe}_{2} \mathrm{O}_{3}$ nanotubes derived from metal organic frameworks for superior lithium ion battery anodes. J. Mater. Chem. A 2014, 2, 8048-8053. [CrossRef]

161. Li, G.C.; Zhu, S.-R.; Wu, M.-K.; Liu, P.-F.; Tao, K.; Yi, F.-Y.; Han, L. MOF-derived hierarchical double-shelled $\mathrm{NiO} / \mathrm{ZnO}$ hollow spheres for high-performance supercapacitors. Dalton Trans. 2016, 45, 13311-13316. [CrossRef]

162. Xu, X.; Cao, K.; Wang, Y.; Jiao, L. 3D hierarchical porous $\mathrm{ZnO} / \mathrm{ZnCo}_{2} \mathrm{O}_{4}$ nanosheets as high-rate anode material for lithium-ion batteries. J. Mater. Chem. A 2016, 4, 6042-6047. [CrossRef]

163. Salunkhe, R.R.; Kaneti, Y.V.; Yamauchi, Y. Metal-Organic Framework-Derived Nanoporous Metal Oxides toward Supercapacitor Applications: Progress and Prospects. ACS Nano 2017, 11, 5293-5308. [CrossRef]

164. Li, T.T.; Qian, J.; Zheng, Y.Q. Facile synthesis of porous $\mathrm{CuO}$ polyhedron from Cu-based metal organic framework (MOF-199) for electrocatalytic water oxidation. RSC Adv. 2016, 6, 77358-77365. [CrossRef]

165. Hu, L.; Yan, N.; Chen, Q.W.; Zhang, P.; Zhong, H.; Zheng, X.; Li, Y.; Hu, X. Fabrication Based on the Kirkendall Effect of $\mathrm{Co}_{3} \mathrm{O}_{4}$ Porous Nanocages with Extraordinarily High Capacity for Lithium Storage. Chem. A Eur. J. 2012, 18, 8971-8977. [CrossRef]

166. Salunkhe, R.R.; Tang, J.; Kamachi, Y.; Nakato, T.; Kim, J.H.; Yamauchi, Y. Asymmetric Supercapacitors Using 3D Nanoporous Carbon and Cobalt Oxide Electrodes Synthesized from a Single Metal-Organic Framework. ACS Nano 2015, 9, 6288-6296. [CrossRef] [PubMed]

167. Wu, R.; Qian, X.; Ruia, X.; Liu, H.; Yadian, B.; Zhou, K.; Wei, J.; Yan, Q.; Feng, X.-Q.; Long, Y.; et al. Zeolitic imidazolate framework 67-derived high symmetric porous $\mathrm{Co}_{3} \mathrm{O}_{4}$ hollow dodecahedra with highly enhanced lithium storage capability. Small 2014, 10, 1932-1938. [CrossRef]

168. Wang, Y.; Wang, B.-F.; Xiao, F.; Huang, Z.-G.; Wang, Y.; Richardson, C.; Chen, Z.; Jiao, L.; Yuan, H. Facile synthesis of nanocage $\mathrm{Co}_{3} \mathrm{O}_{4}$ for advanced lithium-ion batteries. J. Power Sources 2015, 298, 203-208. [CrossRef]

169. Liu, H.; Xia, G.; Zhang, R.; Jiang, P.; Chen, J.; Chen, Q. MOF-derived $\mathrm{RuO}_{2} / \mathrm{Co}_{3} \mathrm{O}_{4}$ heterojunctions as highly efficient bifunctional electrocatalysts for HER and OER in alkaline solutions. RSC Adv. 2017, 7, 3686-3694. [CrossRef]

170. Han, Y.; Zhao, M.; Dong, L.; Feng, J.; Wang, Y.; Li, D.-J.; Li, X.-F. MOF-derived porous hollow $\mathrm{Co}_{3} \mathrm{O}_{4}$ parallelepipeds for building high-performance Li-ion batteries. J. Mater. Chem. A 2015, 3, 22542-22546. [CrossRef]

171. Tian, D.; Zhou, X.L.; Zhang, Y.H.; Zhou, Z.; Bu, X.H. MOF-Derived Porous $\mathrm{Co}_{3} \mathrm{O}_{4}$ Hollow Tetrahedra with Excellent Performance as Anode Materials for Lithium-Ion Batteries. Inorg. Chem. 2015, 54, 8159-8161. [CrossRef] [PubMed]

172. Li, C.; Chen, T.; Xu, W.; Lou, X.; Pan, L.; Chen, Q.; Hu, B. Mesoporous nanostructured $\mathrm{Co}_{3} \mathrm{O}_{4}$ derived from MOF template: A high-performance anode material for lithium-ion batteries. J. Mater. Chem. A 2015, 3, 5585-5591. [CrossRef]

173. Soundharrajan, V.; Sambandam, B.; Song, J.; Kim, S.; Jo, J.; Kim, S.; Lee, S.; Mathew, V.; Kim, J. $\mathrm{Co}_{3} \mathrm{~V}_{2} \mathrm{O}_{8}$ Sponge Network Morphology Derived from Metal-Organic Framework as an Excellent Lithium Storage Anode Material. ACS Appl. Mater. Interfaces 2016, 8, 8546-8553. [CrossRef] [PubMed]

174. Zeng, G.; Chen, Y.; Chen, L.; Xiong, P.; Wei, M. Hierarchical cerium oxide derived from metal-organic frameworks for high performance supercapacitor electrodes. Electrochim. Acta 2016, 222, 773-780. [CrossRef]

175. Zhang, L.; Wu, H.B.; Madhavi, S.; Hng, H.H.; Lou, X.W. Formation of $\mathrm{Fe}_{2} \mathrm{O}_{3}$ microboxes with hierarchical shell structures from metal-organic frameworks and their lithium storage properties. J. Am. Chem. Soc. 2012, 134, 17388-17391. [CrossRef]

176. Zhang, F.; Wei, Y.; Wu, X.; Jiang, H.; Wang, W.; Li, H. Hollow zeolitic imidazolate framework nanospheres as highly efficient cooperative catalysts for [3+3] cycloaddition reactions. J. Am. Chem. Soc. 2014, 136, 13963-13966. [CrossRef]

177. $\mathrm{Xu}, \mathrm{X}$.; Cao, R.; Jeong, S.; Cho, J. Spindle-like mesoporous $\alpha-\mathrm{Fe}_{2} \mathrm{O}_{3}$ anode material prepared from MOF template for high-rate lithium batteries. Nano Lett. 2012, 12, 4988-4991. [CrossRef] 
178. Kim, T.K.; Lee, K.J.; Cheon, J.Y.; Lee, J.H.; Joo, S.H.; Moon, H.R. Nanoporous metal oxides with tunable and nanocrystalline frameworks via conversion of metal-organic frameworks. J. Am. Chem. Soc. 2013, 135, 8940-8946. [CrossRef]

179. Zheng, F.; Xu, S.; Yin, Z.; Zhang, Y.; Lu, L. Facile synthesis of MOF-derived $\mathrm{Mn}_{2} \mathrm{O}_{3}$ hollow microspheres as anode materials for lithium-ion batteries. RSC Adv. 2016, 6, 93532-93538. [CrossRef]

180. Maiti, S.; Pramanik, A.; Mahanty, S. Electrochemical energy storage in $\mathrm{Mn}_{2} \mathrm{O}_{3}$ porous nanobars derived from morphology-conserved transformation of benzenetricarboxylate-bridged metal-organic framework. CrystEngComm 2016, 18, 450-461. [CrossRef]

181. Zhang, B.; Hao, S.; Xiao, D.; Wu, J.; Huang, Y. Templated formation of porous $\mathrm{Mn}_{2} \mathrm{O}_{3}$ octahedra from Mn-MIL-100 for lithium-ion battery anode materials. Mater. Des. 2016, 98, 319-323. [CrossRef]

182. Kong, S.; Dai, R.; Li, H.; Sun, W.; Wang, Y. Microwave Hydrothermal Synthesis of Ni-based Metal-Organic Frameworks and Their Derived Yolk-Shell NiO for Li-Ion Storage and Supported Ammonia Borane for Hydrogen Desorption. ACS Sustain. Chem. Eng. 2015, 3, 1830-1838. [CrossRef]

183. Gou, L.; Ma, L.; Zhao, M.-J.; Liu, P.-G.; Wang, X.-D.; Fan, X.-Y.; Li, D.-L. Co-based metal-organic framework and its derivatives as high-performance anode materials for lithium-ion batteries. J. Mater. Sci. 2019, 54, 1529-1538. [CrossRef]

184. Han, Y.; Zhang, S.; Shen, N.; Li, D.; Li, X. MOF-derived porous NiO nanoparticle architecture for high performance supercapacitors. Mater. Lett. 2017, 188,1-4. [CrossRef]

185. Xiu, Z.; Alfaruqi, M.H.; Gim, J.; Song, J.; Kim, S.; Thi, T.V.; Duong, P.T.; Baboo, J.P.; Mathew, V.; Kim, J. Hierarchical porous anatase $\mathrm{TiO}_{2}$ derived from a titanium metal-organic framework as a superior anode material for lithium ion batteries. Chem. Commun. 2015, 51, 12274-12277. [CrossRef]

186. Zheng, Y.; Zheng, S.; Xue, H.; Pang, H. Metal-organic frameworks for lithium-sulfur batteries. J. Mater. Chem. A 2019, 7, 3469-3491. [CrossRef]

187. Zhang, X.; Wang, M.; Zhu, G.; Li, D.; Yan, D.; Lu, T.; Pan, L. Porous cake-like $\mathrm{TiO}_{2}$ derived from metal-organic frameworks as superior anode material for sodium ion batteries. Ceram. Int. 2017, 43, 2398-2402. [CrossRef]

188. Kimitsuka, Y.; Hosono, E.; Ueno, S.; Zhou, H.; Fujihara, S. Fabrication of porous cubic architecture of ZnO using Zn-terephthalate MOFs with characteristic microstructures. Inorg. Chem. 2013, 52, 14028-14033. [CrossRef]

189. Wang, T.; Shi, L.; Tang, J.; Malgras, V.; Asahina, S.; Liu, G.; Zhang, H.; Meng, X.; Chang, K.; He, J.; et al. $\mathrm{A} \mathrm{Co}_{3} \mathrm{O}_{4}$-embedded porous $\mathrm{ZnO}$ rhombic dodecahedron prepared using zeolitic imidazolate frameworks as precursors for $\mathrm{CO}_{2}$ photoreduction. Nanoscale 2016, 8, 6712-6720. [CrossRef]

190. Feng, Y.; Lu, H.; Gu, X.; Qiu, J.; Jia, M.; Huang, C.; Yao, J. ZIF-8 derived porous N-doped ZnO with enhanced visible light-driven photocatalytic activity. J. Phys. Chem. Solids 2017, 102, 110-114. [CrossRef]

191. Guo, H.; Li, T.; Chen, W.; Liu, L.; Yang, X.-J.; Wang, Y.; Guo, Y. General design of hollow porous $\mathrm{CoFe}_{2} \mathrm{O}_{4}$ nanocubes from metal-organic frameworks with extraordinary lithium storage. Nanoscale 2014, 6, 15168-15174. [CrossRef]

192. Liu, F.; Zhuang, Y.; Guo, M.; Chen, Y.; Tu, J.; Ding, L. 3D Copper Foam-Supported $\mathrm{CuCo}_{2} \mathrm{O}_{4}$ Nanosheet Arrays as Electrode for Enhanced Non-Enzymatic Glucose Sensing. Sensors 2018, 18, 1131. [CrossRef]

193. Zheng, F.; Zhu, D.; Shi, X.; Chen, Q. Metal-organic framework-derived porous $\mathrm{Mn}_{1.8} \mathrm{Fe}_{1.2} \mathrm{O}_{4}$ nanocubes with an interconnected channel structure as high-performance anodes for lithium ion batteries. J. Mater. Chem. A 2015, 3, 2815-2824. [CrossRef]

194. Du, M.; He, D.; Lou, Y.; Chen, J. Porous nanostructured $\mathrm{ZnCo}_{2} \mathrm{O}_{4}$ derived from MOF-74: High-performance anode materials for lithium ion batteries. J. Energy Chem. 2017, 26, 673-680. [CrossRef]

195. Liang, K.; Cheang, T.; Wen, T.; Xie, X.; Zhou, X.; Zhao, Z.; Shen, C.; Jiang, N.; Wangc, Y. Facile Preparation of Porous $\mathrm{Mn}_{2} \mathrm{SnO}_{4} / \mathrm{Sn} / \mathrm{C}$ Composite Cubes as High Performance Anode Material for Lithium-Ion Batteries. J. Phys. Chem. C 2016, 120, 3669-3676. [CrossRef]

196. Zhao, J.; Wang, F.; Su, P.; Li, M.; Chen, J.; Yang, Q.; Li, C. Spinel $\mathrm{ZnMn}_{2} \mathrm{O}_{4}$ nanoplate assemblies fabricated via 'escape-by-crafty-scheme' strategy. J. Mater. Chem. 2012, 22, 13328-13333. [CrossRef]

197. Chen, Y.; Pang, W.K.; Bai, H.; Zhou, T.; Liu, Y.; Li, S.; Guo, Z. Enhanced Structural Stability of Nickel-Cobalt Hydroxide via Intrinsic Pillar Effect of Metaborate for High-Power and Long-Life Supercapacitor Electrodes. Nano Lett. 2017, 17, 429-436. [CrossRef] 
198. Liang, J.; Renzhi, M.; Iyi, N.; Ebina, Y.; Takada, K.; Sasaki, T. Topochemical synthesis, anion exchange, and exfoliation of Co-Ni layered double hydroxides: A route to positively charged Co-Ni hydroxide nanosheets with tunable composition. Chem. Mater. 2010, 22, 371-378. [CrossRef]

199. Liu, H.; Liu, X.; Wang, S.; Liu, H.K.; Li, L. Transition metal based battery-type electrodes in hybrid supercapacitors: A review. Energy Storage Mater. 2020, 28, 122-145. [CrossRef]

200. Feng, D.Y.; Sun, Z.; Huang, Z.H.; Cai, X.; Song, Y.; Liu, X.X. Highly loaded manganese oxide with high rate capability for capacitive applications. J. Power Sources 2018, 396, 238-245. [CrossRef]

201. Lokhande, V.C.; Lokhande, A.C.; Lokhande, C.D.; Kim, J.H.; Ji, T. Supercapacitive composite metal oxide electrodes formed with carbon, metal oxides and conducting polymers. J. Alloys Compd. 2016, 682, 381-403. [CrossRef]

202. Zhao, C.; Zheng, W. A Review for Aqueous Electrochemical Supercapacitors. Front. Energy Res. $2015,3$. [CrossRef]

203. Krishnan, D.; Raidongia, K.; Shao, J.; Huang, J. Graphene Oxide Assisted Hydrothermal Carbonization of Carbon Hydrates. ACS Nano 2014, 8, 449-457. [CrossRef] [PubMed]

204. Hwang, J.Y.; El-Kady, M.F.; Wang, Y.; Wang, L.; Shao, Y.; Marsh, K.; Ko, J.M.; Kaner, R.B. Direct preparation and processing of graphene/ $\mathrm{RuO}_{2}$ nanocomposite electrodes for high-performance capacitive energy storage. Nano Energy 2015, 18, 57-70. [CrossRef]

205. Zhao, D.; Guo, X.; Gao, Y.; Gao, F. An Electrochemical Capacitor Electrode Based on Porous Carbon Spheres Hybrided with Polyaniline and Nanoscale Ruthenium Oxide. ACS Appl. Mater. Interfaces 2012, 4, 5583-5589. [CrossRef] [PubMed]

206. Wang, H.; Zhang, D.; Yan, T.; Wen, X.; Shi, L.; Zhang, J. Graphene prepared via a novel pyridine-thermal strategy for capacitive deionization. J. Mater. Chem. 2012, 22, 23745-23748. [CrossRef]

207. Long, J.W.; Swider, K.E.; Merzbacher, C.I.; Rolison, D.R. Voltammetric Characterization of Ruthenium Oxide-Based Aerogels and Other $\mathrm{RuO}_{2}$ Solids: The Nature of Capacitance in Nanostructured Materials. Langmuir 1999, 15, 780-784. [CrossRef]

208. Ma, H.; Kong, D.; Xu, Y.; Xie, X.; Tao, Y.; Xiao, Z.; Lv, W.; Jang, H.D.; Huang, J.; Yang, Q.-H. Disassembly-Reassembly Approach to $\mathrm{RuO}_{2} /$ Graphene Composites for Ultrahigh Volumetric Capacitance Supercapacitor. Small 2017, 13, 1701026. [CrossRef]

209. Gujar, T.P.; Kim, W.Y.; Puspitasari, I.; Jung, K.D.; Joo, O.S. Electrochemically deposited nanograin ruthenium oxide as a pseudocapacitive electrode. Int. J. Electrochem. Sci. 2007, 2, 666-673.

210. Kim, H.; Popov, B.N. Characterization of hydrous ruthenium oxide/carbon nanocomposite supercapacitors prepared by a colloidal method. J. Power Sources 2002, 104, 52-61. [CrossRef]

211. Kate, R.S.; Khalate, S.A.; Deokate, R.J. Overview of nanostructured metal oxides and pure nickel oxide (NiO) electrodes for supercapacitors: A review. J. Alloys Compd. 2018, 734, 89-111. [CrossRef]

212. Kong, S.; Cheng, K.; Ouyang, T.; Gao, Y.; Ye, K.; Wang, G.; Cao, D. Facile electrodepositing processed of $\mathrm{RuO}_{2}$-graphene nanosheets-CNT composites as a binder-free electrode for electrochemical supercapacitors. Electrochim. Acta 2017, 246, 433-442. [CrossRef]

213. Wang, J.-C.; Yao, H.-C.; Fan, Z.-Y.; Zhang, L.; Wang, J.-S.; Zang, S.-Q.; Li, Z. Indirect Z-Scheme BiOI/g-C $3 \mathrm{~N}_{4}$ Photocatalysts with Enhanced Photoreduction $\mathrm{CO}_{2}$ Activity under Visible Light Irradiation. ACS Appl. Mater. Interfaces 2016, 8, 3765-3775. [CrossRef] [PubMed]

214. Acznik, I.; Lota, K.; Sierczynska, A.; Lota, G. Carbon-supported manganese dioxide as electrode material for asymmetric electrochemical capacitors. Int. J. Electrochem. Sci. 2014, 9, 2518-2534.

215. Chen, S.; Zhu, J.; Wu, X.; Han, Q.; Wang, X. Graphene oxide-Mno 2 nanocomposites for supercapacitors. ACS Nano 2010, 4, 2822-2830. [CrossRef]

216. Zhang, H.; Wang, Z.; Liu, D. A comprehensive review of stability analysis of continuous-time recurrent neural networks. IEEE Trans. Neural Netw. Learn. Syst. 2014, 25, 1229-1262. [CrossRef]

217. Toupin, M.; Brousse, T.; Bélanger, D. Charge storage mechanism of $\mathrm{MnO}_{2}$ electrode used in aqueous electrochemical capacitor. Chem. Mater. 2004, 16, 3184-3190. [CrossRef]

218. Wang, J.G.; Kang, F.; Wei, B. Engineering of $\mathrm{MnO}_{2}$-based nanocomposites for high-performance supercapacitors. Prog. Mater. Sci. 2015, 74, 51-124. [CrossRef]

219. Zhu, J.; Shi, W.; Xiao, N.; Ruia, X.; Tan, H.; Lu, X.; Hng, H.H.; Ma, J.; Yan, Q. Oxidation-Etching Preparation of $\mathrm{MnO}_{2}$ Tubular Nanostructures for High-Performance Supercapacitors. ACS Appl. Mater. Interfaces 2012, 4, 2769-2774. [CrossRef] 
220. Gupta, V.; Kusahara, T.; Toyama, H.; Gupta, S.; Miura, N. Potentiostatically deposited nanostructured $\alpha-\mathrm{Co}(\mathrm{OH})_{2}$ : A high performance electrode material for redox-capacitors. Electrochem. Commun. 2007, 9, 2315-2319. [CrossRef]

221. Subramanian, V.; Zhu, H.; Vajtai, R.; Ajayan, P.M.; Wei, B. Hydrothermal synthesis and pseudocapacitance properties of $\mathrm{MnO}_{2}$ nanostructures. J. Phys. Chem. B 2005, 109, 20207-20214. [CrossRef]

222. Devaraj, S.; Munichandraiah, N. Effect of Crystallographic Structure of $\mathrm{MnO}_{2}$ on Its Electrochemical Capacitance Properties. J. Phys. Chem. C 2008, 112, 4406-4417. [CrossRef]

223. Ghodbane, O.; Pascal, J.-L.; Favier, F. Microstructural Effects on Charge-Storage Properties in $\mathrm{MnO}_{2}-\mathrm{Based}$ Electrochemical Supercapacitors. ACS Appl. Mater. Interfaces 2009, 1, 1130-1139. [CrossRef] [PubMed]

224. Sun, C.; Zhang, Y.; Song, S.; Xue, D. Tunnel-dependent supercapacitance of $\mathrm{MnO}_{2}$ : Effects of crystal structure. J. Appl. Crystallogr. 2013, 46, 1128-1135. [CrossRef]

225. Chang, J.K.; Huang, C.H.; Lee, M.T.; Tsai, W.T.; Deng, M.J.; Sun, I.W. Physicochemical factors that affect the pseudocapacitance and cyclic stability of Mn oxide electrodes. Electrochim. Acta 2009, 54, 3278-3284. [CrossRef]

226. Ghodbane, O.; Pascal, J.-L.; Fraisse, B.; Favier, F. Structural in Situ Study of the Thermal Behavior of Manganese Dioxide Materials: Toward Selected Electrode Materials for Supercapacitors. ACS Appl. Mater. Interfaces 2010, 2, 3493-3505. [CrossRef] [PubMed]

227. Wei, J.; Nagarajan, N.; Zhitomirsky, I. Manganese oxide films for electrochemical supercapacitors. J. Mater. Process. Technol. 2007, 186, 356-361. [CrossRef]

228. Dong, J.; Lu, G.; Wu, F.; Xu, C.; Kang, X.; Cheng, Z. Facile synthesis of a nitrogen-doped graphene flower-like $\mathrm{MnO}_{2}$ nanocomposite and its application in supercapacitors. Appl. Surf. Sci. 2018, 427, 986-993. [CrossRef]

229. Zhao, D.D.; Xu, M.W.; Zhou, W.J.; Zhang, J.; Li, H.L. Preparation of ordered mesoporous nickel oxide film electrodes via lyotropic liquid crystal templated electrodeposition route. Electrochim. Acta 2008, 53, 2699-2705. [CrossRef]

230. Wang, Y.G.; Xia, Y.Y. Electrochemical capacitance characterization of $\mathrm{NiO}$ with ordered mesoporous structure synthesized by template SBA-15. Electrochim. Acta 2006, 51, 3223-3227. [CrossRef]

231. Sun, C. (Ed.) Advanced Battery Materials; Wiley: Hoboken, NJ, USA, 2019.

232. Xiong, S.; Yuan, C.; Zhang, X.; Xi, B.; Qian, Y. Controllable Synthesis of Mesoporous $\mathrm{Co}_{3} \mathrm{O}_{4}$ Nanostructures with Tunable Morphology for Application in Supercapacitors. Chem. A Eur. J. 2009, 15, 5320-5326. [CrossRef]

233. Bae, J.; Song, M.K.; Park, Y.J.; Kim, J.M.; Liu, M.; Wang, Z.L. Fiber supercapacitors made of nanowire-fiber hybrid structures for wearable/flexible energy storage. Angew. Chem. Int. Ed. 2011, 50, 1683-1687. [CrossRef] [PubMed]

234. Pang, H.; Ma, Y.; Li, G.; Chen, J.; Zhang, J.; Zheng, H.; Du, W. Facile synthesis of porous ZnO-NiO composite micropolyhedrons and their application for high power supercapacitor electrode materials. Dalton Trans. 2012, 41, 13284-13291. [CrossRef] [PubMed]

235. Ghosh, D.; Giri, S.; Mandal, M.; Das, C.K. High performance supercapacitor electrode material based on vertically aligned PANI grown on reduced graphene oxide/ $\mathrm{Ni}(\mathrm{OH})_{2}$ hybrid composite. RSC Adv. 2014, 4, 26094-26101. [CrossRef]

236. Ci, S.; Wen, Z.; Qian, Y.; Mao, S.; Cui, S.; Chen, J. NiO-Microflower Formed by Nanowire-weaving Nanosheets with Interconnected Ni-network Decoration as Supercapacitor Electrode. Sci. Rep. 2015, 5, 11919. [CrossRef] [PubMed]

237. Li, B.; Zheng, M.; Xue, H.; Pang, H. High performance electrochemical capacitor materials focusing on nickel based materials. Inorg. Chem. Front. 2016, 3, 175-202. [CrossRef]

238. Goel, S.; Tomar, A.K.; Sharma, R.K.; Singh, G. Highly Pseudocapacitive NiO Nanoflakes through Surfactant-Free Facile Microwave-Assisted Route. ACS Appl. Energy Mater. 2018, 1, 1540-1548. [CrossRef]

239. Aghazadeh, M.; Rashidi, A.; Ganjali, M.R.; Maragheh, M.G. Nickel oxide nano-rods/plates as a high performance electrode materials for supercapacitors; electrosynthesis and evolution of charge storage ability. Int. J. Electrochem. Sci. 2016, 11, 11002-11015. [CrossRef]

240. Pang, H.; Lu, Q.; Li, Y.; Gao, F. Facile synthesis of nickel oxide nanotubes and their antibacterial, electrochemical and magnetic properties. Chem. Commun. 2009, 7542-7544. [CrossRef]

241. Kim, S.I.; Lee, J.S.; Ahn, H.J.; Song, H.K.; Jang, J.H. Facile route to an efficient nio supercapacitor with a three-dimensional nanonetwork morphology. ACS Appl. Mater. Interfaces 2013, 5, 1596-1603. [CrossRef] 
242. Cheng, S.; Yang, L.; Liu, Y.; Lin, W.; Huang, L.; Chen, D.; Wong, C.P.; Liu, M. Carbon fiber paper supported hybrid nanonet/nanoflower nickel oxide electrodes for high-performance pseudo-capacitors. J. Mater. Chem. A 2013, 1, 7709-7716. [CrossRef]

243. Soin, N.; Roy, S.S.; Mitra, S.K.; Thundat, T.; McLaughlin, J.A. Nanocrystalline ruthenium oxide dispersed Few Layered Graphene (FLG) nanoflakes as supercapacitor electrodes. J. Mater. Chem. 2012, 22, 14944-14950. [CrossRef]

244. Lu, Z.; Chang, Z.; Liu, J.; Sun, X. Stable ultrahigh specific capacitance of NiO nanorod arrays. Nano Res. 2011, 4, 658-665. [CrossRef]

245. Kundu, M.; Liu, L. Binder-free electrodes consisting of porous NiO nanofibers directly electrospun on nickel foam for high-rate supercapacitors. Mater. Lett. 2015, 144, 114-118. [CrossRef]

246. Advanced Biosensors for Health Care Applications; Elsevier: Amsterdam, The Netherlands, 2019.

247. Liu, P.; Yang, M.; Zhou, S.; Huang, Y.; Zhu, Y. Hierarchical shell-core structures of concave spherical NiO nanospines@carbon for high performance supercapacitor electrodes. Electrochim. Acta 2019, 294, 383-390. [CrossRef]

248. Zheng, D.; Zhao, F.; Li, Y.; Qin, C.; Zhu, J.; Hu, Q.; Wang, Z.; Inoue, A. Flexible NiO micro-rods/nanoporous $\mathrm{Ni}$ /metallic glass electrode with sandwich structure for high performance supercapacitors. Electrochim. Acta 2019, 297, 767-777. [CrossRef]

249. Ede, S.R.; Anantharaj, S.; Kumaran, K.T.; Mishra, S.; Kundu, S. One step synthesis of Ni/Ni(OH $)_{2}$ nano sheets (NSs) and their application in asymmetric supercapacitors. RSC Adv. 2017, 7, 5898-5911. [CrossRef]

250. Wang, H.; Casalongue, H.S.; Liang, Y.; Dai, H. Ni(OH $)_{2}$ Nanoplates Grown on Graphene as Advanced Electrochemical Pseudocapacitor Materials. J. Am. Chem. Soc. 2010, 132, 7472-7477. [CrossRef]

251. Gomez, I.J.; Arnaiz, B.; Cacioppo, M.; Arcudi, F.; Prato, M. Nitrogen-doped Carbon Nanodots for bioimaging and delivery of paclitaxel. J. Mater. Chem. B 2018, 6, 1-3. [CrossRef]

252. Xu, L.; Ding, Y.-S.; Chen, C.-H.; Zhao, L.; Rimkus, C.; Joesten, R.; Suib, S.L. 3D Flowerlike $\alpha$-Nickel Hydroxide with Enhanced Electrochemical Activity Synthesized by Microwave-Assisted Hydrothermal Method. Chem. Mater. 2008, 20, 308-316. [CrossRef]

253. Oesten, R.; Wohlfahrt-Mehrens, M.; Ströbele, S.; Kasper, M.; Huggins, R.A. Structural aspects of undoped and doped nickel hydroxides. Ionics 1996, 2, 293-301. [CrossRef]

254. Zhao, D.D.; Bao, S.J.; Zhou, W.J.; Li, H.L. Preparation of hexagonal nanoporous nickel hydroxide film and its application for electrochemical capacitor. Electrochem. Commun. 2007, 9, 869-874. [CrossRef]

255. Ramani, M.; Haran, B.S.; White, R.E.; Popov, B.N. Synthesis and Characterization of Hydrous Ruthenium Oxide-Carbon Supercapacitors. J. Electrochem. Soc. 2001, 148, A374. [CrossRef]

256. Kuratani, K.; Kiyobayashi, T.; Kuriyama, N. Influence of the mesoporous structure on capacitance of the $\mathrm{RuO}_{2}$ electrode. J. Power Sources 2009, 189, 1284-1291. [CrossRef]

257. Mohajernia, S.; Hejazi, S.; Mazare, A.; Nguyen, N.T.; Hwang, I.; Kment, Š.; Zoppellaro, G.; Tomanec, O.; Zbořil, R.; Schmuki, P. Semimetallic core-shell $\mathrm{TiO}_{2}$ nanotubes as a high conductivity scaffold and use in efficient 3D- $\mathrm{RuO}_{2}$ supercapacitors. Mater. Today Energy 2017, 6, 46-52. [CrossRef]

258. Kovalenko, V.; Kotok, V.; Bolotin, A. Definition of factors influencing on $\mathrm{Ni}(\mathrm{OH})_{2}$ electrochemical characteristics for supercapacitors. East. Eur. J. Enterp. Technol. 2016, 5, 17-22. [CrossRef]

259. Lang, J.W.; Kong, L.B.; Wu, W.J.; Liu, M.; Luo, Y.C.; Kang, L. A facile approach to the preparation of loose-packed $\mathrm{Ni}(\mathrm{OH})_{2}$ nanoflake materials for electrochemical capacitors. J. Solid State Electrochem. 2009, 13, 333-340. [CrossRef]

260. Lokhande, P.E.; Chavan, U.S. Nanoflower-like $\mathrm{Ni}(\mathrm{OH})_{2}$ synthesis with chemical bath deposition method for high performance electrochemical applications. Mater. Lett. 2018, 218, 225-228. [CrossRef]

261. Li, H.B.; Yu, M.; Wang, F.X.; Liu, P.; Liang, Y.; Xiao, J.; Tong, Y.X.; Yang, G.W.; Wang, C.X. Amorphous nickel hydroxide nanospheres with ultrahigh capacitance and energy density as electrochemical pseudocapacitor materials. Nat. Commun. 2013, 4, 1-7. [CrossRef]

262. Oshitani, M.; Yufu, H.; Takashima, K.; Tsuji, S.; Matsumaru, Y. Development of a Pasted Nickel Electrode with High Active Material Utilization. J. Electrochem. Soc. 1989, 136, 1590-1593. [CrossRef]

263. Park, J.H.; Park, O.O.; Shin, K.H.; Jin, C.S.; Kim, J.H. An Electrochemical Capacitor Based on a $\mathrm{Ni}(\mathrm{OH})_{2}$ /Activated Carbon Composite Electrode. Electrochem. Solid State Lett. 2002, 5, H7. [CrossRef]

264. Zang, X.; Sun, C.; Dai, Z.; Yang, J.; Dong, X. Nickel hydroxide nanosheets supported on reduced graphene oxide for high-performance supercapacitors. J. Alloys Compd. 2017, 691, 144-150. [CrossRef] 
265. Chai, H.; Peng, X.; Liu, T.; Su, X.; Jia, D.; Zhou, W. High-performance supercapacitors based on conductive graphene combined with $\mathrm{Ni}(\mathrm{OH})_{2}$ nanoflakes. RSC Adv. 2017, 7, 36617-36622. [CrossRef]

266. Li, M.; Xu, S.; Zhu, Y.; Yang, P.; Wang, L.; Chu, P.K. Heterostructured $\mathrm{Ni}(\mathrm{OH})_{2}-\mathrm{Co}(\mathrm{OH})_{2}$ composites on 3D ordered $\mathrm{Ni}-\mathrm{Co}$ nanoparticles fabricated on microchannel plates for advanced miniature supercapacitor. J. Alloys Compd. 2014, 589, 364-371. [CrossRef]

267. Su, L.; Gong, L.; Gao, J. The supercapacitive performances of $\mathrm{Co}(\mathrm{OH})_{2} / \mathrm{Ni}(\mathrm{OH})_{2}$ composites in lithium hydroxide solution: Selection of electrolyte and effect of weight ratio. J. Power Sources 2012, 209, 141-146. [CrossRef]

268. Xiao, Z.; Liu, P.; Zhang, J.; Qi, H.; Liu, J.; Li, B.; Sun, X.; Zhang, Q.; Wei, C.; Wang, L. Pillar-Coordinated Strategy to Modulate Phase Transfer of $\alpha-\mathrm{Ni}(\mathrm{OH})_{2}$ for Enhanced Supercapacitor Application. ACS Appl. Energy Mater. 2020, 3, 5628-5636. [CrossRef]

269. Li, J.M.; Chang, K.H.; Hu, C.C. A novel vanadium oxide deposit for the cathode of asymmetric lithium-ion supercapacitors. Electrochem. Commun. 2010, 12, 1800-1803. [CrossRef]

270. Qu, Q.T.; Liu, L.L.; Wu, Y.P.; Holze, R. Electrochemical behavior of $\mathrm{V}_{2} \mathrm{O}_{5} \cdot 0.6 \mathrm{H}_{2} \mathrm{O}$ nanoribbons in neutral aqueous electrolyte solution. Electrochim. Acta 2013, 96, 8-12. [CrossRef]

271. Lee, H.Y.; Goodenough, J.B. Ideal Supercapacitor Behavior of Amorphous $\mathrm{V}_{2} \mathrm{O}_{5} \cdot \mathrm{nH}_{2} \mathrm{O}$ in Potassium Chloride (KCl) Aqueous Solution. J. Solid State Chem. 1999, 148, 81-84. [CrossRef]

272. Yu, D.; Chen, C.; Xie, S.; Liu, Y.; Park, K.; Zhou, X.-Y.; Zhang, Q.; Li, J.-Y.; Cao, G. Mesoporous vanadium pentoxide nanofibers with significantly enhanced Li-ion storage properties by electrospinning. Energy Environ. Sci. 2011, 4, 858-861. [CrossRef]

273. Xiong, C.; Aliev, A.E.; Gnade, B.; Balkus, K.J. Fabrication of Silver Vanadium Oxide and $\mathrm{V}_{2} \mathrm{O}_{5}$ Nanowires for Electrochromics. ACS Nano 2008, 2, 293-301. [CrossRef]

274. Chen, W.; Zhou, C.; Mai, L.; Liu, Y.; Qi, Y.; Dai, Y. Field Emission from $\mathrm{V}_{2} \mathrm{O}_{5} n \mathrm{H}_{2} \mathrm{O}$ Nanorod Arrays. J. Phys. Chem. C 2008, 112, 2262-2265. [CrossRef]

275. Li, M.; Kong, F.; Wang, H.; Li, G. Synthesis of vanadium pentoxide $\left(\mathrm{V}_{2} \mathrm{O}_{5}\right)$ ultralong nanobelts via an oriented attachment growth mechanism. CrystEngComm 2011, 13, 5317-5320. [CrossRef]

276. Wee, G.; Soh, H.Z.; Cheah, Y.L.; Mhaisalkar, S.G.; Srinivasan, M. Synthesis and electrochemical properties of electrospun $\mathrm{V}_{2} \mathrm{O}_{5}$ nanofibers as supercapacitor electrodes. J. Mater. Chem. 2010, 20, 6720-6725. [CrossRef]

277. Zeng, M.; Yin, H.; Yu, K. Synthesis of $\mathrm{V}_{2} \mathrm{O}_{5}$ nanostructures with various morphologies and their electrochemical and field-emission properties. Chem. Eng. J. 2012, 188, 64-70. [CrossRef]

278. Saravanakumar, B.; Purushothaman, K.K.; Muralidharan, G. Interconnected $\mathrm{V}_{2} \mathrm{O}_{5}$ Nanoporous Network for High-Performance Supercapacitors. ACS Appl. Mater. Interfaces 2012, 4, 4484-4490. [CrossRef]

279. Shaikh, J.S.; Pawar, R.C.; Mali, S.S.; Moholkar, A.V.; Kim, J.H.; Patil, P.S. Effect of annealing on the supercapacitor performance of CuO-PAA/CNT films. J. Solid State Electrochem. 2012, 16, 25-33. [CrossRef]

280. Balamuralitharan, B.; Cho, I.H.; Bak, J.S.; Kim, H.J. $\mathrm{V}_{2} \mathrm{O}_{5}$ nanorod electrode material for enhanced electrochemical properties by a facile hydrothermal method for supercapacitor applications. New J. Chem. 2018, 42, 11862-11868. [CrossRef]

281. Zhai, T.; Liu, H.; Li, H.; Fang, X.; Liao, M.; Li, L.; Zhou, H.; Koide, Y.; Bando, Y.; Golberg, D. Centimeter-long $\mathrm{V}_{2} \mathrm{O}_{5}$ nanowires: From synthesis to field-emission, electrochemical, electrical transport, and photoconductive properties. Adv. Mater. 2010, 22, 2547-2552. [CrossRef]

282. Devan, R.S.; Ma, Y.R.; Patil, R.A.; Lukas, S.M. Highly stable supercapacitive performance of one-dimensional (1D) brookite $\mathrm{TiO}_{2}$ nanoneedles. RSC Adv. 2016, 6, 6218-6225. [CrossRef]

283. Cottineau, T.; Toupin, M.; Delahaye, T.; Brousse, T.; Bélanger, D. Nanostructured transition metal oxides for aqueous hybrid electrochemical supercapacitors. Appl. Phys. A Mater. Sci. Process. 2006, 82, 599-606. [CrossRef]

284. Liang, B.; Chen, Y.; He, J.; Chen, C.; Liu, W.; He, Y.; Liu, X.; Zhang, N.; Roy, V.A.L. Controllable Fabrication and Tuned Electrochemical Performance of Potassium Co-Ni Phosphate Microplates as Electrodes in Supercapacitors. ACS Appl. Mater. Interfaces 2018, 10, 3506-3514. [CrossRef]

285. Chen, Z.; Augustyn, V.; Wen, J.; Zhang, Y.; Shen, M.; Dunn, B.; Lu, Y. High-performance supercapacitors based on intertwined $\mathrm{CNT} / \mathrm{V}_{2} \mathrm{O}_{5}$ nanowire nanocomposites. Adv. Mater. 2011, 23, 791-795. [CrossRef] [PubMed]

286. Foo, C.Y.; Sumboja, A.; Tan, D.J.H.; Wang, J.; Lee, P.S. Flexible and Highly Scalable $\mathrm{V}_{2} \mathrm{O}_{5}-\mathrm{rGO}$ Electrodes in an Organic Electrolyte for Supercapacitor Devices. Adv. Energy Mater. 2014, 4, 1400236. [CrossRef] 
287. Qian, T.; Xu, N.; Zhou, J.; Yang, T.; Liu, X.; Shen, X.; Liang, J.; Yan, C. Interconnected three-dimensional $\mathrm{V}_{2} \mathrm{O}_{5}$ /polypyrrole network nanostructures for high performance solid-state supercapacitors. J. Mater. Chem. A 2015, 3, 488-493. [CrossRef]

288. Jayalakshmi, M.; Rao, M.M.; Venugopal, N.; Kim, K.-B. Hydrothermal synthesis of $\mathrm{SnO}_{2}-\mathrm{V}_{2} \mathrm{O}_{5}$ mixed oxide and electrochemical screening of carbon nano-tubes (CNT), $\mathrm{V}_{2} \mathrm{O}_{5}, \mathrm{~V}_{2} \mathrm{O}_{5}-\mathrm{CNT}$, and $\mathrm{SnO}_{2}-\mathrm{V}_{2} \mathrm{O}_{5}-\mathrm{CNT}$ electrodes for supercapacitor applications. J. Power Sources 2007, 166, 578-583. [CrossRef]

289. Borenstein, A.; Hanna, O.; Attias, R.; Luski, S.; Brousse, T.; Aurbach, D. Carbon-based composite materials for supercapacitor electrodes: A review. J. Mater. Chem. A 2007, 5, 12653-12672. [CrossRef]

290. Lee, M.; Balasingam, S.K.; Jeong, H.Y.; Hong, W.G.; Lee, H.-B.-R.; Kim, B.H.; Jun, Y. One-step hydrothermal synthesis of Graphene decorated $\mathrm{V}_{2} \mathrm{O}_{5}$ nanobelts for enhanced electrochemical energy storage. Sci. Rep. 2015, 5, 1-8. [CrossRef] [PubMed]

291. Chen, Z.; Qin, Y.; Weng, D.; Xiao, Q.; Peng, Y.; Wang, X.; Li, H.; Wei, F.; Lu, Y. Design and Synthesis of Hierarchical Nanowire Composites for Electrochemical Energy Storage. Adv. Funct. Mater. 2009, 19, 3420-3426. [CrossRef]

292. Lu, S.; Xue, Z.; Chen, Y.; Wan, F.; Zhu, Q.; Zakharova, G.S. Researches on the structure and electrochemical properties of MoxV2-xO5+y nanosheets. Ionics 2017, 23, 2855-2862. [CrossRef]

293. Zhang, Y.; Jing, X.; Wang, Q.; Zheng, J.; Jiang, H.; Meng, C. Three-dimensional porous $\mathrm{V}_{2} \mathrm{O}_{5}$ hierarchical spheres as a battery-type electrode for a hybrid supercapacitor with excellent charge storage performance. Dalton Trans. 2017, 46, 15048-15058. [CrossRef]

294. Chen, Y.; Muthukumar, K.; Leban, L.; Li, J. Microwave-assisted high-yield exfoliation of vanadium pentoxide nanoribbons for supercapacitor applications. Electrochim. Acta 2020, 330, 135200. [CrossRef]

295. Chen, D.; Li, J.; Wu, Q. Review of $\mathrm{V}_{2} \mathrm{O}_{5}$-based nanomaterials as electrode for supercapacitor. J. Nanoparticle Res. 2019, 21, 9. [CrossRef]

296. Liu, B.; Liu, Y.; Chen, H.; Yang, M.; Li, H. $\mathrm{MnO}_{2}$ Nanostructures Deposited on Graphene-Like Porous Carbon Nanosheets for High-Rate Performance and High-Energy Density Asymmetric Supercapacitors. ACS Sustain. Chem. Eng. 2019, 7, 3101-3110. [CrossRef]

297. Feng, X.; Huang, Y.; Li, C.; Xiao, Y.; Chen, X.; Gao, X.; Chen, C. Construction of carnations-like $\mathrm{Mn}_{3} \mathrm{O}_{4} @ \mathrm{NiCo}_{2} \mathrm{O}_{4} @ \mathrm{NiO}$ hierarchical nanostructures for high-performance supercapacitors. Electrochim. Acta 2019, 308, 142-149. [CrossRef]

298. Sadak, O.; Wang, W.; Guan, J.; Sundramoorthy, A.K.; Gunasekaran, S. $\mathrm{MnO}_{2}$ Nanoflowers Deposited on Graphene Paper as Electrode Materials for Supercapacitors. ACS Appl. Nano Mater. 2019, 2, 4386-4394. [CrossRef]

299. Qi, W.; Li, X.; Wu, Y.; Zeng, H.; Kuang, C.; Zhou, S.; Huang, S.; Yang, Z. Flexible electrodes of $\mathrm{MnO}_{2} / \mathrm{CNTs}$ composite for enhanced performance on supercapacitors. Surf. Coat. Technol. 2017, 320, 624-629. [CrossRef]

300. Jia, H.; Cai, Y.; Zheng, X.; Lin, J.; Liang, H.; Qi, J.; Cao, J.; Feng, J.; Fei, W. Mesostructured Carbon Nanotube-on- $\mathrm{MnO}_{2}$ Nanosheet Composite for High-Performance Supercapacitors. ACS Appl. Mater. Interfaces 2018, 10, 38963-38969. [CrossRef]

301. Jeong, J.H.; Park, J.W.; Lee, D.W.; Baughman, R.H.; Kim, S.J. Electrodeposition of $\alpha-\mathrm{MnO}_{2} / \gamma-\mathrm{MnO}_{2}$ on Carbon Nanotube for Yarn Supercapacitor. Sci. Rep. 2019, 9, 1-8. [CrossRef]

302. Li, L.; Hu, Z.A.; An, N.; Yang, Y.Y.; Li, Z.M.; Wu, H.Y. Facile synthesis of $\mathrm{MnO}_{2} / \mathrm{CNTs}$ composite for supercapacitor electrodes with long cycle stability. J. Phys. Chem. C 2014, 118, 22865-22872. [CrossRef]

303. Ko, W.Y.; Liu, Y.C.; Lai, J.Y.; Chung, C.C.; Lin, K.J. Vertically Standing $\mathrm{MnO}_{2}$ Nanowalls Grown on AgCNT-Modified Carbon Fibers for High-Performance Supercapacitors. ACS Sustain. Chem. Eng. 2019, 7, 669-678. [CrossRef]

304. Sun, X.; Xu, T.; Bai, J.; Li, C. $\mathrm{MnO}_{2}$ Nanosheets Grown on Multichannel Carbon Nanofibers Containing Amorphous Cobalt Oxide as a Flexible Electrode for Supercapacitors. ACS Appl. Energy Mater. 2019, 2, 8675-8684. [CrossRef]

305. Kumar, K.S.; Cherusseri, J.; Thomas, J. Two-Dimensional $\mathrm{Mn}_{3} \mathrm{O}_{4}$ Nanowalls Grown on Carbon Fibers as Electrodes for Flexible Supercapacitors. ACS Omega 2019, 4, 4472-4480. [CrossRef] [PubMed]

306. He, Q.Q.; Wang, H.-Y.; Lun, N.; Qi, Y.-X.; Liu, J.; Feng, J.; Qiu, J.; Bai, Y.-J. Fabricating a $\mathrm{Mn}_{3} \mathrm{O}_{4} / \mathrm{Ni}(\mathrm{OH})_{2}$ Nanocomposite by Water-Boiling Treatment for Use in Asymmetric Supercapacitors as an Electrode Material. ACS Sustain. Chem. Eng. 2018, 6, 15688-15696. [CrossRef] 
307. Wang, T.; Le, Q.; Guo, X.; Huang, M.; Liu, X.; Dong, F.; Zhang, J.; Zhang, Y. Preparation of Porous Graphene@ $\mathrm{Mn}_{3} \mathrm{O}_{4}$ and Its Application in the Oxygen Reduction Reaction and Supercapacitor. ACS Sustain. Chem. Eng. 2019, 7, 831-837. [CrossRef]

308. Samuel, E.; Kim, T.G.; Park, C.W.; Joshi, B.; Swihart, M.T.; Yoon, S.S. Supersonically Sprayed $\mathrm{Zn}_{2} \mathrm{SnO}_{4} / \mathrm{SnO}_{2} / \mathrm{CNT}$ Nanocomposites for High-Performance Supercapacitor Electrodes. ACS Sustain. Chem. Eng. 2019, 7, 14031-14040. [CrossRef]

309. Chakraborty, I.; Chakrabarty, N.; Senapati, A.; Chakraborty, A.K. CuO@NiO/Polyaniline/MWCNT Nanocomposite as High-Performance Electrode for Supercapacitor. J. Phys. Chem. C 2018, 122, 27180-27190. [CrossRef]

310. Das, D.; Borthakur, L.J.; Nath, B.C.; Saikia, B.J.; Mohan, K.J.; Dolui, S.K. Designing hierarchical $\mathrm{NiO} / \mathrm{PAni}-\mathrm{MWCNT}$ core-shell nanocomposites for high performance super capacitor electrodes. RSC Adv. 2016, 6, 44878-44887. [CrossRef]

311. Samuel, E.; Joshi, B.; Kim, Y.I.; Aldalbahi, A.; Rahaman, M.; Yoon, S.S. ZnO/MnOx Nanoflowers for High-Performance Supercapacitor Electrodes. ACS Sustain. Chem. Eng. 2020, 8, 3697-3708. [CrossRef]

312. Jeon, S.; Jeong, J.H.; Yoo, H.; Yu, H.K.; Kim, B.H.; Kim, M.H. $\mathrm{RuO}_{2}$ Nanorods on Electrospun Carbon Nanofibers for Supercapacitors. ACS Appl. Nano Mater. 2020, 3, 3847-3858. [CrossRef]

313. Ryu, I.; Yang, M.; Kwon, H.; Park, H.K.; Do, Y.R.; Lee, S.-B.; Yim, S. Coaxial $\mathrm{RuO}_{2}-\mathrm{ITO}$ nanopillars for transparent supercapacitor application. Langmuir 2014, 30, 1704-1709. [CrossRef]

314. Xu, J.; Wang, Q.; Wang, X.; Xiang, Q.; Liang, B.; Chen, D.; Shen, G. Flexible Asymmetric Supercapacitors Based upon $\mathrm{Co}_{9} \mathrm{~S}_{8} \mathrm{Nanorod} / / \mathrm{Co}_{3} \mathrm{O}_{4} @ \mathrm{RuO}_{2}$ Nanosheet Arrays on Carbon Cloth. ACS Nano 2013, 7, 5453-5462. [CrossRef]

315. Kaipannan, S.; Govindarajan, K.; Sundaramoorthy, S.; Marappan, S. Waste Toner-Derived Carbon/ $/ \mathrm{Fe}_{3} \mathrm{O}_{4}$ Nanocomposite for High-Performance Supercapacitor. ACS Omega 2019, 4, 15798-15805. [CrossRef] [PubMed]

316. Tian, Y.; Hu, X.; Wang, Y.; Li, C.; Wu, X. Fe ${ }_{2} \mathrm{O}_{3}$ Nanoparticles Decorated on Graphene-Carbon Nanotubes Conductive Networks for Boosting the Energy Density of All-Solid-State Asymmetric Supercapacitor. ACS Sustain. Chem. Eng. 2019, 7, 9211-9219. [CrossRef]

317. Gupta, A.; Sardana, S.; Dalal, J.; Lather, S.; Maan, A.S.; Tripathi, R.; Punia, R.; Singh, K.; Ohlan, A. Nanostructured Polyaniline/Graphene/ $\mathrm{Fe}_{2} \mathrm{O}_{3}$ Composites Hydrogel as a High-Performance Flexible Supercapacitor Electrode Material. ACS Appl. Energy Mater. 2020, 3, 6434-6446. [CrossRef]

318. Kumar, A.; Sarkar, D.; Mukherjee, S.; Patil, S.; Sarma, D.D.; Shukla, A. Realizing an Asymmetric Supercapacitor Employing Carbon Nanotubes Anchored to $\mathrm{Mn}_{3} \mathrm{O}_{4}$ Cathode and $\mathrm{Fe}_{3} \mathrm{O}_{4}$ Anode. ACS Appl. Mater. Interfaces 2018, 10, 42484-42493. [CrossRef] [PubMed]

319. Li, L.; Gao, J.; Cecen, V.; Fan, J.; Shi, P.; Xu, Q.; Min, Y. Hierarchical WS $\mathrm{NNiCo}_{2} \mathrm{O}_{4}$ Core-shell Heterostructure Arrays Supported on Carbon Cloth as High-Performance Electrodes for Symmetric Flexible Supercapacitors. ACS Omega 2020, 5, 4657-4667. [CrossRef]

320. Zhang, A.; Yue, L.; Jia, D.; Cui, L.; Wei, D.; Huang, W.; Liu, R.; Liu, Y.; Yang, W.; Liu, J. Cobalt/Nickel Ions-Assisted Synthesis of Laminated $\mathrm{CuO}$ Nanospheres Based on $\mathrm{Cu}(\mathrm{OH})_{2}$ Nanorod Arrays for High-Performance Supercapacitors. ACS Appl. Mater. Interfaces 2020, 12, 2591-2600. [CrossRef]

321. Kwak, C.S.; Ko, T.H.; Lee, J.H.; Kim, H.Y.; Kim, B.S. Flexible Transparent Symmetric Solid-State Supercapacitors Based on NiO-Decorated Nanofiber-Based Composite Electrodes with Excellent Mechanical Flexibility and Cyclability. ACS Appl. Energy Mater. 2020, 3, 2394-2403. [CrossRef]

322. Xia, T.; Zhang, X.; Zhao, J.; Li, Q.; Ao, C.; Hu, R.; Zheng, Z.; Zhang, W.; Lu, C.; Deng, Y. Flexible and Conductive Carbonized Cotton Fabrics Coupled with a Nanostructured $\mathrm{Ni}(\mathrm{OH})_{2}$ Coating for High Performance Aqueous Symmetric Supercapacitors. ACS Sustain. Chem. Eng. 2019, 7, 5231-5239. [CrossRef]

323. Ray, A.; Roy, A.; Saha, S.; Ghosh, M.; Chowdhury, S.R.; Maiyalagan, T.; Bhattacharya, S.K.; Das, S. Electrochemical Energy Storage Properties of Ni-Mn-Oxide Electrodes for Advance Asymmetric Supercapacitor Application. Langmuir 2019, 35, 8257-8267. [CrossRef]

324. Deng, M.J.; Yeh, L.H.; Lin, Y.H.; Chen, J.M.; Chou, T.H. 3D Network $\mathrm{V}_{2} \mathrm{O}_{5}$ Electrodes in a Gel Electrolyte for High-Voltage Wearable Symmetric Pseudocapacitors. ACS Appl. Mater. Interfaces 2019, 11, 29838-29848. [CrossRef] [PubMed] 
325. Chen, H.C.; Lin, Y.C.; Chen, Y.L.; Chen, C.J. Facile fabrication of three-dimensional hierarchical nanoarchitectures of $\mathrm{VO}_{2} / \mathrm{Graphene} @ \mathrm{NiS}_{2}$ hybrid aerogel for high-performance all-solid-state asymmetric supercapacitors with ultrahigh energy density. ACS Appl. Energy Mater. 2019, 2, 459-467. [CrossRef]

326. Bi, W.; Wu, Y.; Liu, C.; Wang, J.; Du, Y.; Gao, Z.; Wu, G.; Cao, G. Gradient oxygen vacancies in $\mathrm{V}_{2} \mathrm{O}_{5} / \mathrm{PEDOT}$ nanocables for high-performance supercapacitors. ACS Appl. Energy Mater. 2019, 2, 668-677. [CrossRef]

327. Wang, D.W.; Li, F.; Zhao, J.; Ren, W.; Chen, Z.; Tan, J.; Wu, Z.-S.; Gentle, I.; Lu, G.; Cheng, H.-M. Fabrication of graphene/polyaniline composite paper via in situ anodic electropolymerization for high-performance flexible electrode. ACS Nano 2009, 3, 1745-1752. [CrossRef] [PubMed]

328. Kalaji, M.; Murphy, P.J.; Williams, G.O. Study of conducting polymers for use as redox supercapacitors. Synth. Met. 1999, 102, 1360-1361. [CrossRef]

329. Gupta, V.; Miura, N. High performance electrochemical supercapacitor from electrochemically synthesized nanostructured polyaniline. Mater. Lett. 2006, 60, 1466-1469. [CrossRef]

330. Ryu, K.S.; Wu, X.; Lee, Y.-G.; Chang, S.H. Electrochemical capacitor composed of doped polyaniline and polymer electrolyte membrane. J. Appl. Polym. Sci. 2003, 89, 1300-1304. [CrossRef]

331. Ammonia, L. The Acid Properties of Ammonium Saltsin. Aust. J. Chem. 1924, 822, 5-10.

332. Shirakawa, H.; Louis, E.J.; MacDiarmid, A.G.; Chiang, C.K.; Heeger, A.J. Synthesis of electrically conducting organic polymers: Halogen derivatives of polyacetylene, $(\mathrm{CH})_{\mathrm{x}}$. J. Chem. Soc. Chem. Commun. 1977, 16, 578-580. [CrossRef]

333. Ramya, R.; Sivasubramanian, R.; Sangaranarayanan, M.V. Conducting polymers-based electrochemical supercapacitors-Progress and prospects. Electrochim. Acta 2013, 101, 109-129. [CrossRef]

334. Ellenbogen, J.C. Supercapacitors: A Brief Overview. 2006. Available online: https://www.mitre.org/sites/ default/files/pdf/06_0667.pdf (accessed on 4 June 2020).

335. Snook, G.A.; Kao, P.; Best, A.S. Conducting-polymer-based supercapacitor devices and electrodes. J. Power Sources 2011, 196. [CrossRef]

336. Sharma, P.; Bhatti, T.S. A review on electrochemical double-layer capacitors. Energy Convers. Manag. 2010, 51, 2901-2912. [CrossRef]

337. Cheng, Q.; Tang, J.; Ma, J.; Zhang, H.; Shinya, N.; Qin, L.C. Graphene and nanostructured $\mathrm{MnO}_{2}$ composite electrodes for supercapacitors. Carbon N. Y. 2011, 49, 2917-2925. [CrossRef]

338. Sharma, R.K.; Rastogi, A.C.; Desu, S.B. Manganese oxide embedded polypyrrole nanocomposites for electrochemical supercapacitor. Electrochim. Acta 2008, 53, 7690-7695. [CrossRef]

339. Rudge, A.; Davey, J.; Raistrick, I.; Gottesfeld, S.; Ferraris, J.P. Conducting polymers as active materials in electrochemical capacitors. J. Power Sources 1994, 47, 89-107. [CrossRef]

340. Giannelis, E.P. Polymer Layered Silicate Nanocomposites. Adv. Mater. 1996, 8, 29-35. [CrossRef]

341. Sivaraman, P.; Thakur, A.; Kushwaha, R.K.; Ratna, D.; Samui, A.B. Poly(3-methyl thiophene)-activated carbon hybrid supercapacitor based on gel polymer electrolyte. Electrochem. Solid State Lett. 2006, 9, 9. [CrossRef]

342. Wang, K.; Huang, J.; Wei, Z. Conducting Polyaniline Nanowire Arrays for High Performance Supercapacitors. J. Phys. Chem. C 2010, 114, 8062-8067. [CrossRef]

343. Cameron, C.G. Electrochemical capacitors. Springer Handb. 2017, 50, 563-589.

344. Hashmi, S.A.; Upadhyaya, H.M. Polypyrrole and poly(3-methyl thiophene)-based solid state redox supercapacitors using ion conducting polymer electrolyte. Solid State Ion. 2002, 152-153, 883-889. [CrossRef]

345. Shi, Y.; Pan, L.; Liu, B.; Wang, Y.; Cui, Y.; Bao, Z.; Yu, G. Nanostructured conductive polypyrrole hydrogels as high-performance, flexible supercapacitor electrodes. J. Mater. Chem. A 2014, 2, 6086-6091. [CrossRef]

346. Ryu, K.S.; Kim, K.M.; Park, Y.J.; Park, N.G.; Kang, M.G.; Chang, S.H. Redox supercapacitor using polyaniline doped with Li salt as electrode. Solid State Ion. 2002, 152-153, 861-866. [CrossRef]

347. Naoi, K.; Suematsu, S.; Manago, A. Electrochemistry of poly(1,5-diaminoanthraquinone) and its application in electrochemical capacitor materials. J. Electrochem. Soc. 2000, 147, 420-426. [CrossRef]

348. Meng, Q.; Cai, K.; Chen, Y.; Chen, L. Research progress on conducting polymer based supercapacitor electrode materials. Nano Energy 2017, 36, 268-285. [CrossRef]

349. Hao, G.P.; Hippauf, F.; Oschatz, M.; Wisser, F.M.; Leifert, A.; Nickel, W.; Mohamed-Noriega, N.; Zheng, Z.; Kaskel, S. Stretchable and semitransparent conductive hybrid hydrogels for flexible supercapacitors. ACS Nano 2014, 8, 7138-7146. [CrossRef] [PubMed]

350. Li, W.; Gao, F.; Wang, X.; Zhang, N.; Ma, M. Strong and Robust Polyaniline-Based Supramolecular Hydrogels for Flexible Supercapacitors. Angew. Chem. Int. Ed. 2016, 55, 9196-9201. [CrossRef] [PubMed] 
351. Wang, Y.; Shi, Y.; Pan, L.; Ding, Y.; Zhao, Y.; Li, Y.; Shi, Y.; Yu, G. Dopant-Enabled Supramolecular Approach for Controlled Synthesis of Nanostructured Conductive Polymer Hydrogels. Nano Lett. 2015, 15, 7736-7741. [CrossRef] [PubMed]

352. Yang, Z.; Shi, D.; Dong, W.; Chen, M. Self-Standing Hydrogels Composed of Conducting Polymers for All-Hydrogel-State Supercapacitors. Chem. A Eur. J. 2020, 26, 1846-1855. [CrossRef]

353. Liu, J.; Huang, J.; Cai, Q.; Yang, Y.; Luo, W.; Zeng, B.; Xu, Y.; Yuan, C.; Dai, L. Design of Slidable Polymer Networks: A Rational Strategy to Stretchable, Rapid Self-Healing Hydrogel Electrolytes for Flexible Supercapacitors. ACS Appl. Mater. Interfaces 2020, 12, 20479-20489. [CrossRef]

354. Cheng, Q.; Tang, J.; Shinya, N.; Qin, L.C. Polyaniline modified graphene and carbon nanotube composite electrode for asymmetric supercapacitors of high energy density. J. Power Sources 2013, 241, 423-428. [CrossRef]

355. Han, G.; Liu, Y.; Zhang, L.; Kan, E.; Zhang, S.; Tang, J.; Tang, W. $\mathrm{MnO}_{2}$ Nanorods Intercalating Graphene Oxide/Polyaniline Ternary Composites for Robust High-Performance Supercapacitors. Sci. Rep. 2015, 4, 4824. [CrossRef] [PubMed]

356. Li, J.; Xie, H.; Li, Y.; Liu, J.; Li, Z. Electrochemical properties of graphene nanosheets/polyaniline nanofibers composites as electrode for supercapacitors. J. Power Sources 2011, 196, 10775-10781. [CrossRef]

357. Hu, C.C.; Chang, K.H.; Lin, M.C.; Wu, Y.T. Design and tailoring of the nanotubular arrayed architecture of hydrous $\mathrm{RuO}_{2}$ for next generation supercapacitors. Nano Lett. 2006, 6, 2690-2695. [CrossRef] [PubMed]

358. Zhou, C.; Zhang, Y.; Li, Y.; Liu, J. Construction of High-Capacitance 3D CoO@Polypyrrole Nanowire Array Electrode for Aqueous Asymmetric Supercapacitor. Nano Lett. 2013, 13, 2078-2085. [CrossRef] [PubMed]

359. Bober, P.; Gavrilov, N.; Kovalcik, A.; Micusik, M.; Unterweger, C.; Pašti, I.A.; Šeděnková, I.; Acharya, U.; Pfleger, J.; Filippov, S.K.; et al. Electrochemical properties of lignin/polypyrrole composites and their carbonized analogues. Mater. Chem. Phys. 2018, 213, 352-361. [CrossRef]

360. Mastragostino, M.; Arbizzani, C.; Soavi, F. Conducting polymers as electrode materials in supercapacitors. Solid State Ion. 2002, 148, 493-498. [CrossRef]

361. Shao, Q.; Tang, J.; Lin, Y.; Li, J.; Qin, F.; Yuan, J.; Qin, L.-C. Carbon nanotube spaced graphene aerogels with enhanced capacitance in aqueous and ionic liquid electrolytes. J. Power Sources 2015, 278, 751-759. [CrossRef]

362. Poonam; Sharma, K.; Arora, A.; Tripathi, S.K. Review of supercapacitors: Materials and devices. J. Energy Storage 2019, 21, 801-825. [CrossRef]

363. Liu, F.; Song, S.; Xue, D.; Zhang, H. Selective crystallization with preferred lithium-ion storage capability of inorganic materials. Nanoscale Res. Lett. 2012, 7, 1-17. [CrossRef]

364. Wang, L.; Feng, X.; Ren, L.; Piao, Q.; Zhong, J.; Wang, Y.; Li, H.; Chen, Y.; Wang, B. Flexible solid-state supercapacitor based on a metal-organic framework interwoven by electrochemically-deposited PANI. J. Am. Chem. Soc. 2015, 137, 4920-4923. [CrossRef]

365. Shan, Y.; Gao, L. Formation and characterization of multi-walled carbon nanotubes $/ \mathrm{Co}_{3} \mathrm{O}_{4}$ nanocomposites for supercapacitors. Mater. Chem. Phys. 2007, 103, 206-210. [CrossRef]

366. Xiang, C.; Li, M.; Zhi, M.; Manivannan, A.; Wu, N. A reduced graphene oxide $/ \mathrm{Co}_{3} \mathrm{O}_{4}$ composite for supercapacitor electrode. J. Power Sources 2013, 226, 65-70. [CrossRef]

367. He, G.; Li, J.; He, G.; Shi, J.; Sun, X.-Q.; Chen, S.; Wang, X. Hydrothermal preparation of $\mathrm{Co}_{3} \mathrm{O}_{4} @$ graphene nanocomposite for supercapacitor with enhanced capacitive performance. Mater. Lett. 2012, 82, 61-63. [CrossRef]

368. Abouali, S.; Garakani, M.A.; Zhang, B.; Xu, Z.-L.; Heidari, E.K.; Huang, J.-Q.; Huang, J.; Kim, J.-K. Electrospun Carbon Nanofibers with in Situ Encapsulated $\mathrm{Co}_{3} \mathrm{O}_{4}$ Nanoparticles as Electrodes for High-Performance Supercapacitors. ACS Appl. Mater. Interfaces 2015, 7, 13503-13511. [CrossRef]

369. Wang, H.; Yi, H.; Chen, X.; Wang, X. Asymmetric supercapacitors based on nano-architectured nickel oxide/graphene foam and hierarchical porous nitrogen-doped carbon nanotubes with ultrahigh-rate performance. J. Mater. Chem. A 2014, 2, 3223-3230. [CrossRef]

370. Du, W.; Wang, Z.; Zhu, Z.; Hu, S.; Zhu, X.; Shi, Y.-F.; Panga, H.; Qian, X. Facile synthesis and superior electrochemical performances of $\mathrm{CoNi}_{2} \mathrm{~S}_{4} /$ graphene nanocomposite suitable for supercapacitor electrodes. J. Mater. Chem. A 2014, 2, 9613-9619. [CrossRef]

371. Perera, S.D.; Patel, B.B.; Nijem, N.; Roodenko, K.; Seitz, O.; Ferraris, J.P.; Chabal, Y.J.; Balkus, K.J., Jr. Vanadium Oxide Nanowire-Carbon Nanotube Binder-Free Flexible Electrodes for Supercapacitors. Adv. Energy Mater. 2011, 1, 936-945. [CrossRef] 
372. Yan, S.; Wang, H.; Qu, P.; Zhang, Y.; Xiao, Z. $\mathrm{RuO}_{2} /$ carbon nanotubes composites synthesized by microwave-assisted method for electrochemical supercapacitor. Synth. Met. 2009, 159, 158-161. [CrossRef]

373. Zhang, C.; Xie, Y.; Zhao, M.; Pentecost, A.E.; Ling, Z.; Wang, J.; Long, D.; Ling, L.; Qiao, W. Enhanced electrochemical performance of hydrous $\mathrm{RuO}_{2} /$ mesoporous carbon nanocomposites via nitrogen doping. ACS Appl. Mater. Interfaces 2014, 6, 9751-9759. [CrossRef]

374. Lee, Y.; Kim, B.; Jung, H.J.; Shim, J.H.; Lee, Y.; Lee, C.; Baik, J.M.; Kim, W.; Kim, M.H. Hierarchically grown single crystalline $\mathrm{RuO}_{2}$ nanorods on vertically aligned few-walled carbon nanotubes. Mater. Lett. 2012, 89, 115-117. [CrossRef]

375. Lee, J.K.; Pathan, H.M.; Jung, K.D.; Joo, O.S. Electrochemical capacitance of nanocomposite films formed by loading carbon nanotubes with ruthenium oxide. J. Power Sources 2006, 159, 1527-1531. [CrossRef]

376. Zhi, M.; Xiang, C.; Li, J.; Li, M.; Wu, N. Nanostructured carbon-metal oxide composite electrodes for supercapacitors: A review. Nanoscale 2013, 5, 72-88. [CrossRef] [PubMed]

377. Ghosh, A.; Lee, Y.H. Carbon-Based Electrochemical Capacitors. ChemSusChem 2012, 5, 480-499. [CrossRef] [PubMed]

378. Wang, P.; Xu, Y.; Liu, H.; Chen, Y.; Yang, J.; Tan, Q. Carbon/carbon nanotube-supported $\mathrm{RuO}_{2}$ nanoparticles with a hollow interior as excellent electrode materials for supercapacitors. Nano Energy 2015, 15, 116-124. [CrossRef]

379. Guan, Q.; Cheng, J.; Wang, B.; Ni, W.; Gu, G.; Li, X.; Huang, L.; Yang, G.; Nie, F. Needle-like $\mathrm{Co}_{3} \mathrm{O}_{4}$ anchored on the graphene with enhanced electrochemical performance for aqueous supercapacitors. ACS Appl. Mater. Interfaces 2014, 6, 7626-7632. [CrossRef] [PubMed]

380. Yuan, C.; Li, J.; Hou, L.; Yang, L.; Shen, L.; Zhang, X. Facile template-free synthesis of ultralayered mesoporous nickel cobaltite nanowires towards high-performance electrochemical capacitors. J. Mater. Chem. 2012, 22, 16084-16090. [CrossRef]

381. Zhang, G.Q.; Wu, H.B.; Hoster, H.E.; Chan-Park, M.B.; Lou, X.W. Single-crystalline $\mathrm{NiCo}_{2} \mathrm{O}_{4}$ nanoneedle arrays grown on conductive substrates as binder-free electrodes for high-performance supercapacitors. Energy Environ. Sci. 2012, 5, 9453-9456. [CrossRef]

382. Zhang, G.; Lou, X.W.D. General Solution Growth of Mesoporous $\mathrm{NiCo}_{2} \mathrm{O}_{4}$ Nanosheets on Various Conductive Substrates as High-Performance Electrodes for Supercapacitors. Adv. Mater. 2013, 25, 976-979. [CrossRef]

383. Umeshbabu, E.; Rajeshkhanna, G.; Justin, P.; Rao, G.R. Synthesis of mesoporous $\mathrm{NiCo}_{2} \mathrm{O}_{4}-\mathrm{rGO}$ by a solvothermal method for charge storage applications. RSC Adv. 2015, 5, 66657-66666. [CrossRef]

384. Wu, H.B.; Pang, H.; Lou, X.W. Facile synthesis of mesoporous $\mathrm{Ni}_{0.3} \mathrm{Co}_{2.7} \mathrm{O}_{4}$ hierarchical structures for high-performance supercapacitors. Energy Environ. Sci. 2013, 6, 3619-3626. [CrossRef]

385. Wang, X.; Han, X.; Lim, M.; Singh, N.; Gan, C.L.; Jan, M.; Lee, P.S. Nickel Cobalt Oxide-Single Wall Carbon Nanotube Composite Material for Superior Cycling Stability and High-Performance Supercapacitor Application. J. Phys. Chem. C 2012, 116, 12448-12454. [CrossRef]

386. Wan, H.; Jiang, J.; Yu, J.; Xu, K.; Miao, L.; Zhang, L.; Chen, H.C.; Ruan, Y. $\mathrm{NiCo}_{2} \mathrm{~S}_{4}$ porous nanotubes synthesis via sacrificial templates: High-performance electrode materials of supercapacitors. CrystEngComm 2013, 15, 7649-7651. [CrossRef]

387. Xiong, G.; He, P.; Liu, L.; Chen, T.; Fisher, T.S. Plasma-grown graphene petals templating Ni-Co-Mn hydroxide nanoneedles for high-rate and long-cycle-life pseudocapacitive electrodes. J. Mater. Chem. A 2015, 3, 22940-22948. [CrossRef]

388. Hareesh, K.; Shateesh, B.; Joshi, R.P.; Williams, J.F.; Phase, D.M.; Haram, S.K.; Dhole, S.D. Ultra high stable supercapacitance performance of conducting polymer coated $\mathrm{MnO}_{2}$ nanorods/rGO nanocomposites. RSC Adv. 2017, 7, 20027-20036. [CrossRef]

389. Peng, W.; Chen, H.; Wang, W.; Huang, Y.; Han, G. Synthesis of $\mathrm{NiCo}_{2} \mathrm{~S}_{4}$ nanospheres/reduced graphene oxide composite as electrode material for supercapacitor. Curr. Appl. Phys. 2020, 20, 304-309. [CrossRef]

390. Soni, R.; Kurungot, $\mathrm{S}$. $\mathrm{Fe}_{2} \mathrm{P}_{4} \mathrm{O}_{12}$-carbon composite as a highly stable electrode material for electrochemical capacitors. New J. Chem. 2019, 43, 399-406. [CrossRef]

391. Shi, K.; Zhitomirsky, I. Electrophoretic nanotechnology of graphene-carbon nanotube and graphene-polypyrrole nanofiber composites for electrochemical supercapacitors. J. Colloid Interface Sci. 2013, 407, 474-481. [CrossRef]

392. Shi, K.; Yang, X.; Cranston, E.D.; Zhitomirsky, I. Efficient Lightweight Supercapacitor with Compression Stability. Adv. Funct. Mater. 2016, 26, 6437-6445. [CrossRef] 
393. Liu, Y.; Shi, K.; Zhitomirsky, I. New colloidal route for electrostatic assembly of oxide nanoparticle-Carbon nanotube composites. Colloids Surfaces A Physicochem. Eng. Asp. 2014, 446, 15-22. [CrossRef]

394. Liu, Y.; Ata, M.S.; Shi, K.; Zhu, G.Z.; Botton, G.A.; Zhitomirsky, I. Surface modification and cathodic electrophoretic deposition of ceramic materials and composites using celestine blue dye. RSC Adv. 2014, 4, 29652-29659. [CrossRef]

395. Shi, K.; Giapis, K.P. Scalable Fabrication of Supercapacitors by Nozzle-Free Electrospinning. ACS Appl. Energy Mater. 2018, 1, 296-300. [CrossRef]

396. Antiohos, D.; Folkes, G.; Sherrell, P.C.; Ashraf, S.; Wallace, G.G.; Aitchison, P.; Harris, A.T.; Chen, J.; Minett, A.I. Compositional effects of PEDOT-PSS/single walled carbon nanotube films on supercapacitor device performance. J. Mater. Chem. 2011, 21, 15987-15994. [CrossRef]

397. Frackowiak, E.; Khomenko, V.; Jurewicz, K.; Lota, K.; Béguin, F. Supercapacitors based on conducting polymers/nanotubes composites. J. Power Sources 2006, 153, 413-418. [CrossRef]

398. Liu, P.; Yan, J.; Guang, Z.; Huang, Y.; Li, X.; Huang, W. Recent advancements of polyaniline-based nanocomposites for supercapacitors. J. Power Sources 2019, 424, 108-130. [CrossRef]

399. Yang, Y.; Xi, Y.; Li, J.; Wei, G.; Klyui, N.I.; Han, W. Flexible Supercapacitors Based on Polyaniline Arrays Coated Graphene Aerogel Electrodes. Nanoscale Res. Lett. 2017, 12, 1931-7573. [CrossRef]

400. Yu, P.; Li, Y.; Yu, X.; Zhao, X.; Wu, L.; Zhang, Q. Polyaniline nanowire arrays aligned on nitrogen-doped carbon fabric for high-performance flexible supercapacitors. Langmuir 2013, 29, 12051-12058. [CrossRef]

401. Mao, L.; Zhang, K.; Chan, H.S.O.; Wu, J. Surfactant-stabilized graphene/polyaniline nanofiber composites for high performance supercapacitor electrode. J. Mater. Chem. 2012, 22, 80-85. [CrossRef]

402. Wang, R.; Han, M.; Zhao, Q.; Ren, Z.; Guo, X.; Xu, C.; Hu, N.; Lu, L. Hydrothermal synthesis of nanostructured graphene/polyaniline composites as high-capacitance electrode materials for supercapacitors. Sci. Rep. 2017, 7, 44562. [CrossRef]

403. Zeng, S.; Chen, H.; Cai, F.; Kang, Y.; Chen, M.; Li, Q. Electrochemical fabrication of carbon nanotube/polyaniline hydrogel film for all-solid-state flexible supercapacitor with high areal capacitance. J. Mater. Chem. A 2015, 3, 23864-23870. [CrossRef]

404. Li, Y.; Zhao, X.; Yu, P.; Zhang, Q. Oriented Arrays of Polyaniline Nanorods Grown on Graphite Nanosheets for an Electrochemical Supercapacitor. Langmuir 2013, 29, 493-500. [CrossRef]

405. Han, Y.; Ding, B.; Tong, H.; Zhang, X. Capacitance properties of graphite oxide/poly(3,4-ethylene dioxythiophene) composites. J. Appl. Polym. Sci. 2011, 121, 892-898. [CrossRef]

406. Keskinen, J.; Tuurala, S.; Sjödin, M.; Kiri, K.; Nyholm, L.; Flyktman, T.; Strømme, M.; Smolander, M. Asymmetric and symmetric supercapacitors based on polypyrrole and activated carbon electrodes. Synth. Met. 2015, 203, 192-199. [CrossRef]

407. Yan, J.; Wei, T.; Fan, Z.; Qian, W.; Zhang, M.; Shen, X.; Wei, F. Preparation of graphene nanosheet/carbon nanotube/polyaniline composite as electrode material for supercapacitors. J. Power Sources 2010, 195, 3041-3045. [CrossRef]

408. Jaidev; Ramaprabhu, S. Poly(p-phenylenediamine)/graphene nanocomposites for supercapacitor applications. J. Mater. Chem. 2012, 22, 18775-18783. [CrossRef]

409. Zhao, X.; Zhang, Q.; Hao, Y.; Li, Y.; Fang, Y.; Chen, D. Alternate Multilayer Films of Poly(vinyl alcohol) and Exfoliated Graphene Oxide Fabricated via a Facial Layer-by-Layer Assembly. Macromolecules 2010, 43, 9411-9416. [CrossRef]

410. Nam, M.S.; Patil, U.; Park, B.; Sim, H.B.; Jun, S.C. A binder free synthesis of 1D PANI and 2D $\mathrm{MoS}_{2}$ nanostructured hybrid composite electrodes by the electrophoretic deposition (EPD) method for supercapacitor application. RSC Adv. 2016, 6, 101592-101601. [CrossRef]

411. Xie, K.; Wei, B. Materials and structures for stretchable energy storage and conversion devices. Adv. Mater. 2014, 26, 3592-3617. [CrossRef]

412. Liu, Y.; Zhang, B.; Yang, Y.; Chang, Z.; Wen, Z.; Wu, Y. Polypyrrole-coated $\alpha-\mathrm{MoO}_{3}$ nanobelts with good electrochemical performance as anode materials for aqueous supercapacitors. J. Mater. Chem. A 2013, 1, 13582-13587. [CrossRef]

413. Zhang, X.; Ji, L.; Zhang, S.; Yang, W. Synthesis of a novel polyaniline-intercalated layered manganese oxide nanocomposite as electrode material for electrochemical capacitor. J. Power Sources 2007, 173, 1017-1023. [CrossRef] 
414. Raj, R.P.; Ragupathy, P.; Mohan, S. Remarkable capacitive behavior of $\mathrm{a} \mathrm{Co}_{3} \mathrm{O}_{4}$-polyindole composite as electrode material for supercapacitor applications. J. Mater. Chem. A 2015, 3, 24338-24348. [CrossRef]

415. Balbuena, J.O.; de Ureta, P.T.; Ruiz, E.R.; Pita, S.M. Electric Field Effect in Atomically Thin Carbon Films. Med. Clin. 2004, 146, 93-94. [CrossRef]

416. Xiao, X.; Yu, H.; Jin, H.; Wu, M.; Fang, Y.; Sun, J.; Hu, Z.; Li, T.; Wu, J.; Huang, L.; et al. Salt-Templated Synthesis of 2D Metallic MoN and Other Nitrides. ACS Nano 2017, 11, 2180-2186. [CrossRef] [PubMed]

417. Luo, S.; Zhao, J.; Zou, J.; He, Z.; Xu, C.; Liu, F.; Huang, Y.; Dong, L.; Wang, L.; Zhang, H. Self-Standing Polypyrrole/Black Phosphorus Laminated Film: Promising Electrode for Flexible Supercapacitor with Enhanced Capacitance and Cycling Stability. ACS Appl. Mater. Interfaces 2018, 10, 3538-3548. [CrossRef] [PubMed]

418. Wang, D.Y.; Chang, C.L.; Ho, W.Y. Microstructure analysis of $\mathrm{MoS}_{2}$ deposited on diamond-like carbon films for wear improvement. Surf. Coat. Technol. 1999, 111, 123-127. [CrossRef]

419. Choi, W.; Choudhary, N.; Han, G.H.; Park, J.; Akinwande, D.; Lee, Y.H. Recent development of two-dimensional transition metal dichalcogenides and their applications. Mater. Today 2017, 20, 116-130. [CrossRef]

420. Yaghi, O.M.; Li, H. Hydrothermal Synthesis of a Metal-Organic Framework Containing Large Rectangular Channels. J. Am. Chem. Soc. 1995, 117, 10401-10402. [CrossRef]

421. Alahakoon, S.B.; Thompson, C.M.; Occhialini, G.; Smaldone, R.A. Design Principles for Covalent Organic Frameworks in Energy Storage Applications. ChemSusChem 2017, 10, 2116-2129. [CrossRef]

422. Yang, W.; Gao, Z.; Wang, J.; Ma, J.; Zhang, M.; Liu, L. Solvothermal one-step synthesis of Ni-Al layered double hydroxide/carbon nanotube/reduced graphene oxide sheet ternary nanocomposite with ultrahigh capacitance for supercapacitors. ACS Appl. Mater. Interfaces 2013, 5, 5443-5454. [CrossRef]

423. Ong, W.J.; Tan, L.L.; Ng, Y.H.; Yong, S.T.; Chai, S.P. Graphitic Carbon Nitride $\left(\mathrm{g}-\mathrm{C}_{3} \mathrm{~N}_{4}\right)$-Based Photocatalysts for Artificial Photosynthesis and Environmental Remediation: Are We a Step Closer to Achieving Sustainability? Chem. Rev. 2016, 116, 7159-7329. [CrossRef]

424. Alhabeb, M.; Maleski, K.; Anasori, B.; Lelyukh, P.; Clark, L.; Sin, S.; Gogotsi, Y. Guidelines for Synthesis and Processing of Two-Dimensional Titanium Carbide ( $\mathrm{Ti}_{3} \mathrm{C}_{2} \mathrm{Tx}$ MXene). Chem. Mater. 2017, 29, 7633-7644. [CrossRef]

425. Naguib, M.; Kurtoglu, M.; Presser, V.; Lu, J.; Niu, J.; Heon, M.; Hultman, L.; Gogotsi, Y.; Barsoum, M.W. Two-dimensional nanocrystals produced by exfoliation of $\mathrm{Ti}_{3} \mathrm{AlC}_{2}$. Adv. Mater. 2011, 23, 4248-4253. [CrossRef] [PubMed]

426. Forouzandeh, P.; Pillai, S.C. Two-dimensional (2D) electrode materials for supercapacitors. Mater. Today Proc. 2020. [CrossRef]

427. Xie, L.M. Two-dimensional transition metal dichalcogenide alloys: Preparation, characterization and applications. Nanoscale 2015, 7, 18392-18401. [CrossRef] [PubMed]

428. Guan, G.; Han, M.Y. Functionalized Hybridization of 2D Nanomaterials. Adv. Sci. 2019, 6, 23. [CrossRef]

429. Wan, J.; Lacey, S.D.; Dai, J.; Bao, W.; Fuhrer, M.S.; Hu, L. Tuning two-dimensional nanomaterials by intercalation: Materials, properties and applications. Chem. Soc. Rev. 2016, 45, 6742-6765. [CrossRef]

430. Zhang, X.; Lai, Z.; Liu, Z.; Tan, C.; Huang, Y.; Li, B.; Zhao, M.; Xie, L.; Huang, W.; Zhang, H. A facile and universal top-down method for preparation of monodisperse transition-metal dichalcogenide nanodots. Angew. Chem. Int. Ed. 2015, 54, 5425-5428. [CrossRef]

431. Pant, A.; Mutlu, Z.; Wickramaratne, D.; Cai, H.; Lake, R.K.; Ozkan, C.S.; Tongay, S. Fundamentals of lateral and vertical heterojunctions of atomically thin materials. Nanoscale 2016, 8, 3870-3887. [CrossRef]

432. Sangwan, V.K.; Hersam, M.C. Electronic Transport in Two-Dimensional Materials. Annu. Rev. Phys. Chem. 2018, 69, 299-325. [CrossRef]

433. Dai, Z.; Liu, L.; Zhang, Z. Strain Engineering of 2D Materials: Issues and Opportunities at the Interface. Adv. Mater. 2019, 31, 1-11. [CrossRef]

434. Bao, W.; Jing, L.; Velasco, J.; Lee, Y.; Liu, G.; Tran, D.; Standley, B.; Aykol, M.; Cronin, S.B.; Smirnov, D.; et al. Stacking-dependent band gap and quantum transport in trilayer graphene. Nat. Phys 2011, 7, 948-952. [CrossRef]

435. Xiong, W.; Hu, X.; Wu, X.; Zeng, Y.; Wang, B.; He, G.; Zhu, Z. A flexible fiber-shaped supercapacitor utilizing hierarchical $\mathrm{NiCo}_{2} \mathrm{O}_{4} @$ polypyrrole core-shell nanowires on hemp-derived carbon. J. Mater. Chem. A 2015, 3, 17209-17216. [CrossRef] 
436. Hong, D.; Yim, S. $\mathrm{RuO}_{2}$ Thin Films Electrodeposited on Polystyrene Nanosphere Arrays: Growth Mechanism and Application to Supercapacitor Electrodes. Langmuir 2018, 34, 4249-4254. [CrossRef]

437. L-Mahdy, A.F.M.E.; Hung, Y.-H.; Mansoure, T.H.; Yu, H.-H.; Hsu, Y.-S.; Wu, K.C.-W.; Kuo, S.-W. Synthesis of $[3+3] \beta$-ketoenamine-tethered covalent organic frameworks (COFs) for high-performance supercapacitance and $\mathrm{CO}_{2}$ storage. J. Taiwan Inst. Chem. Eng. 2019, 103, 199-208. [CrossRef]

438. Das, S.K.; Bhunia, K.; Mallick, A.; Pradhan, A.; Pradhan, D.; Bhaumik, A. A new electrochemically responsive 2D П-conjugated covalent organic framework as a high performance supercapacitor. Microporous Mater. 2018, 266, 109-116. [CrossRef]

439. Xu, Q.; Dalapati, S.; Jiang, D. Charge up in wired covalent organic frameworks. ACS Cent. Sci. 2016, 2, 586-587. [CrossRef] [PubMed]

440. Romero, J.; Rodríguez-San-Miguel, D.; Ribera, A.; Mas-Ballesté, R.; Otero, T.F.; Manet, I.; Licio, F.; Abellán, G.; Zamora, F.; Coronado, E. Metal-functionalized covalent organic frameworks as precursors of supercapacitive porous N-doped graphene. J. Mater. Chem. A 2017, 5, 4343-4351. [CrossRef]

441. Mulzer, C.R.; Shen, L.; Bisbey, R.P.; McKone, J.R.; Zhang, N.; Abruña, H.D.; Dichtel, W.R. Superior charge storage and power density of a conducting polymer-modified covalent organic framework. ACS Cent. Sci. 2016, 2, 667-673. [CrossRef]

442. Chandra, S.; Chowdhury, D.R.; Addicoat, M.; Heine, T.; Paul, A.; Banerjee, R. Molecular Level Control of the Capacitance of Two-Dimensional Covalent Organic Frameworks: Role of Hydrogen Bonding in Energy Storage Materials. Chem. Mater. 2017, 29, 2074-2080. [CrossRef]

443. Xu, Z.; Chowdhury, D.R.; Addicoat, M.; Heine, T.; Paul, A.; Banerjee, R. Construction of extensible and flexible supercapacitors from covalent organic framework composite membrane electrode. Chem. Eng. J. 2020, 387, 124071. [CrossRef]

444. Choi, K.M.; Jeong, H.M.; Park, J.H.; Zhang, Y.B.; Kang, J.K.; Yaghi, O.M. Supercapacitors of nanocrystalline metal-organic frameworks. ACS Nano 2014, 8, 7451-7457. [CrossRef]

445. Jiang, J.W.; Park, H.S. Mechanical properties of $\mathrm{MoS}_{2} /$ graphene heterostructures. Appl. Phys. Lett. 2014, 105, 033108. [CrossRef]

446. Toth, P.S.; Velický, M.; Bissett, M.A.; Slater, T.J.A.; Savjani, N.; Rabiu, A.; Rakowski, A.M.; Brent, J.R.; Haigh, S.J.; O’Brien, P.; et al. Asymmetric $\mathrm{MoS}_{2} /$ Graphene/Metal Sandwiches: Preparation, Characterization, and Application. Adv. Mater. 2016, 28, 8256-8264. [CrossRef]

447. Zhang, X.; Selkirk, A.; Zhang, S.; Huang, J.; Li, Y.; Xie, Y.; Dong, N.; Cui, Y.; Zhang, L.; Blau, W.J.; et al. $\mathrm{MoS}_{2} /$ Carbon Nanotube Core-Shell Nanocomposites for Enhanced Nonlinear Optical Performance. Chem. A Eur. J. 2017, 23, 3321-3327. [CrossRef] [PubMed]

448. Nejati, K.; Akbari, A.R.; Davari, S.; Asadpour-Zeynali, K.; Rezvani, Z. Zn-Fe-layered double hydroxide intercalated with vanadate and molybdate anions for electrocatalytic water oxidation. New J. Chem. 2018, 42, 2889-2895. [CrossRef]

449. Li, M.Y.; Chen, C.H.; Shi, Y.; Li, L.J. Heterostructures based on two-dimensional layered materials and their potential applications. Mater. Today 2016, 19, 322-335. [CrossRef]

450. Huang, X.; Zeng, Z.; Zhang, H. Metal dichalcogenide nanosheets: Preparation, properties and applications. Chem. Soc. Rev. 2013, 42, 1934-1946. [CrossRef] [PubMed]

451. Yang, X.; Niu, H.; Jiang, H.; Wang, Q.; Qu, F. A high energy density all-solid-state asymmetric supercapacitor based on $\mathrm{MoS}_{2}$ /graphene nanosheets and $\mathrm{MnO}_{2}$ /graphene hybrid electrodes. J. Mater. Chem. A 2016, 4, 11264-11275. [CrossRef]

452. Leng, K.; Chen, Z.; Zhao, X.; Tang, W.; Tian, B.; Nai, C.T.; Zhou, W.; Loh, K.P. Phase Restructuring in Transition Metal Dichalcogenides for Highly Stable Energy Storage. ACS Nano 2016, 10, 9208-9215. [CrossRef]

453. Yousaf, M.; Mahmood, A.; Wang, Y.; Chen, Y.; Ma, Z.; Han, R.P.S. Advancement in Layered Transition Metal Dichalcogenide Composites for Lithium and Sodium Ion Batteries. J. Electr. Eng. 2016, 4, 58-74. [CrossRef]

454. Saha, S.; Jana, M.; Khanra, P.; Samanta, P.; Koo, H.; Murmu, N.C.; Kuila, T. Band gap engineering of boron nitride by graphene and its application as positive electrode material in asymmetric supercapacitor device. ACS Appl. Mater. Interfaces 2015, 7, 14211-14222. [CrossRef]

455. Maity, C.K.; Sahoo, S.; Verma, K.; Behera, A.K.; Nayak, G.C. Facile functionalization of boron nitride (BN) for the development of high-performance asymmetric supercapacitors. New J. Chem. 2020, 44, 8106-8119. [CrossRef] 
456. Gomez, I.J.; Arnaiz, B.; Cacioppo, M.; Arcudi, F.; Prato, M. Synthesis of 3D Marigold Flower-Like $\mathrm{rGO} / \mathrm{BN} / \mathrm{Ni}(\mathrm{OH})_{2}$ Ternary Nanocomposites for Supercapacitor Applications. J. Mater. Chem. B 2018, 35. [CrossRef]

457. Zhao, G.; Wang, T.; Shao, Y.; Wu, Y.; Huang, B.; Hao, X. A Novel Mild Phase-Transition to Prepare Black Phosphorus Nanosheets with Excellent Energy Applications. Small 2017, 13, 1602243. [CrossRef] [PubMed]

458. Yu, X.; Ushiyama, H.; Yamashita, K. Comparative Study of Sodium and Lithium Intercalation and Diffusion Mechanism in Black Phosphorus from First-principles Simulation. Chem. Lett. 2014, 43, 1940-1942. [CrossRef]

459. Gopalakrishnan, A.; Badhulika, S. Facile sonochemical assisted synthesis of a hybrid red-black phosphorus/sulfonated porous carbon composite for high-performance supercapacitors. Chem. Commun. 2020, 56, 7096-7099. [CrossRef] [PubMed]

460. Kim, G.; Wang, S.; Jacobson, A.J.; Reimus, L.; Brodersen, P.; Mims, C.A. Rapid oxygen ion diffusion and surface exchange kinetics in $\mathrm{PrBaCo}_{2} \mathrm{O}_{5+x}$ with a perovskite related structure and ordered a cations. J. Mater. Chem. 2007, 17, 2500-2505. [CrossRef]

461. Mishra, M. (Ed.) Encyclopedia of Polymer Applications, 3 Volume Set; CRC Press: Boca Raton, FL, USA, 2018.

462. Yan, X.; Tong, X.; Wang, J.; Gong, C.; Zhang, M.; Liang, L. Synthesis of mesoporous NiO nanoflake array and its enhanced electrochemical performance for supercapacitor application. J. Alloys Compd. 2014, 593, 184-189. [CrossRef]

463. Lu, K.; Shen, F. Long term behaviors of $\mathrm{La}_{0.8} \mathrm{Sr}_{0.2} \mathrm{MnO}_{3}$ and $\mathrm{La}_{0.6} \mathrm{Sr}_{0.4} \mathrm{Co}_{0.2} \mathrm{Fe}_{0.8} \mathrm{O}_{3}$ as cathodes for solid oxide fuel cells. Int. J. Hydrogen Energy 2014, 39, 7963-7971. [CrossRef]

464. Zhang, L.; Zhou, Q.; He, Q.; He, T. Double-perovskites $\mathrm{A}_{2} \mathrm{FeMoO}_{6-\delta}(\mathrm{A}=\mathrm{Ca}, \mathrm{Sr}, \mathrm{Ba})$ as anodes for solid oxide fuel cells. J. Power Sources 2010, 195, 6356-6366. [CrossRef]

465. Wang, X.W.; Zhu, Q.Q.; Wang, X.E.; Zhang, H.C.; Zhang, J.J.; Wang, L.F. Structural and electrochemical properties of $\mathrm{La}_{0.85} \mathrm{Sr}_{0.15} \mathrm{MnO}_{3}$ powder as an electrode material for supercapacitor. J. Alloys Compd. 2016, 675, 195-200. [CrossRef]

466. Ma, P.P.; Lu, Q.L.; Lei, N.; Liu, Y.K.; Yu, B.; Dai, J.M.; Li, S.H.; Jiang, G. Effect of A-site substitution by Ca or Sr on the structure and electrochemical performance of $\mathrm{LaMnO}_{3}$ perovskite. Electrochim. Acta 2020, 332, 135489. [CrossRef]

467. Tomar, A.K.; Singh, G.; Sharma, R.K. Charge storage characteristics of mesoporous strontium titanate perovskite aqueous as well as flexible solid-state supercapacitor cell. J. Power Sources 2019, 426, 223-232. [CrossRef]

468. Du, P.; Hu, X.; Yi, C.; Liu, H.C.; Liu, P.; Zhang, H.-L.; Gong, X. Self-Powered Electronics by Integration of Flexible Solid-State Graphene-Based Supercapacitors with High Performance Perovskite Hybrid Solar Cells. Adv. Funct. Mater. 2015, 25, 16-2420. [CrossRef]

469. Ayman, I.; Rasheed, A.; Ajmal, S.; Rehman, A.; Ali, A.; Shakir, I.; Warsi, M.F. $\mathrm{CoFe}_{2} \mathrm{O}_{4}$ Nanoparticle-Decorated 2D MXene: A Novel Hybrid Material for Supercapacitor Applications. Energy Fuels 2020, 34, 7622-7630. [CrossRef]

470. Yang, J.; Pan, Z.; Yu, Q.; Zhang, Q.; Ding, X.; Shi, X.; Qiu, Y.-C.; Zhang, K.; Wang, J.; Zhang, Y. Free-Standing Black Phosphorus Thin Films for Flexible Quasi-Solid-State Micro-Supercapacitors with High Volumetric Power and Energy Density. ACS Appl. Mater. Interfaces 2019, 11, 5938-5946. [CrossRef]

471. Wang, L.; Liu, F.; Zhao, B.; Ning, Y.; Zhang, L.; Bradley, R.H.; Wu, W.; Lijian, W. Carbon Nanobowls Filled with $\mathrm{MoS}_{2}$ Nanosheets as Electrode Materials for Supercapacitors. ACS Appl. Nano Mater. 2020, 3, 6448-6459. [CrossRef]

472. Kitchamsetti, N.; Choudhary, R.J.; Phase, D.M.; Devan, R.S. Structural correlation of a nanoparticle-embedded mesoporous $\mathrm{CoTiO}_{3}$ perovskite for an efficient electrochemical supercapacitor. RSC Adv. 2020, 10, 23446-23456. [CrossRef]

473. Haldar, S.; Kushwaha, R.; Maity, R.; Vaidhyanathan, R. Pyridine-Rich Covalent Organic Frameworks as High-Performance Solid-State Supercapacitors. ACS Mater. Lett. 2019, 1, 490-497. [CrossRef]

474. Liu, Y.; Wang, Y.; Chen, Y.; Wang, C.; Guo, L. NiCo-MOF nanosheets wrapping polypyrrole nanotubes for high-performance supercapacitors. Appl. Surf. Sci. 2020, 507, 145089. [CrossRef]

475. Shao, Y.; El-Kady, M.F.; Sun, J.; Li, Y.; Zhang, Q.; Zhu, M.; Wang, H.; Dunn, B.; Kaner, R.B. Design and Mechanisms of Asymmetric Supercapacitors. Chem. Rev. 2018, 118, 9233-9280. [CrossRef] 
476. He, Y.; Chen, W.; Li, X.; Zhang, Z.; Fu, J.; Zhao, C.; Xie, E. Freestanding three-dimensional graphene/Mno 2 composite networks as ultralight and flexible supercapacitor electrodes. ACS Nano 2013, 7, 174-182. [CrossRef] [PubMed]

477. Lu, X.; Xia, Y. Electronic materials: Buckling down for flexible electronics. Nat. Nanotechnol. 2006, 1, $163-164$. [CrossRef]

478. Miller, J.R. Reliability of Electrochemical Capacitors. In Supercapacitors; Wiley-VCH Verlag GmbH \& Co. KGaA: Weinheim, Germany, 2013; pp. 473-507.

479. Maggetto, G. Electric vehicles, hybrid electric vehicles and fuel cell electric vehicles: State of the art and perspectives. Ann. Chim. Sci. des Mat ̃̃ riaux 2001, 26, 9-26. [CrossRef]

480. He, Z.; Gao, B.; Li, T.; Liao, J.; Liu, B.; Liu, X.; Wang, C.; Feng, Z.-Q.; Gu, Z. Piezoelectric-Driven Self-Powered Patterned Electrochromic Supercapacitor for Human Motion Energy Harvesting. ACS Sustain. Chem. Eng. 2019, 7, 1745-1752. [CrossRef]

481. Hsu, H.H.; Khosrozadeh, A.; Li, B.; Luo, G.; Xing, M.; Zhong, W. An Eco-Friendly, Nanocellulose/RGO/in Situ Formed Polyaniline for Flexible and Free-Standing Supercapacitors. ACS Sustain. Chem. Eng. 2019, 7, 4766-4776. [CrossRef]

482. Chia, Y.Y.; Lee, L.H.; Shafiabady, N.; Isa, D. A load predictive energy management system for supercapacitor-battery hybrid energy storage system in solar application using the Support Vector Machine. Appl. Energy 2015, 137, 588-602. [CrossRef]

483. Habibzadeh, M.; Hassanalieragh, M.; Ishikawa, A.; Soyata, T.; Sharma, G. Hybrid Solar-Wind Energy Harvesting for Embedded Applications: Supercapacitor-Based System Architectures and Design Tradeoffs. IEEE Circuits Syst. Mag. 2017, 17, 29-63. [CrossRef]

484. Zhang, Y.; Hao, N.; Lin, X.; Nie, S. Emerging challenges in the thermal management of cellulose nanofibril-based supercapacitors, lithium-ion batteries and solar cells: A review. Carbohydr. Polym. 2020, 234, 115888. [CrossRef]

485. Miller, J.R. Market and Applications of Electrochemical Capacitors. In Supercapacitors; Wiley-VCH Verlag GmbH \& Co. KGaA: Weinheim, Germany, 2013; pp. 509-526.

486. Li, Z.; Huang, T.; Gao, W.; Xu, Z.; Chang, D.; Zhang, C.; Gao, C. Hydrothermally Activated Graphene Fiber Fabrics for Textile Electrodes of Supercapacitors. ACS Nano 2017, 11, 11056-11065. [CrossRef]

487. Wu, Q.; Xu, Y.; Yao, Z.; Liu, A.; Shi, G. Supercapacitors based on flexible graphene/polyaniline nanofiber composite films. ACS Nano 2010, 4, 1963-1970. [CrossRef]

488. Zhu, C.; Liu, T.; Qian, F.; Han, T.Y.-J.; Duoss, E.B.; Kuntz, J.D.; Spadaccini, C.M.; Worsley, M.A.; Li, Y. Supercapacitors Based on Three-Dimensional Hierarchical Graphene Aerogels with Periodic Macropores. Nano Lett. 2016, 16, 3448-3456. [CrossRef] [PubMed]

489. Couly, C.; Alhabeb, M.; Van Aken, K.L.; Kurra, N.; Gomes, L.; Anasori, B.; Alshareef, H.N.; Gogotsi, Y.; Navarro-Suárez, A.M. Asymmetric Flexible MXene-Reduced Graphene Oxide Micro-Supercapacitor. Adv. Electron. Mater. 2018, 4, 1700339. [CrossRef]

490. Zhang, C.J.; Anasori, B.; Seral-Ascaso, A.; Park, S.-H.; McEvoy, N.; Shmeliov, A.; Duesberg, G.S.; Coleman, J.N.; Gogotsi, Y.; Nicolosi, V. Transparent, Flexible, and Conductive 2D Titanium Carbide (MXene) Films with High Volumetric Capacitance. Adv. Mater. 2017, 29, 1-9. [CrossRef] [PubMed]

491. Fleischmann, S.; Mitchell, J.B.; Wang, R.; Zhan, C.; Jiang, D.; Presser, V.; Augustyn, V. Pseudocapacitance: From Fundamental Understanding to High Power Energy Storage Materials. Chem. Rev. 2020, 120, 6738-6782. [CrossRef]

492. Miroshnikov, M.; Mahankali, K.; Thangavel, N.K.; Satapathy, S.; Arava, L.M.R.; Ajayan, P.M.; John, G. Bioderived Molecular Electrodes for Next-Generation Energy-Storage Materials. ChemSusChem 2020, 1-20. [CrossRef]

(C) 2020 by the authors. Licensee MDPI, Basel, Switzerland. This article is an open access article distributed under the terms and conditions of the Creative Commons Attribution (CC BY) license (http://creativecommons.org/licenses/by/4.0/). 